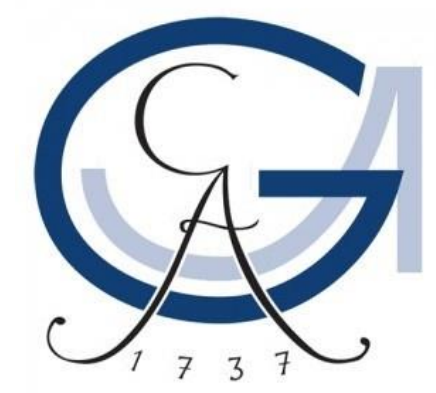

\title{
Leaving a solitary life behind: Evolutionary processes leading to sociality in animals
}

\author{
Dissertation \\ for the award of the degree \\ 'Doctor of Philosophy' (Ph.D.) \\ at the Georg-August-Universität Göttingen \\ within the doctoral program Biology \\ of the Georg-August University School of Science (GAUSS) \\ submitted by \\ Lluís Socias Martínez
}

from Palma de Mallorca, Spain

Göttingen, 2019 



\section{Thesis advisory committee}

Prof. Dr. Peter M. Kappeler

Behavioral Ecology \& Sociobiology Unit, German Primate Center Leibniz Institute for Primate Research, Göttingen, Germany \& Dept. Sociobiology/Anthropology, JohannFriedrich-Blumenbach Institute for Zoology and Anthropology, University of Göttingen, Germany

Dr. Oliver Schülke

Behavioral Ecology Dept., Johann-Friedrich-Blumenbach Institute for Zoology and Anthropology, University of Göttingen, Germany

Dr. Markus Port

Behavioral Ecology Dept., Johann-Friedrich-Blumenbach Institute for Zoology and Anthropology, University of Göttingen, Germany

\section{Members of the examination board:}

Referee: Prof. Dr. Peter M. Kappeler, Behavioral Ecology \& Sociobiology Unit, German Primate Center Leibniz Institute for Primate Research, Göttingen, Germany \& Dept. Sociobiology/Anthropology, Johann-Friedrich-Blumenbach Institute for Zoology and Anthropology, University of Göttingen, Germany

Co-referee: Dr. Oliver Schülke, Behavioral Ecology Dept., Johann-Friedrich-Blumenbach Institute for Zoology and Anthropology, University of Göttingen, Germany

Other members of the Examination Board:

Dr. Markus Port, Behavioral Ecology Dept., Johann-Friedrich-Blumenbach Institute for Zoology and Anthropology, University of Göttingen, Germany

Prof. Dr. Jutta Schneider, Department of Biology, Institut für Zoologie, Behavioural Biology Group, University of Hamburg

Prof. Dr. Julia Fischer, Cognitive Ethology Lab, German Primate Center Leibniz Institute for Primate Research, Göttingen, Germany

Dr. Sven Bradler, Animal Evolution and Biodiversity Department, University of Göttingen, Germany

Day of the oral examination: $13^{\text {th }}$ of December 2019 



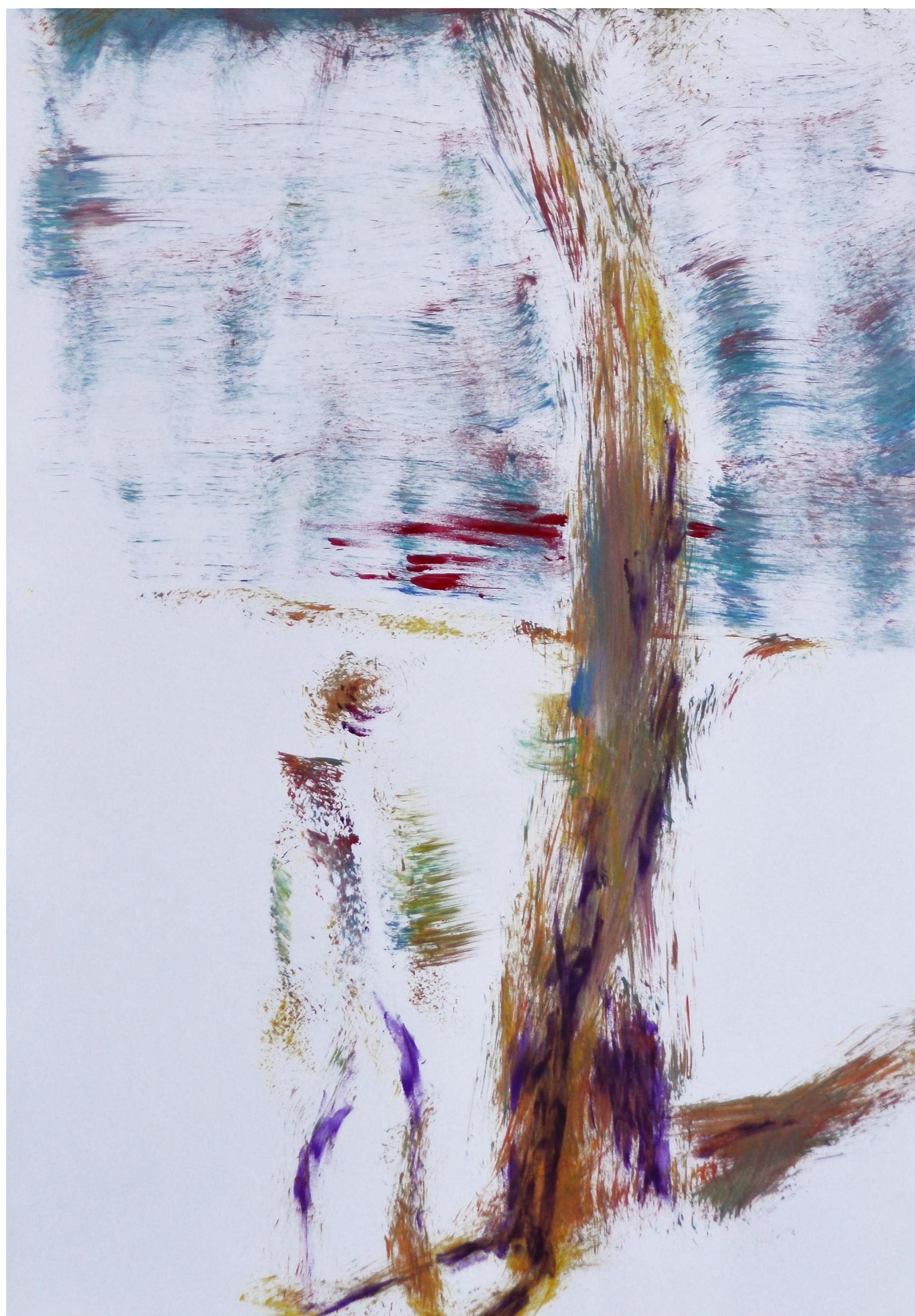


Alone with one-self

Göttingen, Germany 2019

L Socias Martínez 


\section{Summary}

The evolution of stable animal groups is a major transition in evolution entailing changes in population structure and emerging properties due to the selective pressures associated with social interactions. Sociality is based on cooperation, an evolutionary puzzle in Darwinian theory that is grounded on competition for limited resources. In the first chapter, we challenge the importance of kin selection (i.e. nepotism) to explain the appearance of animal groups, which is the current paradigm. This theory suggests that genetic similarity is needed to reduce competition between individuals allowing cooperation to be selected. We propose an alternative framework that takes into account the numerous and diverse ways in which parental care may have catalyzed the evolution of group living. We emphasize the importance of coevolutionary processes between parasites and predators with parental investment strategies long before transitions to sociality may occur. Building on empirical and theoretical evidence from a wide range of taxa, including vertebrates and invertebrates, we suggest that direct fitness benefits arising from selective pressures associated with parental care evolution are the force behind the appearance of animal groups. Under this framework, kin-selection is rather an enhancer or even a by-product derived from evolutionary processes related to parental care and not the main prerequisite for cooperation to evolve. In the second chapter, we focus on studying facultatively social species to understand the processes that lead a solitary species to become group-living. In this sense, we describe the social system of a facultatively social primate with communal breeding, Microcebus murinus, using data on more than 200 individuals from a wild population. By studying sleeping site sharing in this solitary foraging species, we aim to characterize the social flexibility both at the species as well as at the individual levels. We find evidence for social flexibility in philopatric females and dispersing males. Moreover, contrary to previous findings, we show a higher capacity for sociality and social flexibility in males. Thus, our results suggest that female communal breeding may not be the only force driving sociality in this species, criticizing the framework exposed in chapter 1; and that unrelated males may be as prone as related females to form social groups, which suggests that kin-selection is also unable to explain the evolution of mouse lemurs' social systems. While in the first two chapters, we discussed transitions to sociality from an adaptationist perspective, in Chapter 3.1, we examine the possibility that sociality in Microcebus murinus may be a passive result of heterogeneous distribution of food resources and sleeping sites. We find no evidence for an effect of food resource availability or nesting limitation on individual social strategies. Thus, intrinsic benefits associated with sleeping together and sharing a home range with others may be at play in this species. In chapter 3.2, we develop the method used in chapter 3.1 to assess the reliability of information gathered per individual to construct home ranges using Michaelis-Menten modeling. We believe this might be a potentially useful tool for studies in the wild where scarcity of data as well as betweenindividual variation in the amount of data collected may hamper movement ecology analyses. We end by emphasizing that social evolution is a manifold process that embeds and intertwines several layers of life complexity, resisting attempts for unitary explanations of its origins. 


\section{Zusammenfassung}

Die Entwicklung stabiler Tiergruppen ist ein wichtiger Übergang in der Evolution, der aufgrund des selektiven Drucks, der mit sozialen Interaktionen verbunden ist, Veränderungen in der Populationsstruktur und in den aufkommenden Eigenschaften mit sich bringt. Die Sozialität basiert auf Kooperation, ein evolutionäres Puzzle in der darwinistischen Theorie, das auf der Konkurrenz um begrenzte Ressourcen beruht. Im ersten Kapitel stellen wir die Bedeutung der Verwandtschaftsselektion (i.e. Nepotismus) in Frage, um das Auftreten von Tiergruppen zu erklären, das das aktuelle Paradigma darstellt. Diese Theorie legt nahe, dass genetische Ähnlichkeit notwendig ist, um die Konkurrenz zwischen Individuen zu reduzieren, die eine Kooperation ermöglichen. Wir schlagen einen alternativen Rahmen vor, der die zahlreichen und unterschiedlichen Arten berücksichtigt, in denen die elterliche Fürsorge die Entwicklung des Gruppenlebens katalysiert haben könnte. Wir betonen die Bedeutung koevolutiver Prozesse zwischen Parasiten und Raubtieren mit elterlichen Investitionsstrategien, lange bevor ein Übergang zur Sozialität stattfinden kann. Aufbauend auf empirischen und theoretischen Erkenntnissen aus einem breiten Spektrum von Taxa, einschließlich Wirbeltieren und wirbellosen Tieren, schlagen wir vor, dass direkte Fitnessvorteile, die sich aus dem selektiven Druck ergeben, der mit der Evolution der elterlichen Fürsorge verbunden ist, die Kraft hinter dem Auftreten von Tiergruppen sind. In diesem Rahmen ist die Verwandtenselektion eher ein Verstärker oder sogar ein Nebenprodukt aus evolutionären Prozessen, die mit der elterlichen Fürsorge in Verbindung stehen, und nicht die Hauptvoraussetzung für die Entwicklung der Zusammenarbeit. Im zweiten Kapitel konzentrieren wir uns auf die Untersuchung fakultativ sozialer Spezies, um die Prozesse zu verstehen, die eine einsame Spezies zu einem Gruppenleben führen. In diesem Sinne beschreiben wir das Sozialsystem eines fakultativ sozialen Primaten mit gemeinschaftlicher Zucht, Microcebus murinus, anhand von Daten über mehr als 200 Individuen aus einer Wildpopulation. Durch die Untersuchung der gemeinsamen Schlafplatznutzung bei dieser einsamen Futtersuche wollen wir die soziale Flexibilität sowohl auf der Ebene der Art als auch auf der Ebene des Individuums charakterisieren. Wir finden Belege für die soziale Flexibilität bei philopatrischen Weibchen und zerstreuenden Männchen. Darüber hinaus zeigen wir, im Gegensatz zu früheren Ergebnissen, eine höhere Fähigkeit zur Sozialität und sozialen Flexibilität bei den Männchen. Unsere Ergebnisse deuten also darauf hin, dass die weibliche Gemeinschaftszucht möglicherweise nicht die einzige treibende Kraft für die Sozialität bei dieser Art ist, was den in Kapitel 1 dargelegten Rahmen kritisiert; und dass nicht verwandte Männchen genauso anfällig für die Bildung sozialer Gruppen sind wie verwandte Weibchen, was darauf hindeutet, dass die Verwandtschaftsauswahl auch nicht in der Lage ist, die Entwicklung der sozialen Systeme des Mausmakis zu erklären. Während wir in den ersten beiden Kapiteln die Übergänge zur Sozialität aus einer anpassungsorientierten Perspektive diskutiert haben, untersuchen wir in Kapitel 3.1 die Möglichkeit, dass die Sozialität bei Microcebus murinus ein passives Ergebnis der heterogenen Verteilung von Nahrungsressourcen und Schlafplätzen sein könnte. Wir finden keine Belege für einen Effekt der Verfügbarkeit von Nahrungsressourcen oder der Einschränkung der Nistplätze auf individuelle Sozialstrategien. Daher könnten die intrinsischen Vorteile, die mit dem gemeinsamen Schlafen und der gemeinsamen Nutzung eines Heimbereichs mit anderen verbunden sind, bei dieser Art im Spiel sein. In Kapitel 3.2 entwickeln wir die in Kapitel 3.1 angewandte Methode zur Beurteilung der Zuverlässigkeit der für jedes Individuum gesammelten Informationen, um mit Hilfe der Michaelis-Menten-Modellierung Heimatorte zu bauen. Wir glauben, dass dies ein potenziell nützliches Instrument für Studien in der freien Natur sein könnte, wo sowohl die Knappheit der Daten als auch die individuellen Unterschiede in der Menge der gesammelten Daten bewegungsökologische Analysen erschweren können. Abschließend betonen wir, dass die soziale Evolution ein vielfältiger Prozess ist, der mehrere Ebenen der Lebenskomplexität in sich birgt und miteinander verflochten ist und sich den Versuchen einer einheitlichen Erklärung ihrer Ursprünge widersetzt. 


\section{Foreword}

This thesis is the result of four long years of work, of pitfalls and rethinking, of adapting and getting used to, it is a story of growth, both personal and of certain ideas that got refined, lost, abandoned, followed, and encouraged. The coherence of this work is, in my opinion, to be found in its contradictions, in its opposites, as a dialogical process that evolved and is still changing. Such dynamism reflects an ongoing process of transformation and will hopefully be faithful to the forces that generated it.

I decided to include some of the paintings that accompanied this difficult journey to maturing as a scientist and as a young adult. As the work by Carl Gustav Jung and Erich Newmann, among other psychologists, has shown, art is a door to the world within. A world of images that capture an inherently human intuitive knowledge about reality. This thesis wouldn't have been possible without those colorful, deeply subjective and inspiring moments.

The starting point of the project is bound, among other random encounters, to those that put Markus Port, Peter Kappeler, and me into a shared conversation. It is also profoundly bound to the mistakes done in the first field season in which an animal died due to a radiocollar that wasn't well adjusted. A conversation with my closest companion in those dark, hard-to-swallow moments, set for a change in the methodology betting for using artificial nests instead. It was a risky choice, and I must thank my supervisor, Peter Kappeler, for having trusted me to abandon radio-collars in favor of passive monitoring of nests with no guarantee. Fortunately, the trial gave some impressive results and served as the basis for today's thesis.

The line of thought was initially centered around dispersal strategies, on their importance as a determinant of kinship and, through kin selection, on its necessity for cooperation to evolve. However, this line of thought was later followed by a proposition of a different perspective on social evolution, which does not emphasize kinship. In the first chapter we propose a framework that takes into account the numerous and refined ways in which parental care may have catalyzed the evolution of group living. These ideas are published as a review article in Frontiers in Ecology and Evolution. We suggest that kin-selection is not the main force driving the benefits of grouping with others but an enhancer or even a byproduct derived from evolutionary processes related to parental care. By considering knowledge derived from both vertebrates and invertebrates, we put forward the importance of coevolutionary processes between parasites and predators with parental investment strategies long before transitions to sociality may occur.

We proceed by emphasizing the insightful rewards that studying facultatively social species may bring for understanding the processes that lead a solitary species to become groupliving. In this sense, we analyze in the second chapter, the social system of a facultatively 
social primate, Microcebus murinus. By studying sleeping site sharing in a wild population we search to characterize the individual social strategies and their inclusive fitness consequences. Due to a problem in the machinery needed for analyzing parentage we have to postpone our efforts for understanding the fitness consequences to the upcoming year. Nevertheless, characterizing the social system of this basal primate we are able to elaborate and criticize the ideas on parental care and social evolution exposed in Chapter 1 . We introduce among other ideas the necessity for conceptualizing the transition to sociality not as a genetically inherited black and white strategy that eventually invades the population but as a plastic capacity expressed depending on the context.

In the first two chapters, we discussed transitions to sociality from an adaptationist perspective. In Chapter 3, following an interesting critic raised by a member of the DFG Fachkollegium, we examine the possibility that sociality in Microcebus murinus may not relate to fitness benefits but be a passive result of heterogeneous distribution of resources and limitation of sleeping sites. The idea behind being that individuals living in better territories will have more descent due to these better conditions and have more chances of becoming social also due to this surrounding of relatives that share sleeping sites due to their limitation. This is, of course, a possibility, and we test for correlations between individual social strategies and the quality of the territory.

We further discuss the evidence for the different ideas proposed in the three chapters presented. Social evolution is a very complex process that embeds and intertwines several layers of life complexity, from cellular processes to ecological interactions between species on which the individual mind has to position itself and decide whether to become part of a group, the outcome of which natural selection will decide. 


\section{Acknowledgments}

My most deep and profound "thank you" is for Louise Peckre. Tu as été là les jours de soleil et surtout ces beaucoup plus nombreux de pluie (surtout depuis qu'on habite en Allemagne, qu'elle idée). Cette thèse telle qu'elle est aujourd'hui n'existerais pas sans toi, mon amour. Tu as contribué dans les discussions les plus importantes sur le contenu scientifique, mais surtout sur celles qui leur servait de nid en étant celles qu'on partageait au jour le jour, celles du regard au monde, celles du sentiment. Je voudrais juste te dire que c'était dur mais ça a valu le coup, le voyage qu'on a fait et que l'on fait encore, que ça soit à travers le monde, du bitume des banlieues aux forêts tropicales des ancêtres, avec des amis et des dangers, ou à l'intérieur de nous-mêmes en grandissant et en nous connaissant, cela a été une vraie richesse et encore plus de le partager avec toi.

Als meus pares, m'agradaria donar-vos ses gràcies per haver-me cuidat, per haver-me donat es vostre suport i sobretot per haver-me estimat. Un fill no necessita més ni menys. Moltíssimes gràcies des de lo mes profund. A sa meva germana i a nes meu germà per « tres cuartos de lo mismo ", un beso molt fort guapos.

A Ricard, per sa seva positivitat inclús a nes moments més durs. Tu m'has mostrat que tenim bons peus i un camí a recórrer fins es dia on tot s'acabarà per noltros. Moltes gràcies de tot cor.

A Mar, Juan Ma, Jaume i Adrià per haver-me descobert es vertader sentit de s'amistat. Els anys passen i anam visquent. Lo que vàrem compartir viu encara, valent, resistent i ple d'allò mes valuós, sa bona companyia. Vos estim molt.

A Juan y Fito por esos momentos que sintiendo pena de un lado u otro nos consolamos al son de nuestra música y nuestras risas. Mucha suerte amigos.

A Sonia aussi, merci pour ton aide et ta compagnie, qui admet le silence quand il n'y a rien à dire, et ça fais trop du bien. 



\section{Table of content}

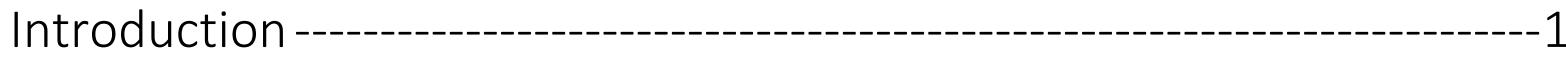

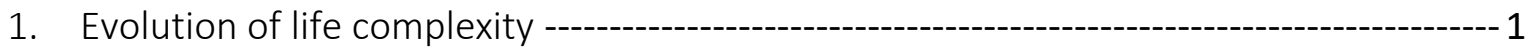

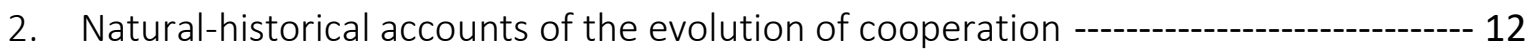

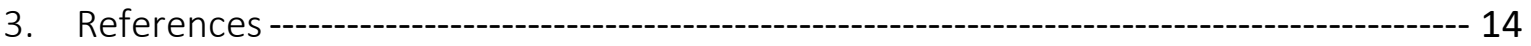

Chapter 1: Catalyzing transitions to sociality: ecology builds on parental care

1. Social evolution--- 23

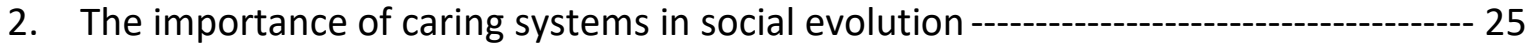

3. A framework incorporating caring system evolution in solitary ancestors ------------ 28

4. Parental care and social transitions in central place foragers -------------------- 32

5. Parental care and social transitions in fortress defenders--------------------------- 40

6. Parental care and social transitions in itinerant foragers ----------------------- 44

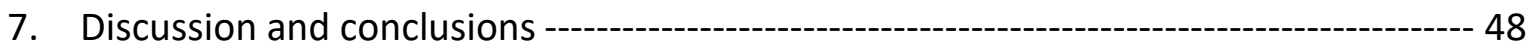

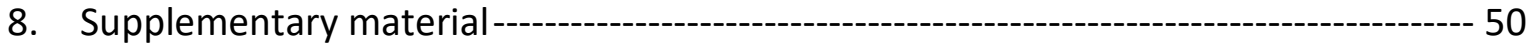

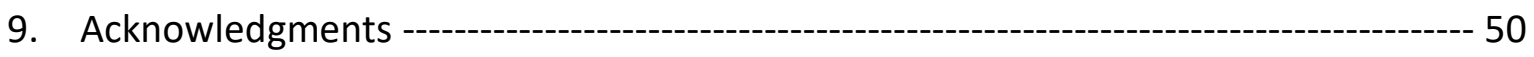

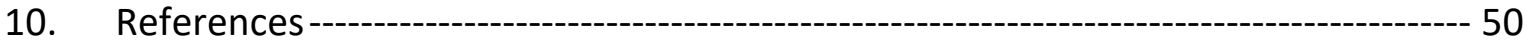

Chapter 2: Social dynamics in a facultatively social primate,

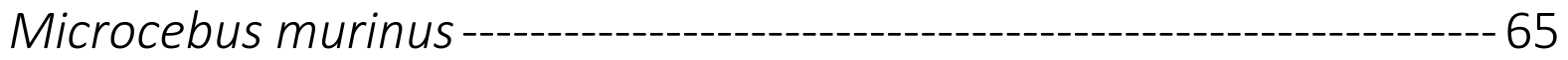

1. Introduction ------o- 65

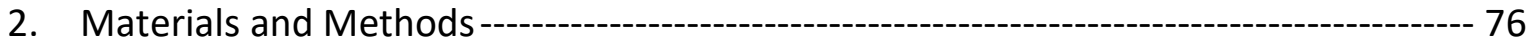

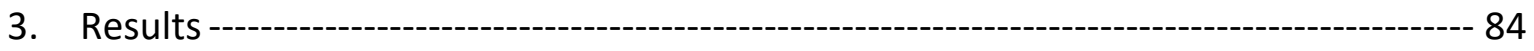

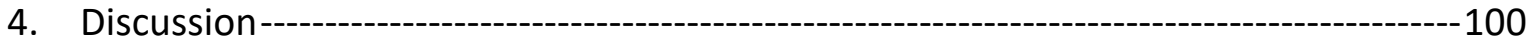

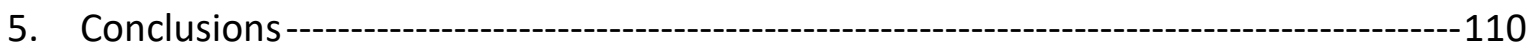

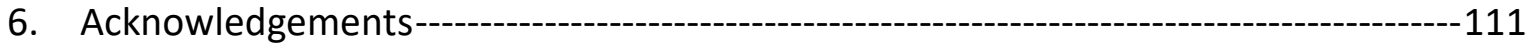

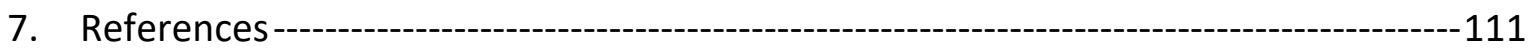

Chapter 3.1: Effects of resources on gray mouse lemur sociality --- 123

1. Introduction ---o-_en 


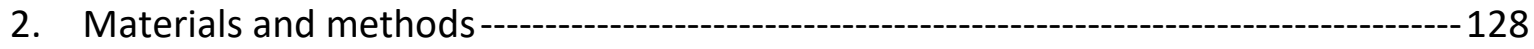

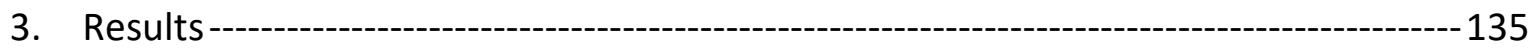

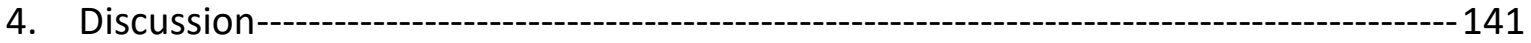

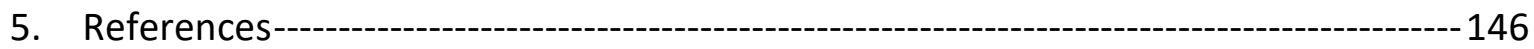

Chapter 3.2: Michaelis-Menten modeling applied to Home Range analyses ------------------------------------------------------------------151

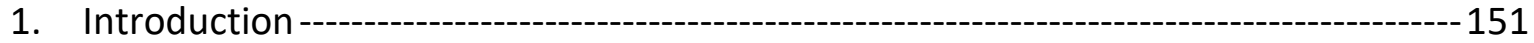

2. Material and Methods -- 154

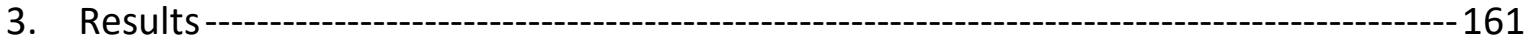

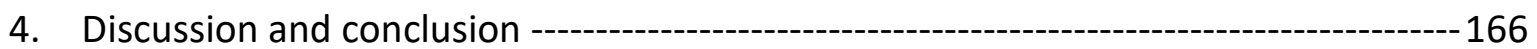

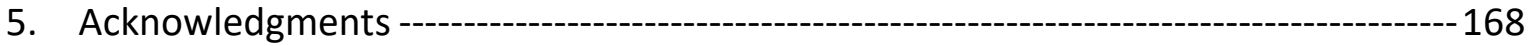

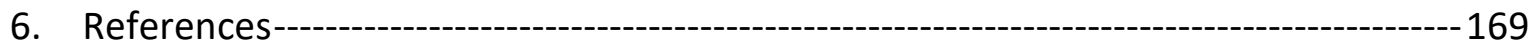

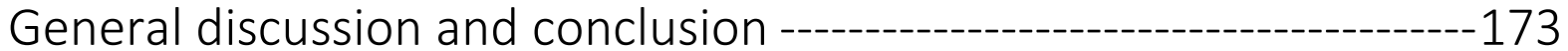

1. Inclusive fitness and social transitions -

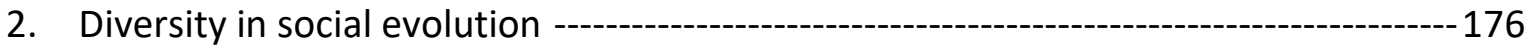

3. Mouse lemurs and primate social evolution--

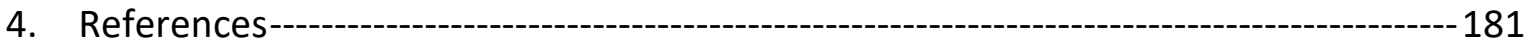




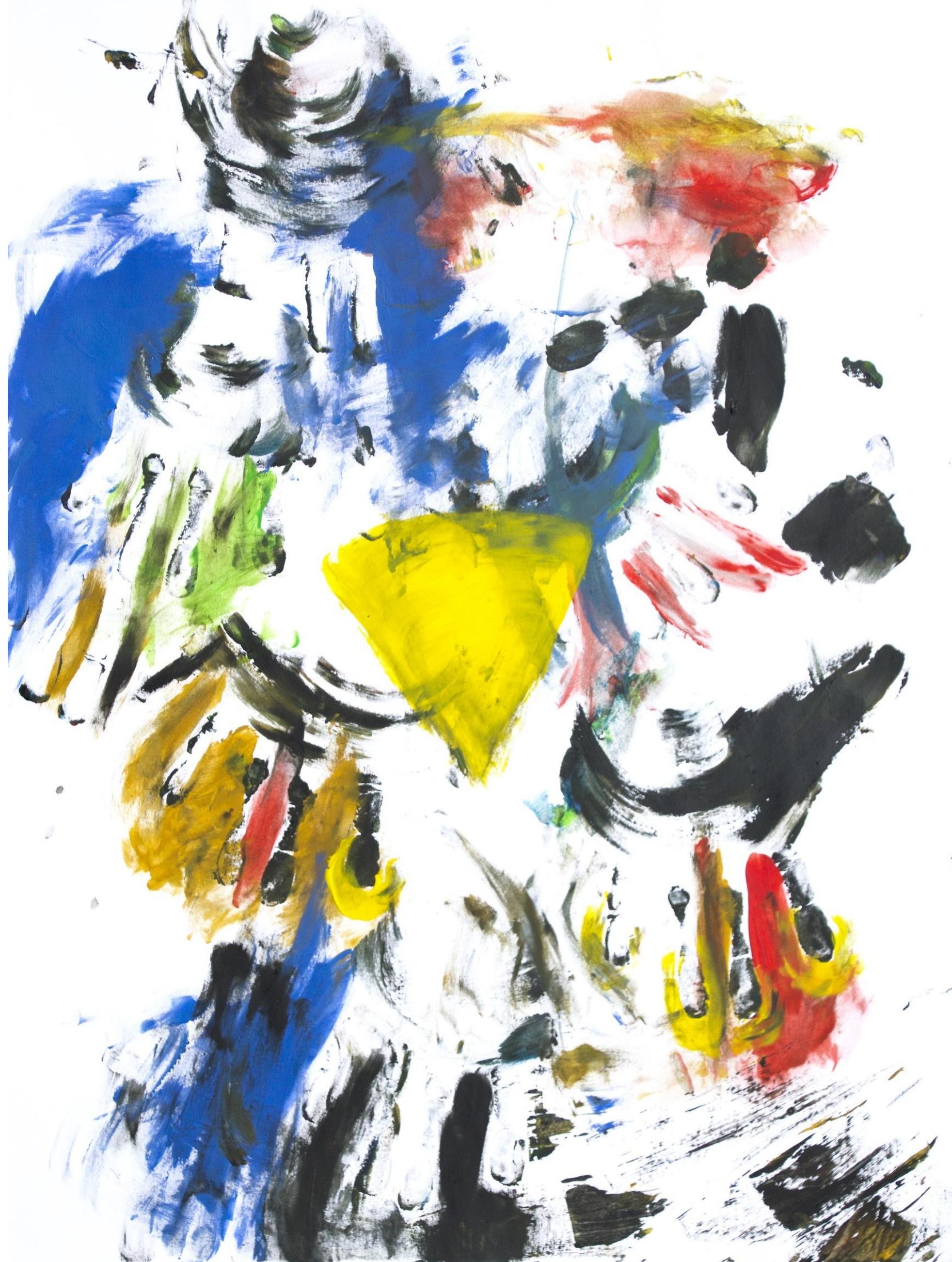




\section{Introduction}

When one gets his or her path on evolutionary biology, it is usually accompanied by a sense of marvel, beauty, and a terrible headache coming from the astonishing simultaneous perspectives one can have on most of the processes studied. Perspectives may encompass from the timescale differences on the mechanisms explaining the presence of a given trait condensed into the four questions of Tinbergen to the multiple levels at which selection can take place, from genes to groups. In this sense, plurality is indissociable from the study of the evolution of life. Now, this plurality is for most of us impossible to grasp simultaneously, and one keeps rediscovering and shifting from one perspective to another. Throughout this manuscript we are going to jump across different levels, and this will come with limitations in depth of each perspective analyzed but hopefully will retain the enchantment that the subject possesses.

\section{Evolution of life complexity}

When looking through evolutionary history, an interesting trend appears. Life becomes more complex in a multiplicity of ways forming what has been called an evolutionary syndrome (Maynard Smith and Szathmary, 1997; McShea, 2001, 2002, 2016; Jablonka and Lamb, 2006; Corning and Szathmáry, 2015). Although defining complexity is challenging, and no agreed scientific definition has been established (Adami, 2002; Peckre et al., 2019), it can be understood intuitively as an increase in quantity, quality, or diversity of relations between the parts of a given system (Pollard and Blumstein, 2012). This increase in complexity can occur, therefore, at different levels, from the information in the genome to the body architecture, to the behavior giving rise to astonishing new ways of increasing reproductive success or survival (Jablonka and Lamb, 2006; McShea, 2016).

The timing of these changes and complexifications in the history of life are uneven (McShea, 2016) and show that entire lineages explode and diversify for short periods and stabilize for more extended periods eventually getting to extinction (Flegr, 2010). Based on evidence from the fossil record as well as from experiments on directed selection, Flegr (2010) proposed the frozen plasticity theory. According to his theory, over evolutionary time, species become so complex that their genetic pool diversity is maintained despite selection through several mechanisms making impossible further macroevolutionary changes. Epistasis and pleiotropy, difficult heritability and positive selection on adaptive traits, while frequency-dependent selection balances phenotype abundance impeding population shifts (Hoffmann, 2013; Pujol et al., 2018). Only when population size is decreased drastically so that the previous genetic pool is imbalanced and frequency-dependent selection inoperative, there is potential for macroevolutionary change. The effects of diversity explosion on islands, adaptive radiations following mass extinctions as well as evolutionary 
stasis following such radiations are explained by the frozen plasticity theory. When systems become too complex and their parts highly interconnected, their capacity for adapting is compromised, and species become elastic not plastic.

It has been proposed that for species into evolutionary traps based on high complexity (i.e., frozen species), the only way to find adaptive solutions to problems arising in the environment might come from major transitions into higher levels of complexity through cooperation (Toman and Flegr, 2018). When highly complex organisms that have been optimized by natural selection become evolutionarily frozen, integration of individuals into groups could allow new potentials for adaptation. For example, if few of the cells maintain the core of necessary metabolic functions in a colony of bacteria, the rest of the colony can redirect their activities into new processes, implying a new potential for becoming more efficient in reproducing or surviving. From these processes, division of labor may be selected and generate different types of parts and more connections between them, which will, in turn, become again by such process, evolutionarily frozen. Thus, evolutionary trends for static systems of highly complex and interrelated lower levels of particles can be overcome temporarily by the integration of the parts into a higher level of complexity. The adaptive value of such integration has been shown experimentally for different transitions (Boraas et al., 1998; Rainey and Rainey, 2003; Nakajima et al., 2009; Mikát et al., 2016) and indirectly by the evolutionary radiations ensuing from the appearance on earth of new types of organisms.

This integration of individuals into a new whole has been termed a major evolutionary transition, and currently, a handful of these transitions are recognized (Maynard Smith and Szathmary, 1997; West et al., 2015). The generation of genomes from the aggregation of genes circa 3.5 billion years ago allowed the creation of the first bacteria. The integration of several bacteria generated the Eukaryotes 1.7 billion years after the emergence of bacteria. In turn, Eukaryotes formed multicellular organisms by aggregating into colonies that further evolved independently into plants, fungi, and animals around 0.6 billion years ago. Animals, in turn, aggregated into social groups, and some lineages of invertebrates carried these social units to a level of integration where individuals cannot reproduce independently anymore, the reproductive unit being the colony, around 0.12 billion years ago.

\section{a. The problem of transitions to higher hierarchical levels or the paradox of cooperation}

When trying to understand major evolutionary transitions, one has to deal with the paradox of sacrifice, cooperation, and altruism. In order for the whole to be sustained, particles in a level of complexity offer services to each other. The transitions into higher hierarchical levels are, therefore, based on cooperative acts. Cooperation has been defined as any behavior that has been selected because it increases the fitness of another individual at the 
expense or the favor of the donor's fitness (West et al., 2007). Thus, paradoxically cells or individuals offer services to or tolerate the activities of other such cells or individuals with whom they are directly in competition over fitness.

Cooperation is a paradox because under natural selection for most competitive phenotypes, one would expect individuals helping others to reproduce being at a disadvantage. Reinforcing this disadvantage is the fact that the recipients of cooperative acts are not obligated to cooperate in turn and should be selected to benefit without paying any cost as "free riders" or defectors. This would reinforce the negative selection on cooperators impeding major transitions in evolution. Thus, sacrifice in a world where natural selection takes place implies previously antagonistically agents despite being optimized for competing to twist their behavior for a higher level of organization to emerge. As Mandeville posed poetically:

Thus every Part was full of Vice,

Yet the whole Mass a Paradise;

Flatter'd in Peace, and fear'd in Wars,

They were th' Esteem of Foreigners,

And lavish of their Wealth and Lives,

The Balance of all other Hives.

(Mandeville, 1705, p. 9, I. 155)

The evidence is, nevertheless, that despite theoretical implausibility, cooperation is widespread in many forms and has been successful in generating new hierarchical levels of complexity (Maynard Smith and Szathmary, 1997; Bekoff, 2004; Okasha, 2006). It is also important to note that even if these major transitions have been accomplished, previously egoistic agents have not turned entirely into a completely harmonious unit. Even genomes or cells are not exempt, and examples of competition for replication can be found in meiotic drivers and tumors (Kozlov, 1996; Lindholm et al., 2016). Even in the most integrated animal groups made up by Hymenopteran colonies, termed "superorganisms," conflicting interests between the queen and the workers over the sex ratio of offspring are at play (Ratnieks et al., 2006). This tension between cooperation and conflict results in a dynamic equilibrium between selective pressures that continue to act at all levels of biological complexity. In this sense, even if individuals of a given species have come to organize themselves around groups, the actual result of the interactions will fall into an intermediate point somewhere 
between the individual optimum and the one of the group as a whole. For example, when living in groups formed by heterogeneous individuals, coordinated activities may result in costs due to different optimal budgets for each activity depending on individual characteristics such as body size, sex, and reproductive activity (Strandburg-Peshkin et al., 2015). Therefore, by staying together and coordinating, each individual deviates from its own optimum and lowers its potential maximum fitness.

\section{b. Evolutionary mechanisms sustaining cooperation \\ 1. Kin selection}

Since genes are inherited, different individuals may share common genes if these individuals are linked through common descent. J. B. S. Haldane proposed that altruism should be directed to relatives and that the cost of altruistic acts should be in accordance with the strength of kinship between these (cited in Dugatkin, 2007). If individuals are related, and if cooperation is maintained by genes, helping relatives means helping cooperators. In this sense, cooperative animals help reproduce carriers of the helping gene, spreading cooperation at the population level. Thus, if individuals interact with kin, cooperation can evolve, and the threats of cheating are suppressed. If cheaters act on cooperators to whom they are related, their inclusive fitness will be negatively affected, and therefore, defecting will be counter selected. Further on, Hamilton condensed this into a mathematical equation known as Hamilton's rule $\left(r^{*} B-C>0\right)$ and helped a new way of understanding natural selection to be born (Hamilton, 1964).

Kin selection has been a fundamental advance in our understanding of the evolution of biological traits in that it generated a broader notion of fitness. Lifetime reproductive success was no longer defined by the number of offspring an individual succeeds in contributing to the mating pool of next generations. The concept of indirect fitness emerged, encompassing the benefits of successful reproduction by kin. By uniting indirect and direct fitness benefits, one gets the inclusive fitness of an individual. In this sense, the insight from Hamilton led to a broader understanding of what natural selection maximizes, that is, the inclusive fitness of individuals.

A current ongoing debate challenges the position of kin selection as the dominant paradigm for understanding the evolution of social behavior and cooperation. Two schools of thought debate about the usefulness and the generality of Hamilton's rule and the validity of inclusive fitness theory as an explanation for the evolution and maintenance of cooperation. The advocates of inclusive fitness theory (West, Frank, Gardner, Grafen, Lehmann, Queller, Rousset, Roze, Taylor, Pen) among others, claim that Hamilton's rule is an intuitive form of describing complex population dynamic processes that takes the point of view of interacting biological entities. Inclusive fitness offers biologists a framework for 
generating clear predictions that take into account magnitudes which can be easily grasped by the mind without the need for sophisticated abstract mathematical formulas. Thus, inclusive fitness is a useful framework of general utility for describing the evolution of costly traits with clear empirical evidence supporting its validity (reviewed in Clutton-Brock, 2009; Abbot et al., 2011). Moreover, inclusive fitness theory discrimination between direct and indirect fitness is crucial for conceptualizing the evolution of traits in nature and offer a way of expanding the traditional view on reproductive success and create a more comprehensive vision of evolution (West et al., 2007).

Despite these facts, quite a number of leading evolutionary biologists state that the assumptions in Price's equation and Hamilton's rule (which constitute the mathematical bases for inclusive fitness theory) apply only under narrow conditions such as weak selection and vanishing mutation (e.g. Wilson and Hölldobler, 2005; Fletcher et al., 2006; Wild and Traulsen, 2007; Fletcher and Doebeli, 2009, 2009; Van Veelen, 2009; Nowak et al., 2010b, 2010a, 2017). Thus, inclusive fitness theory might not be as general as currently recognized for understanding the evolution of cooperation. Three primary intuitive points of flaw can be drawn from their critics to Hamilton's rule and inclusive fitness theory. First, this simple rule is based on the interactions between two individuals, but the result of such interactions can affect other individuals later on. For example, if an individual help another to survive, and the survivor, later-on, helps other related individuals to survive, should all the benefits be traced back to the first cooperative act? Secondly, if the immediate effects of helping an individual diffuse to several individuals, which relatedness coefficient should be used to assess the benefits? It is, therefore, not clear how real-world examples should be dealt within the framework of inclusive fitness. Thirdly, inclusive fitness might depend on which generation of individuals' point of view is used. As Alexander (Alexander, 1974) pointed out, a behavior that is negatively selected through inclusive fitness between two siblings might still be beneficial in the total number of grandchildren produced from the grandparents' point of view. Thus, parental manipulation could be at play, and a conflict of interests and points of view difficult the use of Hamilton's rule. Overall, it is clear that in the upcoming years, changes in the way of understanding inclusive fitness will ensue from the defenses and critics briefly exposed here.

\section{Dispersal, clustering of kin and its implication for cooperation}

In exception of green beard effects, which correspond to identical genes being found in non-kin individuals, kin selection needs from the clustering of close relatives (West et al., 2002). Kin selection is therefore tightly connected with dispersal regimes. Individuals or cells are created by their kin, and the only ways of interacting with them might be through natal philopatry, i.e., by staying near their progenitor/s or by dispersing in cohorts. On the 
one side, dispersing is considered extremely costly navigating, and being exposed to new environments entails higher risks of mortality (Ronce, 2007), which would select for philopatry. On the other side, clustering with kin might be detrimental due to competition for resources or mates and the costs of inbreeding (West et al., 2002). Due to the counteracting forces enhancing dispersal and philopatry, the trade-offs experienced by individuals in these decisions and after them are thought to be of great importance for understanding the evolution of cooperation.

An important variable that may affect the evolution of dispersal and cooperation is sex (see chapter 2). Most species have at least two sexes that are associated with different competing regimes for resources and mates (Trivers, 1972; Kokko and Jennions, 2008). The adoption of dispersal in social species by one of the two sexes is thought to be an effective strategy for reducing inbreeding and competition for mates and resources allowing kin selected benefits to be optimized (Greenwood, 1980; Dobson, 1982; Pusey, 1987; CluttonBrock and Lukas, 2012). Nevertheless, the effects of competition between kin canceling the benefits of kin selection are amplified in models that take into account sex-biases in dispersal (Queller, 1992; Taylor, 1992). Thus, dispersal evolution could be the result of other processes not directly related to kin selection when taking into account the effects of sex. Interestingly, sex-biased dispersal is already present in solitary species, generally as a difference in the extent of dispersal. In most species, this results in the generation of neighborhoods of related individuals from the more philopatric sex. Since variation in the extent to which males or females disperse exists across taxa in a consistent manner with, for example, male-biased dispersal being prominent in mammals while female-biased dispersal being the norm in birds (Pusey, 1987). In chapter 1 we develop a framework that draws attention to the effects of parental care variation on the evolution of cooperation. Here we would like to develop few of the ideas not contained in chapter 1 . Until now, most theoretical research to understand the evolution of sex-biased dispersal has focused on its coevolution with mating systems and reproductive altruism. Less attention has been directed towards the relationship between parental care and dispersal patterns. Since caring systems and mating systems are, to some extent, independent of each other (Komers and Brotherton, 1997; Fromhage et al., 2005; Kappeler, 2019, 201), the respective roles of parental care and mating competition for the evolution of sex-biased dispersal should be investigated further.

A game-theoretical model examined the co-evolution between sex-biased dispersal and mating systems (Perrin and Mazalov, 2000), and as we argue, indirectly between parental care and sex-biased dispersal. Three main axes can be drawn from examining the model construction and variables. There are two major costs of interacting with kin, local competition for resources (LRC), and local competition for mates (LMC). Since this model is 
based on the evolution of groups through retention of offspring, a third component based on inbreeding depression is added. Under its assumptions, the authors predict that when LRC is more pronounced for females than LMC for males, then females are expected to disperse to avoid competing with relatives for resources and vice-versa (Perrin and Mazalov, 2000). Therefore, the prediction is that polygyny and male-biased dispersal reinforce each other because this mating system imposes high costs of competing with male relatives for mates. Interestingly, although the title and the model are intended to apply generally to the evolution of sex-biased dispersal in animals, one of the assumptions of the model that has far-reaching consequences was female-only care. This is arguably a major factor influencing their results on male-biased dispersal and the predictions concerning mate competition. The model by Perrin and Mazalov (2000) can be reformulated as predicting philopatry by the most parental sex when competition for resources needed for raising offspring is low enough. The authors note that an extension of the model that would include the benefits of cooperating with kin in parental duties will also have implications for the predicted results. We predict that when cooperation can take place, the range of abundance or distribution of resources allowing for the caring sex to be philopatric will be widened up (see chapter 1 ).

A recent model examined the co-evolution between sex biases in care and dispersal. This model by Kuijper and Johnstone (2017) deals with parental conflict over care in a biparental species and relate asymmetries in dispersal with parental investment. Their assumptions concern individuals that already live together in patches where reproduction takes place. This implies that sociality has already evolved into a biparental caring species or a communal caring species. Interestingly, their results predict that sex-biases in philopatry lead to sex-biases in the amount of care. This is because whenever an adult of the philopatric sex dies, it is likely to be substituted by a relative. Therefore, if caring for young is costly, as in most cases (e.g., Owens and Bennett, 1994), such costs in terms of mortality are compensated by the presence of kin that will inherit the breeding position. Interestingly, the relationship is as strong as to overcome already well-established relations between operational sex ratio and parental care (Kokko and Jennions, 2008). The more philopatric sex will care more even if it is the more frequent sex. Although this has been seen as evidence that any bias in philopatry, even in solitary species, will lead to biases in care, biases in care have also been pointed out as drivers of philopatry by socioecological models developed for vertebrates (Emlen and Oring, 1977; Wrangham, 1980). This concerns probably a coevolutionary process that would need detailed phylogenetic history for different taxa concerning dispersal and care systems in order to be better understood. Importantly, since some forms of cooperation and sociality arise through non-kin cooperation and this usually concerns the sex that is caring in the ancestral species, caring 
could be driving philopatry and kin structure and not the other way around (Gadagkar, 1990; Socias-Martínez and Kappeler, 2019).

\section{Mutualism}

Direct benefits arising from costly cooperative acts might be a powerful force in the evolution of cooperation. Direct benefit from joint action prevents the effects of free-riding because marauding individuals or particles are not able to defeat (Clutton-Brock, 2009). Such relationships are the basis of eukaryote cell formation, which enabled host cells and mitochondria to benefit simultaneously from their association (Sagan, 1967; Gray, 2017). The pioneering species of lichens are based on mutualistic interactions between photosynthetic algae and fungi where the activities of each member in the association benefit the other and allow the colonization of new niches (Herre et al., 1999). Similarly, symbiotic relationships between gall-inducing insects and fungi are supposed to have catalyzed a high capacity for niche expansion and diversification (Joy, 2013). In animals, within-species mutualism relates to accessing new niches through the dilution of predation pressure, enabled a higher success rate in hunting, and allowed for raising young cooperatively (Alexander, 1974; Kokko et al., 2001; Clutton-Brock, 2009; Socias-Martínez and Kappeler, 2019). It has been suggested that group selection models indeed portray a mutualistic relationship because cooperators in groups also benefit from their own actions directly through increased reproductive success in comparison to non-cooperators in other

groups (West et al., 2007). Thus, as we will discuss further in chapter 1, emphasis on kin selected benefits may have hindered the importance of direct benefits on the origins of cooperation.

\section{Reciprocity}

If cooperators do not obtain a simultaneous advantage like in mutualistic relationships, they should be counter selected. Despite this fact, interactions between individuals may repeat over time, offering potential for adaptive responses to the strategies displayed by the interacting partners and enlarging the scope of the evolution of cooperation (Trivers, 1971). In the context of repeated interactions, for cooperation to evolve, cooperators have to be able to meet defectors with a defector strategy and other cooperators with a cooperative strategy. Matching the partners' strategy has been described as a "mirror" strategy that gives back what received and is generally mostly known in the form of "tit-for-tat" (Nowak and Sigmund, 1992).

By using a flexible strategy such as "tit-for-tat" interactions between cooperators generate higher benefits than those of individuals unwilling to cooperate and leads eventually to cooperation spreading in the population. The spread of cooperation is nevertheless only possible when a certain degree of forgiveness is at play. Individuals make mistakes, and 
even those willing to cooperate may defect at some point. If individuals are not able to forgive and start defecting, cooperation stops, and only defection prevails. Simulations have shown that when direct reciprocity is at play and strategies are allowed to evolve, a dynamic system with no equilibrium emerges in which the population switches from cooperation to defection passing through the possible intermediate strategies circularly (Nowak and Sigmund, 1989; Imhof and Nowak, 2009).

Generally, direct reciprocity needs from individual recognition and certain cognitive capacities allowing for tracking specific relationships over time and the outcome of own and the interacting partners' strategies. Due to this, it has been argued that it might be common in humans while more limited in the animal kingdom. Despite this, evidence suggests that the capacity for direct reciprocity in animals might have been underestimated (Wilkinson, 1988; Clutton-Brock, 2009; Brandl and Bellwood, 2015; Freidin et al., 2017).

Indirect reciprocity is a mechanism that sustains cooperators that are not in direct interaction. A given cooperator will help another individual but will eventually receive back a cooperative act from a third individual. This mechanism needs a way of portraying information about who aided who in a public manner. As David Haig condensed, "For direct reciprocity, you need a face, for indirect reciprocity, you need a name" (Nowak and Highfield, 2011). Reciprocal altruism as a generalized phenomenon is thought to be restricted to humans and the presence of language and gossip (Giardini and Vilone, 2016). Therefore, we will not go in detail here and continue our inquiry.

\section{Group selection}

A framework that is gaining support in the last decades proposes that selection at other levels than the individual may be responsible for the evolution of cooperation. While in animals, for example, it is broadly recognized that the individuals are the unit of selection, other units may appear from how populations are structured or subdivided. If animals aggregate into clusters, competition between individuals may be joined by competition between groups over reproductive success. In this context, individuals that cooperate are at a disadvantage within their group and should be therefore counter selected. Nevertheless, groups with more cooperators may do better either because less competition implies fewer costs (reduced aggression or stress) or because cooperation results in fitness benefits (e.g., increased foraging success). Thus, cooperators despite being at a disadvantage within their group may do better than non-cooperators in other groups, and their progeny may be able to spread in the population. Group selection can be understood as a form of mutualism, because cooperators despite doing worse than others in their group, benefit directly from their cooperative acts since the whole group do better at the population level (West et al., 2007). Moreover, groups may be competing with each other, and bigger groups and/or 
more cooperative groups may outcompete other groups (Wrangham, 1980; Kokko et al., 2001). Moreover, more varied groups may dispose of a greater diversity of tools and capacities for competing with others, and cooperation in a context of diversity might also explain its persistence in the population(Nonacs and Kapheim, 2007). A great number of population genetic models have shown that indeed traits such as cooperation that may be disfavored within groups can thrive at the population level when competition between groups is at play (Gintis, 2000; Boyd et al., 2003; Traulsen and Nowak, 2006; Kulich and Flegr, 2010).

As we have seen above, kin selection, the dominant paradigm in behavioral ecology and sociobiology, is being severely criticized. Important critics have been made to the concept and the mathematical expressions used to calculate inclusive fitness (e.g. Nowak et al., 2010, 2017). Most of these critics come from mathematical biologists and population geneticists, which propose that group selection may be a more general force driving the evolution of costly social behaviors and that this phenomenon does not require genetic relatedness. What is less broadly recognized is the fact that in a general context, this account of multilevel selection and altruism is mathematically virtually equivalent to kin selection (Kramer and Meunier, 2016).

\section{Spatial selection}

If interactions are made on a local basis, i.e., if individuals in proximity tend to interact more often than individuals further apart, the evolution of cooperation may be affected by such spatial structure. Indeed, some models show that spatial clustering can be an effective mechanism that is independent of kin and group selection (Nowak et al., 2010a; Su et al., 2019). In this type of model, cooperation is enhanced by social learning, and the spatial structure generates cooperative neighborhoods that sustain cooperation and deter cheaters. Other models have coupled this spatial structure with kin selection. A model by Eliassen and Jørgensen (2014) shows how extra-pair paternity may enhance cooperative actions in neighborhoods because parents may have offspring in very different nests and their interests become aligned with those of the entire neighborhood.

\section{c. The other side of the coin, the effect of the environment}

The mechanisms explained above coincide in generating assortment between cooperators. These abstractions focus on individual interactions and seeking simplicity, the environment where these interactions take place is ignored. However, the environment is key to understand the evolution of cooperation because it determines the magnitude of costs and benefits of cooperative activities as well as the nature of the cooperative activities from which individuals can benefit (chapter 1 and 3). 
1. Temporal heterogeneity

Recent theoretical frameworks have demonstrated that cooperation may be an evolutionarily stable strategy through stabilizing fitness under variable environments (Starrfelt and Kokko, 2012; Kennedy et al., 2018). Even if cooperating individuals and their kin have lower reproductive success due to the costs of cooperation, the fitness across generations of these lineages might be greater than those of non-cooperating individuals. When conditions vary, the reproductive success of individuals fluctuates accordingly. The change in fitness depending on environmental conditions is nevertheless severely affected by cooperation. The effects of cooperative interactions allow to mild the negative effects of harsh environmental conditions on reproductive success. Thus, when conditions are bad, cooperation expresses its most important adaptive value and makes the difference. This results from the fact that when everybody does bad because the environment is harsh, cooperating individuals do better, and in such moments, their contribution to the next generation is extremely influential. Since fitness is relative to the population reproductive success, a small difference when reproduction is low at the population level, such as when the environment is harsh, becomes exceptionally relevant and makes cooperation an evolutionarily stable strategy. Evidence from white-browed sparrow weavers suggests that the benefits of cooperative breeding in this species is indeed a form of bet-hedging (Pablo Capilla-Lasheras and Andrew J. Young personal communication). Additionally, indirect evidence comes from studies linking the distribution of cooperative breeding in birds with environmental variation (Rubenstein and Lovette, 2007; Jetz and Rubenstein, 2011). Evidence for the role of variability in the evolution of cooperation can also be found in mammals and invertebrates (Lovegrove and Wissel, 1988; Sheehan et al., 2015).

Interestingly, a recent model opposing kin-selection and mutualism in fluctuating environments suggests that mutualism might do better in such conditions. Under fluctuations, kin suffer similarly because they resemble each other. On the contrary, mutualists are able to associate with individuals that have a different optimum environment (Uitdehaag, 2011). By doing so, mutualism prevails over kin-selected strategies.

Non-adaptive mechanisms have also been proposed to explain sociality in variable environments. Spatiotemporal variability in resource distribution coupled with a territorial ancestor might favor sharing a territory but without a need for cooperation or costs. This explanation has been inspired by comparative studies of carnivorans, whose diets are based on patchily distributed resources. It is thought that due to the variability of the prey (because they appear suddenly or because might be very different in size), the minimum territory size to support a solitary individual or a reproductive couple might regularly produce a surplus that would allow other individuals to live in it at no cost (Macdonald and 
Johnson, 2015). Accordingly, a putative ancestral species secured a territory that allowed survival and reproduction, but, because of the minimum size needed to account for "bad days", it also provided more resources than needed during any other day. If animals can support scarcity during low productivity periods, other individuals may join.

\section{Spatial heterogeneity}

This is dealt with in more detail in the introduction of chapter 3. Briefly, if resources are not evenly distributed in space, the payoffs of cooperative activities might change, and cooperating might offer greater benefits than costs. Since animals are limited in their digestive and metabolic capacities (Speakman and Król, 2005), living in an area where food resources are extremely abundant can decrease the level of competition between individuals. Moreover, if individuals compete over access to resources, cooperation may ensue as the socio-ecological model in primatology suggests (Wrangham, 1980) implying group selection if between-group competition is the primary driver of the benefits of cooperation.

\section{Natural-historical accounts of the evolution of cooperation}

We have shown that the evolution of cooperation might result from a bewildering range of mechanisms that result in the assortment of cooperating individuals to interact with each other. Furthermore, temporal and spatial environmental variability is suggested as a motor facilitating and enhancing the benefits of cooperation. However, knowledge on the evolution of life complexity through cooperation is difficult to gather clearly, and several controversies in the field are today present hindering or enhancing a further comprehension of this fascinating evolutionary paradox. This is in part because theories and models of the evolution of cooperation are abstractions that reflect simultaneous points of view of the changes in complex evolutionary systems. The predictions of models and different accounts can be deeply affected by the variables considered in the analyses and the weight given to them. The factors intervening in the evolution of a species are extremely complex and may even relate to environmental or other species' evolutionary dynamics. For example, an interesting area for further research concerns coevolutionary dynamics with other species such as parasites, predators, prey, or mutualist relationships such as those between pollinators and dispersers of fruiting plants (Hunt and Toth, 2017; Wcislo and Fewell, 2017). It appears therefore that there is a whole new range of hypotheses and effects to consider when going from individual interactions to those that appear at the population or the ecosystem level. For example, could fruiting plants modulate the cost-benefit because of higher or lower benefits of fruit dispersal depending on the social organization of their dispersing species? Another example concerns predators; predator avoidance has been suggested as playing an important role in several taxa for the evolution of sociality and even in unicellular organisms (Alexander, 1974; Boraas et al., 
1998). However, to our knowledge, there is no hypothesis relating the position in the trophic chain of a given species to its probability of generating higher levels of complexity. The position in the trophic chain can relate to the number and diversity of predators, which could, in turn, relate to the evolution of cooperation.

To further understand the transitions from one level of complexity to the next, a more historical account is needed where reconstruction of transitions between solitary and social ancestors is helped by phylogeny and information from putative solitary ancestors. Phylogenetic accounts have given insights into the contexts of social evolution. For example, the importance of genetic relatedness for eusociality to evolve has been shown through several phylogenetic studies. Monogamy and the high relatedness among siblings that it generates have been shown as the ancestral state for eusociality in wasps, bees, and ants (Hughes et al., 2008). The same pattern has been found in eusocial snapping shrimps (Duffy, 2007) and cooperative breeding societies in birds and mammals (Cornwallis et al., 2010, 2010; Lukas and Clutton-Brock, 2012). Nevertheless, other accounts suggest that monogamy might be correlated with other ecological variables favoring cooperation (Nonacs, 2011). Similarly, the role of predation pressure has been suggested fundamental for the evolution of sociality from solitary ancestors in primates based on phylogenetic reconstructions (Shultz et al., 2011). Nevertheless, a controversy surrounding a similar study on the evolution of monogamy warns against conclusions based on phylogenetic reconstructions alone since subjective classification of social systems may render different results with similar datasets (Lukas and Clutton-Brock, 2012; Opie et al., 2013). The benefits of such an approach may be well illustrated by the work of (Griesser et al., 2017) which has shed some light on the evolution of sociality and cooperative breeding in birds. Their informed reconstruction allowed to portray a story where family living (i.e. the transition from solitary to group living) occurred in stable habitats through habitat saturation. Further on, such families evolved cooperative breeding and were able to colonize and thrive in harsh and unpredictable habitats. Phylogenetical account may show a pattern, but the actual causes may remain casted since a given pattern may result from different causes.

Another concern for the evolution of life complexity and sociality in particular concerns the nature of the empirical knowledge on costs and benefits of social strategies. The vast majority concern the most derived forms of cooperation with reproductive altruism. The second major source comes from species that have a long evolutionary history of sociality. By relying exclusively on this evidence, our perception of the processes that led solitary ancestors to form social groups may be distorted due to several confounding effects. These effects may arise from derived traits that hinder solitary strategies and the payoffs of these to be observed like social need for correct development, functioning, reproducing, and 
surviving. Nevertheless, some species show simultaneously social and solitary strategies, called facultatively social species. Knowledge from dynamics, costs, and benefits of different strategies in these species may be extremely useful in the future to help disentangle the controversies surrounding social evolution.

In the first chapter, we bring forward a new framework to study the evolution of sociality that emphasizes the role of parental care evolution in solitary ancestors as a key for understanding transitions to sociality in disparate taxa and pays special attention to facultatively social species. In the second chapter, we describe the social dynamics of a facultative social primate. We discuss possible mechanisms with special emphasis on mutualism and kin, group and spatially selected benefits and costs of cooperation. In the third chapter, we evaluate the possible correlates between sociality and the environment measured as the abundance and diversity of resources.

\section{References}

Abbot, P., Abe, J., Alcock, J., Alizon, S., Alpedrinha, J. A., Andersson, M., et al. (2011). Inclusive fitness theory and eusociality. Nature 471, E1.

Adami, C. (2002). What is complexity? BioEssays 24, 1085-1094. doi:10.1002/bies.10192.

Alexander, R. D. (1974). The evolution of social behavior. Annual review of ecology and systematics $5,325-383$.

Bekoff, M. (2004). Wild justice and fair play: cooperation, forgiveness, and morality in animals. Biology \& Philosophy 19, 489-520. doi:10.1007/sBIPH-004-0539-x.

Boraas, M. E., Seale, D. B., and Boxhorn, J. E. (1998). Phagotrophy by a flagellate selects for colonial prey: a possible origin of multicellularity. Evolutionary Ecology 12, 153-164.

Boyd, R., Gintis, H., Bowles, S., and Richerson, P. J. (2003). The evolution of altruistic punishment. Proceedings of the National Academy of Sciences 100, 3531-3535.

Brandl, S. J., and Bellwood, D. R. (2015). Coordinated vigilance provides evidence for direct reciprocity in coral reef fishes. Scientific Reports 5, 14556. doi:10.1038/srep14556.

Clutton-Brock, T. (2009). Cooperation between non-kin in animal societies. Nature 462, 5157. doi:10.1038/nature08366.

Clutton-Brock, T. H., and Lukas, D. (2012). The evolution of social philopatry and dispersal in female mammals. Molecular Ecology 21, 472-492.

Corning, P. A., and Szathmáry, E. (2015). "Synergistic selection": A Darwinian frame for the evolution of complexity. Journal of Theoretical Biology 371, 45-58. doi:10.1016/j.jtbi.2015.02.002. 
Cornwallis, C. K., West, S. A., Davis, K. E., and Griffin, A. S. (2010). Promiscuity and the evolutionary transition to complex societies. Nature 466, 969-972. doi:10.1038/nature09335.

Dobson, F. S. (1982). Competition for mates and predominant juvenile male dispersal in mammals. Animal behavior 30, 1183-1192.

Duffy, J. E. (2007). "Ecology and evolution of eusociality in sponge-dwelling shrimp," in Evolutionary Ecology of Social and Sexual Systems: Crustaceans As Model Organisms (Oxford University Press, USA).

Dugatkin, L. A. (2007). Inclusive Fitness Theory from Darwin to Hamilton. Genetics 176, 1375-1380.

Eliassen, S., and Jørgensen, C. (2014). Extra-pair mating and evolution of cooperative neighborhoods. PLOS ONE 9, e99878. doi:10.1371/journal.pone.0099878.

Emlen, S. T., and Oring, L. W. (1977). Ecology, sexual selection, and the evolution of mating systems. Science 197, 215-223. doi:10.1126/science.327542.

Flegr, J. (2010). Elastic, not plastic species: Frozen plasticity theory and the origin of adaptive evolution in sexually reproducing organisms. Biology Direct 5, 1-16.

Fletcher, J. A., and Doebeli, M. (2009). A simple and general explanation for the evolution of altruism. Proceedings of the Royal Society B: Biological Sciences 276, 13-19.

Fletcher, J. A., Zwick, M., Doebeli, M., and Wilson, D. S. (2006). What's wrong with inclusive fitness? Trends in Ecology \& Evolution 21, 597.

Freidin, E., Carballo, F., and Bentosela, M. (2017). Direct reciprocity in animals: The roles of bonding and affective processes. Int J Psychol 52, 163-170. doi:10.1002/ijop.12215.

Fromhage, L., Elgar, M. A., and Schneider, J. M. (2005). Faithful without care: the evolution of monogyny. Evolution 59, 1400-1405.

Gadagkar, R. (1990). Evolution of eusociality: the advantage of assured fitness returns. Phil. Trans. R. Soc. Lond. B 329, 17-25. doi:10.1098/rstb.1990.0146.

Giardini, F., and Vilone, D. (2016). Evolution of gossip-based indirect reciprocity on a bipartite network. Scientific Reports 6, 37931. doi:10.1038/srep37931.

Gintis, H. (2000). Strong reciprocity and human sociality. Journal of theoretical biology 206, 169-179.

Gray, M. W. (2017). Lynn Margulis and the endosymbiont hypothesis: 50 years later. MBoC 28, 1285-1287. doi:10.1091/mbc.e16-07-0509. 
Greenwood, P. J. (1980). Mating systems, philopatry and dispersal in birds and mammals. Animal behavior 28, 1140-1162.

Griesser, M., Drobniak, S. M., Nakagawa, S., and Botero, C. A. (2017). Family living sets the stage for cooperative breeding and ecological resilience in birds. PLOS Biology 15, e2000483. doi:10.1371/journal.pbio.2000483.

Hamilton, W. D. (1964). The genetical evolution of social behaviour. II. Journal of theoretical biology 7, 17-52.

Herre, E., Knowlton, N., Mueller, U., and Rehner, S. (1999). The evolution of mutualisms: exploring the paths between conflict and cooperation. Trends in Ecology \& Evolution 14, 49-53. doi:10.1016/S0169-5347(98)01529-8.

Hoffmann, A. (2013). "III.8. Evolutionary Limits and Constraints," in The Princeton Guide to Evolution, eds. J. B. Losos, D. A. Baum, D. J. Futuyma, H. E. Hoekstra, R. E. Lenski, A. J. Moore, et al. (Princeton: Princeton University Press), 247-252. doi:10.1515/9781400848065-034.

Hughes, W. O., Oldroyd, B. P., Beekman, M., and Ratnieks, F. L. (2008). Ancestral monogamy shows kin selection is key to the evolution of eusociality. Science 320, 1213-1216.

Hunt, J. H., and Toth, A. L. (2017). "Sociality in wasps," in Comparative social evolution, eds. D. R. Rubenstein and P. Abbot (Cambridge, United Kingdom: Cambridge University Press), 84-123.

Imhof, L. A., and Nowak, M. A. (2009). Stochastic evolutionary dynamics of direct reciprocity. Proceedings of the Royal Society B: Biological Sciences 277, 463-468.

Jablonka, E., and Lamb, M. J. (2006). The evolution of information in the major transitions. Journal of Theoretical Biology 239, 236-246. doi:10.1016/j.jtbi.2005.08.038.

Jetz, W., and Rubenstein, D. R. (2011). Environmental uncertainty and the global biogeography of cooperative breeding in birds. Current Biology 21, 72-78.

Joy, J. B. (2013). Symbiosis catalyses niche expansion and diversification. Proceedings of the Royal Society B: Biological Sciences 280, 20122820. doi:10.1098/rspb.2012.2820.

Kappeler, P. M. (2019). A framework for studying social complexity. Behavioral ecology and sociobiology $73,13$.

Kennedy, P., Higginson, A. D., Radford, A. N., and Sumner, S. (2018). Altruism in a volatile world. Nature 555, 359.

Kokko, H., and Jennions, M. D. (2008). Parental investment, sexual selection and sex ratios. Journal of evolutionary biology 21, 919-948. 
Kokko, H., Johnstone, R. A., and Clutton-Brock, T. H. (2001). The evolution of cooperative breeding through group augmentation. Proc Biol Sci 268, 187-196. doi:10.1098/rspb.2000.1349.

Komers, P. E., and Brotherton, P. N. (1997). Female space use is the best predictor of monogamy in mammals. Proc Biol Sci 264, 1261-1270.

Kozlov, A. P. (1996). Gene competition and the possible evolutionary role of tumours. Med. Hypotheses 46, 81-84. doi:10.1016/s0306-9877(96)90005-5.

Kramer, J., and Meunier, J. (2016). Kin and multilevel selection in social evolution: a neverending controversy? F1000Res 5. doi:10.12688/f1000research.8018.1.

Kuijper, B., and Johnstone, R. A. (2017). How sex-biased dispersal affects sexual conflict over care. The American Naturalist 189, 501-514.

Kulich, T., and Flegr, J. (2010). Effects of multiple gene control on the spread of altruism by group selection. arXiv:1002.4204 [q-bio]. Available at: http://arxiv.org/abs/1002.4204 [Accessed October 6, 2019].

Lindholm, A. K., Dyer, K. A., Firman, R. C., Fishman, L., Forstmeier, W., Holman, L., et al. (2016). The ecology and evolutionary dynamics of meiotic drive. Trends in ecology \& evolution 31, 315-326.

Lovegrove, B. G., and Wissel, C. (1988). Sociality in molerats: metabolic scaling and the role of risk sensitivity. Oecologia 74, 600-606. doi:10.1007/BF00380059.

Lukas, D., and Clutton-Brock, T. (2012). Cooperative breeding and monogamy in mammalian societies. Proceedings of the Royal Society of London B: Biological Sciences, rspb20112468.

Macdonald, D. W., and Johnson, D. D. P. (2015). Patchwork planet: the resource dispersion hypothesis, society, and the ecology of life. Journal of Zoology 295, 75-107.

Mandeville, B. (1705). THE Grumbling Hive: or, knaves Turn'd HONEST. Printed in the year.

Maynard Smith, J., and Szathmary, E. (1997). The major transitions in evolution. Oxford, United Kingdom: Oxford University Press.

McShea, D. W. (2001). The hierarchical structure of organisms: a scale and documentation of a trend in the maximum. pbio 27, 405-423. doi:10.1666/00948373(2001)027<0405:THSOOA>2.0.CO;2.

McShea, D. W. (2002). A Complexity Drain on Cells in the Evolution of Multicellularity. Evolution 56, 441-452. doi:10.1111/j.0014-3820.2002.tb01357.x. 
McShea, D. W. (2016). Three Trends in the History of Life: An Evolutionary Syndrome. Evol Biol 43, 531-542. doi:10.1007/s11692-015-9323-x.

Mikát, M., Černá, K., and Straka, J. (2016). Major benefits of guarding behavior in subsocial bees: implications for social evolution. Ecology and Evolution 6, 6784-6797. doi:10.1002/ece3.2387.

Nakajima, T., Sano, A., and Matsuoka, H. (2009). Auto-/heterotrophic endosymbiosis evolves in a mature stage of ecosystem development in a microcosm composed of an alga, a bacterium and a ciliate. BioSystems 96, 127-135. doi:10.1016/j.biosystems.2008.12.006.

Nonacs, P. (2011). Monogamy and high relatedness do not preferentially favor the evolution of cooperation. BMC Evolutionary Biology 11, 58.

Nonacs, P., and Kapheim, K. M. (2007). Social heterosis and the maintenance of genetic diversity. J. Evol. Biol. 20, 2253-2265. doi:10.1111/j.1420-9101.2007.01418.x.

Nowak, M. A., McAvoy, A., Allen, B., and Wilson, E. O. (2017). The general form of Hamilton's rule makes no predictions and cannot be tested empirically. PNAS 114, 5665-5670. doi:10.1073/pnas.1701805114.

Nowak, M. A., and Sigmund, K. (1992). Tit for tat in heterogeneous populations. Nature 355, 250.

Nowak, M. A., Tarnita, C. E., and Antal, T. (2010a). Evolutionary dynamics in structured populations. Philosophical Transactions of the Royal Society B: Biological Sciences 365, 19-30. doi:10.1098/rstb.2009.0215.

Nowak, M. A., Tarnita, C. E., and Wilson, E. O. (2010b). The evolution of eusociality. Nature 466, 1057.

Nowak, M., and Highfield, R. (2011). Supercooperators: Altruism, evolution, and why we need each other to succeed. Simon and Schuster, Free Press, New York.

Nowak, M., and Sigmund, K. (1989). Oscillations in the evolution of reciprocity. Journal of Theoretical Biology 137, 21-26.

Okasha, S. (2006). The levels of selection debate: philosophical issues. Philosophy Compass $1,74-85$.

Opie, C., Atkinson, Q. D., Dunbar, R. I. M., and Shultz, S. (2013). Male infanticide leads to social monogamy in primates. Proc. Natl. Acad. Sci. U.S.A. 110, 13328-13332. doi:10.1073/pnas.1307903110. 
Owens, I. P. F., and Bennett, P. M. (1994). Mortality costs of parental care and sexual dimorphism in birds. Proceedings of the Royal Society of London. Series B: Biological Sciences 257, 1-8. doi:10.1098/rspb.1994.0086.

Peckre, L., Kappeler, P. M., and Fichtel, C. (2019). Clarifying and expanding the social complexity hypothesis for communicative complexity. Behav Ecol Sociobiol 73, 11. doi:10.1007/s00265-018-2605-4.

Perrin, N., and Mazalov, V. (2000). Local competition, inbreeding, and the evolution of sexbiased dispersal. The American Naturalist 155, 116-127.

Pollard, K. A., and Blumstein, D. T. (2012). Evolving communicative complexity: insights from rodents and beyond. Philos Trans $R$ Soc Lond B Biol Sci 367, 1869-1878. doi:10.1098/rstb.2011.0221.

Pujol, B., Blanchet, S., Charmantier, A., Danchin, E., Facon, B., Marrot, P., et al. (2018). The Missing Response to Selection in the Wild. Trends in Ecology \& Evolution 33, 337346. doi:10.1016/j.tree.2018.02.007.

Pusey, A. E. (1987). Sex-biased dispersal and inbreeding avoidance in birds and mammals. Trends in Ecology \& Evolution 2, 295-299. doi:10.1016/0169-5347(87)90081-4.

Queller, D. C. (1992). Does population viscosity promote kin selection? Trends in Ecology \& Evolution 7, 322-324. doi:10.1016/0169-5347(92)90120-Z.

Rainey, P. B., and Rainey, K. (2003). Evolution of cooperation and conflict in experimental bacterial populations. Nature 425, 72-74. doi:10.1038/nature01906.

Ratnieks, F. L., Foster, K. R., and Wenseleers, T. (2006). Conflict resolution in insect societies. Annu. Rev. Entomol. 51, 581-608.

Ronce, O. (2007). How does it feel to be like a rolling stone? Ten questions about dispersal evolution. Annu. Rev. Ecol. Evol. Syst. 38, 231-253.

Rubenstein, D. R., and Lovette, I. J. (2007). Temporal environmental variability drives the evolution of cooperative breeding in birds. Current Biology 17, 1414-1419.

Sagan, L. (1967). On the origin of mitosing cells. Journal of theoretical biology 14, 225-IN6.

Sheehan, M. J., Botero, C. A., Hendry, T. A., Sedio, B. E., Jandt, J. M., Weiner, S., et al. (2015). Different axes of environmental variation explain the presence vs. extent of cooperative nest founding associations in Polistes paper wasps. Ecology letters 18, 1057-1067.

Shultz, S., Opie, C., and Atkinson, Q. D. (2011). Stepwise evolution of stable sociality in primates. Nature 479, 219. 
Socias-Martínez, L., and Kappeler, P. M. (2019). Catalyzing Transitions to Sociality: Ecology Builds on Parental Care. Front. Ecol. Evol. 7. doi:10.3389/fevo.2019.00160.

Speakman, J. R., and Król, E. (2005). Limits to sustained energy intake IX: a review of hypotheses. J Comp Physiol B 175, 375-394. doi:10.1007/s00360-005-0013-3.

Starrfelt, J., and Kokko, H. (2012). Bet-hedging: a triple trade-off between means, variances and correlations. Biol Rev Camb Philos Soc 87, 742-755. doi:10.1111/j.1469185X.2012.00225.x.

Strandburg-Peshkin, A., Farine, D. R., Couzin, I. D., and Crofoot, M. C. (2015). Shared decision-making drives collective movement in wild baboons. Science 348, 13581361. doi:10.1126/science.aaa5099.

Su, Q., Li, A., Wang, L., and Eugene Stanley, H. (2019). Spatial reciprocity in the evolution of cooperation. Proceedings of the Royal Society B: Biological Sciences 286, 20190041. doi:10.1098/rspb.2019.0041.

Taylor, P. D. (1992). Inclusive fitness in a homogeneous environment. Proceedings of the Royal Society of London. Series B: Biological Sciences 249, 299-302. doi:10.1098/rspb.1992.0118.

Toman, J., and Flegr, J. (2018). A Virtue Made of Necessity: Is the Increasing Hierarchical Complexity of Sexual Clades an Inevitable Outcome of Their Declining (Macro) evolutionary Potential? Evolutionary Biology 45, 374-394.

Traulsen, A., and Nowak, M. A. (2006). Evolution of cooperation by multilevel selection. PNAS 103, 10952-10955. doi:10.1073/pnas.0602530103.

Trivers, R. L. (1971). The evolution of reciprocal altruism. The Quarterly review of biology 46, 35-57.

Trivers, R. L. (1972). Parental investment and sexual selection. Sexual Selection \& the Descent of Man, Aldine de Gruyter, New York, 136-179.

Uitdehaag, J. C. M. (2011). Bet hedging based cooperation can limit kin selection and form a basis for mutualism. Journal of Theoretical Biology 280, 76-87. doi:10.1016/j.jtbi.2011.04.002.

Van Veelen, M. (2009). Group selection, kin selection, altruism and cooperation: when inclusive fitness is right and when it can be wrong. Journal of theoretical biology 259, 589-600.

Wcislo, W., and Fewell, J. H. (2017). "Sociality in bees," in Comparative social evolution, eds. D. R. Rubenstein and P. Abbot (Cambridge, United Kingdom: Cambridge University Press), 50-83. 
West, S. A., Fisher, R. M., Gardner, A., and Kiers, E. T. (2015). Major evolutionary transitions in individuality. PNAS 112, 10112-10119. doi:10.1073/pnas.1421402112.

West, S. A., Griffin, A. S., and Gardner, A. (2007). Social semantics: altruism, cooperation, mutualism, strong reciprocity and group selection. Journal of Evolutionary Biology 20, 415-432. doi:10.1111/j.1420-9101.2006.01258.x.

West, S. A., Pen, I., and Griffin, A. S. (2002). Cooperation and competition between relatives. Science 296, 72-75. doi:10.1126/science.1065507.

Wild, G., and Traulsen, A. (2007). The different limits of weak selection and the evolutionary dynamics of finite populations. Journal of Theoretical Biology 247, 382-390.

Wilkinson, G. S. (1988). Reciprocal altruism in bats and other mammals. Evolution and Human Behavior 9, 85-100.

Wilson, E. O., and Hölldobler, B. (2005). Eusociality: origin and consequences. Proceedings of the National Academy of Sciences 102, 13367-13371.

Wrangham, R. W. (1980). An ecological model of female-bonded primate groups. Behaviour 75, 262-300. 



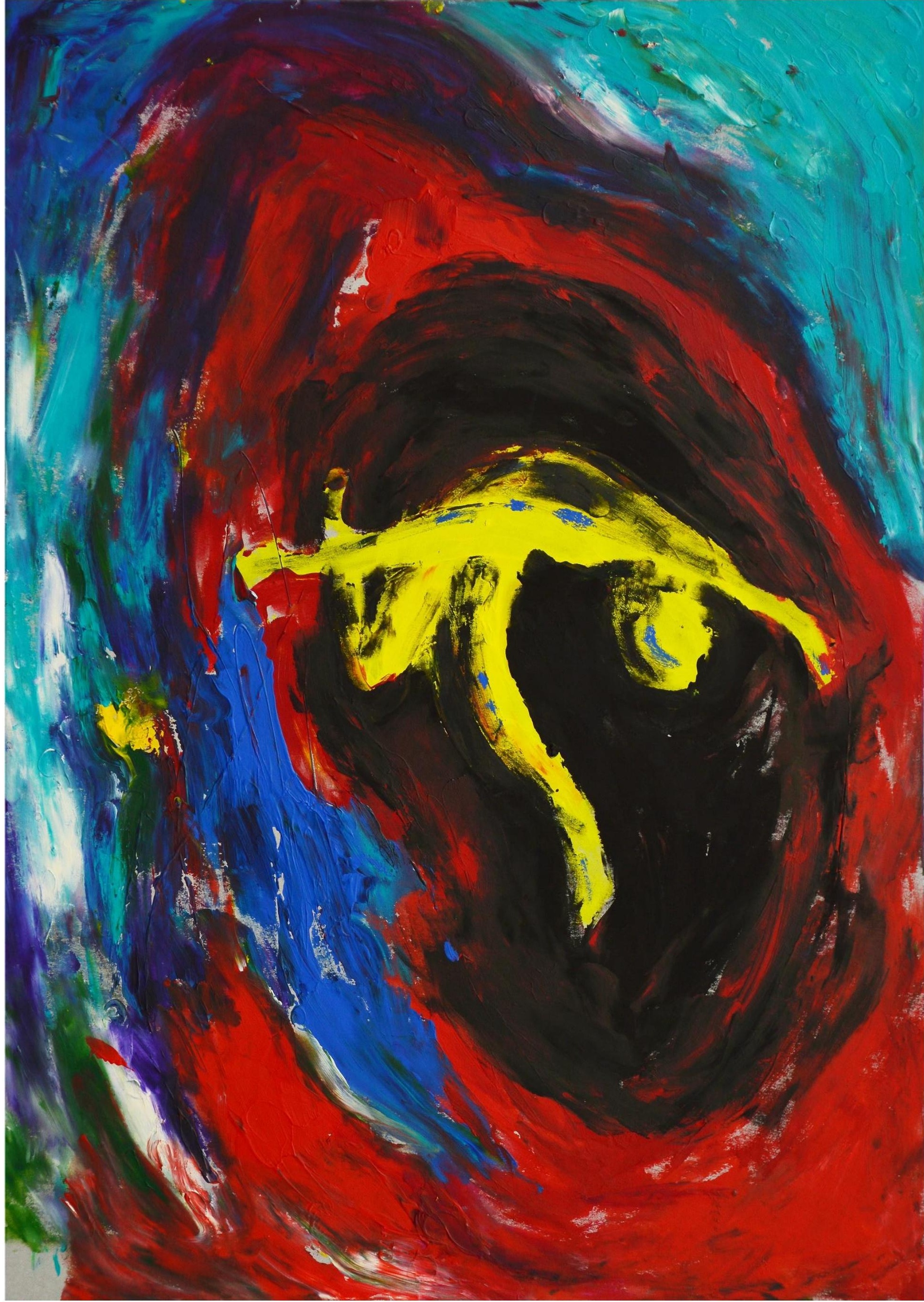




\section{Chapter 1: Catalyzing transitions to sociality: ecology builds on parental care}

Socias-Martínez L and Kappeler PM (2019) Catalyzing Transitions to Sociality: Ecology Builds on Parental Care. Front. Ecol. Evol. 7:160. doi: 10.3389/fevo.2019.00160

Author contributions: LS-M: original idea and drawings. LS-M and PK: writing of the manuscript.

\section{Social evolution}

The complexity of life has increased through successive transitions toward higher levels of organization (Maynard Smith and Szathmary, 1997; Okasha, 2006). Major steps in evolution have been explained by shifts from predominantly competitive toward more cooperative interactions between previously antagonistic entities in stressful ecological contexts (Kikvidze and Callaway, 2009). The evolution of group living (typically referred to as "sociality") is one example of these major steps in the evolution of life complexity that has occurred several times independently across vertebrates and invertebrates (Maynard Smith and Szathmary, 1997). Selfish individuals have come to align their fitness interests in cooperative interactions by some evolutionary process that provides the basis for living in groups.

We use the following definition of sociality: The permanent association between at least two adult individuals of the same sex that interact with each other more than with other individuals (Kappeler and van Schaik, 2002). This definition excludes pairs and associations between parents and immature offspring. This important distinction allows the targeting of efforts at understanding the origins of animal groups independently from the origins of family living. Although recent studies have attempted to integrate studies on the origins of sociality with those of family living (Costa, 2018; Kramer and Meunier, 2018), we prefer to keep sociality and family living conceptually separated in this review for several reasons. First, most current frameworks on social evolution consider variation in adult group size and sex composition (i.e., social organization) as the core for defining different social categories (Rubenstein and Abbot, 2017b). Thus, considering adults as core components of definitions of sociality is in accordance with previous definitions and studies. Second, the emphasis on adult sociality in previous definitions of sociality relates to a qualitative difference between species in which adults are solitary compared to those in which adults engage in regular social interactions with other adults, as for example reflected in studies linking social complexity with communicative complexity and cognition (Dunbar, 2009; Kappeler, 2019; 
Peckre et al., 2019). Third, equating family living with sociality may preclude the integration of mammals and birds in frameworks on the origins of sociality, since virtually all species have post-birth parental care and would accordingly be classified as social. Fourth, evolutionary transitions from solitary to social adults may occur in species where parents do not cohabitate with offspring (e.g., in parasocial mass-provisioning Hymenoptera). Thus, a definition of sociality based on adults is needed to include most vertebrate and invertebrate examples in a common framework. Finally, the evolutionary origins of pair living and family living have been extensively studied within the frameworks of sexual selection and parental care evolution, so that amalgamating parental care concepts with those of social evolution may result in misunderstandings hampering attempts to bridge both fields of inquiry.

Although group living is associated with numerous costs, the interactions that generate groups should yield positive fitness outcomes based on mutualism, cooperation or altruism. Such fitness benefits might not necessarily be synchronized; expected future fitness benefits of grouping might be sufficient to make individuals prone to associate (Kokko and Johnstone, 1999). Group formation thus relies on decisions that maximize either current or future fitness of individuals, or both.

Identifying determinants of sociality across species has proved difficult for several reasons (Elgar, 2015). First, research on social evolution has proceeded predominantly in a taxonspecific manner. As a result, frameworks developed for different taxa inevitably emphasized taxon-specific factors (Rubenstein and Abbot, 2017b). Secondly, most previous studies focused on observed fitness costs and benefits of sociality in species that evolved sociality long ago. Deducing the origins of group living in these species may confound current functions and consequences of social behaviors with the actual causes of early forms of sociality. Addressing this issue is not trivial because several recent studies suggest that selective pressures at the origins of social life differed from those operating at derived stages, even in the same lineages (e.g., Sheehan et al., 2015; Griesser et al., 2017). Third, the most socially complex societies (i.e., cooperative breeding vertebrates and eusocial insects) are overrepresented in the literature and have thus been disproportionally influential in developing theories on social evolution. For instance, the kin selection and the ecological constraints models (Hamilton, 1964; Emlen, 1982) focus on conditions under which mature offspring would delay dispersal and help their parents or relatives to reproduce. Nonetheless, many other societies arise through mutualism between adult individuals of the same generation that might even be unrelated (Wcislo and Tierney, 2009). These latter types of explanations have received much less attention.

Recent calls for "social syntheses" that take into account the three limitations mentioned above (Elgar, 2015; Rubenstein and Abbot, 2017b) argue that studies on the causes of 
sociality should (i) rely on information from a wide variety of study organisms, (ii) give priority to information from species in which sociality is a recently evolved trait, and (iii) incorporate phylogenetically informed reconstructions of ancestral states and their subsequent derivate stages to generate a comprehensive framework of social evolution. Inspired by a recent volume summarizing work on social evolution in both vertebrates and invertebrates (Rubenstein and Abbot, 2017a), we suggest that revisiting the link between parental care, ecology, and social evolution might offer great potential for contributing to a social synthesis. Phylogenetically distant group-living species resemble each other in the way they develop and reproduce, as well as in the role they play in their ecosystem. Since these factors might impact the relative costs and benefits of grouping, we argue that there are pre-adaptations and environmental contexts that foster the evolution of sociality.

In this paper, we explore the idea that the appearance of sociality can result from a long history of coevolution between the caring system of a solitary species and its biotic and abiotic environment. The caring system has been suggested to represent one of four core elements of any social system that co-evolves with the three other components (social organization, social structure, and mating system) (Kappeler, 2019). We first present an overview of the ideas that linked parental care and social evolution in the past, then proceed to clarify our framework and close by reviewing the empirical evidence related to this notion.

\section{The importance of caring systems in social evolution}

\section{a. Subsocial societies}

Several authors have argued that family units with extensive parental care might represent a common ancestral state that preceded the transition to cooperatively breeding societies in vertebrates and eusocial colonies in invertebrates (Wheeler, 1928; Emlen, 1995; Nalepa, 2010). Indeed, an association between post-birth forms of parental care and sociality relies on the fact that these groups are formed by the retention of adult offspring that delay or suppress dispersal and cooperate with their parents in parental care behaviors directed toward siblings. This process involving multiple generations has been described as the "subsocial route" toward eusociality in Hymenoptera (Michener, 1969, 1974) or the "extended family" in cooperatively breeding vertebrate societies (Emlen, 1995; Emlen et al., 1995). Even though the link between cooperative breeding/eusociality and parental care is at first glance self-evident, the causes for the appearance of these societies are still subject to controversy.

\section{Invertebrates}

An emphasis on indirect fitness benefits has characterized attempts to explain the evolution of sociality among invertebrates because individuals in these societies are in most cases 
highly related. Accordingly, societies were more likely to form where average interindividual relatedness was high due to haplodiploidy, genetic monogamy, inbreeding or a combination thereof (Hamilton, 1964; Boomsma et al., 2011). However, another school of thought placed more importance on the caring system (Wheeler, 1928; Alexander, 1974; Emlen, 1995; Nalepa, 2010). Alexander (1974) already pointed out that parental manipulation, and not kin selection, was behind the origins of eusociality. He suggested that, because natural selection operates first in the parental generation, offspring altruism evolves when the parents' inclusive fitness is maximized independently of the effects on offspring's inclusive fitness. He emphasized that this process was dependent on the fact that parents, through parental care behaviors, could "manipulate" offspring development. Some recent empirical findings indeed support parental manipulation and not kin selection as an explanation for the evolution of eusociality (e.g., Kapheim et al., 2015). In addition, Nowak et al. (2010) suggested nest defense and extensive maternal care as the reasons for the evolution of eusociality. Thus, the caring system of eusocial lineages, and not only their average relatedness coefficients, may have to be considered in explanations of the origins of sociality.

Kramer and Meunier (2018) recently discussed the origins of invertebrate families with post-natal parental care and its relation to the evolution of sociality. They widened the taxonomic diversity considered by giving weight to examples of family interactions in precocial species. Moreover, they incorporated a "diachronic" explicit reasoning on social evolution by taking into account that caring systems evolved during the transition from precocial to altricial species and that "simple" precocial families might have preceded complex societies in which young are altricial (i.e., cooperative breeding and eusocial colonies). They suggested that to understand the origins of sociality, cooperative and competitive relationships among family members beyond parental care should be taken into account. Thus, the caring system needs to be considered in explaining the appearance of relatively simple societies as well.

\section{Vertebrates}

In vertebrates, the relationship between parental care and social evolution has been examined based on two main perspectives that emphasize the role of the environment. The first perspective posits that parental care sets the context for sociality to evolve because it creates the family unit. Once the family has evolved, depending on ecological conditions, offspring will or will not disperse ("Ecological constraints model") (Emlen, 1982). Such constraints have indeed been identified in several vertebrate (Komdeur, 1992; Walters et al., 1992; Hayes, 2000; Lucia et al., 2008) and invertebrate species (Brockmann, 1997). The second perspective views the family as a context in which parental care behaviors can be used by group members to increase their fitness ("Benefits of philopatry model") (Stacey 
and Ligon, 1991; Emlen, 1994). Indeed, many advantages, both in direct and indirect fitness, have been shown for philopatric individuals in the form of territory or breeding position inheritance, increased group size benefits on survival, and increased information or skills acquisition (Stacey and Ligon, 1991; Heg et al., 2011).

Nevertheless, the two perspectives are not mutually exclusive, and the example of the evolution of cooperative breeding in birds might well illustrate it. Avian cooperative breeding is associated with unpredictable and harsh environments, suggesting that philopatry evolved because of the indirect fitness benefits of cooperation under harsh conditions (Cornwallis et al., 2017). However, more informed phylogenetic reconstructions showed that philopatry without cooperation evolved previously in stable environments, preceding the appearance of cooperative breeding and the colonization of harsher biomes (Griesser et al., 2017). Thus, the study of the evolution of cooperative breeding in vertebrates suggests that the environment plays an essential role in social evolution. It does so by interacting with the caring system of the species and reinforces the idea that it is necessary to reconstruct the series of steps that sociality has followed.

Parental care in these examples is both the target of altruistic or cooperative interactions and the basis for evolving groups because these arise by adding adult offspring. However, if the numerous independent transitions toward sociality are analogous phenomena, our understanding of this process will come through comparing the origins of cooperative breeders with the origins of other types of societies.

Other "subsocial" societies-for example, communal breeders-neither show extensive alloparental care nor reproductive skew. This form of sociality is the most abundant among group-living vertebrates (Lewis and Pusey, 1997; Silk and Kappeler, 2017). The origins of these kinds of societies have also been explained as a result of an interaction between the caring system and ecological conditions. Emlen and Oring (1977) incorporated sex differences in parental investment to predict under which conditions polygynous vs. monogamous mating systems would evolve among mammals. In doing so, they also predicted under which conditions previously solitary females would become social. However, why females and not males? As females make higher parental investment and their fitness is therefore more dependent on the availability of resources, maternal investment would result in competition between females. Thus, only under certain conditions would females tolerate each other and become social.

Similarly, Wrangham (1980) predicted under which ecological conditions the transition toward group living would occur among primates. He hypothesized that female competition for resources arising from maternal care would give rise to a sort of prisoner's dilemma. A 
social phenotype would invade the population because groups, even though suffering from the costs of shared resources, would out-compete solitary individuals. Teaming up with related females against other females would produce the matrilineal societies characterizing most extant group-living primates. Therefore, even for communal breeders without cooperation in caring, social evolution may depend on the caring system of the ancestral solitary species.

One could test the importance of parental investment on social evolution by asking what the trajectory of social transitions would be in taxa where males are the sex investing more in care in the ancestral solitary species. Interestingly, in birds - a taxon characterized by pronounced paternal investment, and in which paternal care is supposed to be the common ancestral state (Wesolowski, 1994; Varricchio et al., 2008; but see Tullberg et al., 2002)groups grow through an aggregation of males and not females. This pattern of group formation contrasts with most other societies and holds even in species where groups are composed of non-kin (Riehl, 2013). Thus, parental care might have played an essential role in the origin of sociality under various conditions.

\section{b. Parasocial societies}

In some species, groups form through aggregation of individuals from the same generation after dispersal. This way of forming groups has been called the "parasocial route" toward eusociality in Hymenoptera (Michener, 1969, 1974). Because group formation occurs after dispersal, groups are formed in most cases by unrelated individuals. Interestingly, many of these parasocial non-kin societies cooperate in offspring care in diverse taxa (Clutton-Brock, 2002; Wcislo and Tierney, 2009; Riehl, 2013). For instance, in many species of bees and wasps, unrelated individuals join to cooperate in parental behaviors at a common nest (Wcislo and Tierney, 2009). In taxa with reproductive skew, parasocial societies may form as well (Brockmann, 1997). Such processes also occur in several vertebrate taxa, like fish and birds (Heg et al., 2011; Riehl, 2013). Thus, the relationship between sociality and parental care might relate to direct fitness benefits as well.

Taken together, theoretical frameworks and empirical evidence suggest that the interaction between caring systems and environmental conditions might be crucial for understanding the transition toward group living. Moreover, the role of parental care does not appear to be restricted to the origins of family-based societies and may apply as well to parasocial non-kin sociality.

\section{A framework incorporating caring system evolution in solitary ancestors}

Offspring are usually the most vulnerable stage of the life of an individual because perception and mobility are reduced compared to adults in most species. Predators and parasites might, therefore, be selected to preferentially target young individuals, creating 
complex interactions between a given species' range of parasites and predators and the evolution of parental care behaviors (Tallamy and Wood, 1986; Royle et al., 2016). These behaviors aim at increasing the survival and reproductive capacities of offspring. It is suggested that parental care is favored because of positive feedback loops that maximize the benefits of such behaviors for offspring. These loops are based on the evolving adaptation of the offspring phenotype that becomes increasingly dependent on the parents for correct development and survival (Royle et al., 2016; Kramer and Meunier, 2018).

In this article, we posit that parental care sets the preconditions for ecological factors to catalyze a transition toward sociality. We propose a series of evolutionary steps leading to sociality based on the coevolution between parental care and several environmental factors (Figure 1). The interaction between the environment and the caring system affects offspring survival and the available breeding opportunities, resulting in effects on the cost/benefit ratio of sociality.

An absence of parental care is the ancestral condition from which some form of parental care evolved (Royle et al., 2012). Firstly, (1, Figure 1) biotic or abiotic conditions that challenge offspring survival select for parental care (Brown et al., 2010; Klug and Bonsall, 2010; Pike et al., 2016; Royle et al., 2016). Parental care is by definition costly to the parents and should compensate for the adverse effects of the environment on offspring (Royle et al., 2012). Once parental care behaviors have evolved, two processes foster a further increase in parental expenditure. On the one hand, a self-reinforcing process on parental care arises from the fact that offspring adapt their mode of development to the care behaviors and become more dependent in a unidirectional trend (2, Figure 1) (Gardner and Smiseth, 2011; Royle et al., 2016; Kramer and Meunier, 2018). Simultaneously, coevolution with predators and parasites that challenge developing offspring sets up an arms race (3, Figure 1), generating more significant investment in parental care behaviors in turn (4, Figure 1) (Field and Brace, 2004; Royle et al., 2012; Yip and Rayor, 2014; Pike et al., 2016). Differences in the strength of processes 2 and 3 result in interspecific variation in the level of dependence on parental care for successful development and survival (i.e., precocialaltricial spectrum). For parents, increasing altriciality of offspring corresponds to increasing the minimum investment needed to raise offspring (4, Figure 1). Thus, any successful breeding attempt consumes more resources. Therefore, given this higher necessity, the carrying capacity of a given habitat becomes lower. In this sense, raising offspring successfully becomes increasingly complicated and the opportunities for breeding more limited (5, Figure 1). At this point, species under ecological pressures that favor increased parental care (i.e., 2 and 3, Figure 1) possess parental care behaviors and a window for increasing fitness. The possibility of parental care behaviors and offspring benefits in 
solitary species with extensive parental care make the latter prone to benefit from social interactions (6, Figure 1). Byproduct mutualism or cooperation among previously competing individuals becomes adaptive in a context where a solitary breeder has low prospects of success because they buffer against processes 1, 3, or 4 (6 and 7, Figure 1). Positive interactions may come from other parents that possess a similar behavioral repertoire and are under the same burden of care (e.g., costs of constructing a nest), or from previous offspring whose fitness prospects of reproducing independently are too low.

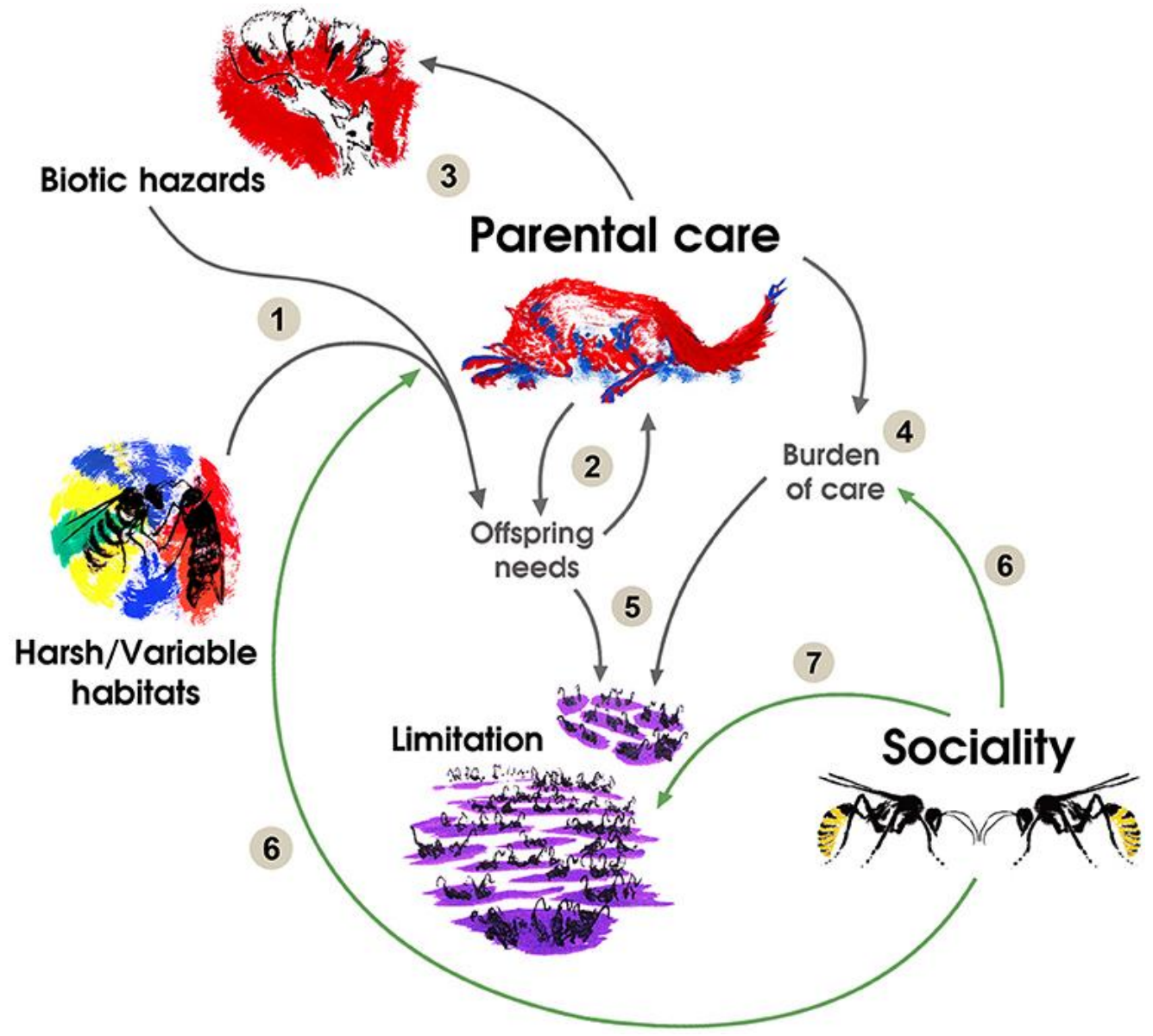

Figure 1. The relationships between the evolution of parental care, environmental factors and social transitions can be summarized as follows: (1) Habitats or biotic hazards affecting offspring survival increase offspring needs. (2) This increase in offspring needs selects for parental care and generates a first positive feedback loop due to coevolution between offspring altriciality and care behaviors. (3) Predators and parasites coevolve with parental care in a second positive feedback loop selecting for more care. (4) Increases in care result in a higher burden per reproductive bout. (5) More sophisticated needs of offspring and a higher burden of care result in a lower carrying capacity and may result in limitation of breeding possibilities. (6) Sociality is heavily selected in species under processes $(1,2,3$, and 4$)$ because it reduces the burden of care through mutualism or cooperative behaviors and reduces the impact of environmental pressures on offspring development and survival. (7) Sociality is selected in species under previous processes because it allows reducing limitation through sharing a reproductive resource, such as a suitable nesting place. In species with 
reproductive skew, social queuing for the breeding position is selected under limited possibilities for solitary breeding resulting from processes (1, 2, 3, and 4). Drawings by LS-M.

Below, we review evidence for these processes from studies across vertebrates and invertebrates (see Supplementary Table 1). We proceed separately for societies that relate differently to their environment. We do so because how animals forage and rest could profoundly impact the evolutionary processes that we investigate (e.g., how parents can attempt to breed and avoid offspring mortality). Indeed, some authors have suggested the existence of broad types of societies based on how individuals interact with their milieu in terms of activity patterns and space usage for foraging and reproduction (Korb and Heinze, 2008). Two main types have been identified, named central place foragers (CPF) and fortress defenders (FD). Importantly, such idiosyncrasies in space use and activity patterns of societies were already present in their respective solitary ancestors. Thus, differentiating these categories is essential for testing the ecological scenarios in which sociality arose and the role played by parental care.

Central place foraging (CPF) characterizes a life structured around a specific place, usually a shelter, burrow or nest that serves as the home base for resting and rearing young. Spatial clustering of biologically relevant activities is a significant determinant of the ways through which sociality may enhance reproductive success in CPF species. CPF characterizes ants, bees, wasps, modern termites (i.e., separate-life-type), most communal and cooperative birds and mammals, kin-based societies in lizards and some cooperatively breeding cichlids (Rubenstein and Abbot, 2017b). Ants and separate-life-type termites will not be further discussed below because all extant species in the former are eusocial and the ancestral state of the latter was already social (Heinze et al., 2017; Korb and Thorne, 2017). Fortress defender (FD) societies live inside food resources, and the significant advantage of this way of life is to provide defense for developing offspring against predators or parasites. This lifestyle characterizes basal termites (i.e., one-piece of life type termites), polyembryonic wasps, gall-living aphids and thrips, snapping shrimps, ambrosia beetles and eusocial mole rats (Rubenstein and Abbot, 2017b).We suggest adding a third category, itinerant foragers (IF). Itinerant foraging species consist of groups of animals that move together during foraging and do not have a specific place for reproduction and resting. This pattern characterizes most diurnal group-living primates and ungulates, but also macropods and pelagic fish schools, among others.

Below, we review evidence for the proposed evolutionary processes in our framework in the proposed transitions to sociality in central place foragers first, followed by a comparison with fortress defenders and itinerant foragers. The structure of the text for each type of society analyzes first the evidence for processes leading to increases in parental care ( 1 and 
2, Figure 1), followed by evidence on social buffering against processes 3,4 and 5, followed by the evidence that sociality buffers against such factors ( 6 and 7, Figure 1 ).

\section{Parental care and social transitions in central place foragers}

Central place foraging is related to the presence of a nest structure in which offspring reside during development. In this sense, many central place foraging taxa, such as wasps, bees, altricial birds and nesting mammals exhibit similar parental behaviors: nest construction, guarding and/or provisioning offspring (Royle et al., 2012). Finding, constructing and defending suitable nests are adaptive responses to protect offspring from their major sources of mortality (Royle et al., 2012; Ibáñez-Álamo et al., 2015). Therefore, central place foraging is a combination of behaviors that ultimately allow securing a microenvironment for offspring development. Nevertheless, species in invertebrates and vertebrates show great variation in the extent of investment in or the presence of different types of care (Royle et al., 2012, 2016). We argue that there is a link between the processes that promote variation in the extent of parental care and social transitions. Thus, we first examine the processes that intensify parental care and then connect these evolutionary trajectories to the evolution of sociality.

\section{a. Factors increasing parental care \\ 1. Parental care self-reinforcement}

Once parental care evolved, it created a microhabitat for offspring. These improved conditions create opportunities for offspring to reallocate energy invested in traits that are not immediately necessary anymore, such as muscles or vision, toward growing, making them more altricial (Royle et al., 2016). Examples can be found in birds and mammals where nesting selected for offspring born without the capacity for foraging or thermoregulating autonomously (Royle et al., 2012).

Offspring adaptation, in turn, affects the efficiency of parental care behaviors already in place and may trigger competition among offspring for those components of care that are not shareable (Gardner and Smiseth, 2011). Parents may then be forced to invest more in care to compensate for the competitive disadvantages of some offspring, generating a positive feedback loop between parental care and offspring altriciality (Royle et al., 2016; Kramer and Meunier, 2018). Thus, parental care implies a coevolutionary process between parent and offspring phenotypes that may generate trends toward more care. However, parents and offspring occur in an environment with multiple biotic and abiotic factors that may also affect the evolution of parental care.

\section{Challenges to Offspring Survival or Development}

Abiotic or biotic challenges may promote the appearance of parental care (Tallamy and Wood, 1986; Royle et al., 2016). However, these challenges may persist due to their 
unpredictable character, their severity or because offspring have become more altricial. For instance, the transition toward provisioning through body reserves in the reptile taxa that gave rise to mammals is related to the unpredictability of the resources upon which they depended (Royle et al., 2012).

Moreover, the biotic hazards that parents try to reduce may evolve in response, creating a Red Queen effect between parental care and predation strategies, for example (Liow et al., 2011). These processes might be more important than previously thought. For instance, Bois and Mullin (2017) argue that non-avian dinosaur extinction relates to the appearance of new types of nest predators during the late Cretaceous. Nevertheless, explicit theories and tests for an arms race between parental care and biotic hazards for offspring have not yet been incorporated into models of parental care evolution.

A key example of the impact of biotic hazards on the enhancement of parental investment comes from Hymenoptera. Two main ways of offspring food provisioning exist in this taxon. The most primitive and common form is "mass provisioning," where females collect the food offspring will need to develop before laying the egg(s) and then put them together into a constructed nest (Field, 2005). In the derived form of "progressive provisioning," mothers continuously bring food to the developing larvae, which is costly in terms of productivity (Field, 2005). The transition from mass to progressive provisioning has been related to the risks of predation and parasitism. Following the evolution of nesting with mass provisioning, some parasites adapted by finding their way to larvae either concealed inside the prey items provided or during the brief moments where parents introduce the egg with the prey into the nest cell. Progressive provisioning decreases this risk because mothers malaxate prey before delivering it to their offspring, thereby destroying potential parasites that would otherwise attack larvae (Field and Brace, 2004; Hunt and Toth, 2017). Moreover, contrary to mass provisioning species, offspring encounter kleptoparasites more often after the egg stage, and larvae resist parasites better than eggs (Field and Brace, 2004). Thus, although both types of provisioning include nesting and certain protection, coevolution with predators fostered the evolution of more complex modes of provisioning in Hymenoptera. Importantly, the mode of provisioning has been related to the evolution of eusociality (see section Assuring Care: Shared Provisioning). Therefore, given the plausible importance of coevolutionary processes with other species on parental care, we argue that research focusing specifically on this link might offer great potential for understanding social evolution.

Overall, abiotic and biotic hazards as well as interactions among family members appear to drive increases in parental care. In an evolutionary process selecting for innovations against ever increasing pressures on offspring survival, sociality may appear as a new solution to an 
old problem because it may buffer the costs of care and/or increase the efficiency of care. Next, we review examples of proposed selective forces for the transition toward sociality that build on these two types of benefits arising from associations between individuals.

\section{b. Sociality buffers against harsh or variable environments}

Harsh or variable environments have been suggested as contexts in which grouping might offer benefits to both parents and offspring. Several types of abiotic properties or agents, their spatial and temporal variability as well as the distribution of food resources play a role in this context.

\section{Increasing the efficiency of care: sharing a nest}

Homoeothermic vertebrates are energetically challenged by temperatures exceeding a certain range. Most of these species have altricial young that need to be assisted in thermoregulation and provisioned with food by their parents to survive. The time parents spend foraging creates a trade-off with offspring thermoregulation, as offspring left at nonoptimal temperatures may die or develop less efficiently. Groups of several adults may reduce the impact of this tradeoff for reproducing individuals via social thermoregulation. For instance, in bats, matrilines are prevalent in species that inhabit cold environments and are thought to have arisen because grouping helps lactating females by increasing thermoregulation efficiency of pups and mothers (Kerth, 2008). Similarly, some group-living rodents and primates inhabiting thermally challenging environments are thought to benefit from grouping through improved thermoregulation (Madison, 1984; Perret, 1998). Such environments offer an incentive for parents to join their nests, which increases the efficiency of thermoregulation (i.e., reached optimal temperature lasts longer) or metabolism (i.e., conversion of food into body mass). Thus, for species with altricial young, harsh abiotic conditions may generate opportunities for increasing fitness by cooperating with other parents.

Environmental variability may constitute a different dimension of ecological harshness. Variability of the environment may concern abiotic factors like temperature, $\mathrm{pH}$ or humidity, or the spatial or temporal heterogeneity of food or shelters. A recent gametheoretical model suggested that environmental variability can enhance the benefits of altruism between relatives, making altruism an evolutionarily stable strategy (Kennedy et al., 2018). This effect arises because in a variable environment cooperation results in bethedging. Cooperation reduces variability in reproductive success between generations exposed to different environments, offering an advantage to lineages with altruists. These lineages might be at a disadvantage when conditions are benign but make a greater difference when conditions become harsher by maintaining a similar level of reproductive success overall (Kennedy et al., 2018). During harsh times, the mean reproductive success of 
a population is low, and a subtle difference in the number of offspring produced makes a big difference in terms of relative contribution to the next generation. Non-cooperators are at the mercy of environmental variability, while lineages with altruists buffer such changes. A recent evaluation of the environmental correlates of sociality in Polistes wasps indicated that variability in ambient temperature, rendering the conditions for larvae development and adult foraging less suitable, has favored a parasocial transition toward nest sharing (Sheehan et al., 2015). The evolutionary mechanism underlying these patterns may involve bet-hedging in foraging success under challenging environments.

Indeed, an older model proposed a similar bet-hedging effect arising from group foraging. Groups might be at an advantage because grouping reduces variability in foraging success (Wenzel and Pickering, 1991). In this model, it is assumed that foraging bouts by a group lead to more constant foraging success (e.g., Baker et al., 1981; Caraco, 1981; Stevens et al., 2007). Interestingly, a similar explanation was proposed for the appearance of eusocial groups in mole rats. In the few rodent species exhibiting this social system, foraging is very costly and at high risk of bearing no reward due to the patchiness of the tubercles they depend on (Lovegrove and Wissel, 1988). Group foraging is thought to reduce the risk of a zero-reward bout happening and therefore reduces overall variability in foraging success. Hence, cooperation would help group members to overcome environmental variability at the expenses of the current payoffs. Although this notion has been phrased in a kin selection perspective, mutualism, reciprocal altruism or social queuing could also offer a context for such benefits of sociality against environmental variability. Therefore, the generality of this mechanism could be greater than previously thought.

Overall, caring activities performed in groups or by more than one individual separately may reduce the detrimental effects of environmental variability by flattening differences in outcomes of parental activities. This effect translates into benefits because variability of conditions might result in non-optimal development of offspring (e.g., Marczak and Richardson, 2008; Kingsolver et al., 2009). If cooperative behaviors can buffer against harshness or variability in environmental conditions, sociality can be seen as the vehicle to generate stability. If sociality buffers against variability, it should translate into more constant reproductive success between generations (Kennedy et al., 2018). Long-term data on reproductive success in different generations of facultative social species would be required to test this prediction.

\section{c. Sociality buffers against biotic hazards}

Nesting in CPF has major implications for social evolution because, firstly, in many species nesting implies costs of finding and constructing a nest that can be shared. Secondly, due to the concealment of offspring in safe places, parents face a trade-off between foraging and 
guarding/incubating in the solitary ancestors of social CPF species. The severity of such a tradeoff can be alleviated by the presence of other parents.

\section{Increasing the efficiency of care: shared nest guarding}

In CPF species, guarding the nest to deter predators and protect offspring is traded off against foraging. Adults may increase guarding time as by-product mutualism just by increasing proximity to other nests (Wcislo and Fewell, 2017). The time offspring are guarded increases with any temporal mismatch in visits by parents even in the absence of turn-taking. Shared nest guarding might thus be one of the earliest benefits of sociality in species facing these constraints and may not require any specific trait besides an increase in tolerance among parents (Wcislo and Fewell, 2017).

Despite its theoretical importance, only a few studies have investigated the effect of shared nest guarding on reduced predation or parasitism in bees and wasps, and they found mixed results (Abrams and Eickwort, 1981; McCorquodale, 1989; Wcislo et al., 1993; Soucy and Giray, 2003; Prager, 2014; Ohkubo et al., 2018). Among mammals, female rodents benefit from communal nesting with respect to guarding time. They are able to spend more time away from the nest when engaging in communal nesting while letting pups alone for a similar amount of time than solitary nesting females (Auclair et al., 2014). Because outside activities relate to the amount of resources females will obtain, mothers might benefit directly from communal nesting, and pups should benefit from enhanced maternal condition. Additionally, female black-and-white ruffed lemurs that nested near other females experienced higher reproductive success due to arising antipredator benefits of proximity (Baden, 2019). These few vertebrate examples illustrate our point that sharing a nest may offer parents the possibility to alleviate the tradeoff between guarding and foraging that solitary central place foraging species face.

\section{Intraspecific Threats: Shared Nest Guarding}

The presence of intraspecific exploitative strategies may develop and act as an additional motor for the evolution of grouping. Infanticide risk is thought to be one such evolutionary force, but nesting communally can increase pup survival by reducing infanticide risk (Manning et al., 1995; Hayes, 2000). In fact, in the only group-living felid, lionesses defend their cubs better against infanticidal males when living in groups (Lewis and Pusey, 1997). In the few social species of lizards in the genus Egernia, infanticide is thought to have favored the retention of offspring in extended families because the presence of the parents decreases aggression toward young (Lanham and Bull, 2000; Post, 2000; O'Connor and Shine, 2004).

Additionally, marauding conspecifics may try to usurp costly breeding resources, such as already built nests, especially when time runs out for seasonal breeders. For instance, 
parasocial associations of reproductive females in Polistes wasps with reproductive skew, have been used as models for the study of early benefits of nest sharing (Hunt and Toth, 2017). In these species, nests that have a near-to-emergence worker generation are of great value because emerging workers will raise the offspring of any reproductive, even an eventual usurper. Sharing a nest is thought to help prevent this type of intraspecific parasitism in several species, as cooperating females are better able to deter marauding conspecifics [reviewed in Brockmann (1997)].

Interestingly, in the handful of bird species where females lay eggs in the same nest and care for them communally, this reproductive strategy has evolved in species whose ancestors suffered from intraspecific brood parasitism, or where both strategies coexist in the same population (Zink, 2000; Riehl, 2013).One of the processes that could make associations adaptive would be that females laying communally are better able to defend their nests against brood parasites. No test of this hypothesis has been carried out to our knowledge. Interspecific brood parasitism has also been suggested to have acted as a driving force in the evolution of cooperative breeding in birds, but it is not clear whether it is a force promoting the appearance of groups or a force enhancing cooperation once the transition has already occurred (Feeney et al., 2013).

Thus, CPF species that nest with dependent offspring in response to selective pressures from the environment still face inter- and intraspecific offspring mortality arising from the tradeoff between nest guarding and foraging. Nest sharing appears to provide a widespread and convergent solution to ameliorate this tradeoff.

\section{Assuring Care: Shared Provisioning}

In some species, parental care has evolved toward provisioning offspring when parents are more efficient than offspring at finding food or when food provisioned by parents is of higher quality (Gardner and Smiseth, 2011). Parental feeding of young is extremely costly to the residual reproductive value of parents (Royle et al., 2012), and it may lead to a point of no return when offspring become completely dependent on parents for survival (Kramer and Meunier, 2018). At this point, offspring and parental survival become coupled, which can have implications for social evolution (Gadagkar, 1990).

A strong link between the evolution of eusociality and the presence of extensive parental care in the form of progressive provisioning has been established for Hymenoptera (Michener, 1985; Schwarz et al., 2003; Field and Brace, 2004; Field, 2005). Although nesting with progressive provisioning provides benefits against several types of offspring predators (see previous section Challenges to Offspring Survival or Development), two important costs are associated with this type of parental care. Contrary to mass provisioning, in species with 
progressive provisioning, offspring survival is dependent on the presence of the mother during the entire developmental period (Field, 2005).

Sharing the nest with other females can reduce this cost. Nest sharing allows increased guarding time (see section Increasing the Efficiency of Care: Shared Nest Guarding), and, if provided by an alloparent, it decouples parental and offspring mortality. If a provisioning adult dies, other parents in the nest can continue caring for the young, providing dependent offspring in progressive provisioning species with central place foraging with a survival possibility (West-Eberhard, 1975; Gadagkar, 1990). The evolution of eusociality in Hymenoptera has been related more strongly to this "life insurance" strategy than to kin selection by some authors (West-Eberhard, 1975; Gadagkar, 1990). A similar explanation has been offered for the evolution of communal nesting in a facultatively social primate species, the gray mouse lemur (Eberle and Kappeler, 2006) and in several species of mice (Boyce and Boyce, 1988). Thus, "life insurance" can act as a driver of sociality in taxonomically distant CPF species. Importantly, this benefit might drive sociality in species with and without reproductive skew, as the above examples show. Thus, parental care and its evolution in relation to hazards from the environment impose constraints that can be ameliorated by grouping, and this might be a common ground for the evolution of different types of sociality.

\section{d. Limited breeding possibilities lead to sociality}

Researchers studying altricial birds have long pointed out that the appearance of cooperative breeding may be linked to a limitation in the availability of breeding sites (Emlen, 1982). Accordingly, to this habitat saturation hypothesis, in stable habitats species reach their carrying capacity where resources for breeding are in shortage. Unpredictable variation in environmental conditions may also lead to mismatches between previous productivity and current capacity of the habitat. Furthermore, habitat variability has been linked to the regular production of more offspring than can be supported by the environment (Royle et al., 2012). This is thought to be a form of bet-hedging mediated through the production of offspring that vary phenotypically as an outcome of enhanced competition for parental resources. Thus, the caring system of a species, together with its evolutionary history and the environment, may influence the availability of breeding positions.

Similar to the effects of limitation of food resources or the territories that sustain them, shortage in nesting site availability might promote sociality. The primitive way of nesting in bees depends on the excavation of ground nests (Wcislo and Fewell, 2017). In many habitats, soil characteristics constrain the possibility of excavating to suitable patches, which is thought to have led same-generation individuals to share a nest, cooperating in 
nest excavation and guarding. Likewise, in reptiles the aggregation of unrelated individuals has been linked to a limitation of refuges (Graves and Duvall, 1995), and the few squamate reptiles that live in extended family groups all depend on patchily distributed refuges, such as tree hollows and rock outcrops (Chapple, 2003; Michael et al., 2010; Davis et al., 2011; Rabosky et al., 2012). In mammals, group formation by related females in rodents and bats is supposed to be facilitated by a limitation of suitable burrows or roosts required for reproduction (e.g., Moses and Millar, 1992; Wolff, 1994; Chaverri et al., 2007; Kerth, 2008). In birds, it has been proposed that habitat saturation, and therefore a limitation of breeding sites, has selected for delayed dispersal and helping (Emlen, 1982; Komdeur, 1992). This hypothesis has been supported by a phylogenetic analysis showing that delayed dispersal and family-living in stable habitats preceded the appearance of cooperative breeding (Griesser et al., 2017). There is therefore strong evidence that the limitation of the space or the resources necessary for breeding favors sharing in central place foragers.

\section{Limited breeding opportunities lead to social queuing in societies with reproductive skew}

Reproductive skew is a complex phenomenon, involving decisions by dominants and subordinates on group composition and reproduction. Societies with reproductive skew may arise directly from solitary ancestors and not through intermediate steps where reproduction is progressively monopolized (Rubenstein et al., 2016). Their transition to sociality also builds on the limitations arising from the needs of extensive parental care. In Stenogastrine wasps, for example, social queuing for a breeding position under limitation of nesting sites offers a more plausible explanation for the evolution of sociality than kin selection since relatedness between females is below 0.5 (Strassmann et al., 1994). In other wasp families, such as Polistes and sphecid wasps, the high costs of independent reproduction discussed above have been proposed as the main drivers of kin-based groups (Brockmann, 1997). Nevertheless, although suitable breeding sites might not be limiting in Polistes, the fact that independent breeding is extremely costly makes social queuing also a suitable strategy for them (Queller et al., 2000). Therefore, the limitation of reproductive opportunities may have contributed importantly to the evolution of reproductive skew societies.

Similar evidence for the role of nest limitation in facilitating transitions to sociality has been reported for vertebrates. For instance, parasocial groups of coral reef goby fish are made up by a reproductive couple that monopolizes reproduction and unrelated individuals that join them in a common coral. Joining individuals queue to attain a breeding position under a situation of habitat saturation (Wong et al., 2007), and limitation of coral shelter has been experimentally supported as a mechanism for group formation (Holbrook et al., 2000; Wong, 2010; Wong et al., 2012). Similarly, cooperative breeding in birds has been explained 
by means of social queuing (e.g., Reyer, 1986; Piper et al., 1995; Sloane, 1996). Contrary to Hymenoptera, however, cooperative societies in birds are mainly based on male helping (Riehl, 2013). This difference might be due to a combination of social queuing and sexual selection pressures arising from biparental care. As an initial benefit, birds in groups are suggested to experience lower predation risk, which allows the evolution of strategies that maximize future fitness (Koenig and Mumme, 1987). Parental care plays an important role here because male helpers are chosen as future breeding partners based on their previous parental performance (e.g., Griggio et al., 2004), and this type of female choice has been proposed as a general mechanism for the evolution of paternal care (Alonzo, 2012).

\section{e. Overview of social transitions in central place foragers}

In summary, the evidence reviewed above suggests that parental care might be a common catalyst for the independent evolution of societies with and without reproductive skew in CPF species. When young depend on parental care due to the coevolution with biotic hazards or to abiotic conditions that threaten offspring survival, two effects on sociality ensue. First, the costs of parental care can be shared with other parents. Second, the costs of parental care coupled with offspring altriciality restraints reproductive possibilities, which, in turn, enhances the relative benefits of shared parental activities. In species with reproductive skew, these benefits, compared to solitary breeding, are so important as to sacrifice current fitness by queuing for the breeding position.

\section{Parental care and social transitions in fortress defenders}

Fortress defender societies consist of eusocial or cooperative families living inside a structure that serves both as protection against biotic and abiotic hazards and as their main feeding resource. Next, we review evidence for an interaction between environmental hazards and the caring system of ancestral species and their relation to social transitions in fortress defenders across different taxa. We consider web spiders as fortress defenders because their activities occur in the web and they do not need to leave offspring unattended to forage.

\section{a. Factors increasing parental care}

Different forms of nesting in fortress defenders are thought to serve a protective function against biotic and abiotic challenges. These nesting strategies were already present before the transitions toward sociality. For example, the evolution of gall-inducing behaviors in thrips and aphids, or different nesting strategies in other species, such as gluing together phyllodes (leaf-like plant structures) to build up nests, may be understood as a form of parental care (Crespi et al., 1997). Because gall-forming has evolved multiple times, but has never been lost, such unidirectionality may indicate the presence of similar selfreinforcement or coevolutionary processes as in central place foragers. In support of this 
notion, gall-forming species of thrips have an array of specialized gall predators and parasitoids that coevolved with them. Similarly, maternal care in spiders is common and has been shown to protect against egg desiccation, and against parasites and predators (Yip and Rayor, 2014).

\section{b. Sociality buffers against harsh environments}

The evolution of sociality might also be mediated through a certain scarcity or difficulty of exploiting food resources that impact offspring development. For instance, in both aphids and thrips, eusociality has been linked to slow development of larvae in non-optimal host plants (Stern, 1998; Crespi et al., 2004). It has also been suggested that slow development selects for the evolution of soldiers that protect offspring during a prolonged period of vulnerability. Similarly, the evolution of termite eusociality from a family-living ancestor with biparental care has been explained by means of a dietary-induced slow developmental mode (Nalepa, 1994). In Cryptotermes species, sister taxa of termites used as a model for their ancestral condition, development into adult morphs requires several years, an unusually long developmental period for an insect. In addition, in order to digest wood, termites and their ancestors depend on endosymbiotic cellulose-degrading bacteria. These bacteria need to be socially transmitted after each molt, making family living obligatory (Thorne, 1997). This suggests that altriciality and parental care coevolved long before the transition toward eusociality occurred in the termites. The enlargement of the time window for offspring development has negative consequences because parasites and predators have more opportunities to prey on them (see next section Sociality Buffers Against Biotic Hazards). Taken together, evidence from aphids, thrips and termites suggests that the scarcity or low quality of the main food resources resulted in prolonged offspring development, creating a window for primitive forms of sociality (parent-offspring and sibling-sibling associations) to become lifelong.

Communal breeding groups of thrips occur within closely related lineages of those containing eusocial species. Groups are founded by unrelated females, and nests are not gall structures but constructed by gluing plant parts together. These groups share the costs of nest construction and enjoy benefits for offspring against aridity of the environment (Gilbert, 2014; Abbot and Chapman, 2017).

Spider transitions toward cooperative sociality have occurred in lineages where there is construction of a web and where maternal care takes place beyond the first instar (Yip and Rayor, 2014; Avilés and Guevara, 2017; Viera and Agnarsson, 2017). Harsh habitats, i.e., where strong rains are common, are associated with extended families exhibiting cooperative breeding (Avilés et al., 2007). In these species, webs are expensive to construct and periodical destructions by intense rains represent an important constraint on solitary 
living (Purcell and Avilés, 2008). Forming groups with relatives is supposed to be advantageous because periodical nest-reconstruction costs are shared (Avilés and Guevara, 2017). Thus, species in which maternal care went beyond the egg phase were able to colonize harsh habitats through retention of mature offspring.

Thus, sociality in fortress defenders appears to buffer them against direct impacts of abiotic conditions on offspring survival. Moreover, benefits from cooperating in nest construction in these conditions foster social transitions through both the subsocial and parasocial route.

\section{c. Sociality buffers against biotic hazards}

Fortress defenders do not have to leave their offspring unattended because they nest on their feeding source. Nevertheless, coevolution with predators and parasites might have driven their transitions to sociality to some extent as well. For instance, despite having evolved a concealed mode of life inside gall structures, thrips and aphids suffer from attacks by specialist predators and parasitoids (Crespi et al., 1997; Abbot and Chapman, 2017). The evolution of thrip eusociality from a family-living ancestor has therefore been linked to the presence of specific gall invading species (Crespi et al., 2004). In the ancestral species, mothers found a gall after mating and care for their developing offspring through producing antimicrobial secretions and displaying defensive behaviors against predators until dispersal. In eusocial species, soldiers are the first brood to be born in the gall and help to protect the future offspring (Crespi et al., 2004; Kutsukake et al., 2009; Turnbull et al., 2012). The evolution of soldiers (which entails sociality between adults) is selected by predation pressure and may be seen as a means of protecting offspring. Furthermore, soldier behavioral repertoires derive from maternal behaviors in brood defense behaviors against parasites and predators in solitary ancestors (Crespi et al., 2004). Moreover, in some species, parasocial societies made up by unrelated adult females may perform coordinated nest guarding and defense with repellent chemicals against potential predators (Crespi et al., 1997). Thus, the first forms of adult sociality both through the subsocial and parasocial routes relate to cooperation against biotic threats.

In spiders, sociality through the subsocial route has been linked to habitats where predation pressure is especially salient due to a high diversity of predator species (Yip and Rayor, 2014; Viera and Agnarsson, 2017). Moreover, cooperative breeding in the genus Anelosimus has been linked to high probability of maternal death analogously to the "life insurers" in CPF (Viera and Agnarsson, 2017) (see section Assuring Care: Shared Provisioning). Sociality through the retention of mature offspring has evolved in lineages that already disposed of antipredator adaptations to biotic hazards through maternal care. Sociality is therefore a further response toward predation risk, allowing successful colonization of certain habitats. 
Biotic hazards may also relate to the evolution of fortress defenders in the marine environment, but here they impact adult survival. Snapping shrimp and coral reef gobies living inside sponges and corals, respectively, suffer from high predation risk outside their shelter (Herler et al., 2011; Hultgren et al., 2017). This risk is thought to have forced unrelated individuals to share refuges through the parasocial route (Herler et al., 2011; Hultgren et al., 2017). In shrimps, this risk has resulted in pairs sharing a common sponge, with each pair reproducing independently, and in species where eusociality has evolved through retention of larvae (Chak et al., 2017). In gobies, some species form groups with one breeding pair monopolizing reproduction and no cooperation in egg care by subordinates (Wong, 2010). Therefore, although predation risk selected for a concealed mode of life in the solitary ancestors of these marine fortress defenders, this is not a result of offspring vulnerability and parental care. In these species, biotic hazards that foster a concealed mode of life for adults resulted in transitions to sociality through a limitation of shelter.

Thus, predation and parasitism relate to sociality in very different types of fortress defenders. Maternal or biparental care initially evolved in response to biotic hazards, and their reinforcement further selected for cooperation with conspecifics for the defense of dependent offspring. Such benefits of sociality on processes derived from parental care evolution appear to be common for subsocial and parasocial transitions in FD species belonging to different taxa. An exception may be found in marine societies of FD, because predation risk driving sociality in these habitats acted more strongly on adults.

\section{d. Limited breeding possibilities lead to sociality}

In social aphids and thrips, limitation of suitable sites to form galls has been suggested to favor parasocial associations between adult females that cofound galls (Kiester and Strates, 1984; Abbot and Chapman, 2017). In snapping shrimp, the sponges where these animals live are in short supply (Macdonald et al., 2006), making it difficult for juveniles to find unoccupied hosts. This limitation is thought to favor the sharing of nests between multiple reproducing pairs in communal species that form through the parasocial route.

The appearance of eusocial snapping shrimp has occurred through the evolution of a nondispersing larval stage. In non-eusocial species, larvae develop in the water column and then settle in a new sponge after dispersal (Duffy and Macdonald, 2010). This evolutionary transition might have occurred for two reasons in relation to habitat saturation. On the one hand, larvae may be using this strategy to increase their inclusive fitness by helping their parents to reproduce instead of trying to colonize a new sponge and face their current occupants. On the other hand, by staying and cooperating, young shrimps improve the ability of their colony to monopolize a sponge in the face of habitat saturation. This benefit 
of philopatry is indirectly confirmed by the fact that eusocial species are ecologically dominant (Macdonald et al., 2006; Chak et al., 2017).

Thus, animals with very different life histories might have evolved sociality in response to situations of shortage of shelters or food resources. This transition mainly occurred either because passive sharing of a common resource might indeed be the best response to a general situation of shortage. Alternatively, sharing might be the basis for the development of a cooperative group that defends resources against other conspecifics in a situation of general competition.

\section{e. Overview of social transitions in fortress defenders and comparison with central place foragers}

The evolution of a concealed mode of life in fortress defenders is a response to environmental hazards analogous to the evolution of nesting in CPF. Certain fortress defender ancestors made a transition toward sociality by the specialization of first broods into soldier morphs that defend developing siblings. These soldiers protect developing offspring against specialized predators, and their defensive capacity is an exaptation of parental defensive behaviors in their solitary ancestors. In this case, the coevolution between predators and parental behaviors made cooperation with offspring or with other parents (in the case of parasocial transitions) advantageous. This process matches the described evolution of joint nesting in central place foragers. Limitation of suitable places for breeding is also a derived feature from the previous processes that is common for both subsocial and parasocial transitions in fortress defenders and in central place foragers. Although some authors have proposed that CPF and FD are different types of societies because offspring in the former can feed independently, offspring vulnerability might be an analogous problem in both groups. Thus, we conclude that there is evidence for a common role of parental care and its relation to the environmental conditions at the origins of these two types of societies.

\section{Parental care and social transitions in itinerant foragers}

Itinerant foraging societies are characterized by a nomadic lifestyle. Permanent movement of adults hampers concealed nesting of dependent offspring and offers a striking contrast to central place foragers and fortress defenders. In itinerant foragers, social evolution coincides with shifts in the mode of offspring care and transitions toward new niches characterized by high predation risk. The order of these changes remains unknown, but our review below will help to identify predictions for future comparative tests.

\section{a. Factors increasing parental care}

The same biotic and abiotic hazards that affect the ancestors of central place foragers and fortress defenders may have shaped the forms of parental care found among itinerant 
foragers. In both ungulates and primates, caching offspring is the ancestral form of maternal care; in more derived species, offspring accompany adults during foraging (Kappeler, 1998; Fisher et al., 2002). Comparative analyses suggested that in ungulate species that colonized open habitats, young were selected to develop a following strategy due to increased visibility and the associated predation risk (Fisher et al., 2002). Although following young are classified as precocial, these ungulates have longer developmental times, and comparisons between sympatric hider and follower species suggested higher maternal investment in the latter (Carl and Robbins, 1988). Thus, following may represent a derived anti-predatory strategy associated with higher maternal investment as a response to predation risks for offspring in open habitats.

In primates, the colonization of the diurnal niche is associated with the loss of nesting and the adoption of infant transport on the maternal body (Kappeler, 1998). Infant carrying is associated with reduced infanticide risk (van Schaik and Kappeler, 1997), and it may also reduce infants' predation risk. Other benefits of infant carrying, like unrestricted maternal foraging, must be traded off against attendant costs, especially the energetic costs of carrying, which are particularly high for smaller species where the offspring/mother weight ratio is higher (Ross, 2001). Species with infant carrying have smaller home ranges, which has been interpreted as evidence for increased maternal energetic burden (Ross, 2001). Thus, it appears that for both primates and ungulates, the evolution of a new mode of parental care with increased maternal investment is associated with the colonization of a new niche entailing higher predation risk.

\section{b. Sociality buffers against biotic hazards}

In IF, social evolution coincides with transitions toward new niches characterized by high predation risk. Groups of itinerant foragers are more conspicuous but are also able to detect predators earlier and, in some species, mount a collective defense (Berger, 1979; Dehn, 1990). Moreover, the individual risk of being predated upon decreases in groups (Hamilton, 1971). Thus, sociality has been interpreted primarily as an antipredator strategy. Independently, the evolution of offspring transport has also been associated with the transition toward the new niches that promoted sociality (Fisher et al., 2002). Thus, it is possible that this social transition was influenced by the modes of care of solitary ancestors in primates and ungulates.

Evidence suggests that offspring hiding strategies preclude group membership during infant dependence (e.g., Costelloe and Rubenstein, 2015). An offspring following strategy, on the contrary, might have facilitated the evolution of permanent sociality in IF species. The Alaskan moose may serve as a model species to understand social transitions in ungulates from this perspective (Molvar and Bowyer, 1994). This species appears to have only recently 
become social, and calves use a following strategy (Popp et al., 2018). There is variability in the social organization ranging from solitary to small foraging groups usually composed of several related females occasionally joined by males (Miquelle et al., 1992; Colson et al., 2016). Traditional theory states that foraging efficiency increases with sociality because per capita vigilance should decrease. Nevertheless, in this primitively social ungulate, foraging efficiency decreased with group size due to within-group aggression and increased per capita time of vigilance. At the same time, groups were able to forage further from forest cover where they have access to additional food resources (Molvar and Bowyer, 1994). Interestingly, females adopted a solitary strategy when having dependent offspring. Therefore, infant following might not be sufficient to trigger permanent sociality, and other factors may be needed.

Since no grooming and no cooperative defense were ever observed during the Alaskan moose study, the authors suggested that in the absence of cooperative behaviors to deter predators, grouping could result in higher mortality of offspring because predators would preferentially target them due to their reduced mobility. Supporting this idea, several studies have indeed found predator preferences for offspring (Mech and Boitani, 2003; Hayward et al., 2006; Barber-Meyer and Mech, 2008). Moreover, early joining of the herd by calves has been associated with group defense in African bovids (Estes, 1974). Findings in the Alaskan moose might be a model for understanding the transition in other ungulate species, because the clade shares a general intolerance toward conspecifics (Molvar and Bowyer, 1994) that could preclude cooperation in the early stages of sociality. Thus, it is possible that cooperation in parental care behaviors at the group level is necessary for ungulates to overcome higher mortality risks for offspring when living in groups.

In primates, the transition to group living is thought to be associated with the colonization of the diurnal niche by a nocturnal ancestor. The diurnal niche offered an advantage of aggregating with other individuals against predation while foraging through visual detection (Alexander, 1974; van Schaik, 1983). Phylogenetic reconstructions appear to support this hypothesis with a transition from an ancestral solitary forager to a species with loose aggregations of unrelated individuals of both sexes (Shultz et al., 2011). However, group living in diurnal primates is also associated with infant carrying (Kappeler, 1998; Nakamichi and Yamada, 2009). Thus, it is possible that from the variation shown in the modes of care in nocturnal primates, species that readily took advantage of the diurnal niche were those that already transported their offspring. Nevertheless, reconstructions of social transitions in primates did not take into account the complexity of social systems among nocturnal strepsirrhines, which include species where female groups cooperatively raise offspring (Radespiel et al., 2001; Schülke and Kappeler, 2003; Eberle and Kappeler, 2006). This fact 
may suggest that sociality evolved before a transition into the diurnal niche and that it was based on female cooperation for raising offspring.

Predation risk likely determined the evolution of group living in these evolutionary transitions in ungulates and primates. However, if the transitions occurred while colonizing open areas or a diurnal niche, respectively, permanent group living evolved only when caring of infants was possible while foraging in group. Although female ungulates regularly attack predators to protect offspring, only group cooperation may have allowed permanent group living. In primates, sociality also benefited adults with respect to antipredator behavior, but the transition occurred together with a change in infant carrying. This coevolutionary pattern suggests that the ecological pressures driving sociality built on the caring system of the solitary ancestors of both primates and ungulates.

\section{c. Limited breeding possibilities lead to sociality}

Group living ungulates inhabit mostly open habitats and feed mainly on herbaceous vegetation. Dependence on such low-quality food and the fact that following strategies are costly suggest a certain limitation for females that has resulted in slower life histories (Fisher et al., 2002). However, limitation for resources may have played little role in the social evolution of ungulates since the food they depend on is nearly ubiquitous and their offspring care strategies are independent of specific resources, such as nesting sites.

In primates, competition for limited food resources, such as fruiting trees, may have promoted transition to communal breeding. Wrangham (1980) hypothesized that female competition for resources would give rise to cooperative female associations out-competing solitary individuals for access to clumped resources. The fact that most group-living primates retain female offspring could support this hypothesis (Clutton-Brock and Lukas, 2012), but the relative role of limitation of feeding resources compared with the role of predation is still unresolved (Janson, 2000; Thierry, 2008). Moreover, inbreeding avoidance might also determine female philopatry (Lukas and Clutton-Brock, 2011). Cooperative breeding in primates has evolved only once in callitrichids from a pair-living ancestor (Lukas and Clutton-Brock, 2012). This transition is thought to relate to a general limitation of suitable territories that result in social queuing mostly by unrelated males (Yamamoto, 2006). Moreover, these species have among the highest offspring/mother weight ratio, resulting in costs of care that benefit from male helpers. Since groups are at an advantage at raising offspring (Bales et al., 2000), groups may be considered as a breeding resource for breeders analogously to colonies in primitively eusocial Hymenoptera or groups in cooperatively breeding birds. 
d. Overview of social transitions in itinerant foragers and comparison with central place foragers and fortress defenders

A transition to itinerant foraging sociality appears to be linked predominantly to predation on adults. However, reconstruction of the ancestral caring systems and the ecological contexts where sociality appeared reveals that the modes of infant care shaped this process. Firstly, it is possible that species that already had infant transport or following were those that transitioned toward sociality, or at least this transition was made more often by these species. Secondly, in ungulates further cooperative behaviors between adults in defense against predation events may be necessary for the evolution of permanent sociality. Thirdly, in the few primate species with cooperative breeding, the high costs of care of infant transport in small-bodied species promoted cooperation with other individuals.

Infant transport is a derived trait in IF species that evolved prior to the emergence of sociality. Sociality was favored in concert with changes of the previous niche and attendant changes in predation risk. Thus, in CPF and FD species, coevolution with predators may have led to nesting, altriciality and limitation in breeding possibilities that together made sociality advantageous, while in IF species ecological changes permitted or necessitated a change of the infant caring mode that may have precipitated the change toward group living. Thus, there are differences in the nature of the processes leading to sociality in the three different types of societies. In IF species, the change in predation risk was the result of a niche change, while in CPF and FD species, this change occurred passively through coevolution with predators and parasites.

\section{Discussion and conclusions}

The origins and complexity of social systems in different taxa have been explained by a bewildering diversity of factors (Rubenstein and Abbot, 2017a). This diversity has hampered identifying general patterns of social evolution across the animal kingdom (Elgar, 2015). In this review, we have established a link between parental care and the ecological contexts promoting evolutionary transitions in social systems. In very different taxa, abiotic and biotic challenges to offspring survival and dynamics between parents and offspring lead to more complex parental care behaviors over time, and these behaviors become increasingly expensive $(1,2,3$, and 4, Figure 1). This increasing burden of care, together with vulnerability of offspring and further environmental challenges, leads to a limitation in breeding possibilities that sets the stage for cooperative or mutualistic strategies to invade the population $(5,6$, and 7 , Figure 1$)$.

By linking social evolution and parental care we have 1) shown that factors promoting the appearance of parental care (i.e., environmental hazards) also relate to its maintenance and 
further modification through coevolutionary feedbacks with predators and parasites. This idea contrasts with mainstream theory on parental care evolution, where the link between origins and subsequent modification is not made explicit or is even denied (e.g., Royle et al., 2012 , 2016). It is possible that a predominant emphasis on interactions within the "family" (i.e., sexual conflict over care, parent-offspring conflict and sibling rivalry) has precluded including ecological interactions with other species that could play an important role in parental care evolution. We have presented evidence from different taxa indicating that parasites, predators and changing conditions do not only foster the appearance of caring behaviors, but may also deeply enhance their expression and further change.

Moreover, our framework posits 2) that parental care is a main piece in the evolutionary puzzle leading to sociality. This notion appears to be in contrast with suggestions that other interactions than parent-offspring care may be more important to understand the changes in caring systems that led to sociality (Kramer and Meunier, 2018), for two reasons. First, the two frameworks differ in how much emphasis is paid on interactions within the family. Kramer and Meunier (2018) emphasize knowledge on the subsocial route toward sociality and consider parasociality only for aggregations of larvae, whereas we try to explain the subsocial and parasocial routes toward adult sociality by emphasizing that cooperation between adults may be a widespread phenomenon independent of kinship.

Second, different conclusions also arise from different definitions of parental care. Kramer and Meunier (2018) consider only immediate parent-offspring interactions as parental care, whereas we consider any parental behavior, also if it is displayed by another adult individual. Furthermore, Kramer and Meunier (2018) consider that family systems evolve from precocial to altricial, and that the evolution of sociality might be affected by withinfamily interactions during these changes. Although we agree with this conclusion, we point out that quite a few solitary species have single offspring (mammals) and the shift from precocial to altricial is not made in a context where cooperation or competition between siblings or parents can take place (Hymenoptera). Moreover, we also take into account that parental care components prior to hatching or birth may affect social evolution as well. The construction of a nest, which is induced by coevolution with predators and parasites or harsh environments, appears as a major feature catalyzing subsocial and parasocial transitions across vertebrates and invertebrates. Thus, instead of being alternative, the two frameworks might nourish each other in a complementary way when differences in perspective and definitions are made evident.

Reviewing evidence for the present framework we have shown 3) that the origins of sociality may be triggered by similar processes in societies with different kin structure and degrees of reproductive skew. In particular, our survey revealed a key role for the caring 
systems of a species in promoting sociality. However, explicit tests of this hypothesis will need phylogenetically informed reconstructions of changes in parental care, environmental hazards and social systems.

Research on social evolution has to date paid much attention to the evolution of sociality through reproductive altruism and the derived cooperative activities and conflicts that arise in such societies. In this paper, we have tried to emphasize that understanding the transition from a solitary to a social lifestyle is intrinsically connected to an understanding of the patterns of parental care in the ancestral solitary species. We encourage researchers in social and parental care evolution to further investigate the possible links between these two key evolutionary processes with comparative methods in a wide range of taxa.

\section{Supplementary material}

The Supplementary Material for this article can be found online at: https://www.frontiersin.org/articles/10.3389/fevo.2019.00160/full\#supplementary$\underline{\text { material }}$

\section{Acknowledgments}

LS-M is very grateful to Louise Peckre for precious encouragement and discussions during the writing and revision of the first drafts of the manuscript and to Antoni Socias Albaladejo for digital processing of figures. LS-M and PK thank the reviewers, Joël Meunier and ShengFeng Shen, for helping improving the quality of the manuscript with their valuable critics and insights. This research was funded by the Deutsches Primatenzentrum GmbH.

\section{References}

Abbot, P., and Chapman, T. (2017). "Sociality in aphids and thrips," in Comparative Social Evolution, eds D. R. Rubenstein and P. Abbot (Cambridge, UK: Cambridge University Press), 154-187.

Abrams, J., and Eickwort, G. C. (1981). Nest switching and guarding by the communal sweat bee Agapostemon virescens (Hymenoptera, Halictidae). Insectes Sociaux 28, 105-116. doi: 10.1007/BF02223699

Alexander, R. D. (1974). The evolution of social behavior. Annu. Rev. Ecol. Syst. 5, 325-383. doi: 10.1146/annurev.es.05.110174. 001545

Alonzo, S. H. (2012). Sexual selection favours male parental care, when females can choose. Proc. R. Soc. Lond. B Biol. Sci. 279, 1784-1790. doi: 10.1098/rspb.2011.2237 
Auclair, Y., König, B., Ferrari, M., Perony, N., and Lindholm, A. K. (2014). Nest attendance of lactating females in a wild house mouse population: benefits associated with communal nesting. Anim. Behav. 92, 143-149. doi: 10.1016/j.anbehav.2014.03.008

Avilés, L., Agnarsson, I., Salazar, P. A., Purcell, J., Iturralde, G., Yip, E. C., et al. (2007). Altitudinal patterns of spider sociality and the biology of a new midelevation social Anelosimus species in Ecuador. Am. Nat. 170, 783-792. doi: 10.1086/521965

Avilés, L., and Guevara, J. (2017). "Sociality in spiders," in Comparative Social Evolution, eds D. R. Rubenstein and P. Abbot (Cambridge, UK: Cambridge University Press), 188-223.

Baden, A. L. (2019).A description of nesting behaviors, including factors impacting nest site selection, in black-and-white ruffed lemurs (Varecia variegata). Ecol. Evol. 9, 1010-1028. doi: 10.1002/ece3.4735

Baker, M. C., Belcher, C. S., Deutsch, L. C., Sherman, G. L., and Thompson, D. B. (1981). Foraging success in junco flocks and the effects of social hierarchy. Anim. Behav. 29, 137142. doi: 10.1016/S0003-3472(81)80160-1

Bales, K., Dietz, J., Baker, A.,Miller, K., and Tardif, S. D. (2000). Effects of allocaregivers on fitness of infants and parents in callitrichid primates. Folia Primatol. (Basel) 71, 27-38. doi: $10.1159 / 000021728$

Barber-Meyer, S., and Mech, L. (2008). Factors influencing predation on juvenile ungulates and natural selection implications. USGS North. Prairie Wildl. Res. Cent. 4, 8-29. doi: 10.2461/wbp.2008.4.2

Berger, J. (1979). "Predator harassment" as a defensive strategy in ungulates. Am. Midl. Nat. 102, 197-199. doi: 10.2307/2425087

Bois, J., and Mullin, S. J. (2017). Dinosaur nest ecology and predation during the Late Cretaceous: was there a relationship between upper Cretaceous extinction and nesting behavior? Hist. Biol. 29, 976-986. doi: 10.1080/08912963.2016.1277423

Boomsma, J. J., Beekman,M., Cornwallis, C. K., Griffin, A. S., Holman, L., Hughes, W. O., et al. (2011). Only full-sibling families evolved eusociality. Nature 471, E4-E5; author reply E9-10. doi: $10.1038 /$ nature09832

Boyce, C. C., and Boyce, J. L. (1988). Population biology of Microtus arvalis. I. Lifetime reproductive success of solitary and grouped breeding females. J. Anim. Ecol. 57, 711-722. doi: $10.2307 / 5088$ 
Brockmann, H. J. (1997). Cooperative breeding in wasps and vertebrates: the role of ecological constraints. Evol. Soc. Behav. Insects Arachn. 347, 348-371. doi: 10.1017/CBO9780511721953.018

Brown, J. L., Morales, V., and Summers, K. (2010). A key ecological trait drove the evolution of biparental care and monogamy in an amphibian. Am. Nat. 175, 436-446. doi: $10.1086 / 650727$

Caraco, T. (1981). Risk-sensitivity and foraging groups. Ecology 62, 527-531. doi: $10.2307 / 1937716$

Carl, G. R., and Robbins, C. T. (1988). The energetic cost of predator avoidance in neonatal ungulates: hiding versus following. Can. J. Zool. 66, 239-246. doi: 10.1139/z88-034

Chak, S. T. C., Duffy, J. E., Hultgren, K. M., and Rubenstein, D. R. (2017). Evolutionary transitions towards eusociality in snapping shrimps. Nat. Ecol. Evol. 1:0096. doi: 10.1038/s41559-017-0096

Chapple, D. G. (2003). Ecology, life-history, and behavior in the Australian scincid genus Egernia, with comments on the evolution of complex sociality in lizards. Herpetol. Monogr. 17, 145-180. doi: 10.1655/0733- 1347(2003)017[0145:ELABIT]2.0.CO;2

Chaverri, G., Quirós, O. E., Gamba-Rios, M., and Kunz, T. H. (2007). Ecological correlates of roost fidelity in the tent-making bat Artibeus watsoni. Ethology 113, 598-605. doi: 10.1111/j.1439-0310.2007.01365.x

Clutton-Brock, T. (2002). Breeding together: kin selection and mutualism in cooperative vertebrates. Science 296, 69-72. doi: 10.1126/science.296.5565.69

Clutton-Brock, T. H., and Lukas, D. (2012). The evolution of social philopatry and dispersal in female mammals. Mol. Ecol. 21, 472-492. doi: 10.1111/j.1365-294X.2011.05232.x

Colson, K. E., White, K. S., and Hundertmark, K. J. (2016). Parturition site selection in moose (Alces alces): evidence for social structure. J. Mammal. 97, 788-797. doi: 10.1093/jmammal/gyw006

Cornwallis, C. K., Botero, C. A., Rubenstein, D. R., Downing, P. A., West, S. A., and Griffin, A. S. (2017). Cooperation facilitates the colonization of harsh environments. Nat. Ecol. Evol. 1:0057. doi: 10.1038/s41559-016-0057

Costa, J. T. (2018). The other insect societies: overview and new directions. Curr. Opin. Insect Sci. 28, 40-49. doi: 10.1016/j.cois.2018.04.008 
Costelloe, B. R., and Rubenstein, D. I. (2015). Coping with transition: offspring risk and maternal behavioural changes at the end of the hiding phase. Anim. Behav. 109, 217-225. doi: 10.1016/j.anbehav.2015.08.022

Crespi, B. J., Carmean, D. A., and Chapman, T. W. (1997). Ecology and evolution of galling thrips and their allies. Annu. Rev. Entomol. 42, 51-71. doi: 10.1146/annurev.ento.42.1.51

Crespi, B. J., Morris, D. C., and Mound, L. A. (2004). Evolution of Ecological and Behavioural Diversity: Australian Acacia Thrips as Model Organisms. Canberra, ACT: Australian Biological Resources Study.

Davis, A. R., Corl, A., Surget-Groba, Y., and Sinervo, B. (2011). Convergent evolution of kinbased sociality in a lizard. Proc. R. Soc. Lond. B Biol. Sci. 278, 1507-1514. doi: $10.1098 /$ rspb.2010.1703

Dehn, M. M. (1990). Vigilance for predators: detection and dilution effects. Behav. Ecol. Sociobiol. 26, 337-342. doi: 10.1007/BF00171099

Duffy, J. E., and Macdonald, K. S. (2010). Kin structure, ecology and the evolution of social organization in shrimp: a comparative analysis. Proc. R. Soc. Lond. B Biol. Sci. 277, 575-584. doi: $10.1098 /$ rspb.2009.1483

Dunbar, R. I. (2009). The social brain hypothesis and its implications for social evolution. Ann. Hum. Biol. 36, 562-572. doi: 10.1080/03014460902960289

Eberle, M., and Kappeler, P. M. (2006). Family insurance: kin selection and cooperative breeding in a solitary primate (Microcebus murinus). Behav. Ecol. Sociobiol. 60, 582-588. doi: 10.1007/s00265-006-0203-3

Elgar, M. A. (2015). Integrating insights across diverse taxa: challenges for understanding social evolution. Front. Ecol. Evol. 3:124. doi: 10.3389/fevo.2015.00124

Emlen, S. T. (1982). The evolution of helping. I. An ecological constraints model. Am. Nat. 119, 29-39. doi: 10.1086/283888

Emlen, S. T. (1994). Benefits, constrainsts and the evolution of the family. Trends Ecol. Evol. 9, 282-285. doi: 10.1016/0169-5347(94)90030-2

Emlen, S. T. (1995). An evolutionary theory of the family. Proc. Natl. Acad. Sci. U.S.A. 92, 8092-8099. doi: 10.1073/pnas.92.18.8092

Emlen, S. T., and Oring, L.W. (1977). Ecology, sexual selection, and the evolution of mating systems. Science 197, 215-223. doi: 10.1126/science.327542 
Emlen, S. T., Wrege, P. H., and Demong, N. J. (1995). Making decisions in the family: an evolutionary perspective. Am. Sci. 83, 148-157.

Estes, R. D. (1974). Social organization of the African Bovidae. Behav. Ungulates Relat. Manag. 1, 166-205.

Feeney, W. E., Medina, I., Somveille, M., Heinsohn, R., Hall, M. L., Mulder, R. A., et al. (2013). Brood parasitism and the evolution of cooperative breeding in birds. Science 342, 1506-1508. doi: 10.1126/science.1240039

Field, J. (2005). The evolution of progressive provisioning. Behav. Ecol. 16, 770-778. doi: 10.1093/beheco/ari054

Field, J., and Brace, S. (2004). Pre-social benefits of extended parental care. Nature 428, 650-2. doi: 10.1038/nature02427

Fisher, D. O., Blomberg, S. P., and Owens, I. P. (2002). Convergent maternal care strategies in ungulates and macropods. Evolution 56, 167-176. doi: 10.1111/j.00143820.2002.tb00858.x

Gadagkar, R. (1990). Evolution of eusociality: the advantage of assured fitness returns. Phil. Trans. R. Soc. Lond. B 329, 17-25. doi: 10.1098/rstb.1990.0146

Gardner, A., and Smiseth, P. T. (2011). Evolution of parental care driven by mutual reinforcement of parental food provisioning and sibling competition. Proc. R. Soc. B Biol. Sci. 278, 196-203. doi: 10.1098/rspb.2010.1171

Gilbert, J. D. (2014). Thrips domiciles protect larvae from desiccation in an arid environment. Behav. Ecol. 25, 1338-1346. doi: 10.1093/beheco/aru128

Graves, B. M., and Duvall, D. (1995). Aggregation of squamate reptiles associated with gestation, oviposition, and parturition. Herpetol. Monogr. 9, 102-119. doi: $10.2307 / 1466999$

Griesser,M., Drobniak, S.M., Nakagawa, S., and Botero, C. A. (2017). Family living sets the stage for cooperative breeding and ecological resilience in birds. PLoS Biol. 15:e2000483. doi: 10.1371/journal.pbio.2000483

Griggio, M., Matessi, G., and Pilastro, A. (2004). Should I stay or should I go? Female brood desertion and male counterstrategy in rock sparrows. Behav. Ecol. 16, 435-441. doi: 10.1093/beheco/ari009 
Hamilton, W. D. (1964). The genetical evolution of social behaviour. II. J. Theor. Biol. 7, 1752. doi: 10.1016/0022-5193(64)90039-6

Hamilton,W. D. (1971). Geometry for the selfish herd. J. Theor. Biol. 31, 295-311. doi: 10.1016/0022-5193(71)90189-5

Hayes, L. D. (2000). To nest communally or not to nest communally: a review of rodent communal nesting and nursing. Anim. Behav. 59, 677-688. doi: 10.1006/anbe.1999.1390

Hayward, M. W., O'Brien, J., Hofmeyr, M., and Kerley, G. I. H. (2006). Prey preferences of the African wild dog Lycaon pictus (Canidae: Carnivora): ecological requirements for conservation. J. Mammal. 87, 1122-1131. doi: 10.1644/05-MAMM-A-304R2.1

Heg, D., Rothenberger, S., and Schürch, R. (2011). Habitat saturation, benefits of philopatry, relatedness, and the extent of co-operative breeding in a cichlid. Behav. Ecol. 22, 82-92. doi: 10.1093/beheco/arq170

Heinze, J., Kellner, K., and Seal, J. (2017). "Sociality in ants," in Comparative Social Evolution, eds D. R. Rubenstein and P. Abbot (Cambridge, UK: Cambridge University Press), 21-49.

Herler, J.,Munday, P. L., and Hernaman, V. (2011). "Gobies on coral reefs," in The Biology of Gobies, eds R. A. Patzner, J. L. Van Tassell, M. Kovacic, and B. G. Kapoor (Jersey, NJ: CRC Press), 493-529.

Holbrook, S. J., Forrester, G. E., and Schmitt, R. J. (2000). Spatial patterns in abundance of a damselfish reflect availability of suitable habitat. Oecologia 122, 109-120. doi: 10.1007/PL00008826

Hultgren, K., Duffy, J. E., and Rubenstein, D. R. (2017). "Sociality in shrimps," in Comparative Social Evolution, eds D. R. Rubenstein and P. Abbot (Cambridge, UK: Cambridge University Press), 224-250.

Hunt, J. H., and Toth, A. L. (2017). "Sociality in wasps," in Comparative Social Evolution, eds D. R. Rubenstein and P. Abbot (Cambridge, UK: Cambridge University Press), 84-123.

Ibáñez-Álamo, J. D., Magrath, R. D., Oteyza, J. C., Chalfoun, A. D., Haff, T. M., Schmidt, K. A., et al. (2015). Nest predation research: recent findings and future perspectives. J. Ornithol. 156, 247-262. doi: 10.1007/s10336-015-1207-4

Janson, C. H. (2000). Primate socio-ecology: the end of a golden age. Evol. Anthropol. Issues News Rev. Issues News Rev. 9, 73-86. doi: 10.1002/(SICI)1520-6505(2000)9:2<73::AIDEVAN2>3.0.CO;2-X 
Kapheim, K.M., Nonacs, P., Smith, A. R.,Wayne, R. K., andWcislo,W. T. (2015). Kinship, parental manipulation and evolutionary origins of eusociality. Proc. R. Soc. B Biol. Sci. 282:20142886. doi: 10.1098/rspb.2014.2886

Kappeler, P. M. (1998). Nests, tree holes, and the evolution of primate life histories. Am. J. Primatol. 46, 7-33. doi: 10.1002/(SICI)1098-2345(1998)46:1<7::AID-AJP3>3.3.CO;2-D

Kappeler, P. M. (2019). A framework for studying social complexity. Behav. Ecol. Sociobiol. 73:13. doi: 10.1007/s00265-018-2601-8

Kappeler, P. M., and van Schaik, C. P. (2002). Evolution of primate social systems. Int. J. Primatol. 23, 707-740. doi: 10.1023/A:1015520830318

Kennedy, P., Higginson, A. D., Radford, A. N., and Sumner, S. (2018). Altruism in a volatile world. Nature 555:359. doi: 10.1038/nature25965 Kerth, G. (2008). Causes and consequences of sociality in bats. AIBS Bull. 58, 737-746. doi: 10.1641/B580810

Kiester, A. R., and Strates, E. (1984). Social behaviour in a thrips from Panama. J. Nat. Hist. 18, 303-314. doi: 10.1080/00222938400770231

Kikvidze, Z., and Callaway, R. M. (2009). Ecological facilitation may drive major evolutionary transitions. Bioscience 59, 399-404. doi: 10.1525/bio.2009.59.5.7

Kingsolver, J. G., Ragland, G. J., and Diamond, S. E. (2009). Evolution in a constant environment: thermal fluctuations and thermal sensitivity of laboratory and field populations of Manduca sexta. Evolution 63, 537-541. doi: 10.1111/j.15585646.2008.00568.x

Klug, H., and Bonsall,M. B. (2010). Life history and the evolution of parental care. Evol. Int. J. Org. Evol. 64, 823-835. doi: 10.1111/j.1558-5646.2009.00854.x

Koenig, W. D., and Mumme, R. L. (1987). Population Ecology of the Cooperatively Breeding Acorn Woodpecker. Princeton University Press.

Kokko, H., and Johnstone, R. A. (1999). Social queuing in animal societies: a dynamic model of reproductive skew. Proc. $R$. Soc. Lond. B Biol. Sci. 266, 571-578. doi: 10.1098/rspb.1999.0674

Komdeur, J. (1992). Importance of habitat saturation and territory quality for evolution of cooperative breeding in the Seychelles warbler. Nature 358, 493. doi: 10.1038/358493a0

Korb, J., and Heinze, J. (2008). "The ecology of social life: a synthesis," in Ecology of Social Evolution, eds J. Korb and J. Heinze (Berlin; Heidelberg: Springer), 245-259. 
Korb, J., and Thorne, B. (2017). "Sociality in termites," in Comparative Social Evolution, eds D. R. Rubenstein and P. Abbot (Cambridge, UK: Cambridge University Press), 124-153.

Kramer, J., and Meunier, J. (2018). The other facets of family life and their role in the evolution of animal sociality. Biol. Rev. 94, 199-215. doi: 10.1111/brv.12443

Kutsukake, M., Shibao, H., Uematsu, K., and Fukatsu, T. (2009). Scab formation and wound healing of plant tissue by soldier aphid. Proc. R. Soc. Lond. B Biol. Sci. 276, 1555-1563. doi: 10.1098/rspb.2008.1628

Lanham, E. J., and Bull, C. M. (2000). Maternal care and infanticide in the Australian skink, Egernia stokesii. Herpetol. Rev. 31:151.

Lewis, S. E., and Pusey, A. E. (1997). "Factors influencing the occurrence of communal care in plural breeding mammals," in Communal Breeding in Mammals, eds N. G. Solomon and J. A. French (Cambridge, UK: Cambridge University Press), 335-363.

Liow, L. H., Van Valen, L., and Stenseth, N. Chr. (2011). Red Queen: from populations to taxa and communities. Trends Ecol. Evol. 26, 349-358. doi: 10.1016/j.tree.2011.03.016

Lovegrove, B. G., and Wissel, C. (1988). Sociality in molerats: metabolic scaling and the role of risk sensitivity. Oecologia 74, 600-606. doi: 10.1007/BF00 380059

Lucia, K. E., Keane, B., Hayes, L. D., Lin, Y. K., Schaefer, R. L., and Solomon, N. G. (2008). Philopatry in prairie voles: an evaluation of the habitat saturation hypothesis. Behav. Ecol. 19, 774-783. doi: 10.1093/beheco/ arn028

Lukas, D., and Clutton-Brock, T. (2012). Cooperative breeding and monogamy in mammalian societies. Proc. R. Soc. Lond. B Biol. Sci. 279, 2151-2156. doi: 10.1098/rspb.2011.2468

Lukas, D., and Clutton-Brock, T. H. (2011). Group structure, kinship, inbreeding risk and habitual female dispersal in plural-breeding mammals. J. Evol. Biol. 24, 2624-2630. doi: 10.1111/j.1420-9101.2011.02385.x

Macdonald, K. S., Ríos, R., and Duffy, J. E. (2006). Biodiversity, host specificity, and dominance by eusocial species among sponge-dwelling alpheid shrimp on the Belize Barrier Reef. Divers. Distrib. 12, 165-178. doi: 10.1111/j.1366-9516.2005.00213.x

Madison, D. M. (1984). "Group nesting and its ecological and evolutionary significance in overwintering microtus rodents," in Winter Ecology of Small Mammals, ed J. F. Merritt (Pittsburg, CA: Carnegie Museum of Natural History), 267-274. 
Manning, C. J., Dewsbury, D. A., Wakeland, E. K., and Potts, W. K. (1995). Communal nesting and communal nursing in house mice, Mus musculus domesticus. Anim. Behav. 50, 741-751. doi: 10.1016/0003-3472(95) 80134-0

Marczak, L. B., and Richardson, J. S. (2008). Growth and development rates in a riparian spider are altered by asynchrony between the timing and amount of a resource subsidy. Oecologia 156, 249-258. doi: 10.1007/s00442-008-0989-y

Maynard Smith, J., and Szathmary, E. (1997). The Major Transitions in Evolution. Oxford, UK: Oxford University Press.

McCorquodale, D. B. (1989). Nest defense in single-and multifemale nests of Cerceris antipodes (Hymenoptera: Sphecidae). J. Insect Behav. 2, 267-276. doi: 10.1007/BF01053298

Mech, L. D., and Boitani, L. (2003). Wolf: Behavior, Ecology, and Conservation. Chicago, IL: University of Chicago Press.

Michael, D. R., Cunningham, R. B., and Lindenmayer, D. B. (2010). The social elite: habitat heterogeneity, complexity and quality in granite inselbergs influence patterns of aggregation in Egernia striolata (Lygosominae: Scincidae). Austral. Ecol. 35, 862-870. doi: 10.1111/j.1442-9993.2009. 02092.x

Michener, C. D. (1969). Comparative social behavior of bees. Annu. Rev. Entomol. 14, 299342. doi: 10.1146/annurev.en.14.010169.001503

Michener, C. D. (1974). The Social Behavior of the Bees: A Comparative Study. Cambridge, MA: Harvard University Press.

Michener, C. D. (1985). "From solitary to eusocial: need there be a series of intervening species?" in Experimental Behavioural Ecology and Sociobiology, ed L. Holldobler (Fortschr Zool), 293-305.

Miquelle, D. G., Peek, J. M., and Van Ballenberghe, V. (1992). Sexual segregation in Alaskan moose.Wildl. Monogr. 122, 3-57.

Molvar, E. M., and Bowyer, R. T. (1994). Costs and benefits of group living in a recently social ungulate: the Alaskan moose. J. Mammal. 75, 621-630. doi: 10.2307/1382509

Moses, R. A., and Millar, J. S. (1992). Behavioural asymmetries and cohesive motheroffspring sociality in bushy-tailed wood rats. Can. J. Zool. 70, 597-604. doi: 10.1139/z92-088

Nakamichi, M., and Yamada, K. (2009). Distribution of dorsal carriage among simians. Primates 50:153. doi: 10.1007/s10329-009-0134-5 
Nalepa, C. A. (1994). "Nourishment and the origin of termite eusociality," in Nourishment and Evolution in Insect Societies West view Studies in Insect Biology, eds J. H. Hunt and C. A. Nalepa (Boulder, CO:Westview Press), 57-104.

Nalepa, C. A. (2010). Altricial development in subsocial cockroach ancestors: foundation for the evolution of phenotypic plasticity in termites. Evol. Dev. 12, 95-105. doi: 10.1111/j.1525-142X.2009.00394.x

Nowak,M. A., Tarnita, C. E., and Wilson, E.O. (2010). The evolution of eusociality. Nature 466:1057. doi: 10.1038/nature09205

O'Connor, D. E., and Shine, R. (2004). Parental care protects against infanticide in the lizard Egernia saxatilis (Scincidae). Anim. Behav. 68, 1361-1369. doi: 10.1016/j.anbehav.2004.02.014

Ohkubo, Y., Yamamoto, T., Ogusu, N., Watanabe, S., Murakami, Y., Yagi, N., et al. (2018). The benefits of grouping as a main driver of social evolution in a halictine bee. Sci. Adv. 4:e1700741. doi: 10.1126/sciadv. 1700741

Okasha, S. (2006). The levels of selection debate: philosophical issues. Philos. Compass 1, 74-85. doi: 10.1111/j.1747-9991.2006.00001.x

Peckre, L., Kappeler, P. M., and Fichtel, C. (2019). Clarifying and expanding the social complexity hypothesis for communicative complexity. Behav. Ecol. Sociobiol. 73:11. doi: 10.1007/s00265-018-2605-4

Perret, M. (1998). Energetic advantage of nest-sharing in a solitary primate, the lesser mouse lemur (Microcebus murinus). J. Mammal. 79, 1093-1102. doi: 10.2307/1383001

Pike, D. A., Clark, R. W., Manica, A., Tseng, H.-Y., Hsu, J.-Y., and Huang, W.-S. (2016). Surf and turf: predation by egg-eating snakes has led to the evolution of parental care in a terrestrial lizard. Sci. Rep. 6:22207. doi: 10.1038/srep22207

Piper, W. H., Parker, P. G., and Rabenold, K. N. (1995). Facultative dispersal by juvenile males in the cooperative stripe-backed wren. Behav. Ecol. 6, 337-342. doi: 10.1093/beheco/6.3.337

Popp, J. N., Hamr, J., Larkin, J. L., and Mallory, F. F. (2018). Black bear (Ursus americanus) and wolf (Canis spp.) summer diet composition and ungulate prey selectivity in Ontario, Canada. Mammal Res. 63, 433-441. doi: 10.1007/s13364-018-0368-y 
Post, M. J. (2000). The captive husbandry and reproduction of the Hosmer's Skink Egernia hosmeri. Herpetof. Syd. 30, 2-6.

Prager, S. M. (2014). Comparison of social and solitary nesting carpenter bees in sympatry reveals no advantage to social nesting. Biol. J. Linn. Soc. 113, 998-1010. doi: 10.1111/bij.12395

Purcell, J., and Avilés, L. (2008). Gradients of precipitation and ant abundance may contribute to the altitudinal range limit of subsocial spiders: insights from a transplant experiment. Proc. R. Soc. B Biol. Sci. 275, 2617-2625. doi: 10.1098/rspb.2008.0582

Queller, D. C., Zacchi, F., Cervo, R., Turillazzi, S., Henshaw, M. T., Santorelli, L. A., et al. (2000). Unrelated helpers in a social insect. Nature 405, 784-787. doi: 10.1038/35015552

Rabosky, A. R., Corl, A., Liwanag, H. E., Surget-Groba, Y., and Sinervo, B. (2012). Direct fitness correlates and thermal consequences of facultative aggregation in a desert lizard. PLOS ONE 7:e40866. doi: 10.1371/journal.pone.0040866

Radespiel, U., Sarikaya, Z., Zimmermann, E., and Bruford, M. W. (2001). Sociogenetic structure in a free-living nocturnal primate population: sexspecific differences in the grey mouse lemur (Microcebus murinus). Behav. Ecol. Sociobiol. 50, 493-502. doi: $10.1007 / \mathrm{s} 002650100402$

Reyer, H.-U. (1986). Breeder-helper-interactions in the pied kingfisher reflect the costs and benefits of cooperative breeding. Behaviour 96, 277-302. doi: 10.1163/156853986X00522

Riehl, C. (2013). Evolutionary routes to non-kin cooperative breeding in birds. Proc. R. Soc. Lond. B Biol. Sci. 280:20132245. doi: 10.1098/rspb.2013.2245

Ross, C. (2001). Park or ride? Evolution of infant carrying in primates. Int. J. Primatol. 22, 749-771. doi: 10.1023/A:1012065332758

Royle, N. J., Alonzo, S. H., and Moore, A. J. (2016). Co-evolution, conflict and complexity: what have we learned about the evolution of parental care behaviours? Curr. Opin. Behav. Sci. 12, 30-36. doi: 10.1016/j.cobeha.2016.08.004

Royle, N. J., Smiseth, P. T., and Kölliker, M. (Eds.). (2012). The Evolution of Parental Care. Oxford; New York, NY: Oxford University Press.

Rubenstein, D. R., and Abbot, P. (2017a). Comparative Social Evolution. Cambridge, UK: Cambridge University Press. 
Rubenstein, D. R., and Abbot, P. (2017b). "Social synthesis: opportunities for comparative social evolution," in Comparative Social Evolution, eds D. R. Rubenstein and P. Abbot (Cambridge, UK: Cambridge University Press), 427-452.

Rubenstein, D. R., Botero, C. A., and Lacey, E. A. (2016). Discrete but variable structure of animal societies leads to the false perception of a social continuum. R. Soc. Open Sci. 3:160147. doi: 10.1098/rsos.160147

Schülke, O., and Kappeler, P.M. (2003). So near and yet so far: territorial pairs but low cohesion between pair partners in a nocturnal lemur, Phaner furcifer. Anim. Behav. 65, 331343. doi: 10.1006/anbe.2003.2018

Schwarz, M. P., Bull, N. J., and Cooper, S. J. (2003). Molecular phylogenetics of allodapine bees, with implications for the evolution of sociality and progressive rearing. Syst. Biol. 52, 1-14. doi: 10.1080/10635150390132632

Sheehan, M. J., Botero, C. A., Hendry, T. A., Sedio, B. E., Jandt, J. M., Weiner, S., et al. (2015). Different axes of environmental variation explain the presence vs. extent of cooperative nest founding associations in Polistes paper wasps. Ecol. Lett. 18, 1057-1067. doi: 10.1111/ele.12488

Shultz, S., Opie, C., and Atkinson, Q. D. (2011). Stepwise evolution of stable sociality in primates. Nature 479:219. doi: 10.1038/nature10601

Silk, J. B., and Kappeler, P.M. (2017). "Sociality in primates," in Comparative Social Evolution, eds D. R. Rubenstein and P. Abbot (Cambridge, UK: Cambridge University Press), 253-283.

Sloane, S. A. (1996). Incidence and origins of supernumeraries at bushtit (Psaltriparus minimus) nests. Auk 113, 757-770. doi: 10.2307/4088855

Soucy, S. L., and Giray, T. (2003). Solitary and group nesting in the orchid bee Euglossa hyacinthina (Hymenoptera, Apidae). Insectes Sociaux 50, 248-255. doi: 10.1007/s00040003-0670-8

Stacey, P. B., and Ligon, J. D. (1991). The benefits-of-philopatry hypothesis for the evolution of cooperative breeding: variation in territory quality and group size effects. Am. Nat. 137, 831-846. doi: 10.1086/285196

Stern, D. L. (1998). Phylogeny of the tribe Cerataphidini (Homoptera) and the evolution of the horned soldier aphids. Evolution 52, 155-165. doi: 10.1111/j.1558-5646.1998.tb05148.x 
Stevens, M. I., Hogendoorn, K., and Schwarz, M. P. (2007). Evolution of sociality by natural selection on variances in reproductive fitness: evidence from a social bee. BMC Evol. Biol. 7:153. doi: 10.1186/1471-2148-7-153

Strassmann, J. E., Hughes, C. R., Turillazzi, S., Solis, C. R., and Queller, D. C. (1994). Genetic relatedness and incipient eusociality in stenogastrine wasps. Anim. Behav. 48, 813-821. doi: 10.1006/anbe.1994.1305

Tallamy, D.W., andWood, T. K. (1986). Convergence patterns in subsocial insects. Annu. Rev. Entomol. 31, 369-390. doi: 10.1146/annurev.en.31.010186.002101

Thierry, B. (2008). Primate socioecology, the lost dream of ecological determinism. Evol. Anthropol. Issues News Rev. Issues News Rev. 17, 93-96. doi: 10.1002/evan.20168

Thorne, B. L. (1997). Evolution of eusociality in termites. Annu. Rev. Ecol. Syst. 28, 27-54. doi: 10.1146/annurev.ecolsys.28.1.27

Tullberg, B. S., Ah-King, M., and Temrin, H. (2002). Phylogenetic reconstruction of parentalcare systems in the ancestors of birds. Philos. Trans. R. Soc. Lond. B. Biol. Sci. 357, 251-257. doi: $10.1098 /$ rstb.2001.0932

Turnbull, C., Caravan, H., Chapman, T., Nipperess, D., Dennison, S., Schwarz,M., et al. (2012). Antifungal activity in thrips soldiers suggests a dual role for this caste. Biol. Lett. 8, 526-529. doi: $10.1098 /$ rsbl.2012.0184

van Schaik, C. (1983). Why are diurnal primates living in groups? Behaviour 87, 120-144. doi: 10.1163/156853983X00147

van Schaik, C. P., and Kappeler, P. M. (1997). Infanticide risk and the evolution of malefemale association in primates. Proc. R. Soc. Lond. B Biol. Sci. 264, 1687-1694. doi: 10.1098/rspb.1997.0234

Varricchio, D. J., Moore, J. R., Erickson, G. M., Norell, M. A., Jackson, F. D., and Borkowski, J. J. (2008). Avian paternal care had dinosaur origin. Science 322, 1826-1828. doi: $10.1126 /$ science. 1163245

Viera, C., and Agnarsson, I. (2017). "Parental care and sociality," in Behaviour and Ecology of Spiders, eds C. Viera and M. Gonzaga (Cham: Springer), 351-381.

Walters, J. R., Copeyon, C. K., and Carter lii, J. H. (1992). Test of the ecological basis of cooperative breeding in red-cockaded woodpeckers. Auk 109, 90-97. doi: 10.2307/4088269 
Wcislo, W., and Fewell, J. H. (2017). "Sociality in bees," in Comparative Social Evolution, eds D. R. Rubenstein and P. Abbot (Cambridge, UK: Cambridge University Press), 50-83.

Wcislo,W. T., and Tierney, S.M. (2009). "The evolution of communal behavior in bees and wasps: an alternative to eusociality", in Organization of Insect Societies: From Genome to Sociocomplexity, eds J. Gadau and J. H. Fewell (Cambridge, MA: Harvard University Press), 148-169.

Wcislo,W. T.,Wille, A., and Orozco, E. (1993). Nesting biology of tropical solitary and social sweat bees, Lasioglossum (Dialictus) figueresi Wcislo and L. (D.) aeneiventre (Friese) (Hymenoptera: Halictidae). Insectes Sociaux 40, 21-40. doi: 10.1007/BF01338830

Wenzel, J. W., and Pickering, J. (1991). Cooperative foraging, productivity, and the central limit theorem. Proc. Natl. Acad. Sci. U.S.A. 88, 36-38. doi: 10.1073/pnas.88.1.36

Wesolowski, T. (1994). On the origin of parental care and the early evolution of male and female parental roles in birds. Am. Nat. 143, 39-58. doi: 10.1086/285595

West-Eberhard, M. J. (1975). The evolution of social behavior by kin selection. Q. Rev. Biol. 50, 1-33. doi: 10.1086/408298

Wheeler, W. M. (1928). The Social Insects: Their Origin and Evolution. Abingdon: Routledge.

Wolff, J. O. (1994). Reproductive success of solitarily and communally nesting white-footed mice and deer mice. Behav. Ecol. 5, 206-209. doi: 10.1093/beheco/5.2.206

Wong, M. Y. (2010). Ecological constraints and benefits of philopatry promote group-living in a social but non-cooperatively breeding fish. Proc. R. Soc. B Biol. Sci. 277, 353-358. doi: $10.1098 /$ rspb.2009.1453

Wong, M. Y., Buston, P. M., Munday, P. L., and Jones, G. P. (2007). The threat of punishment enforces peaceful cooperation and stabilizes queues in a coral-reef fish. Proc. R. Soc. B Biol. Sci. 274, 1093-1099. doi: 10.1098/rspb.20 06.0284

Wong, M. Y. L., Fauvelot, C., Planes, S., and Buston, P. M. (2012). Discrete and continuous reproductive tactics in a hermaphroditic society. Anim. Behav. 84, 897-906. doi: 10.1016/j.anbehav.2012.07.013

Wrangham, R.W. (1980). An ecological model of female-bonded primate groups. Behaviour 75, 262-300. doi: 10.1163/156853980X00447

Yamamoto,M. E. (2006). Infant care in callitrichids: cooperation and competition. Annu. Rev. Biomed. Sci. 7, 149-160. 
Yip, E. C., and Rayor, L. S. (2014). Maternal care and subsocial behaviour in spiders. Biol. Rev. 89, 427-449. doi: 10.1111/brv.12060

Zink, A. G. (2000). The evolution of intraspecific brood parasitism in birds and insects. Am. Nat. 155, 395-405. doi: 10.1086/303325 


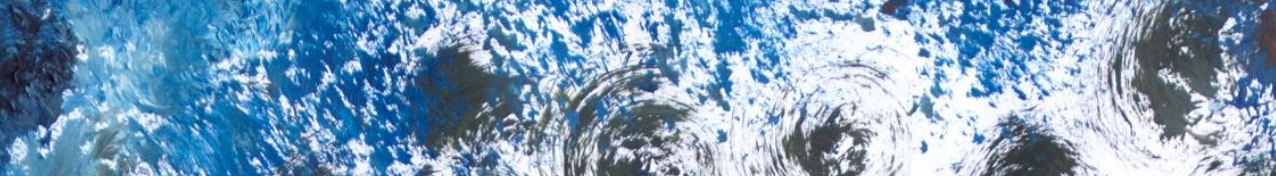

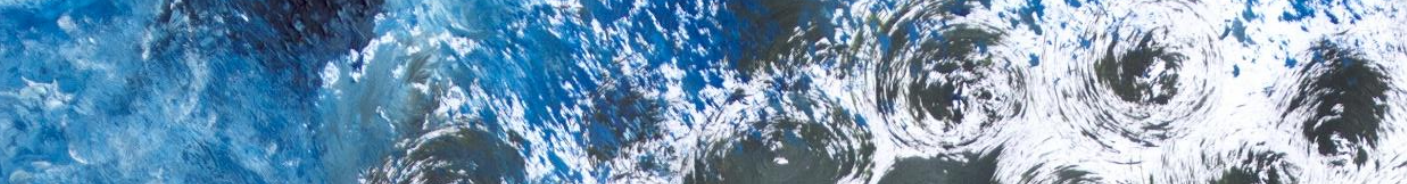

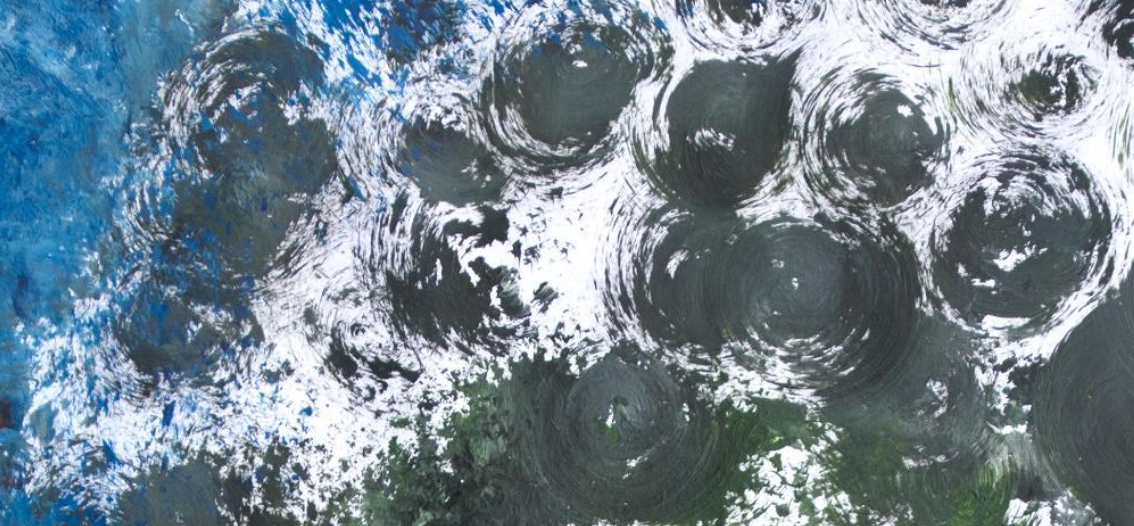

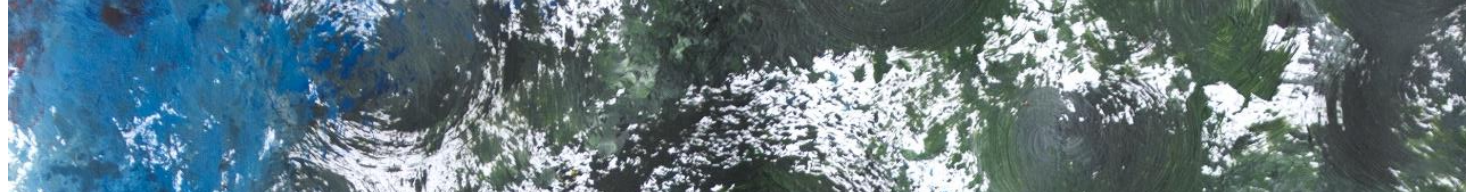
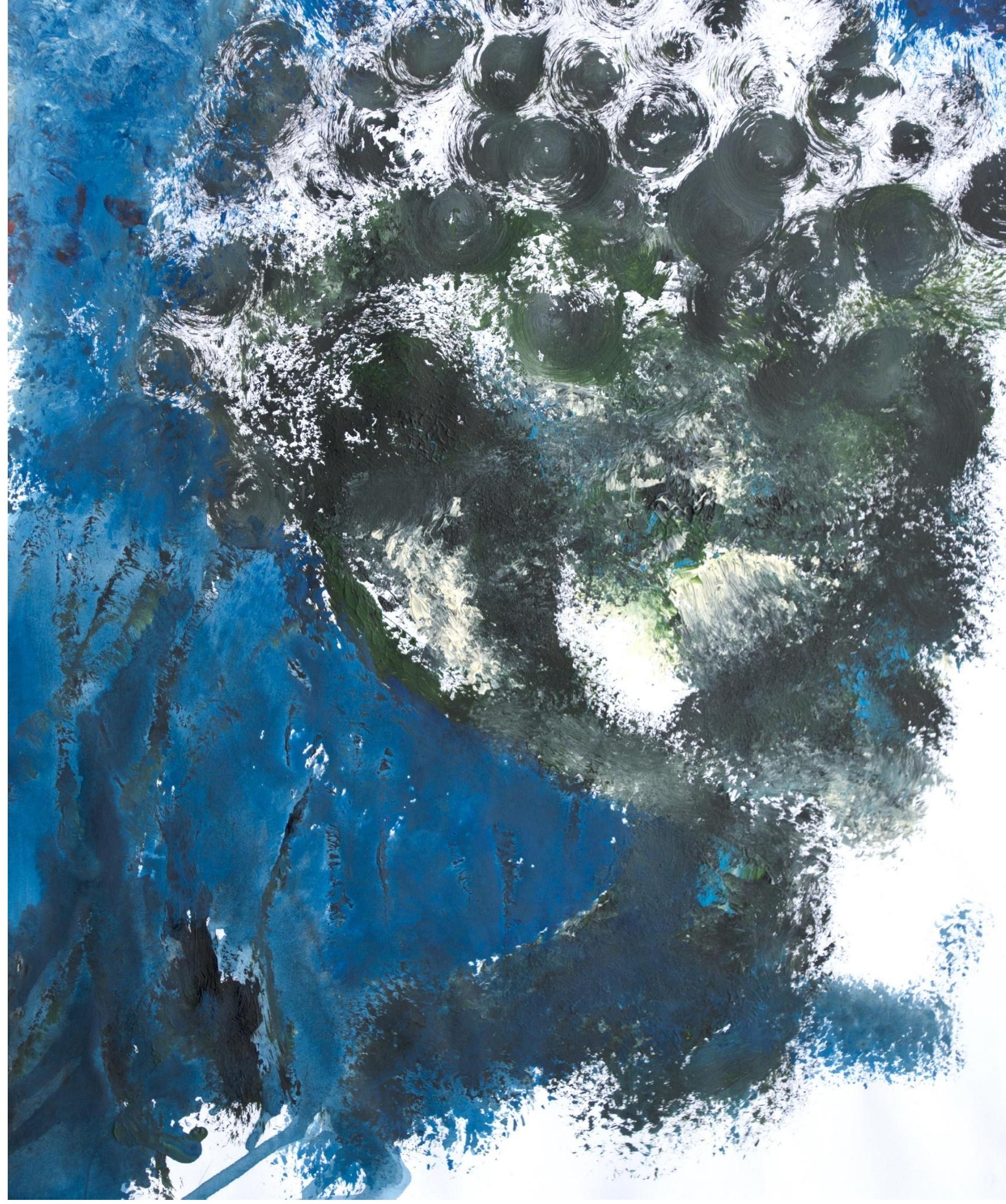


\section{Chapter 2: Social dynamics in a facultatively social primate, Microcebus murinus}

\section{Introduction}

The evolution of group-living is associated with the appearance of cooperation and is considered a major transition in evolution. Due to the inherent difficulties of studying the processes during this major transition to sociality, the vast majority of research on the origins of sociality is based on theoretical models (e.g. Kokko \& Johnstone, 1999; Traulsen \& Nowak, 2006) or is inferred from empirical research on already social species (e.g. Dalerum, 2007; Shultz, Opie, \& Atkinson, 2011). Both of these approaches have several limitations, however.

First, theoretical models offer powerful tools for exploring the role of certain variables in an evolutionary process. Nevertheless, since mathematical tractability and computational efficiency require a certain amount of simplicity, and the entire system is to be specified by the researcher, the outcome of these analyses is very sensitive to the variables chosen as well as their interactions. Assumptions made about population size, migration, reproduction, the presence of sexes and parental care, the longevity of the animals, may all prove to have an effect (Kokko \& Johnstone, 1999; Kokko, Johnstone, \& Clutton-Brock, 2001; Traulsen \& Nowak, 2006; Kokko \& Jennions, 2008). Thus, a given model might reveal little about the origins of sociality and may only be informative of the behavior of the system under the specified conditions.

Secondly, as species evolve, traits serve new functions, and this new status quo will, in turn, create new pressures for the evolution of new traits or changes in already existing ones (Gould, 1991). From such processes of coevolution, exaptation and drift, an intricate web of interrelated traits is generated. The impact of each trait on fitness can therefore only be understood when evaluating their relationships (Flegr, 2010). In the case of sociality, it may be difficult to understand the costs and benefits of being social in an obligately group-living species because individuals literally need to be social for successful survival and reproduction. Individuals in these species are not free to choose between group and solitary living without suffering extreme costs resulting from the negative effects of isolation. In the case of predation, for example, solitary individuals may not be able to survive if natural predators have become efficient enough to capture animals living in groups or simply because when having to choose, predators should be selected for targeting the easiest prey. Nevertheless, such costs may not exist in the transition from solitary to social lifestyles. Thus, conclusions about the evolution of social systems based on costs and benefits of 
sociality in already social species might be misleading. In other words, current functions and constraints may not reflect the adaptive value and the mechanisms sustaining sociality at its first stages.

Thirdly, phylogenetic reconstructions have provided a "map" for the evolutionary transition to sociality in several taxa (Hughes, Oldroyd, Beekman, \& Ratnieks, 2008; Shultz et al., 2011; Lukas \& Clutton-Brock, 2012). Nevertheless, the resolution and the shapes in the maps are extremely influenced by the quality and amount of available information on traits in extant species. If certain species of a genus or clade are more studied than others, the unbalanced state of the art will affect the reconstruction of ancestral states and their changes (Borries, Gordon, \& Koenig, 2013; Valomy, Hayes, \& Schradin, 2015). Moreover, subjective aspects based on the classification of certain traits like social systems, which may be variable within a species, might also impact results and their interpretation (Schradin, 2013; Valomy et al., 2015; Schradin, Hayes, Pillay, \& Bertelsmeier, 2018). Finally, while a phylogenetic reconstruction will reveal evolutionary changes, it will not identify the selective pressures and the mechanisms behind the observed patterns (Nunn, 2011).

A complementary approach that may help uncover the processes behind the evolution of sociality might come from the study of facultatively social species (Wcislo \& Fewell, 2017; Schradin et al., 2018; Shell \& Rehan, 2018). These species are characterized by flexibility in their social organization that may encompass solitary and pair- or group-living strategies. Current theoretical frameworks emphasize that this flexibility can be expressed at the species (between-population variation), at the population (inter-individual differences) and at the individual level (between context variation) (Schradin et al., 2012, 2018; Ferrari, Lindholm, \& König, 2018; Shell \& Rehan, 2018; Solomon \& Keane, 2018). Such an approach has also been suggested and applied successfully for studying other evolutionary processes, like the appearance and maintenance of sexual reproduction (Becks \& Agrawal, 2012; Gray \& Goddard, 2012; Soper, King, Vergara, \& Lively, 2014) and the evolution of mating systems (Davies, 1992). Regarding social organization, experimental evidence is comparatively scarce due to a more prominent focus on understanding the evolution of other components of social systems in already group-living species.

However, to determine whether a given facultatively social species is suitable for studying social evolution, one needs to know whether the variation shown in the species is the result of an adaptive or a stochastic process. When the variation in intraspecific social organization is an evolved trait, then it becomes a suitable model for the study of costs and benefits associated with different strategies in different contexts (Schradin et al., 2012). However, if it is a temporary result of a short disturbance and not an evolved trait, conclusions from comparisons of the different social organizations would have no biological nor evolutionary meaning. Four mechanisms have been evoked to explain the appearance 
and evolution of facultative sociality: 1) environmental disrupters, 2) genetic differentiation, 3) developmental plasticity and 4) social flexibility (Schradin, 2013).

Environmental disrupters are external sources of mortality that impact the social organization. The resulting social system represents a transient state that does not correspond to the emerging properties of evolved and optimized strategies of individuals and is therefore non-adaptive. For example, if in a species characterized by polygynous units with two females, one of them dies, the social organization changes to "pair living". However, this is not a selected strategy aiming to maximize fitness under present conditions. Similarly, in pair-living wolves, solitary animals can be derived from the death of a partner (Milleret et al., 2017). In Hymenoptera, between-population variation in social organization results from social strategies being expressed depending on environmental variables such as season length, which varies with altitude and latitude (Field, Paxton, Soro, \& Bridge, 2010; Kocher et al., 2014). In some species, short breeding seasons impede the development of the worker caste and no eusociality develops; but translocation experiments show that the potential for eusociality is intact (Field et al., 2010; Kocher et al., 2014). Thus, comparisons of fitness measures between strategies in such conditions would not contribute to the understanding of the evolution of eusociality.

The second mechanism, genetic differentiation, is at play when differences in genomes lead to different social organizations within a species. This is expected if different populations from the same species live in different but stable environments that through selection lead to differences in social organization sustained by genetic adaptations. For example, current theoretical frameworks in bees suggest that early stages of sociality are characterized by flexibility and are associated with changes in gene regulation (Rehan \& Toth, 2015). More derived social systems characterized by more rigid social strategies are believed to be the result of eco-evo-devo canalizations of early plasticity into the evolution of new genes favoring fixation of caste differentiation and division of labor (Rehan \& Toth, 2015; Shell \& Rehan, 2018). Whereas these examples correspond to changes in gene regulation evidence of genetic differences leading to different social phenotypes is scarce. An exception is shown in the ant Solenopsis invicta, where a single gene is responsible for queens' solitary or group founding of new colonies (Gotzek \& Ross, 2007).

Developmental plasticity refers to mechanisms such as epigenetics or learning, whereby individuals of a population develop a fixed phenotype depending on the conditions experienced during maturation. This type of mechanism is expected to evolve in environments that are variable, but where some periodicity allows prediction of the environment in adulthood to be inferred from conditions experienced during development (Schradin et al., 2018). Although there is widespread confirmation for the importance of 
early developmental conditions of personality, body condition and reproductive success in both humans and non-human animals (Bell \& Sih, 2007; Stamps, 2007; Alvergne, Jokela, \& Lummaa, 2010; Rödel \& Meyer, 2011; Dall, Houston, \& McNamara, 2018), there is currently no evidence for alternative social organizations being dependent on developmental plasticity (Schradin et al., 2018).

Social flexibility corresponds to the capacity of adapting strategies to the current environment and are expected to evolve in unpredictable environments, especially in shortlived species that cannot wait for better times (Schradin et al., 2018). Facultative sociality being dependent on social flexibility through varying environmental conditions is supported by evidence in a range of animal taxa. In burying beetles, both males and females can adopt different reproductive tactics that result in different social organizations and mating systems with solitary, pair-living and one-male-multi-female units with communal breeding and allocare (Eggert \& Müller, 1992; Müller, Braunisch, Hwang, \& Eggert, 2007). Although all strategies coexist in a population, experimental evidence shows that the abundance of resources is the main determinant. In Hymenoptera, the saturation and limitation of breeding sites is also an important driver of sociality in facultatively social species (Brockmann, 1997). In facultatively social rodents, the main determinant of sociality is population density (e.g. prairie voles and montane voles (Jannett, 1978; Lucia et al., 2008), yellow-bellied marmots (Armitage \& Schwartz, 2000), African striped mice (Schoepf \& Schradin, 2012), deer mice (Wolff, 1994). In lizards, facultative family living is expressed under high population density and results in higher survival due to reduced aggression by non-kin (Halliwell et al., 2017). In birds, studies in Seychelles warblers have shown that cooperative breeding is facultative and depends on population density and the availability of territories (Komdeur, 1992). Generally speaking, these examples show support for the notion that habitat saturation might be an important factor for the evolution of sociality.

Thus, studying the mechanisms underlying facultative sociality can offer an important perspective for unraveling the origins of sociality. Only when these strategies are the result of an evolutionary process can tests be meaningful. Social flexibility appears to be the more widespread mechanism leading to intraspecific variation in social organization. To understand social transitions, fitness outcomes of different flexibly expressed strategies should be assessed to understand the conditions that could result in a social strategy invading the population. Although reviewed evidence and theoretical analyses suggest the advantages of living in groups under certain conditions (Socias-Martínez \& Kappeler, 2019), studies comparing fitness outcomes of different social strategies in the same species are scarce and do not show a general benefit of sociality. 
In prairie voles, when comparing females of different populations that show either a solitary or a communal strategy, no difference in reproductive success nor survival was observed (Solomon \& Keane, 2018). Nevertheless, the authors indicated that a trend for decreased reproductive success is at play in bigger groups. Long-term research on variation in social organization within populations of yellow-bellied marmots, revealed that there is an optimal group size in terms of reproductive success with solitary individuals and large groups being at a disadvantage. Larger groups suffered from increased aggression and solitary animals from increased predation (Armitage \& Schwartz, 2000). White-footed mice and deer mice show solitary and communal breeding with no difference in reproductive success between strategies (Wolff, 1994). Octodon degus females derive no benefits from communal breeding when compared with solitary ones, or may even pay a cost (Ebensperger, Hurtado, \& León, 2007). Wild female and male house mice also express different social strategies (Latham \& Mason, 2004). Females exhibit solitary and communal breeding strategies that may change throughout life. In this species, communal breeding is associated with younger females and lower reproductive success (Ferrari et al., 2018). European badgers are mostly solitary, but, in some populations, female groups form through retention of offspring. In group-living populations, group size does not affect reproductive success, but individuals in groups experience more reproductive failure compared to solitary individuals (Silva, Macdonald, \& Evans, 1994). In an elegant study, (Kapheim, Nonacs, Smith, Wayne, \& Wcislo, 2015) showed that there is variation between solitary and eusocial strategies in a tropical sweat bee, Megalopta genalis, with lower inclusive fitness in altruistic workers than in those living a solitary life. Thus, the benefits of different social strategies favoring different social organizations might be weighted by the environment, but there are no general benefits of one over the other strategy.

From a historical account of the evolution of sociality, two main non-exclusive hypotheses that address facultative sociality can be distinguished. On the one hand, researchers of hymenopteran sociality have pointed out that social flexibility might be inherent to the early stages of sociality (Rehan \& Toth, 2015). This implies that intraspecific variation in social organization precedes the evolution of stable social groups. This hypothesis is supported by the fact that intermediate stages in the social spectrum between solitary and eusocial bees are characterized by some degree of facultative sociality (Shell \& Rehan, 2018). This variation may even be cryptic, as it is experimentally possible to transform a solitary species into a group-living one (reviewed in Shell \& Rehan, 2018), even with division of labor emerging (Sakagami \& Maeta, 1995; Holbrook et al., 2009). On the other hand, the current emerging framework for studying the evolution of vertebrate sociality suggests that facultative sociality might be an adaptation to unpredictable habitats and might neither be related to a stage in social evolution nor to genetic variation (Schradin et al., 2018). 
Currently, studies testing these hypotheses are rare and hampered by a trend to neglect intraspecific variation in social organization in phylogenetic reconstructions. Being an exception in this respect, the reconstruction of carnivoran social organization revealed that sociality did not progress from solitary to group living only, but that socially flexible organization tends to precede more stable group living (Dalerum, 2007). Nevertheless, the two hypotheses are not mutually exclusive, and sociality could have evolved through intermediate stages, characterized by originally solitary species adapting to varying environmental conditions through social flexibility. In a subsequent step, facultative sociality could become more fixed, and permanent sociality could evolve. Future studies taking into account facultative sociality and ecological conditions should therefore contribute to a better understanding of the evolutionary transitions from solitary ancestors to group-living species.

Despite much theoretical work conceptualizing the evolution of cooperation and sociality as a genetic mutation that invades the population e.g. (Traulsen \& Nowak, 2006; Kulich \& Flegr, 2010), in our opinion the reviewed examples from various vertebrate and invertebrate taxa indicate instead that individuals in solitary species are already capable of engaging in cooperation and group living. Linking this notion with the role of parental care explained in Chapter 1, upcoming theories on the origins of vertebrate sociality focus on the common neural and hormonal bases for parental and social behaviors between adults (Michael Griesser, personal communication). Thus, some solitary species may readily engage in sociality, depending on environmental conditions by exaptation of mechanisms initially devoted to parental care.

We want to contribute to the study of facultative sociality by describing the dynamics of social and solitary strategies in a small basal primate with facultative sociality, the grey mouse lemur (Microcebus murinus). Grey mouse lemurs inhabit a very unpredictable habitat and may, therefore, be predicted to exhibit social flexibility as an adaptation. Since mouse lemurs have been proposed as models for the evolution of sociality in ancestral primates (Kessler et al., 2016), I briefly summarize the current understanding of the origins of primate sociality next.

\section{a. Origins of sociality in Primates}

Primates have played a central role in unraveling the various determinants of variation in social complexity in vertebrates (Kappeler \& van Schaik, 2002; Kappeler, 2019). However, despite their prominence in the literature on costs and benefits of engaging in different types of cooperative and competitive interactions, little is known about the transition from solitary nocturnal foragers to diurnal group-living species. According to the socioecological model, female sociality pioneered the transition (Wrangham, 1980). Females aggregated 
with close kin in order to defend patches of resources against other females; a strategy that could rapidly invade a population due to its superiority against solitary females in agonistic encounters. This explanation is both compatible with kin-selected benefits and group selection through between-group competition over resources and is facilitated by the predominant matriline structure of most group-living primates. Moreover, the change in female numbers preceded the change in male numbers, as shown by phylogenetic reconstructions (Lindenfors, Fröberg, \& Nunn, 2004). Thus, female sociality is suspected to be the stepping-stone from solitary to group living in primates. Other authors contributing to the socioecological framework have given more weight to the role of predation pressure (Alexander, 1974; van Schaik, 1983). Since permanent sociality in primates is associated with the diurnal niche, it appears plausible that previously nocturnal solitary animals aggregated as an adaptation to this new niche. Foraging under daylight, where visibility is enhanced, could lead to antipredatory benefits for animals in groups where more individuals can detect or deter predators more efficiently and individuals can be less susceptible to being chosen as prey (Dehn, 1990). Thus, under these hypotheses, social transitions are not expected to be preceded by one or the other sex since predation on adults and the benefits of associations would impact them alike.

The socio-ecological model has recently been criticized because some of its predictions are not matched by current evidence. The model has particularly failed to explain amongspecies variation in female philopatry, which constitutes a central aspect of the model to account for the evolution of cooperation in primates (Thierry, 2008; Clutton-Brock \& Janson, 2012). A comparative phylogenetic study suggested a scenario for the transition to sociality in primates that reinforced the importance of predation pressure (Shultz et al., 2011). Accordingly, the transition to sociality was made without kin structure by large aggregations of unrelated individuals foraging together. The matrilineal societies of most contemporary primates are then proposed to be derived from these foraging aggregations, with social philopatry being a consequence rather than a cause of sociality. The scenario proposed by Shultz et al. (2011) is thus in stark contrast to Wrangham's (1980) original approach, and seems to support claims that kin selection could be less important than previously thought in social evolution (Wilson \& Hölldobler, 2005; Nowak, Tarnita, \& Wilson, 2010; Socias-Martínez \& Kappeler, 2019).

Nevertheless, phylogenetic approaches suffer from limitations when dealing with intraspecific variation in social organization (Schradin et al., 2018). A recently published analysis of social organization in strepsirrhine primates (Agnani, Kauffmann, Hayes, \& Schradin, 2018) shows how different authors arrive at disparate conclusions, depending on the authors' subjectivity and literature sources (i.e. primary vs. secondary). Agnani and 
colleagues (2018) compared their results from search on the primary literature with those of Shultz and colleagues (2011) and those of (Lukas \& Clutton-Brock, 2013) and found differences in the number of species classified in different types of social organization. For example, Shultz and colleagues (2011) classified 38\% of strepsirrhines as solitary, CluttonBrock and Lukas 61\%, while Agnani and colleagues found evidence for only $7 \%$ of species. Such subjectivity in classifying social organizations can have major impacts in the reconstruction of ancestral states as well as transitions between different types of social organization. Thus, the origins of sociality in primates remain an active field of research.

\section{b. A living model for ancestral primate transition to sociality}

The last common ancestor of primates is believed to be a nocturnal solitary forager, which separated from a common ancestor with Scandentia and Dermopthera between 90 and 55 million years ago (Bloch, Silcox, Boyer, \& Sargis, 2007; Martin, Soligo, \& Tavaré, 2007; Silcox \& López-Torres, 2017). Based on this fact, one approach to studying the evolution of primate sociality has focused on the social organization of strepsirrhines. This primate clade includes lemurs, galagos, and lorises and is believed to be representative of the ancestral primates by retention of small body size, nocturnality and solitary foraging (CharlesDominique \& Martin, 1970).

During the past decades, the idea that ancestral primates were small insectivorous animals has been challenged, however. Recent phylogenetic reconstructions suggest that the putative primate ancestors were as big as 1-2 kg and had a diet consisting mainly of fruit (Andrews, Rambeloarivony, Génin, \& Masters, 2016). This new vision challenging the usefulness of nocturnal strepsirrhines as models for primate ancestors is further sustained by phylogenetic reconstructions showing that small body size in cheirogaleids is the result of an evolutionary dwarfism process undergone recently from a larger-sized ancestor (Masters, Génin, Silvestro, Lister, \& DelPero, 2014). In contrast, investigations of the fossil record advocate for a small insectivorous ancestor ( $N i$, Wang, Hu, \& Li, 2004; Dagosto, Gebo, Ni, \& Smith, 2018). Thus, the model of a primate ancestor remains unequivocally reconstructed, but the majority view holds that it was probably a relatively small, nocturnal and arboreal animal (Silcox \& López-Torres, 2017).

Irrespective of the controversy on the combination of ancient primate characteristics, strepsirrhines are basal primates and contribute substantially to phylogenetic reconstructions of transitions and ancestral states. Fostering the study of strepsirrhines is also necessary because, to date, knowledge on their social organization is only available for less than $50 \%$ of species (Agnani et al., 2018). Moreover, strepsirrhines might be a good model for the study of the origins of sociality in general because of their intra-specific variation in key social traits (Schradin et al., 2018; Shell \& Rehan, 2018). Interestingly, most 
diurnal lemurs exhibit comparatively less variation than more ancestral nocturnal species (Kappeler \& Fichtel, 2016; Agnani et al., 2018); see also (Shultz et al., 2011), suggesting that variation in social organization may have preceded the evolution of stable sociality, as suggested for bees (Shell \& Rehan, 2018). It is possible therefore that if we are to understand the origins of sociality, we are to understand this intra-specific variation in social organization in the first place.

Within strepsirrhines, the genus Microcebus has been suggested to be particularly important to understand both, intraspecific variability in social organization (Agnani et al., 2018) and the evolution of stable sociality in primates (Kessler et al., 2016). Microcebus are the smallest primates, are nocturnal, and forage solitarily in search of prey and insects, making them good models for ancient primates. Most importantly, Microcebus exhibit variation both between and within species in social organization, with social units ranging from solitary to multi-male multi-female sleeping associations to communal breeding units with a high degree of allomaternal care (Table 1 ).

Previous work focusing on explaining inter-specific variation has focused on population density as a proxy for kin availability. Kin availability sets the stage for females to form communal breeding units and anti-predatory and thermoregulatory benefits of sleeping in groups in open vegetation (Schülke \& Ostner, 2005). In this sense, a survey of the studies describing Microcebus sociality shows high between and within-species variation in social organization as well as several limitations in the data reported (Table 1).

1. Species vary in:

a. the relative frequencies of within and between-sex sleeping associations

b. the relative proportions of days slept solitary versus in groups

c. sex differences in a. and b.

d. Individual social flexibility in 1.a and 1.b

2. Overall there is an absence of standardized reports of social measures with high variation among studies in reporting:

a. Between-individual differences in 1.a

b. Within-individual strategies (differences in the extent of grouping days per individual) $1 . b$

c. Sampling effort per individual, including monitored days and the seasons for this monitoring. 


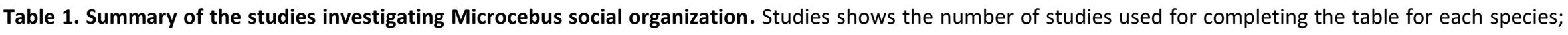

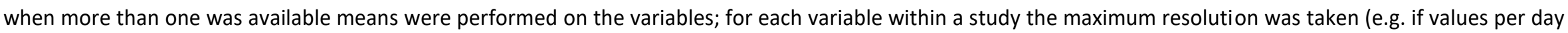

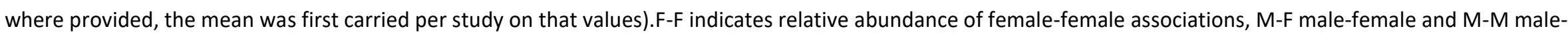

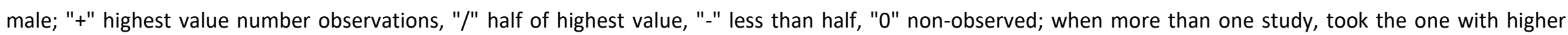

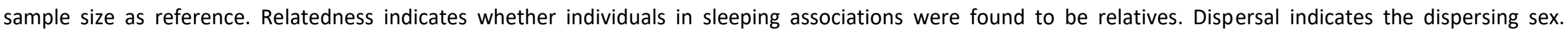

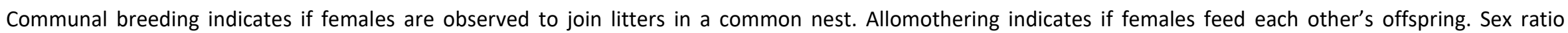

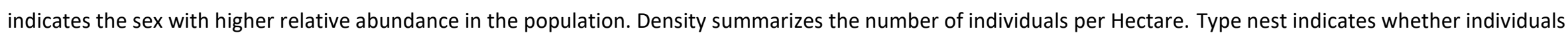

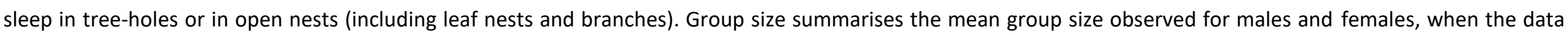

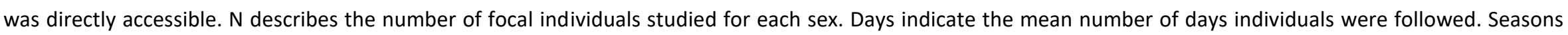

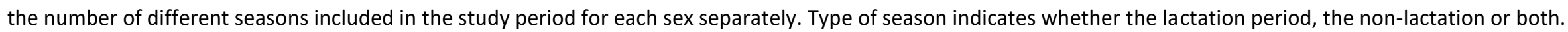
were encompassed by the studies.

\begin{tabular}{|c|c|c|c|c|c|c|c|c|c|c|c|c|c|c|c|c|c|}
\hline sp & Studies & F-F & M-F & $\begin{array}{l}M- \\
M\end{array}$ & Relatedness & Dispersal & $\begin{array}{c}\text { Communal } \\
\text { breeding }\end{array}$ & $\begin{array}{c}\text { Allo- } \\
\text { mothering }\end{array}$ & $\begin{array}{l}\text { Sex } \\
\text { ratio }\end{array}$ & Density & $\begin{array}{l}\text { Type } \\
\text { nest }\end{array}$ & $\begin{array}{l}\text { Group } \\
\text { size }\end{array}$ & N & Days & Seasons & $\begin{array}{c}\text { Type } \\
\text { season }\end{array}$ & Ref \\
\hline M. berthae & 2 & / & + & + & - & M & ? & ? & $M$ & $\begin{array}{c}0.36- \\
0.7\end{array}$ & open & $2 \mathrm{~F}$ & $\begin{array}{c}14.5 \mathrm{~F} \\
19 \mathrm{M}\end{array}$ & $\begin{array}{c}66 \mathrm{~F} \\
129 \mathrm{M}\end{array}$ & $3 \mathrm{~F}, 1 \mathrm{M}$ & $\begin{array}{l}\text { Non- } \\
\text { lact }\end{array}$ & $1,2,3$ \\
\hline $\begin{array}{c}\text { M. } \\
\text { griseorufus }\end{array}$ & 1 & + & - & / & $?$ & $?$ & Y & Y & $\mathrm{F}$ & $2.2-4.3$ & open & $\begin{array}{l}2 \mathrm{~F}, \\
2 \mathrm{M}\end{array}$ & $\begin{array}{l}14 \mathrm{~F} \\
12 \mathrm{M}\end{array}$ & NA & NA & Both & 4 \\
\hline $\begin{array}{c}M . \\
\text { lehilahytsara }\end{array}$ & 2 & / & 0 & + & $?$ & $?$ & $?$ & $?$ & $M$ & $3-4$ & NA & NA & $\begin{array}{c}2.5 \mathrm{~F} \\
4 \mathrm{M}\end{array}$ & NA & 1 & Both & $5,6,7$ \\
\hline M. murinus & 6 & + & - & - & $\mathrm{F}$ & M & Y & Y & $M$ & $\begin{array}{c}0.8- \\
1.3,7.1\end{array}$ & treehole & $\begin{array}{l}2.5 \mathrm{~F} \\
1.5 \mathrm{M}\end{array}$ & $\begin{array}{c}13.83 \mathrm{~F} \\
7,5 \mathrm{M}\end{array}$ & $\begin{array}{l}63.2 \mathrm{~F} \\
53.3 \mathrm{M}\end{array}$ & $\begin{array}{l}2.4 \mathrm{~F} \\
2.7 \mathrm{M}\end{array}$ & Both & $\begin{array}{c}2,8,9, \\
10,11, \\
12,13, \\
14,15\end{array}$ \\
\hline present study & 1 & + & - & + & ? & M & $Y$ & Y & M & $12-15 ?$ & treehole & 2 & $\begin{array}{l}85 \mathrm{~F} \\
55 \mathrm{M}\end{array}$ & $\begin{array}{l}35.7 \mathrm{~F} \\
28.3 \mathrm{M}\end{array}$ & 3 & Both & 16 \\
\hline $\begin{array}{c}M . \\
\text { ravelobensis }\end{array}$ & 2 & / & + & - & $\mathrm{F}$ and $\mathrm{M}$ & M & ? & ? & $\mathrm{F}$ & $\begin{array}{l}7.3- \\
10.9\end{array}$ & open & $3 F, 3 F$ & $\begin{array}{c}9 \mathrm{~F}, \\
10 \mathrm{M}\end{array}$ & $\begin{array}{l}56.3 \mathrm{~F} \\
41 \mathrm{M}\end{array}$ & 1 & $\begin{array}{l}\text { Non- } \\
\text { lact }\end{array}$ & $\begin{array}{c}17,18 \\
19\end{array}$ \\
\hline M. rufus & 1 & NA & & & $?$ & $?$ & $?$ & $?$ & NA & NA & $\begin{array}{l}\text { open/ } \\
\text { treehole }\end{array}$ & NA & $1 F, 6 \mathrm{M}$ & $\begin{array}{c}31 \mathrm{~F}, \\
14.5 \mathrm{M}\end{array}$ & 2 & $\begin{array}{l}\text { Non- } \\
\text { lact }\end{array}$ & 20 \\
\hline $\begin{array}{c}M . \\
\text { sambiranensis }\end{array}$ & 1 & / & + & + & ? & ? & ? & ? & $M$ & NA & open & NA & $3 F, 5 \mathrm{M}$ & 30 & 1 & $\begin{array}{l}\text { Non- } \\
\text { lact }\end{array}$ & 21 \\
\hline
\end{tabular}

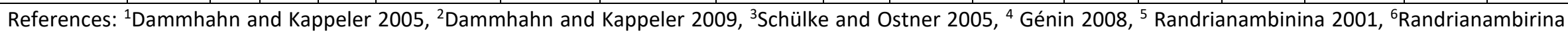

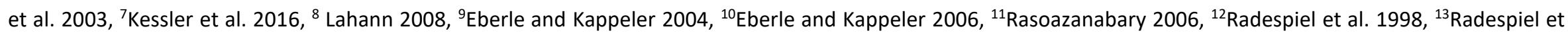

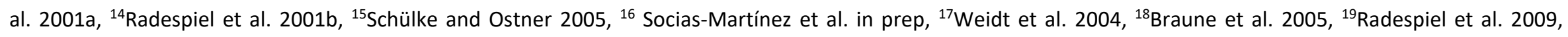
${ }^{20}$ Karanewsky and Wright 2015, ${ }^{21}$ Hending et al. 2017 
3. The methodology is characterized by:

a. Relatively low sample sizes ( $<15$ individuals per sex and species) with high sampling effort (between 30 and 60 days per individual)

b. Monitoring sensitive to the presence of unmarked individuals in sleeping associations

c. Absence of monitoring during the lactation period for 5 out of 7 species

d. Absence of relatedness data for sleeping partners on 4 of the 7 species

e. Poor sampling over the genus, with only 7 species studied to date out of 21 currently recognized

The current state of the art indicates that current knowledge on mouse lemur sociality is subject to potential biases arising from incomplete monitoring of unmarked populations and hamper a test of the socioecological model of Schülke \& Ostner (2005) and other hypotheses for the evolution of sociality and the evolution of social flexibility. The absence of reports of important measures of within and between-individual variation in social strategies is explained by the fact that frameworks for studying species with variation in social organization have only recently emerged (Schradin et al., 2018).

All studies with the exception of one, Eberle \& Kappeler (2006) have used radio-telemetry for following individual associations. This technology is expensive and impedes monitoring a large number of individuals, although it allows for high sampling effort. Moreover, longterm research that could allow marking and monitoring large numbers of individuals in the population is scarce and would need considerable investment for enlarging the number of species studied.

Overall, an absence of monitoring during the lactation period impedes comprehension of causes of Microcebus sociality. In the only two species studied during the lactation period, one confirmed the presence of extensive allomaternal care with adoptions (Eberle \& Kappeler, 2006) and the other suggested that allonursing was present (Génin, 2008). Both studies thus indicate that females might use a strategy that assures care for altricial offspring until maturity, supporting the insurance of care hypothesis developed in Hymenoptera (Gadagkar, 1990).

Thus, a more in-depth investigation of Microcebus sleeping associations may offer new insights into mouse lemur sociality. Specifically, we want to contribute to the study of social flexibility by monitoring a population of wild Microcebus murinus and assessing differences over time in between-individual and within-individual variation in social organization. We use an approach pioneered by Eberle \& Kappeler (2006), that relies on the use of artificial nest boxes. By doing so, we monitored sleeping associations in large numbers of individuals 
over a period of several years during and outside the lactation season. We assess the patterns of within- and between-sex associations, the number of individuals that are exclusively solitary, as well as the percentage of days spent alone in group-sleeping individuals and the strength of partnerships within and across seasons. According to Schradin and colleagues (2018), we predicted that social organization at the population level should change according to seasons reflecting environmental variability in food resources as well as temperatures. Moreover, based on previous findings, males were expected to be mainly solitary while females should engage more often in sociality and be more stable in their partnerships due to kin-based associations.

\section{Materials and Methods}

\section{a. Study area and species}

Grey mouse lemurs are small (60g) nocturnal cheirogaleids inhabiting different habitats throughout the western and southern Madagascar. They are classified as ecological generalists and adapt their diet of fruit, gum, insects, and homopteran secretions to the relative abundance of these sources throughout the year (Dammhahn \& Kappeler, 2008a). Their social system is characterized by home range overlap of males and females with multiple conspecifics of both sexes and a polygynandrous mating system (Eberle \& Kappeler, 2004a, 2004b). Whereas they forage solitarily at night, they sleep during the day in tree-holes in groups of variable composition with marked sexual segregation. During the dry season when food is scarce, and temperatures drop below $5^{\circ} \mathrm{C}$ at night, most females hibernate while males remain active (Schmid, 1998). At the end of the dry season, females emerge from hibernation, and a mating season of one month takes place. Females are receptive for one night only and are asynchronously estrous. Males compete over access to females with mixed scramble and contest competition (Eberle \& Kappeler, 2004b). Gestation takes two months, and one to three offspring are born at the beginning of the wet season (Eberle \& Kappeler, 2006). Females have been shown to communally breed with kin and exhibit high levels of allomothering (Eberle \& Kappeler, 2006). Offspring stay in the nest for two to three weeks. After that time mothers bring their own offspring outside and park them on trees where these remain inactive while mothers forage. Two months after birth young are weaned. Males usually disperse soon after reaching maturity (SchlieheDiecks, Eberle, \& Kappeler, 2012), while most females remain within their mothers' home range and sleeping group (Eberle \& Kappeler, 2006). Mortality rates are high due to predation (Fichtel, 2016), with a potential for more than 10 years life span in captivity but a mean of 2.5 years for males and 3.5 for females in the wild (Hämäläinen et al., 2014).

The study was conducted at a field station of the Deutsches Primatenzentrum in Kirindy Forest, Western Madagascar. Capture procedures to mark animals individually with subdermal RFID transponders are embedded in a long-term research agenda investigating 
various socio-ecological aspects of lemur species inhabiting the dry deciduous forest of Kirindy. Seasonality is pronounced with pronounced wet and dry seasons (Kappeler \& Fichtel, 2012). The local study area ("N5 west"), has an approximate surface of 21 ha. It is equipped with a grid system with intersections every $25 \mathrm{~m}$. Population density is higher than in the areas where previous research on mouse lemur socioecology was carried out (Dammhahn \& Kappeler, 2008b).

\section{b. Nest installation and monitoring}

Based on a pilot study with radio-collared females in another area of Kirindy Forest, we determined the mean height of natural nests $(4 \mathrm{~m})$. We constructed 32 artificial nests that were installed at this height. The nests were constructed in two different sizes using $2 \mathrm{~cm}$ boards; a large model $(40 \times 15 \times 11 \mathrm{~cm})$, and a small model $(20 \times 15 \times 11 \mathrm{~cm})$ (Fig.1). We did so to account for possible preferences of groups and solitary individuals for each model. We included platforms inside each nest to allow the animals to distribute vertically, as seen during a previous study carried out in a different area of the same forest. Big nests had 2 platforms and small nest only one. The platforms had holes in the distal part from the entrance hole to allow individuals to change from different platforms once inside the nest (see Fig. 1). Lateral holes were installed at each level of the nest to allow further measurements in the interior, such as temperature oscillations.

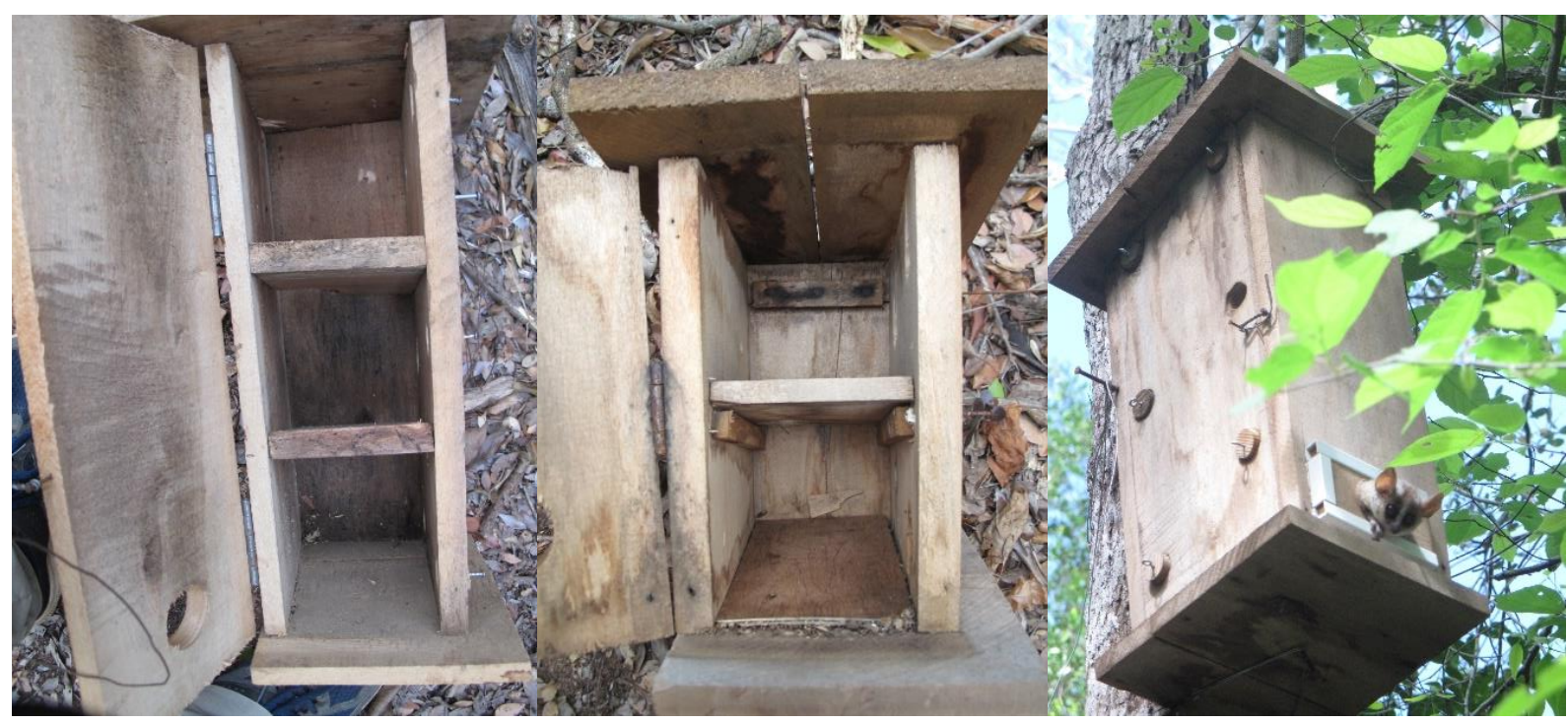

Figure 1. Overview of artificial nests interior and exterior. Large model interior (left), small model (middle), exterior of large model installed (right).

Nests were distributed in 8 parallel lines of the grid system $75 \mathrm{~m}$ apart from each other. The type of nest was randomized to avoid biases of preference due to location. Thirty-three individuals occupied these nests between December 2016 and February 2017. We 
subsequently installed 50 more nests, 25 large and 25 small, in May 2017 to cover intermediate sites (Fig.2).

Between December and February 2018, we searched systematically for natural sleeping holes throughout the grid system where artificial nests were installed. The height of the

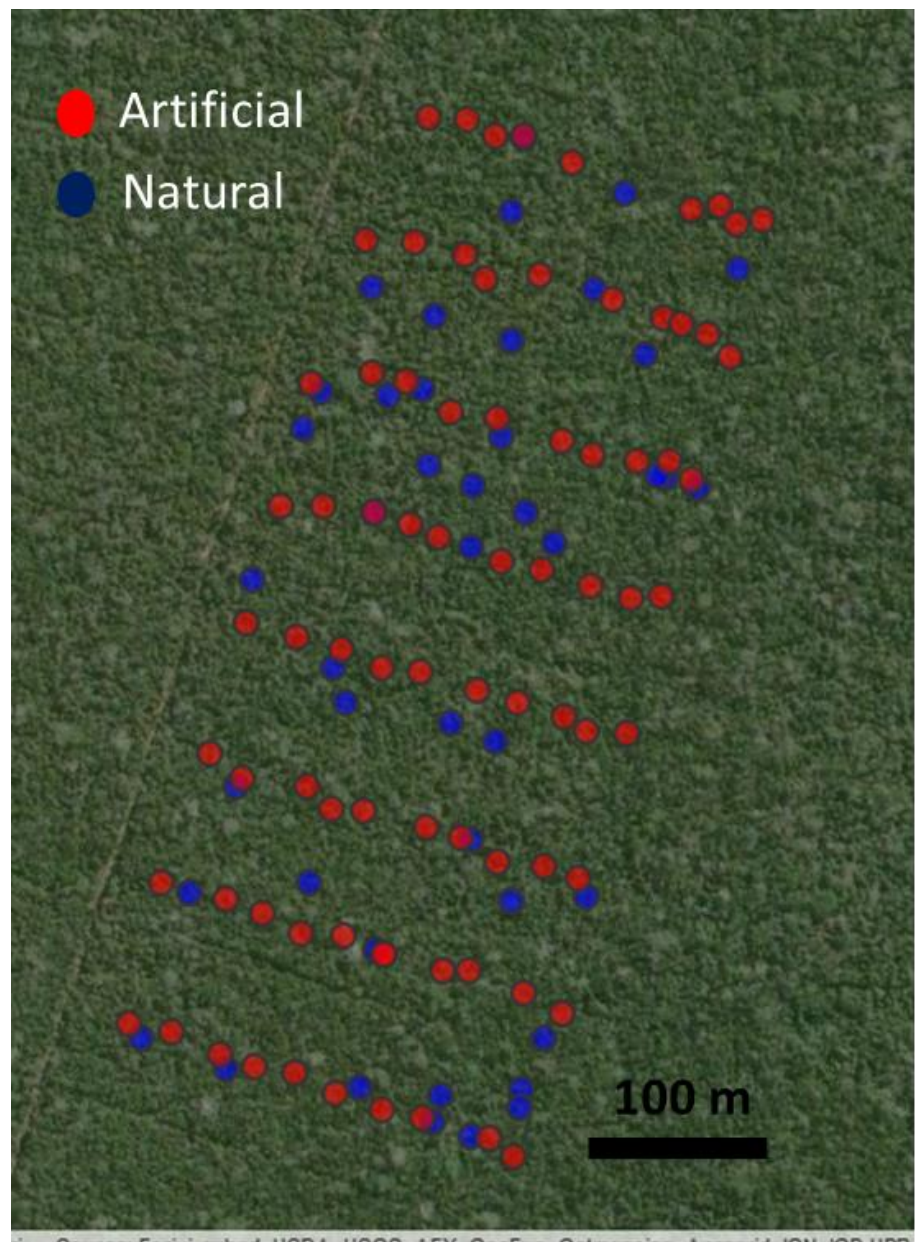

ri-Source: Esri, i-cubed, USDA, USGS, AEX, GeoEye, Getmapping, Aerogrid, IGN, IGP, UPR

Figure 2. Map of the study site with spatial distribution of nests: Emplacement of artificial nests are marked with red dots; natural nests are marked in blue. search was from ground level to about $5 \mathrm{~m}$ in height and about $4 \mathrm{~m}$ distance from the trail. By manually checking natural tree holes with an RFID reading device, we managed to identify 50 naturally occupied nests (Fig 2).

From the moment of installation or discovery, nests were checked on a regular basis with the aid of an RFID reading transponder. We coupled this RFID reading device with a telescopic stick, allowing flexible use at different heights of the nests. The interval of days between checks ranged from 1 to 20, with a median of 1 for a total number of 288 days. A total number of 249 individuals were detected in the natural and artificial nests. Individuals sleeping in the same nest a given day were considered as having decided to share and engage in social interactions.

c. Defining the seasons and the study period

For each year, we divided the seasons according to the described seasonality of rainy and dry season in order to compare the population levels of sociality as well as the individuals' history throughout different seasons. Different seasons are characterized by varying resource abundance and the associated important life-history events that may impact sociality (see details below).

The birth season corresponds to the interval between December $1^{\text {st }}$ to $30^{\text {th }}$ of March, which includes two-thirds of the average gestation period (mid-November to December $31^{\text {st }}$ ), 
lactation ( $31^{\text {st }}$ December to $15^{\text {th }}$ February) and weaning (15 th February to $30^{\text {th }}$ March) (Eberle \& Kappeler, 2006). The birth season is characterized by regular rainfall, warm temperatures and an abundance of flowers, fruits, and insects. The non-reproductive season covers dispersal by young males in early April (Schliehe-Diecks et al. 2012), the hibernation period for some females (from June to September; Schmid and Kappeler ,1998) and the mating season (from mid-October to mid-November; Eberle and Kappeler, 2004b).

Due to the fact that most artificial nests were installed during the non-reproductive season of 2017 and that natural nests were detected during the early birth season 2017-2018, we only included data in the analyses that were collected from December 2017 onward. Following the classification based on environmental and the associated life-history processes of mouse lemurs, we monitored the population of our study area in three different seasons, the birth seasons of 2017-2018 and 2018-2019 and the non-reproductive season from 2018.

\section{d. Describing sociality in grey mouse lemurs}

We first use a set of measures describing sleeping groups experienced by males and females in the two seasons. We then proceed to investigate the variation in sleeping groups experienced by individuals to understand the extent of variation in the social organization a given individual may encounter. The analyses continue by exploring whether this variation can be attributed to individual idiosyncrasies through examining changes in this variation across seasons.

\section{Population-level variation in social organization:}

\section{Group composition}

To describe the size and composition of grey mouse lemur sleeping groups, we counted the number of unique social units observed in one of 8 categories: solitary males and females, male-female pairs, one-male-multi-female groups, one-female-multi-male groups, multimale-multi-female groups, all-male and all-female groups. As argued previously (SociasMartínez \& Kappeler, 2019), we consider a pair of same-sex individuals as a group, but a combination of one male and one female as a pair. We further compare the distribution of the relative abundance of these social categories between each type of season, using chisquared goodness of fit test. We use the observed proportions from the non-reproductive season as the expected values to test against for the birth season.

\section{Group size}

We assessed the mean group size each individual experienced in a given season. We then tested for possible differences in means and variances between sexes within a season and between seasons. 


\section{Number of partners}

We assessed the total number of different partners an individual slept with during each season. We then tested for possible differences in means and variances between sexes within a season and between seasons. We also determined the number of individuals that had no partners for males and females in the two seasons.

\section{Social flexibility of individuals within seasons:}

We here investigate whether individuals show changes in their social strategies both within and across seasons. We calculate the variation within individuals for several measures of sociality. We further test for sex differences in individual variation and seasonal differences within sexes.

\section{Group size variation}

For all individuals, we compiled the daily group size recorded for each of their observations. We then calculated the individual mean group size and its corresponding standard deviation. We extracted the coefficient of variation by dividing the standard deviation by the mean. The coefficient of variation was used as a measure of variation in group size from the perspective of each individual.

\section{Relative number of days sleeping in groups}

We calculated the proportion of solitary days over the total number of observations per season as a measure of the frequency of each strategy within individuals.

\section{Temporal distribution of group sleeping days: switching}

We evaluate whether individuals often switch from solitary to group-sleeping or tend to remain in one strategy for longer periods. Any two consecutive days of observation for an individual were considered as an opportunity for switching the social tactics. We then evaluated the proportion of these opportunities that resulted in a change of social tactic.

\section{Diversity in group composition: Number of social units and evenness}

We calculated the frequency and equitability of group compositions recorded for each individual. We applied Simpson's index of diversity to the individual composition of groups in which a focal animal was seen. To calculate this index, we adapted the Simpson's equation of diversity to our data on sleeping associations by taking into account the number of nights spent in each sleeping group and the number of different sleeping groups (for more details see statistical analyses below). Using this index, we characterized the social flexibility of individuals quantitatively, not only as the number of partners but also considering their identity. 
An overall strategy? A combined index of individuals' flexibility in social tactics within seasons

In order to describe within-individual variability in sociality captured by our previous analyses in a lower-dimensional space, we performed a principal component analysis. We included the variables described above:
a. Number of partners
b. Coefficient of variation in group size
c. The proportion of days group sleeping
d. The proportion of days with switching between tactics
e. Simpson's diversity index on group conformation

\section{II. Social flexibility of individuals across seasons:}

Individual strategies changes across seasons

We wanted to know whether individuals changed their variability in social tactics across seasons. To assess the magnitude of this continuity, we tested for changes in the PCA parameter space for the same individuals in different seasons.

\section{Effects of mortality of partners}

Since changes between seasons in individual strategies may also depend on the specific partners and their behaviors, changes may be due to changes in specific partners. These changes might be due to mortality or by individuals choosing new partners despite the former one still being alive. To this end, we calculated the percentage of partners of the same and opposite sex that survived from a given season into the next as well as the percentage of those that survived and were retained as partners in the next season. In order to test for possible effects of subjective division between seasons that could then relate to the same bout of nest sharing, the retained partners analyses were repeated for individuals observed in non-consecutive seasons. Nevertheless, due to reduced sample size, consecutive seasons were used for further analyses. We then correlated the changes in parameter space of the PCA with the percentage of partners that survived and with the percentage of retained surviving partners.

\section{Statistical analyses}

In the analyses concerning population-level variation in social organization, when establishing the relative frequencies of each of the eight categories of social organization, the contribution of each social unit was made independent of the number of repetitions. For example, if a given pair of females were seen together twenty days, their contribution to the total number of all-female groups was 1 . Moreover, the data from the two birth seasons were combined for describing the relative frequency of each social organization. 
Importantly, we used all data on all sampled sleeping groups each month since the variation in social organization any given month would be independent of the sampling effort per individual. When comparing the patterns between June to August with the rest of the year near 0 values in the proportions of some of the categories of social organization impeded a Chi-squared test comparing months. Thus, we distinguished between mixed-sex and sexually segregated units and combined the data for the months of June to August and for the rest of the year. We then conducted Chi-squared goodness of fit test to compare the proportions of sexually segregated and mixed-sex groups in these two periods.

For the other analyses, we established a minimum threshold of observations per individual in each season of 14 days. We did so since our analyses targeted individual variation within and across seasons. Applying this threshold reduced the sample size drastically (see Table 2). When analyzing associations between individuals, all individuals monitored in the nests were taken into account. Nevertheless, only individuals fulfilling the two weeks observation period criterium were used for further analyses. By doing so we aimed at reporting measures of sociality for well-sampled individuals while nonetheless considering their possible associations with other poorly sampled individuals.

Table 2. Total and effective sample size for each season and sex. $\mathrm{N}$ denotes the total number of individuals recorded sleeping in the nests. $\mathrm{N}>14$ obs denotes the number of individuals recorded at least 14 days in the nests for each season.

\begin{tabular}{|c|c|c|c|}
\hline \multicolumn{1}{|c|}{ season } & sex & N & N 14 obs \\
\hline Birth 2017-18 & F & 63 & 37 \\
\hline Birth 2017-18 & M & 95 & 25 \\
\hline Non-reproductive 2018 & F & 58 & 19 \\
\hline Non-reproductive 2018 & M & 65 & 61 \\
\hline Birth 2018-19 & F & 87 & 16 \\
\hline
\end{tabular}

In the analyses of group size variation, the number of partners, as well as the different measures of within-individual variation, some individuals had multiple values because they were studied in multiple seasons. When comparing sexes within a type of season, for those individuals seen in the two birth seasons, we randomly selected data from one of the two 
birth seasons only. When comparing same-sex associations between types of seasons, we used only individuals seen in one or the other type, and when more than one datum per birth season was available, we randomly chose one of the two. We preferred to use individuals not seen in both seasons because the sample size was greater. Individuals seen in both types of seasons were rare $(F=14, M=9)$. By applying these criteria, we avoided having paired and unpaired data for statistical comparisons and equilibrated contributions between individuals. For comparing means between sexes and between seasons within sexes, two-sample Wilcoxon-Mann-Whitney $U$ Test were used to account for non-normal distributions and unbalanced sample sizes. When comparing variances, two-sided $F$ tests were used.

Table 3. Statistical comparisons and corresponding sample sizes per sex and season. $F$ indicates females and $\mathrm{M}$ males.

\begin{tabular}{|c|c|c|c|}
\hline Type test & Type season & $\mathbf{F}$ & $\mathbf{M}$ \\
\hline \multirow[t]{2}{*}{ Sex comparison } & Non-reproductive & 25 & 19 \\
\hline & Birth & 74 & 45 \\
\hline \multirow[t]{2}{*}{ Season comparison } & Non-reproductive & 11 & 10 \\
\hline & Birth & 60 & 36 \\
\hline
\end{tabular}

For principal component analyses, we tested for the adequacy of the variables chosen using Barlett's test of sphericity and we used the Kaiser-Mayer-Olkin test for assessing sampling adequacy. Variables were scaled before analyses and only principal components with an eigenvalue superior to one were retained for interpretation. To avoid unbalanced contributions when individuals were sampled in more than one season, we selected one season randomly. Then we predicted the coordinates on the principal components plot created with the values of the variables in other seasons. For analyses concerning the changes across seasons, when individuals were sampled in three seasons, they obtained three values of coordinate changes (i.e. from birth season 2017-8 to non-reproductive 2018, from non-reproductive 2018 to birth 2018-9 and from birth 2017-8 to birth 2018-9). To avoid unbalanced contributions between individuals we selected one of the three values randomly. Due to our small sample size, we combined all changes in coordinates between seasons. For comparisons between sexes, we used two-sample Wilcoxon-Mann-Whitney U Test for means and two-sided $\mathrm{F}$ tests for variances.

When correlating variables, Pearson's product-moment coefficient was used. When conducting multiple correlation analyses, Holm's method was used to correct for increased probability of type-I error. 
When calculating the Simpson's diversity index, we used the following formula:

$$
S D I=\frac{\sum n(n-1)}{\sum N(N-1)}
$$

$\mathrm{N}$ denoted the total number of different sleeping groups an individual was seen in and in the number of times each sleeping group was recorded. Groups were defined by the specific individuals inside. A given dyad and the same dyad forming a triplet on a different day with a new individual were treated as different groups. This index allowed us to capture the diversity in number of different group conformations as well as the abundance of each conformation (i.e. more group conformations increase diversity; more evenly distributed group conformations also increase diversity). This index ranged from 0 to 1 ; with 0 representing no diversity, 1 infinite diversity.

\section{Results}

\section{a. Population-level variation in social organization:}

\section{Group composition}

Figure 5 represents the relative abundance of different types of social organization throughout the year. All major types described for primates were observed in this Microcebus murinus population. Across the year, sexually segregated social organizations dominated, except for three consecutive months of June, July and August. The proportions observed in the randomly selected month were retained as the expected value and compared with the values of July. The proportion of expected solitary females was $50 \%$, for solitary males $90 \%$, all-female groups $62 \%$, all-male groups $10 \%$. Male-female pairs were encountered 10 times more often than expected, single female, multi-male units 6 times more often, and single-male-multi-female units and multi-female-multi-male units were expected to be 0 , but were observed with 6 and $9 \%$, respectively. Significant differences between the proportions of mixed-sex groups observed between June and August and the rest of the year were found (June-August: $51.95 \%$ vs. September-May: $7.87 \%$ mixed-sex units; Chi-squared goodness of fit test: $X^{2}=206.32, p<0.0001, N=2$; Fig. 3). Thus, all sexually segregated social organizations, with all-male groups, and to a lesser extent solitary and all-female groups, decreased, whereas all types of mixed-sex groups increased during the heart of the austral winter. 


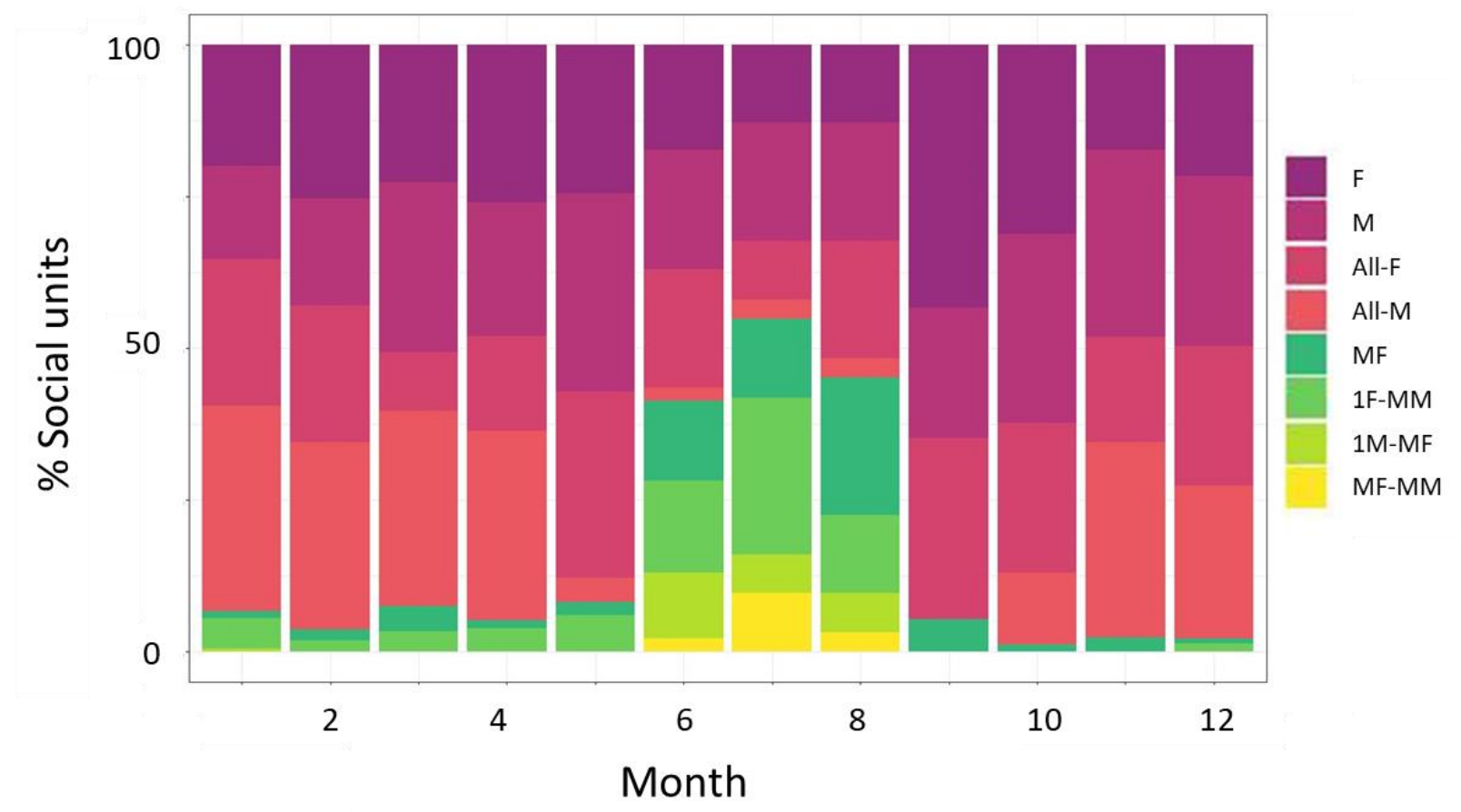

Figure 3. Monthly frequencies of different social organizations. The first two colors on the top represent females and males observed in a solitary tactic respectively and together with the next two down the line, all-female and all-male groups, sum up for the sexually segregated social organizations. M-F represent male-female pairs and are followed by single-female-multi-male, single-male-multi-female and multi-malemulti-female groups. N: 340, 272, 146, 77, 49, 46, 31, 31, 37, 77, 81, 139 from January to December

\section{Group size}

The mean group size for females was $2.10 \pm 0.65$ during the non-reproductive season and $1.95 \pm 0.56$ during the birth season, and the two means did not differ significantly (Wilcoxon-Mann-Whitney rank-sum test: $W=417.5, p>0.1 ; F$ variance test: $F=0.90, p>$ 0.1 ; $\mathrm{Nb}$. non-rep $=11$, Nb. birth = 60; Fig. 4). Males were seen in groups consisting of on average, $1.84 \pm 0.78$ individuals during the non-reproductive, and $2.60 \pm 0.37$ individuals during the birth season. These means, but not the variances, differed significantly (Wilcoxon-Mann-Whitney rank-sum test: $W=106.5, p=0.046 ; F$ variance test: $F=0.85, p>$ 0.1 , Nb. non-rep = 10, Nb. birth = 36; Fig. 4). 


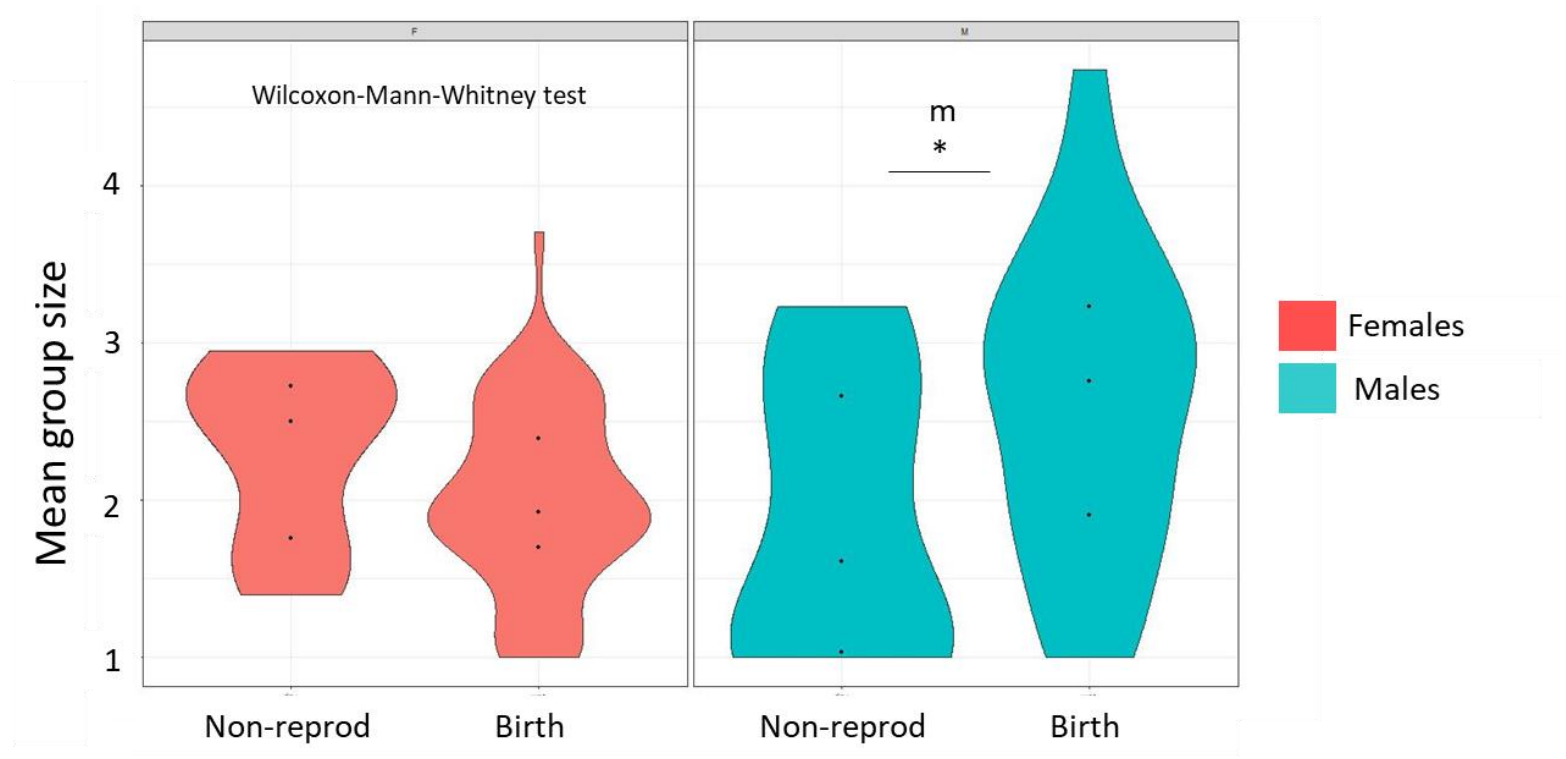

Figure 4. Comparison of mean group size within sexes across seasons. Violin plot of mean group size per sex and season. Dots within the distributions represent quartiles. " $\mathrm{m}$ " represents mean and " $\mathrm{v}$ " variance comparisons. *indicates significant differences.

Mean group size did not differ for males and females during the non-reproductive seasons (Wilcoxon-Mann-Whitney rank-sum test: $W=293, p>0.1 ; F$ variance test: $F=0.68, p>0.1$; $\mathrm{Nb} . \mathrm{F}=25, \mathrm{Nb} . \mathrm{M}=19$; Fig. 5 ), but did so significantly during the birth season. Males showed, on average, 0.7 higher mean group sizes than females during the birth season (Wilcoxon-Mann-Whitney rank-sum test: $\mathrm{W}=992, \mathrm{p}<0.001 ; \mathrm{F}$ variance test: $\mathrm{F}=0.36, \mathrm{p}<$ $0.001 ; \mathrm{Nb} . \mathrm{F}=74$, Nb. $\mathrm{M}=45$ ) (Fig. 5).

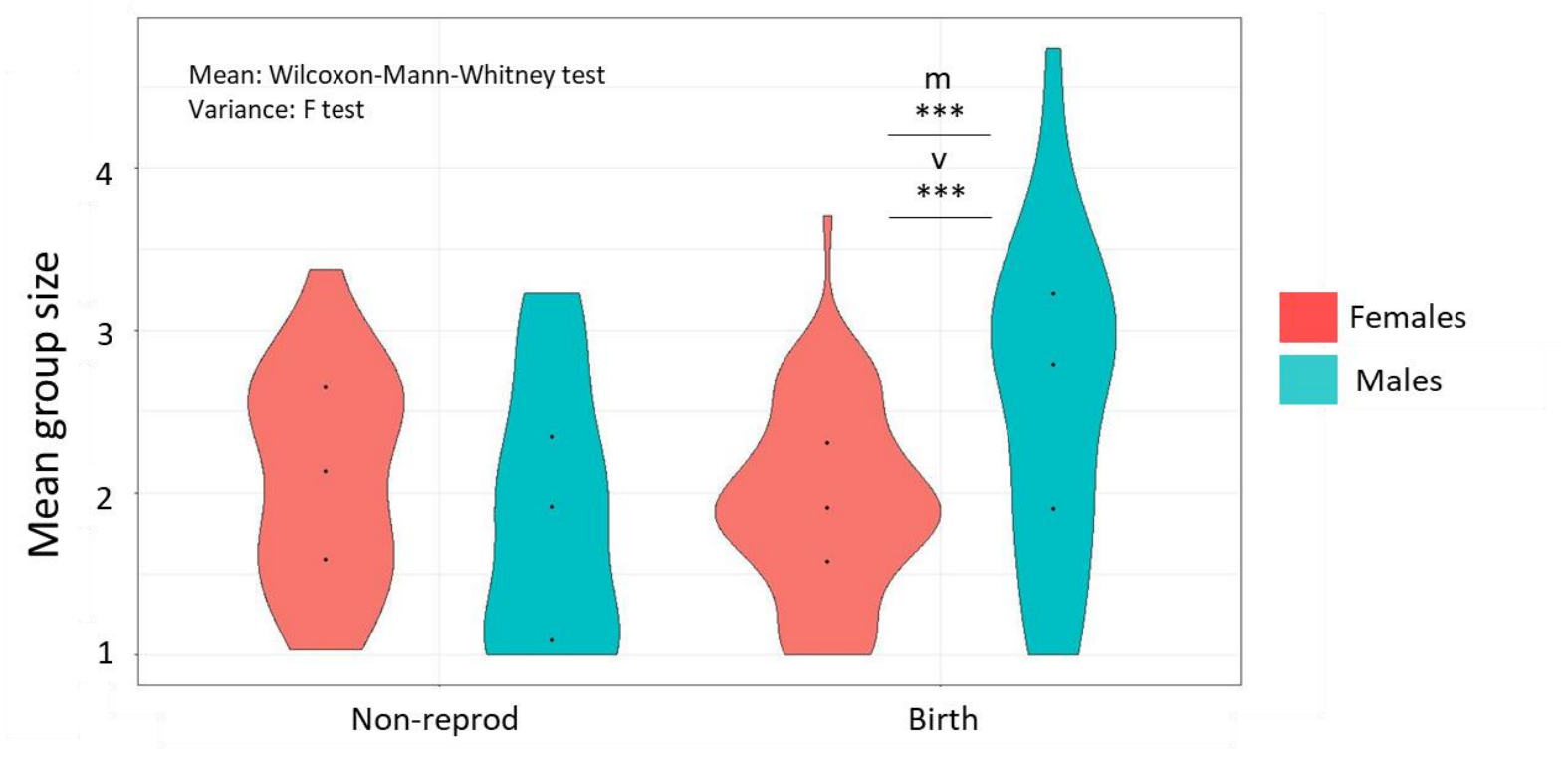

Figure 5. Comparison of mean group size between sexes within seasons. Violin plot of mean group size per sex and season. Dots within the distributions represent quartiles. " $m$ " represents mean and " $v$ " variance comparisons. *indicates significant differences. 


\section{II. Number of partners}

Females showed a significantly lower mean and variance in total number of partners during the birth season ( $4.55 \pm 3.5$ vs. $2.04 \pm 1.74$; Wilcoxon-Mann-Whitney rank-sum test: $\mathrm{W}=$ 513.5, $p<0.01$; F variance test: $F=4.03 p<0.0001$; Nb. non-rep = 10, Nb. birth = 36)(Fig.3). Males, on the contrary, showed a significantly higher number of partners during the birth season with no difference in the variance $(4 \pm 3.65$ vs. $7.19 \pm 4.83$; Wilcoxon-MannWhitney rank-sum test: $W=110.5, p<0.01 ; F$ variance test: $F=0.53, p>0.1 ;$ Nb. non-rep $=$ 10, Nb. birth = 36)(Fig.6).

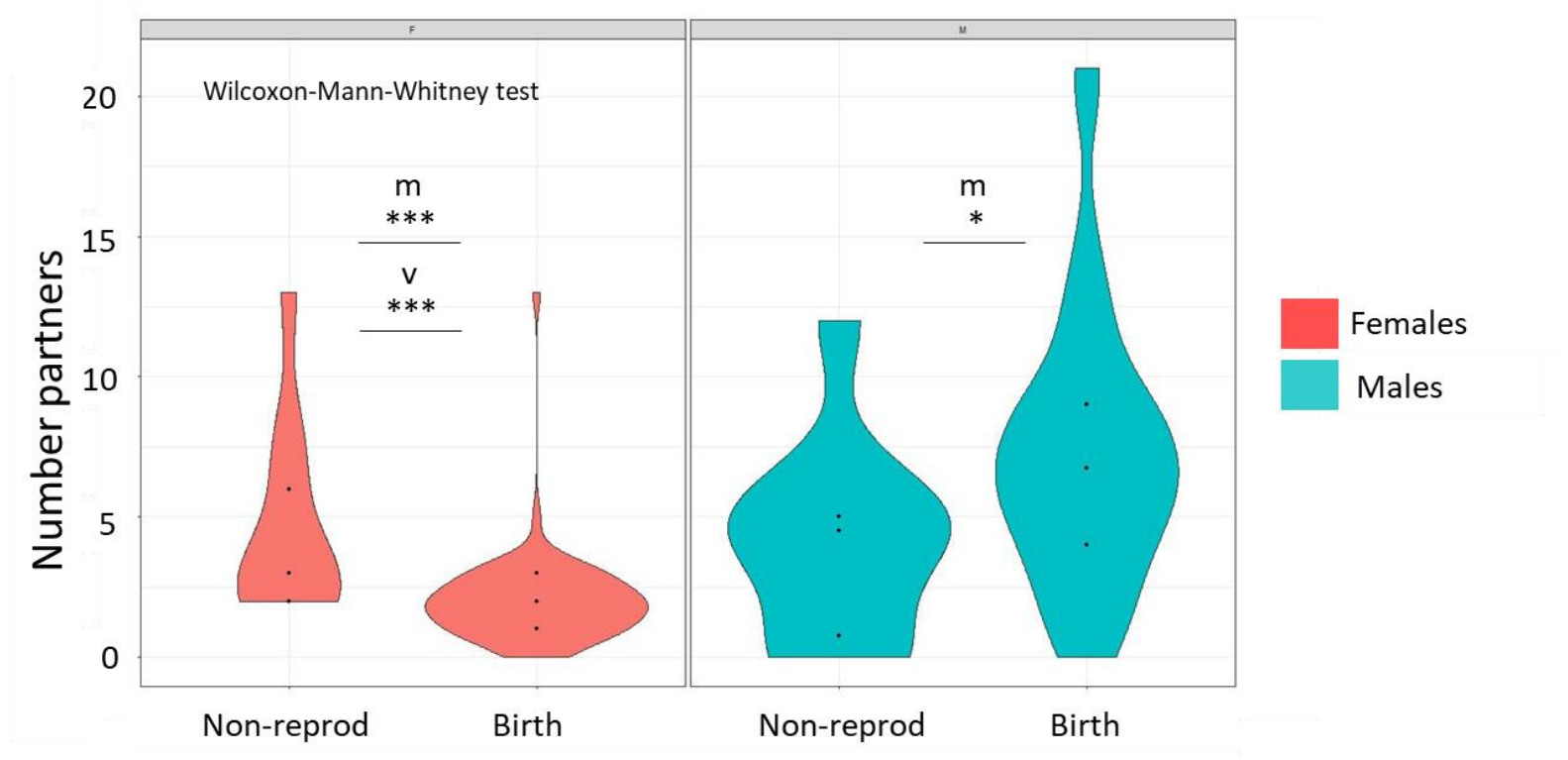

Figure 6. Comparison of number of partners within sexes across seasons. Violin plot of number of partners per sex and season. Dots within the distributions represent quartiles. " $m$ " represents mean and " $v$ " variance comparisons. *indicates significant differences.

Males and females did not differ significantly in their mean number of partners during the dry season (F: $3.80 \pm 2.65$ vs. $M: 4.11 \pm 3.2$; Wilcoxon-Mann-Whitney rank-sum test: $W=$ 217.5, $p>0.1$; F variance test: $F=0.68, p>0.1 ; \mathrm{Nb} . \mathrm{F}=25, \mathrm{Nb} . \mathrm{M}=19$ )(Fig. 7 ). On the contrary, males showed a significantly higher mean and variance in the number of partners during the birth season (F: $1.95 \pm 1.63$ vs. M: $7.24 \pm 4.84$, Wilcoxon-Mann-Whitney ranksum test: $W=515, p<0.001 ; F$ variance test: $F=0.11, p<0.001 ; N b . F=74, N b . M=45)$ (Fig. $7)$. 


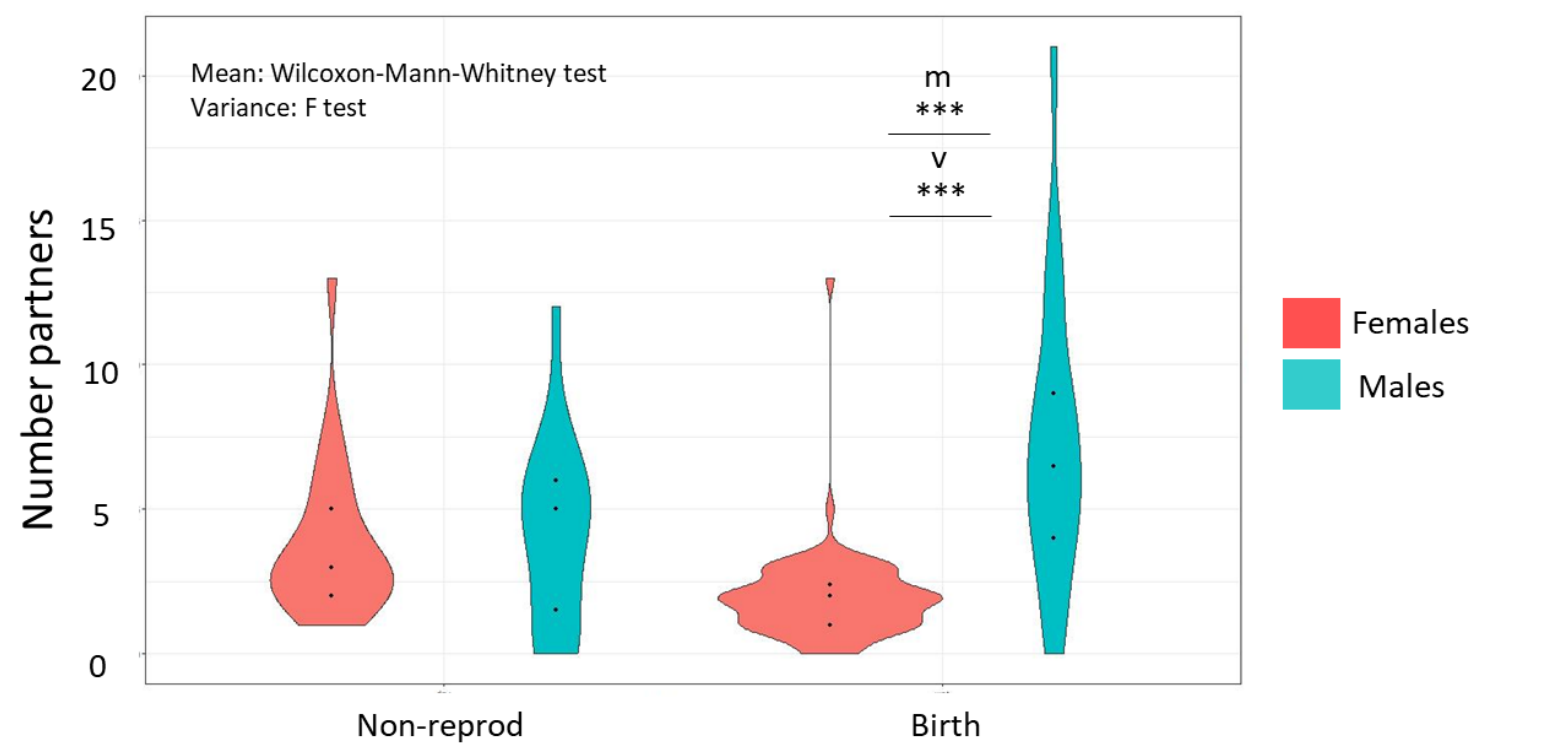

Figure 7. Comparison of number of partners between sexes within seasons. Violin plot of number of partners per sex and season. Dots within the distributions represent quartiles. " $\mathrm{m}$ " represents mean and "v" variance comparisons. *indicates significant differences.

Truly solitary females were rare in the population. None was observed during the nonreproductive season, while they amounted to $12 \%$ during the birth seasons. For males, a higher proportion of $21 \%$ was observed alone during the non-reproductive season; this value decreased to $6 \%$ during the birth season. Importantly, these were not the same individuals, suggesting different optimal strategies for different individuals in different seasons or non-adaptive changes depending on the mortality of partners.

\section{b. Social flexibility of individuals within seasons:}

\section{Group size variation}

Over $75 \%$ of the individuals for both sexes in all seasons showed a coefficient of variation in group size that was lower than 0.5 (Fig. 8). Thus, most individuals varied less than $50 \%$ around their mean group size, indicating low inter-specific variation in this aspect of sociality.

Females mean and variance in coefficient of variation in group size did not differ significantly between non-reproductive and birth season, although variance showed a trend (F $0.28 \pm 0.08$ vs. $0.25 \pm 0.12$; Wilcoxon-Mann-Whitney rank-sum test: $W=409, p>0.1$; $F$ variance test: $F=0.39, p=0.066$; Fig. 8). Males showed a higher mean in their coefficient of variation in group size during the birth season compared with the non-reproductive season, while their variance did not change (M $0.27 \pm 0.22$ vs. $0.42 \pm 0.18$; Wilcoxon-Mann-Whitney 
rank-sum test: $\mathrm{W}=107, \mathrm{p}=0.047 ; \mathrm{F}$ variance test: $\mathrm{F}=1.53, \mathrm{p}>0.1$; Fig.8). Thus, males showed a switch towards higher variation in group size during the birth season, while

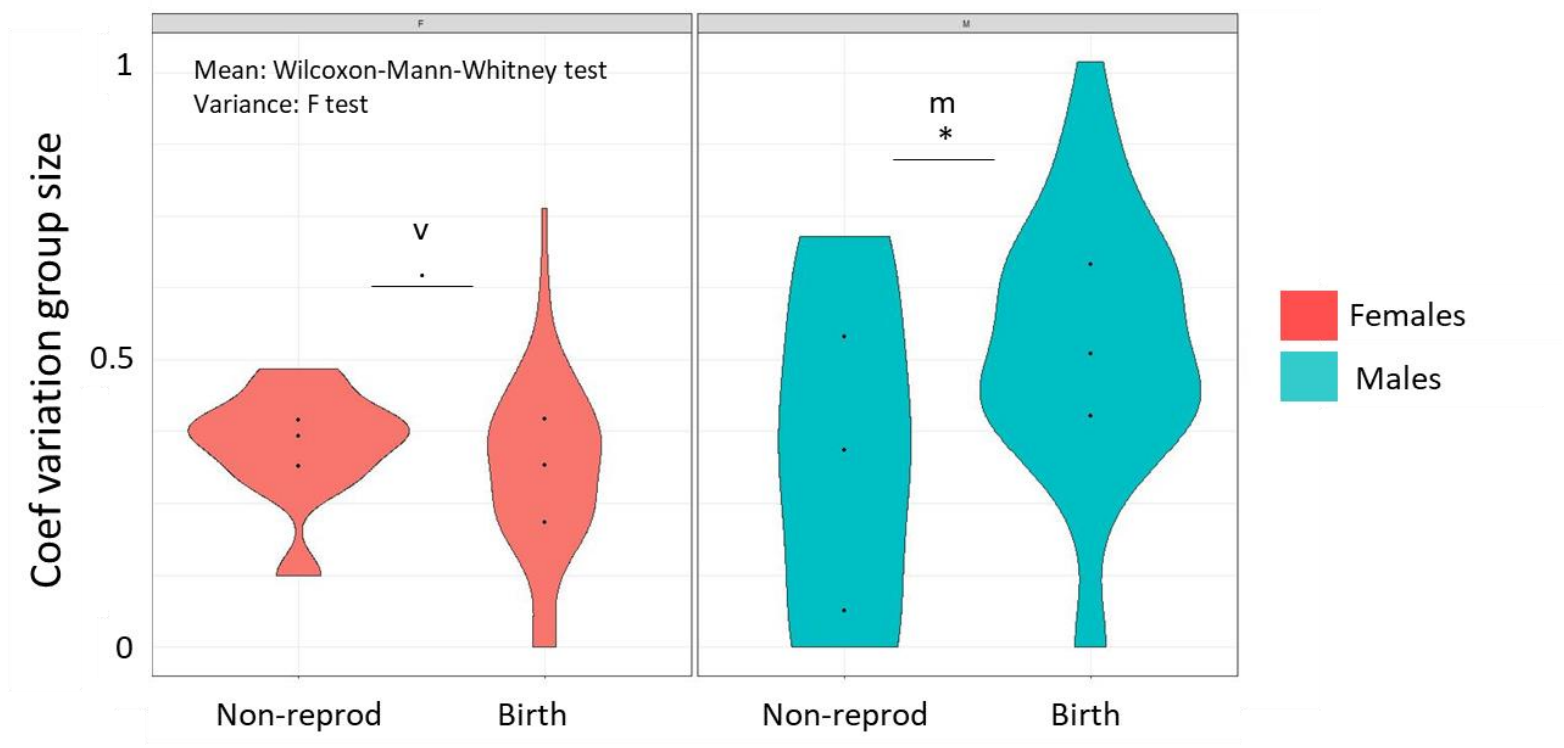

Figure 8. Comparison of coefficient of variation in group size within sexes across seasons. Violin plot of coefficient of variation per sex and season. Dots within the distributions represent quartiles. " $\mathrm{m}$ " represents mean and " $v$ " variance comparisons. *indicates significant differences.

females remained constant but showed more between-individual differences during the birth season.

During the non-reproductive season, males and females did not differ in their mean coefficient of variation in group size (F: $0.3 \pm 0.09$ vs. $M: 0.33 \pm 0.23$; Wilcoxon-MannWhitney rank-sum test: $W=215.5, p>0.1 ; N . F=25, N . M=19 ;$ Fig. 9). Nevertheless, the variance differed significantly ( $F$ variance test: $F=0.14, p<0.0001$ ), indicating that females resemble more each other in the variation in group size than males do. During the reproductive season, males and females differed in their mean coefficient of variation in group size (F: $0.25 \pm 0.12$ vs. $M: 0.41 \pm 0.16$; Wilcoxon-Mann-Whitney rank-sum test: $W=$ $633, p=0.006)$, indicating that males are on average more variable. The variance likewise differed significantly ( $F$ variance test: $F=0.50, p<0.0001$ ), indicating that males differed more from each other in this trait than females did.

\section{Relative amount of days sleeping in groups}

Most females preferred the group sleeping strategy during both seasons, although individuals varied in their preference, especially during the breeding season when the entire social spectrum was observed. Interestingly, males in the non-reproductive season appear 


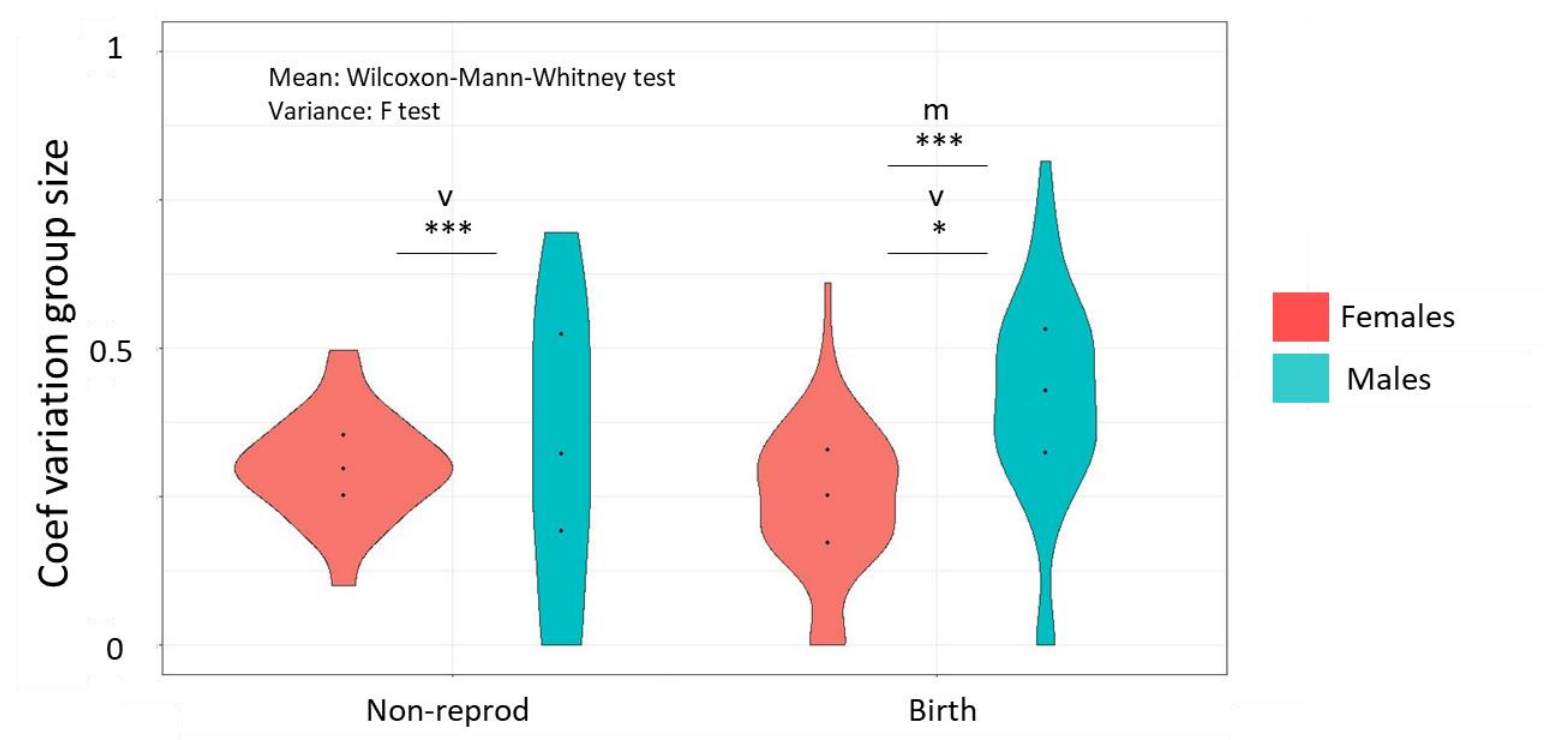

Figure 9. Comparison of coefficient of variation between sexes within seasons. Violin plot of coefficient of variation per sex and season. Dots within the distributions represent quartiles. " $\mathrm{m}$ " represents mean and "v" variance comparisons. *indicates significant differences.

to have a non-majoritarian rule with a bimodal distribution where most males preferred either solitary or group sleeping. This situation changed to a clear preference of most males for sleeping in groups during the birth season.

Females mean and variance in relative time spent in group did not differ significantly between non-reproductive and birth season (F: $0.81 \pm 0.21$ vs. $0.71 \pm 0.31$; WilcoxonMann-Whitney rank-sum test: $\mathrm{W}=376.5, \mathrm{p}>0.1$; $F$ variance test: $\mathrm{F}=0.41, \mathrm{p}>0.1$; Fig.10). Males likewise did not differ in their mean and variance in relative time spent in group between non-reproductive and birth season (M: $0.47 \pm 0.48$ vs. $0.69 \pm 0.31$; WilcoxonMann-Whitney rank-sum test: $\mathrm{W}=150.5, \mathrm{p}>0.1$; $\mathrm{F}$ variance test: $\mathrm{F}=2.28, \mathrm{p}=0.068$; Fig. 10). Nevertheless, the variance showed a trend for significant difference supporting the observation of a change in the distribution changed from bimodal during the nonreproductive to a more skewed towards a preference for grouping during the birth season. 


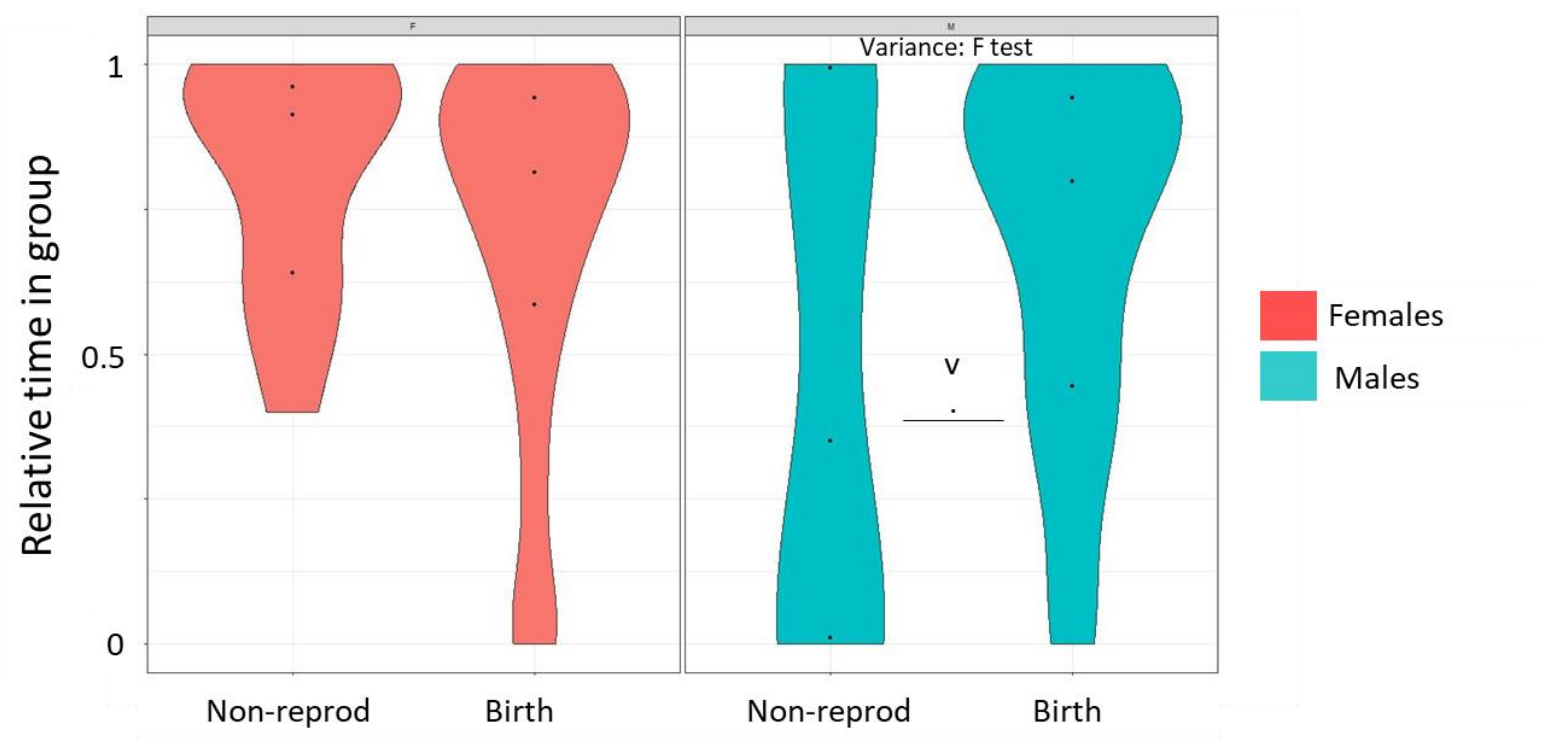

Figure 10. Comparison of relative time spent in groups within sexes across seasons. Violin plot of relative time spent in groups per sex and season. Dots within the distributions represent quartiles. " $m$ " represents mean and " $\mathrm{v}$ " variance comparisons. *indicates significant differences.

When comparing the time spent in groups between males and females, the two sexes did neither differ in their mean nor variance in any type of season (Non-reprod F: $0.30 \pm 0.09$ vs. M: $0.33 \pm 0.23$; Wilcoxon-Mann-Whitney rank-sum test: $\mathrm{W}=317, \mathrm{p}=0.06$; $\mathrm{F}$ variance test: $F=0.57, p>0.1 ; N . F=25, N . M=19$; Birth F: $0.68 \pm 0.32$ vs. $M: 0.69 \pm 0.31$; Wilcoxon-Mann-Whitney rank-sum test: $W=1673.5, F=1.09, p>0.1 ; F$ variance test: $p>$ $0.1 ; \mathrm{Nb} . \mathrm{F}=74, \mathrm{Nb} . \mathrm{M}=45 ; \mathrm{Fig} .11$ ). Nevertheless, there was a trend for significantly lower amounts of time in group by males compared to females in the non-reproductive season. 


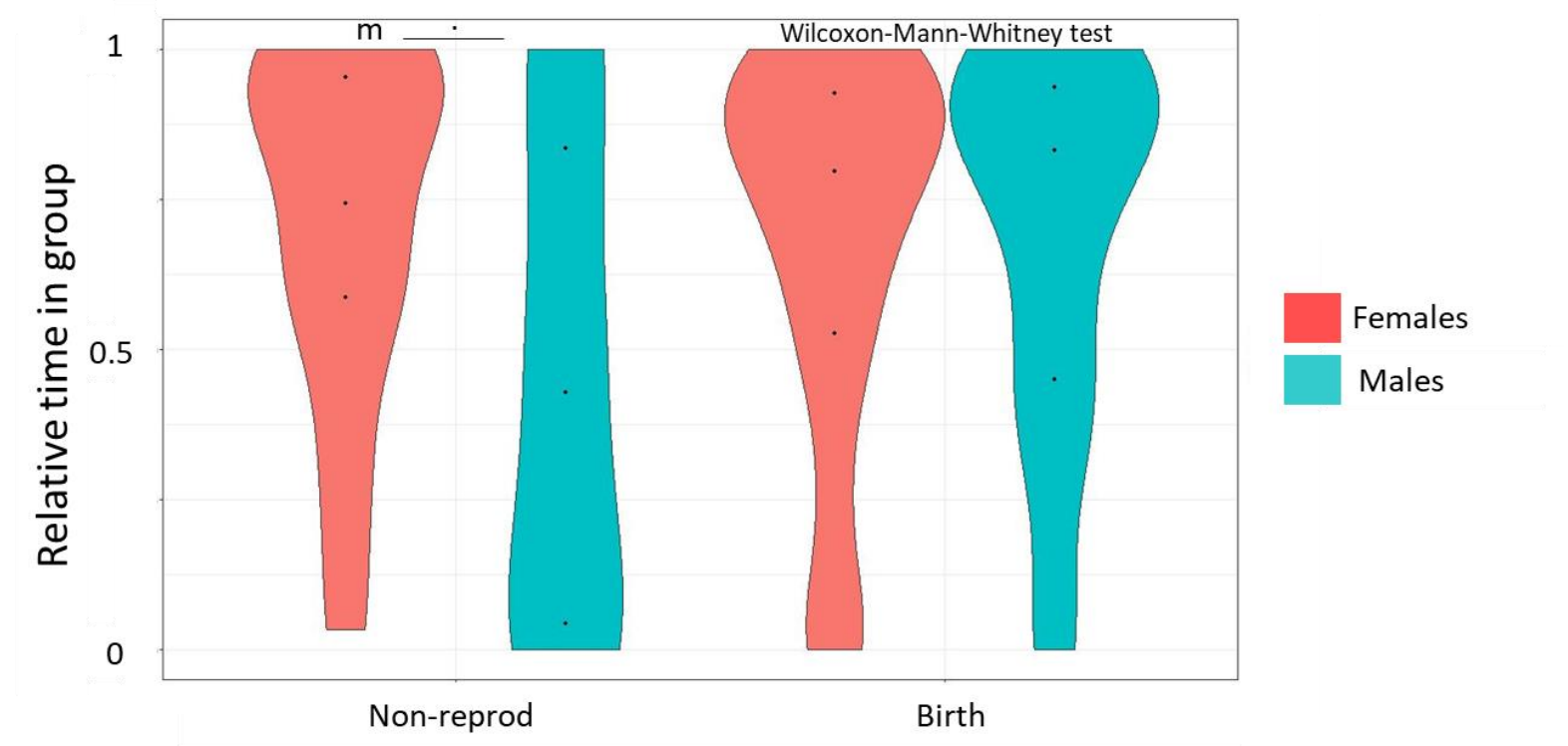

Figure 11. Comparison of relative time spent in groups between sexes within seasons. Violin plot of relative time spent in groups per sex and season. Dots within the distributions represent quartiles. " $m$ " represents mean and " $v$ " variance comparisons. *indicates significant differences.

\section{Temporal distribution of group sleeping: switching}

More than $75 \%$ of individuals showed changes between social tactics in less than $25 \%$ of their observed possibilities. This indicates that there is no switching on a daily basis, but that individuals switch social tactics between longer bouts of around 10 days.

Females mean and variance in the relative amount of switching did not differ significantly between non-reproductive and birth season (F $0.08 \pm 0.11$ vs. $0.12 \pm 0.12$; Wilcoxon-MannWhitney rank-sum test: $W=266.5, p>0.1$; F variance test: $F=0.75, p>0.1$; Fig.12), perhaps as a result of the small sample size in the non-reproductive season. The distributions indicate that switching, at least for a part of the female population, becomes more pronounced during the birth season. Males differed significantly in their mean and variance of the relative frequency of switching with a higher proportion during the birth season, indicating shorter bouts of each tactic (M $0.01 \pm 0.03$ vs. $0.10 \pm 0.13$; Wilcoxon-MannWhitney rank-sum test: $W=103.5, p=0.03$; F variance test: $F=0.05, p<0.0001$; Fig.12).

Males and females differed in changes between social tactics only during the nonreproductive season. Males showed significantly lower amounts of switching than females as well as lower variance in this trait during the non-reproductive season (Non-reprod $\mathrm{F}$ : $0.09 \pm 0.10$ vs. $M: 0.03 \pm 0.05$; Wilcoxon-Mann-Whitney rank-sum test: $W=352, p=0.005$; F variance test: $F=4.24, p=0.003 ; N b . F=25, N b . M=19 ;$ Birth F: $0.13 \pm 0.12$ vs. $M: 0.11 \pm$ 0.13 ; Wilcoxon-Mann-Whitney rank-sum test: $W=1915, p>0.1 ; F$ variance test: $F=0.05, p$ 
$>0.1 ; \mathrm{Nb} . \mathrm{F}=74, \mathrm{Nb} . \mathrm{M}=45 ; \mathrm{Fig} .13)$. Thus, switching is overall less pronounced during the non-reproductive season, with males decreasing more than females, while both sexes show similar patterns during the birth season.

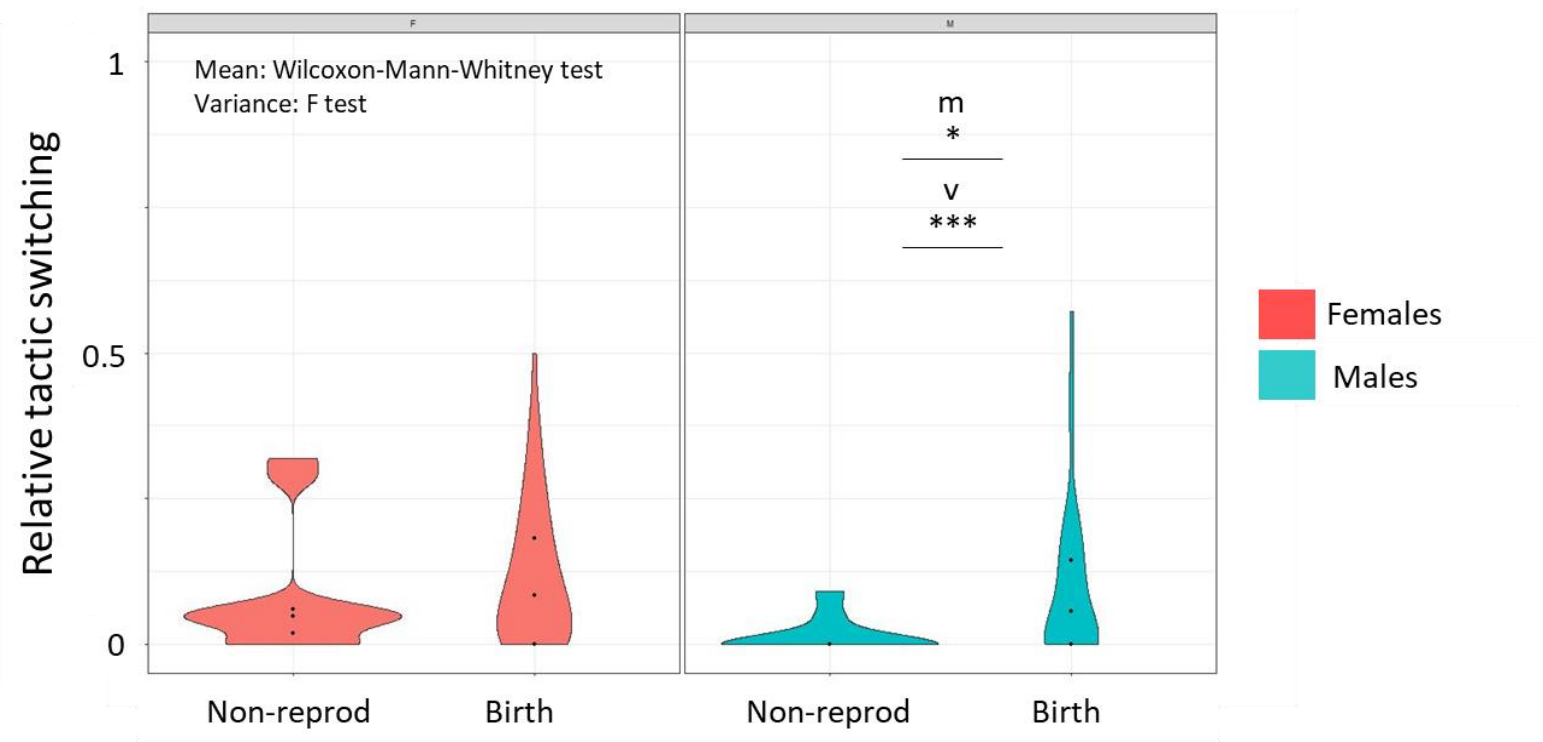

Figure 12. Comparison of frequency of switching between solitary and group sleeping tactics within sexes across seasons. Violin plot of frequency of switching per sex and season. Dots within the distributions represent quartiles. " $\mathrm{m}$ " represents mean and " $\mathrm{v}$ " variance comparisons. ${ }^{*}$ indicates significant differences.

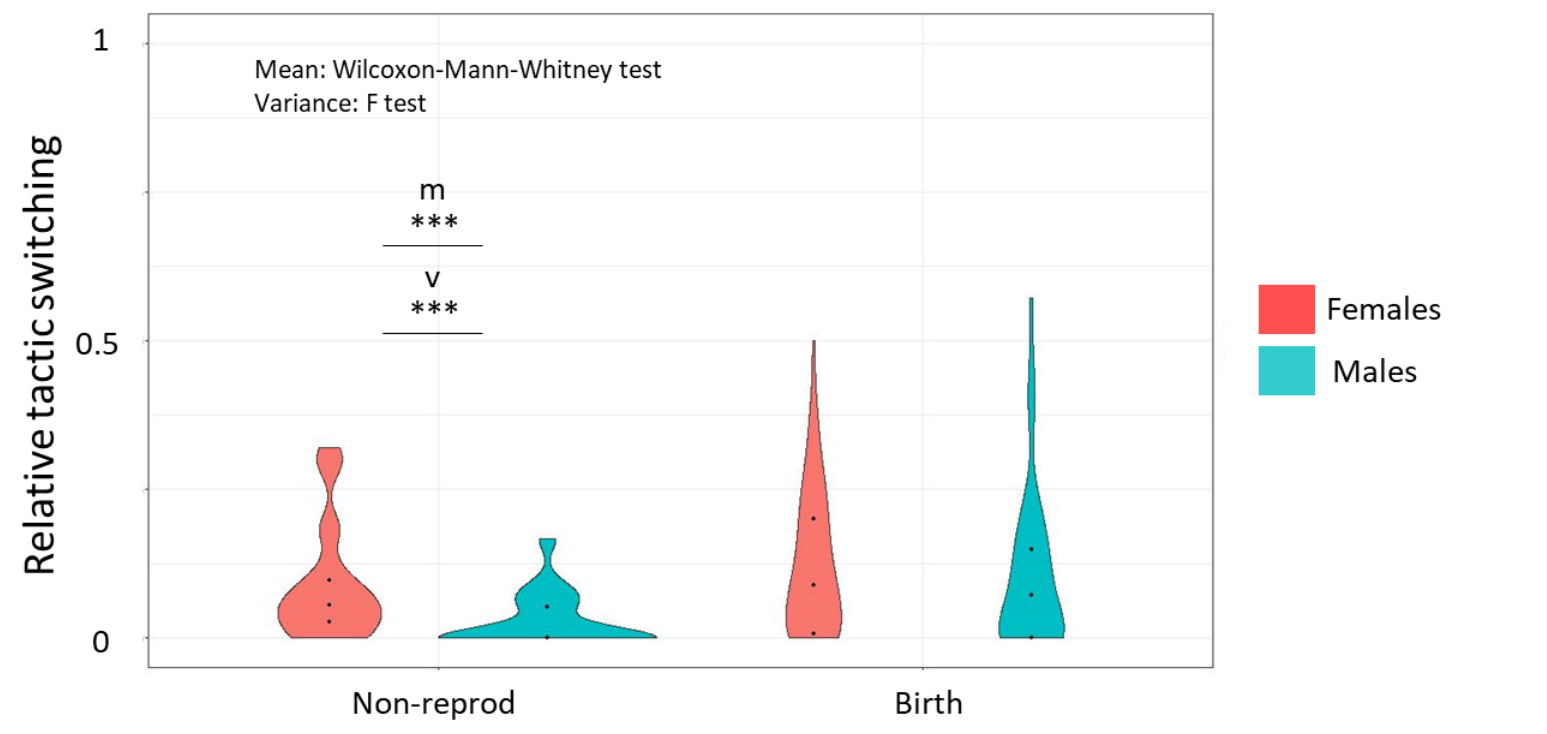

Figure 13. Comparison of relative time spent in groups between sexes within seasons. Violin plot of relative time spent in groups per sex and season. Dots within the distributions represent quartiles. " $\mathrm{m}$ " represents mean and " $\mathrm{v}$ " variance comparisons. ${ }^{*}$ indicates significant differences. 


\section{Diversity in group composition: Number of social units and evenness}

There appears to be a wide range of possibilities in the SDI scores of both males and females. In both sexes, at least $75 \%$ of the individuals had scores greater than 0.5 in one season, indicating large numbers of social units and evenness in their distribution for most of the population (females during the non-reproductive season, males during the birth season). Nevertheless, males in the non-reproductive season showed a bimodal distribution, with $50 \%$ of the population divided between the two extremes of the range of SDI values. In contrast, females in the birth season approached a more concentrated distribution, with most individuals showing intermediate values of diversity (Fig. 14).

Females showed higher mean Simpson's diversity index of social units during the birth season compared to the non-reproductive, while no difference in the variance was detected ( $F 0.61 \pm 0.20$ vs. $0.44 \pm 0.24$; Wilcoxon-Mann-Whitney rank-sum test: $W=467, p=0.03 ; F$ variance test: $F=0.65, p>0.1$; Fig.7). Nevertheless, the distribution during the birth season was much wider, covering a major part of the lower end, indicating that the population covered lower values of diversity during this season. Males showed a significantly higher mean SDI of social units during the birth season, while no difference in the variance was observed ( $\mathrm{M} 0.41 \pm 0.39$ vs. $0.72 \pm 0.27$; Wilcoxon-Mann-Whitney rank-sum test: $\mathrm{W}=85, \mathrm{p}$ $=0.01 ; \mathrm{F}$ variance test: $\mathrm{F}=1.93, \mathrm{p}>0.1$; Fig.14). Nevertheless, the distribution shows a switch from a bimodal distribution with a predominance towards lower values during the non-reproductive season to a clear skew towards high values during the birth season.

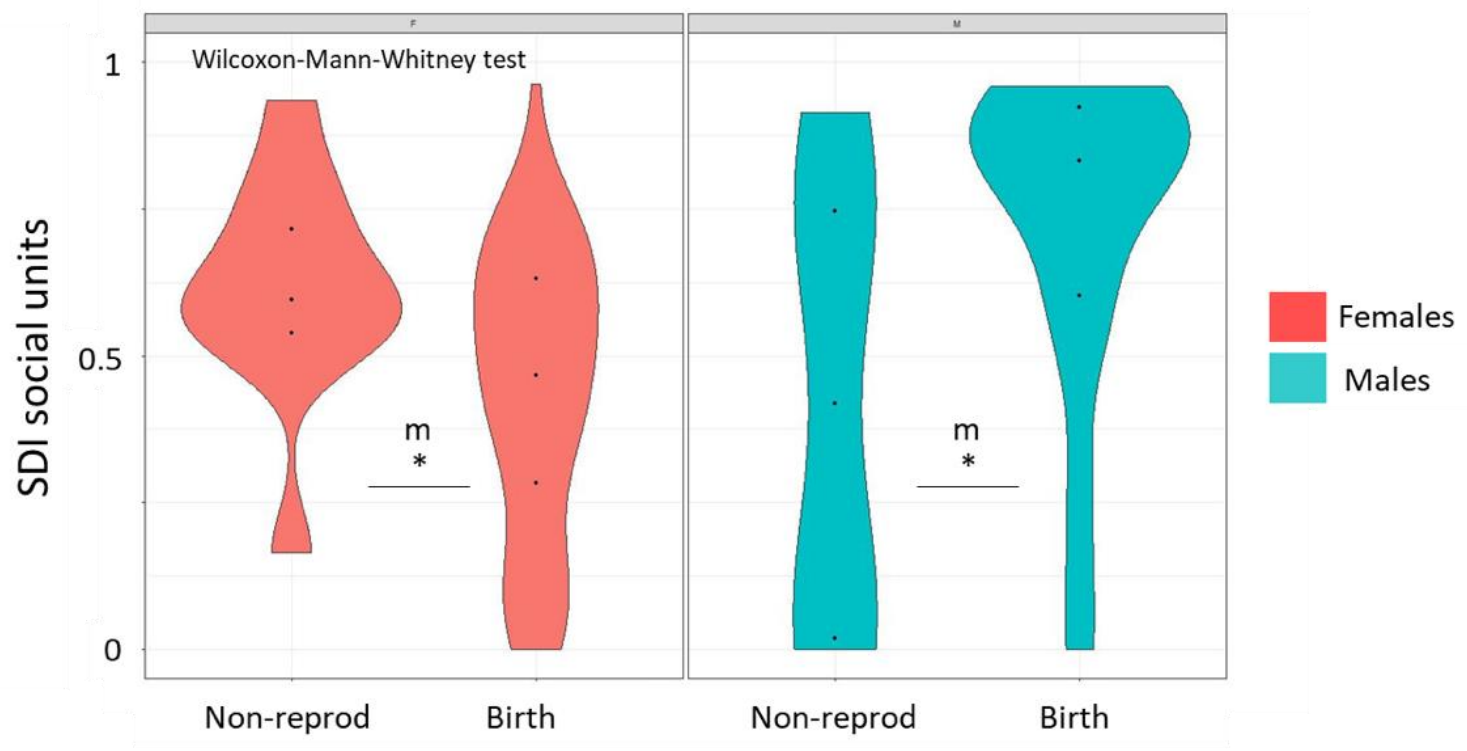

Figure 14. Comparison of Simpsons' diversity index on group composition within sexes across seasons. Violin plot of frequency of Simpsons' diversity index on group composition per sex and season. Dots within the distributions represent quartiles. " $\mathrm{m}$ " represents mean and " $\mathrm{v}$ " variance comparisons. *indicates 
Males and females did not differ in their mean SDI of social units during the nonreproductive seasons, although males showed a higher variance (Non-reprod F: $0.57 \pm 0.22$ vs. $M: 0.46 \pm 0.35$; Wilcoxon-Mann-Whitney rank-sum test: $W=262.5, p>0.1$; F variance test: $F=0.39, p=0.037 ; \mathrm{Nb} . \mathrm{F}=25, \mathrm{Nb} . \mathrm{M}=19$; Fig. 15). During the birth season, however, males showed a higher mean value of SDI of social units while no significant difference in the variance was observed (Birth F: $0.43 \pm 0.24$ vs. M: $0.72 \pm 0.28$; Wilcoxon-MannWhitney rank-sum test: $\mathrm{W}=630, \mathrm{p}>0.1$; F variance test: $\mathrm{F}=0.71, \mathrm{p}>0.1 ; \mathrm{Nb} . \mathrm{F}=74, \mathrm{Nb} . \mathrm{M}$ $=45$; Fig. 15). Thus, males reduced their variance through a pronounced increase in the diversity of social units during the birth seasons.

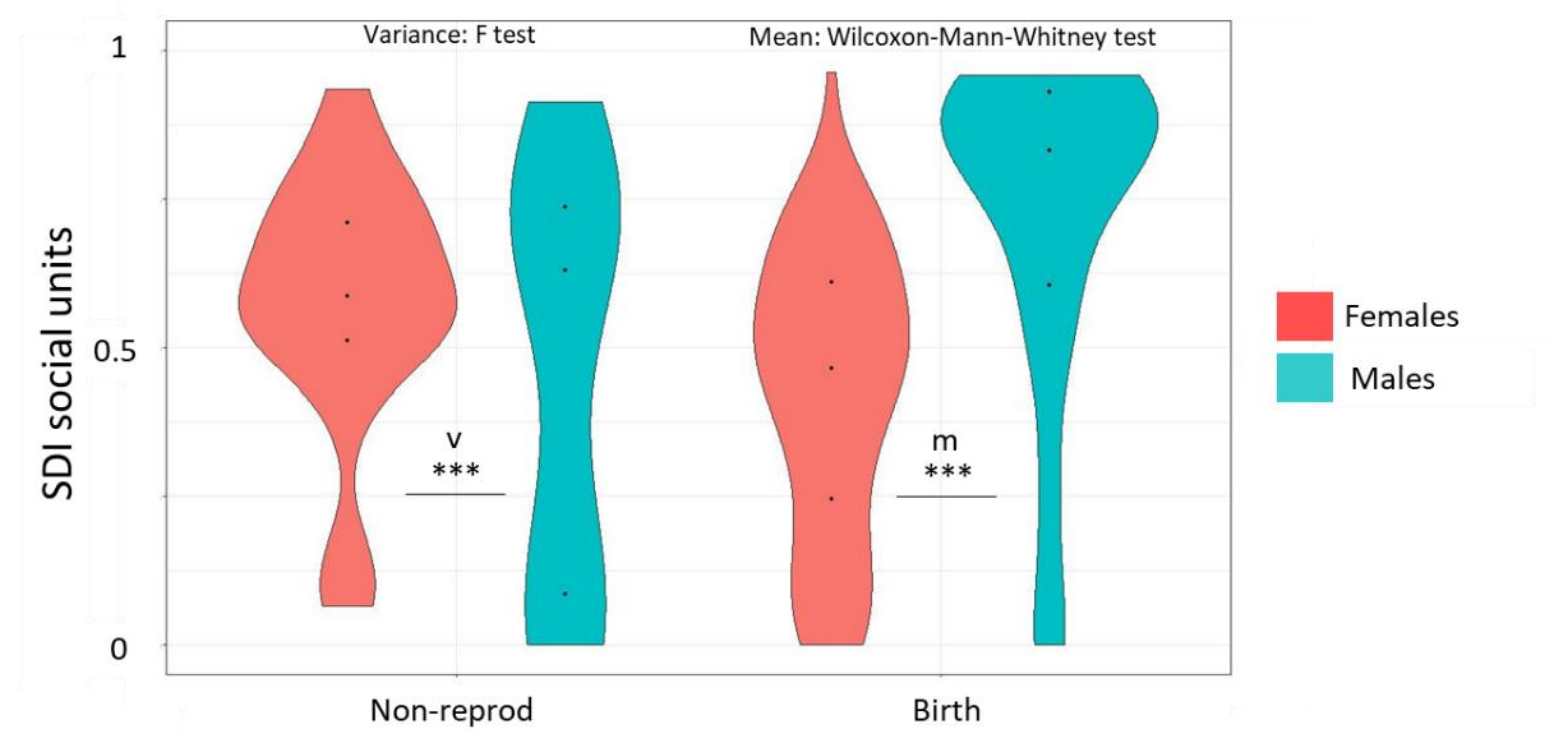

Figure 15. Comparison of Simpsons' diversity index on group composition between sexes within seasons. Violin plot of Simpsons' diversity index on group composition per sex and season. Dots within the distributions represent quartiles. " $\mathrm{m}$ " represents mean and " $\mathrm{v}$ " variance comparisons. *indicates

\section{An overall strategy? A combined descriptor of individuals' flexibility in social tactics within seasons}

Barlett's test for sphericity proved significant $(p<0.001)$. Moreover, the Kaiser-Mayer-Olkin test revealed a score of 0.55 , an intermediate value of sampling adequacy. Therefore, the data appeared to be adequate for factor analysis.

The first component explained $52.4 \%$ of the variance, with an eigenvalue superior to 2.5 , while the second component explained $22.7 \%$ of the variance with an eigenvalue superior to 1.1 (Fig. 16). The other components did not show an eigenvalue greater than one and were therefore not used further. All variables loaded positively on the first principal component; however, only number of partners, variation in group size, relative proportion of days sleeping in groups, and SDI in group composition did so to a greater value than $50 \%$ with $84,75,64$, and $94 \%$, respectively. The relative amount of change in tactic loaded with 
$21 \%$. These variables contributed to explaining this component by $27.20,21.72,15.52,33.92$ and $1.64 \%$, respectively. Thus, individuals with a large number of partners experienced greater variation in group size, slept a greater proportion of days in groups, and had a higher SDI for group composition score. This variation was independent of the relative number of changes between solitary and group sleeping. Thus, the first principal component suggests that how individuals modify their sleeping groups (in longer or shorter bouts), is independent of how diverse they are in terms of number of partners, group size, and social unit diversity and evenness. Furthermore, individuals that are more diverse in their partnerships spend most of the time in groups.

The frequency of switching between tactics and variation in group size loaded -84 and -43\% respectively in the second principal component and explained $62.56 \%$ and $16.15 \%$ of the variance in this component, respectively (Fig. 16). The relative frequency of sleeping in groups loaded positively with $46.43 \%$ and explained $18.99 \%$ of the variance. Thus, individuals switching more often experienced more variation in group size and were less often found in sleeping groups. Hence, the second component adds further information to the conclusions of the first component by suggesting that individuals with shorter bouts in each tactic where those that slept more often solitarily.

c. Individual flexibility across seasons:

1. Do individuals' social tactics change across seasons?

All samples differed significantly from 0 , implying that both males and females changed their position in principal components 1 and 2 across seasons (One-sample Wilcoxon signed-rank test: PC1 F $p<0.001, \mathrm{M} \mathrm{p}<0.001$; PC2 F $\mathrm{p}<0.001, \mathrm{M} p<0.001$ ). Males and females did not differ in their mean or variance in the change in principal component 1 or 2 across seasons (PC1 F $1.26 \pm 1.02$ vs. M $1.27 \pm 0.95$; Wilcoxon-Mann-Whitney rank-sum test: $W=246, p>0.1 ; F$ variance test: $F=2.22, p>0.1 ; P C 2 ~ F 1.09 \pm 0.70$ vs. $M 1.04 \pm 1.02$; Wilcoxon-Mann-Whitney rank-sum test: $W=96, p>0.1 ; F$ variance test: $F=1.02, p>0.1$; Nb. $M=14$, Nb. $F=24$; Fig. 17).

\section{Effect of maintained relationships and mortality of partners}

Males and females did neither differ in the mean nor the variance in percentage of partners maintained from the same or the opposite sex (Same-sex F $0.74 \pm 0.42$ vs. M $0.71 \pm 0.29$; Wilcoxon-Mann-Whitney rank-sum test: $W=114, p>0.1$; $F$ variance test: $F=1.92, p>0.1$; Nb. $F=19$, Nb. $M=13$; Opposite sex F $1.09 \pm 0.70$ vs. M $1.04 \pm 1.02$; Wilcoxon-MannWhitney rank-sum test: $\mathrm{W}=14, \mathrm{p}>0.1$; F variance test: $\mathrm{F}=0.59, \mathrm{p}>0.1 ; \mathrm{Nb} . \mathrm{F}=5, \mathrm{Nb} . \mathrm{M}=$ 6; Fig. 18). When considering only non-consecutive seasons, only same sex partners could be analyzed. The same trend was found reinforced with males and females retaining $0.94 \pm$ 0.14 and $0.93 \pm 0.19$ of their previous partners that remained alive in non-consecutive 
seasons respectively ( $\mathrm{Nb} . \mathrm{F}=7, \mathrm{Nb} . \mathrm{M}=6$ ). Thus, both males and females tended to retain the same partners over the seasons if these were alive.

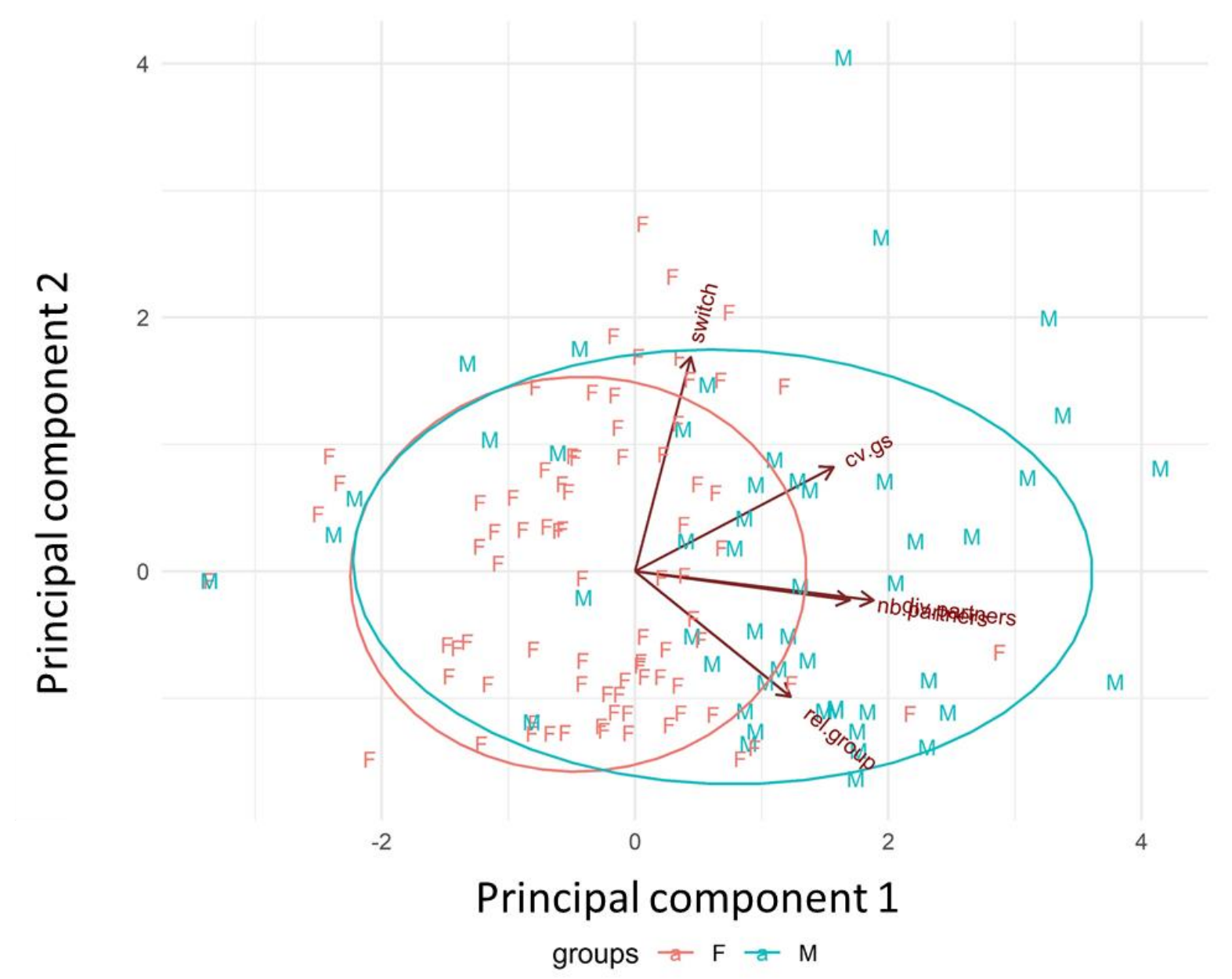

Figure 16. Principal component analyses relating the different variables of sociality. Principal component 1 explains 52.56\% of the variance while PC2 explained 22.94\%. " $F$ " codes for Females, "M" for males. "Switch" codes for the frequency of switching between tactics, "cv.gs" the coefficient of variation in group size, "div. partners" the Simpson's Diversity Index on group compositions, "nb. partners" codes for the total number of partners and "rel. group" the relative time spent in groups.

Males and females differed in the correlations between the variables of interest. In males, no significant correlation was found between the change in principal component 1 , the change in principal component 2 , the percentage of same-sex partners alive retained as partners, and the percentage of same-sex partners that survived. For females, on the contrary, the changes in principal components 2 and the percentage of same-sex partners 


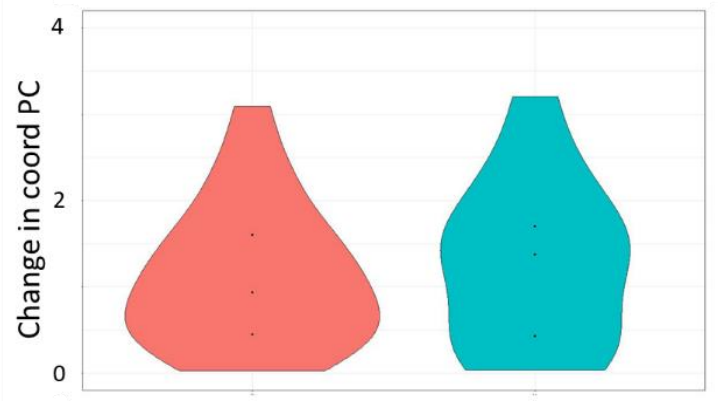

PC 1

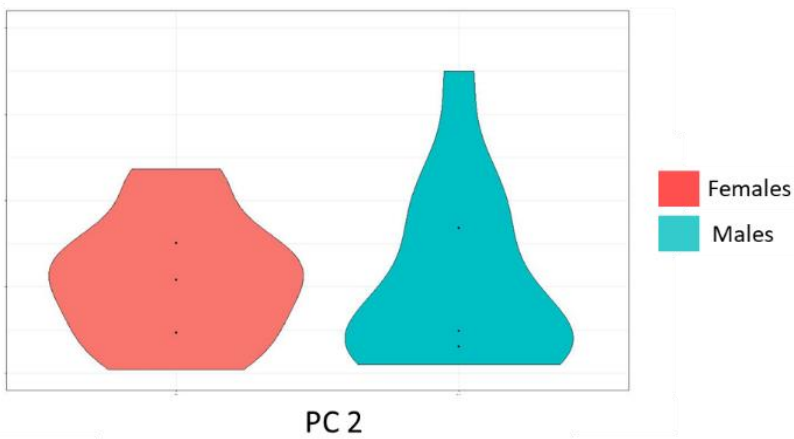

PC 2

Figure 17. Comparison of Simpsons' diversity index on group composition between sexes within seasons. Violin plot of Simpsons' diversity index on group composition per sex and season. Dots within the distributions represent quartiles. " $\mathrm{m}$ " represents mean and " $\mathrm{v}$ " variance comparisons. *indicates significant that survived were independent of any other variable, the change in principal component 1 and the percentage of same-sex partners alive retained as partners were negatively correlated with each other. Females that changed more in the principal component 1 which relates to their tactic in terms of time spent in a group, diversity of social organizations, number of partners and variation in group size had retained less available female partners from previous seasons (Pearson's product-moment correlation $r=-0.68$, Holm's $p^{\prime}=0.011$ ). Interestingly, the percentage of partners that survived was not correlated with the percentage of partners retained. Overall, males and females appear to change their social tactics, which are defined by the variability in their social tactics within seasons.
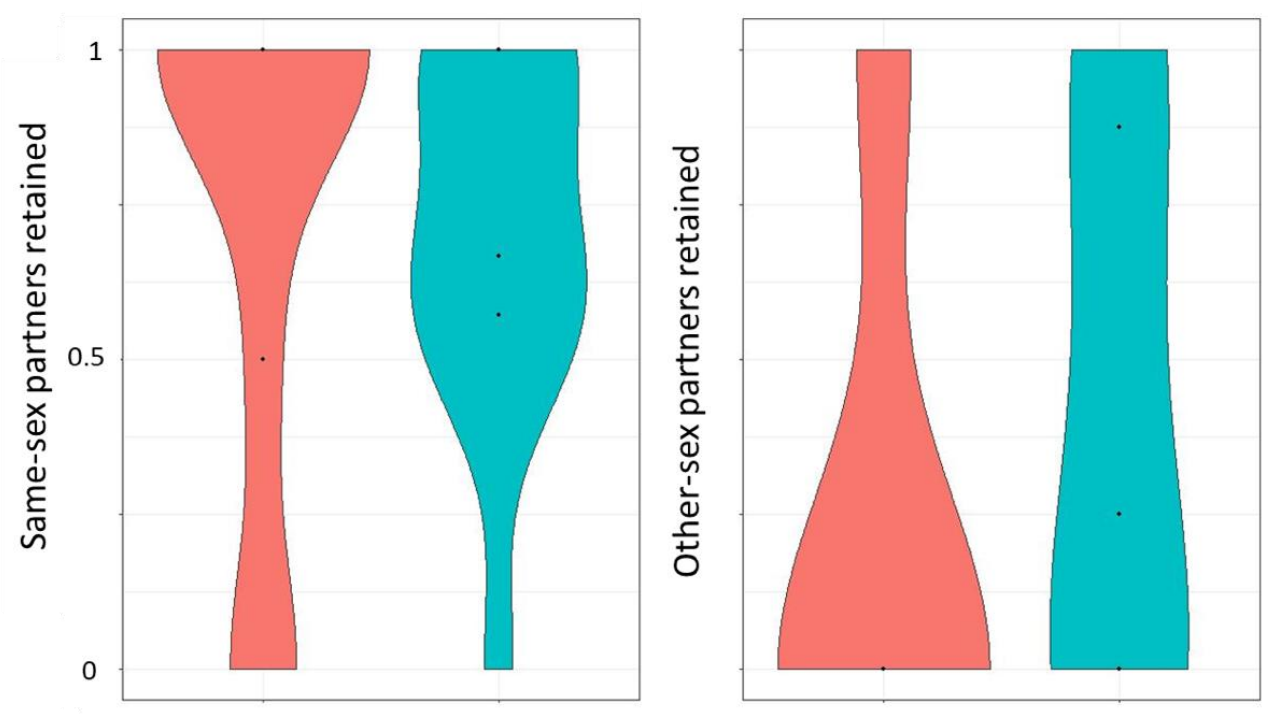

Females

Males

Figure 18. Comparison of same-sex and other-sex partners retained between sexes. Violin plot of partners from past season alive in the current one retained as partners. Dots within the distributions represent quartiles. " $\mathrm{m}$ " represents mean and " $\mathrm{v}$ " variance comparisons. *indicates significant differences. 
Nevertheless, the change in female tactics appears to relate to changes in the identity of their female partners, whereas male changes did not correlate with changes in partner identity. Thus, changes in male and female social behavior may be affected differently by specific dyadic relationships.

\section{d. Summary of results:}

This study revealed that during the dry season, most female gray mouse lemurs form groups with one or two other individuals and spend most of the days in groups. About a quarter of the male population appeared to apply the same tactic by forming all-male groups, while another quarter spent most of their time alone. The rest of the male population appears to be intermediate between these two extremes. Importantly, during the non-reproductive season individuals sleep in mixed-sex groups during the coldest months of the austral winter. During the birth season, males and females segregate, and mixed-sex groups occur only on rare occasions, when a few females join large groups of males (Fig. 19). Most females spend similar amounts of time in groups during the birth and the non-reproductive season, but the diversity and number of their partners decreases, probably as a consequence of sexual segregation (Fig. 19). Among males, in contrast, about a quarter of them continue to be predominantly solitary with a low number of partners, whereas the rest changes towards a more social strategy. The latter males form larger groups that often change in composition and spend about as much time in group as females do (Fig. 19). 

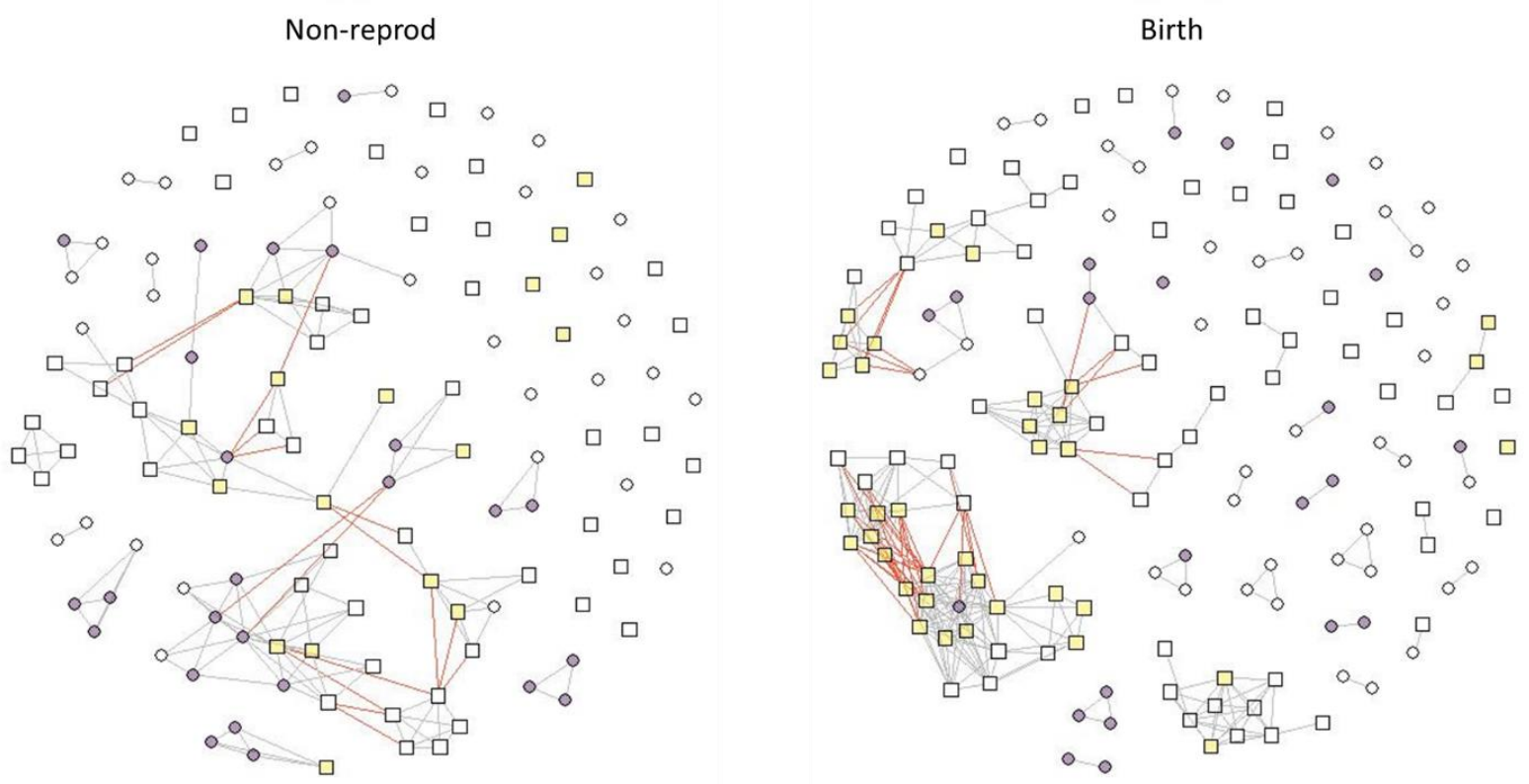

Figure 19. Social network of Microcebus murinus in two seasons, Non-reprod 2018 and Birth 2017-18. Individuals are represented as either dots (Females) or squares (Males), and associations in sleeping groups are depicted as links between individuals. White shapes are those for which less than 14 days of information was available. Connections within clusters are shown in grey, connections between clusters are shown in orange.

\section{Discussion}

This study revealed five salient phenomena about the social system of Microcebus murinus in Kirindy forest: 1. A diversity in social organization of sleeping groups encompassing all social categories described for primates (Kappeler \& van Schaik, 2002), resulting from 2. pronounced individual variation in social flexibility, 3. a clear predominance of sexual segregation year-round with a switch towards mixed-sex groups during the coldest months of the year, 4. a stable group size in females most of the year and 5. a higher than previously reported level of male-male sociality with a pronounced increase during the birth season.

The diversity of social organizations observed in the sleeping groups of grey mouse lemurs at Kirindy Forest encompasses all types of group composition described for primates. This diversity supports claims about the neglected complexity of social systems of nocturnal strepsirrhines and the necessity for considering intraspecific variation in social organization in comparative research. Microcebus murinus exhibit individual social flexibility, resulting in different types of groups, the frequency of which depends most likely on environmental conditions such as temperature and humidity. Therefore, the observed variation is likely an adaptive response to seasonality and not the result of environmental disrupters. Since mouse lemurs live in highly variable and unpredictable environments, these results support 
the notion of ecological variation promoting adaptation through social flexibility, resulting in intraspecific variation in social organization (Schradin et al., 2018), making mouse lemurs good models for studying the processes that characterized evolutionary transitions in ancestral primates (Kessler et al., 2016). Thus, the present results also support the idea that social flexibility is inherent to the early stages of sociality (Rehan \& Toth, 2015; Shell \& Rehan, 2018).

Since these two hypotheses are not mutually exclusive, environmental variability might select for variation in social organization in solitary ancestors that, in some lineages, promote transitions towards social groups. This scenario would be in agreement with the notion that numerous benefits of sociality mitigate the effects of variable environments on fitness (reviewed in: Kennedy, Higginson, Radford, \& Sumner, 2018; Socias-Martínez \& Kappeler, 2019). Only one study has examined social transitions and environmental correlates in a phylogenetic framework, showing that bird sociality in the form of natal philopatry evolved first in stable environments, and only after colonizing variable habitats (Griesser, Drobniak, Nakagawa, \& Botero, 2017). This study suggests, therefore, that habitat saturation is a major force in social transitions in birds, but that cooperation gets reinforced under variable conditions. Variable habitats can also lead to habitat saturation, as shown in several rodent species (e.g. Wolff, 1994; Lucia et al., 2008; Schradin et al., 2012). Thus, it is unclear whether habitat saturation alone is responsible for transitions to sociality through different routes or whether different environmental factors generated social transitions in different taxa. Thus, more studies, taking into account both intraspecific variation in social organization as well as environmental variability, are needed to shed light on key social transitions.

The nature and composition of mouse lemur sleeping groups appear to vary according to season, sex, and individuals. Variation occurs within a season and individuals change tactics (solitary vs. group sleeping) in bouts of variable length. Different dimensions of intraindividual variation in sociality appear to be correlated and can be described as social strategies using PCA. Note that most of the parameter space was covered, indicating a possible continuum between mostly solitary and highly flexible individuals in groups. Variation in social organization was the result of the combination of individual strategies. The determinants of variation between individuals within a season could not be determined in this study, but future studies could focus on the role of immunocompetence and the ontogeny of social relationships since these factors have been shown to be important in other species (Ferrari et al., 2018).

Variability in sociality across seasons was independent of whether partners survived and were retained as partners in males but, correlated with the percentage of retained partners 
in females. The availability of adult kin for both males and females has been suggested to play a key role in explaining the extent of social versus solitary strategies in mouse lemurs (Eberle \& Kappeler, 2006; Dammhahn \& Kappeler, 2009; Jürges, Kitzler, Zingg, \& Radespiel, 2013). Both sexes appear to retain most of the partners remaining alive. Since most associated males are unrelated whereas females associate with kin (Eberle \& Kappeler, 2006; Dammhahn \& Kappeler, 2009), either different mechanisms sustain sociality in males and females or cooperation is based on other mechanisms than kin selection in both sexes.

\section{a. Female perspective}

We discuss in the next sections the other salient results from the female and male perspective because the socioecological model is grounded on sex differences arising from asymmetries in parental investment (Kappeler \& van Schaik, 2002; Schülke \& Ostner, 2005; Dammhahn \& Kappeler, 2009). First, female associations in mouse lemurs have been predicted to depend on population density and nest availability (Schülke \& Ostner, 2005). However, our results suggest that female groups are stable in composition and size throughout the year, while population density and probably the adaptive value of nests change. During winter, nests might be most important for thermoregulation (Schmid, 1998), while during the summer the best nests might be those that provide a safe base for a newborn litter. Population density must be highest during the late birth season when juveniles start entering the adult niche, and young males have not yet dispersed. This multitude of selective forces suggests that the advantages of grouping are diverse and that maintenance of female groups throughout the year yields more benefits than a more flexible social organization.

There is also mixed evidence for an effect of population density on female-female associations in other populations of mouse lemurs. In the two species with the highest population densities, $M$. murinus and $M$. ravelobensis, female groups were prominent and stable, showing high degrees of cooperation in nest sharing (Table 1). Nevertheless, in a population of $M$. murinus in Ampijoroa, where the density is seven times lower, female groups are still prominent, suggesting the presence of groups is not just a by-product of population density (Table 1). Moreover, in the two species with intermediate values of population density, M. lehilahytsara, and $M$. grisorufus, the former has a higher abundance of male-male associations than female-female associations, while in the latter stable female groups were relatively abundant (Génin, 2008). In $M$. berthae, which has the lowest population density observed, the level of sociality is also lower than in other species, but female-female associations occurred as well (Dammhahn \& Kappeler, 2005). Thus, it appears that population density alone is a poor predictor of female sociality, and it is possible that other factors relating to the benefits of groups or the constraints of solitary living might generate the observed diversity in female sociality across mouse lemurs. 


\section{Birth season}

During the birth season, females followed a similar strategy in terms of group size than during the rest of the year, but their average number of partners decreased. Interestingly, although they tolerated males during the three coldest months of the year as sleeping partners, mixed-sex groups virtually disappeared during the birth season. During the birth season, two factors may constrain group nesting in females. On the one hand, high humidity and temperatures may promote the diversity of parasitic bacteria, fungi and nematodes constraining nesting group composition. Recent research in the same population has shown that males have a higher parasite load than females and that they are less hygienic (Poirotte $\&$ Kappeler, 2019). Males more often defecate inside their sleeping sites and show less avoidance of food and water contaminated with fecal matter. Thus, although these tests were conducted during the non-reproductive, a lactating female might be exposing its offspring to a higher risk of parasitism in the most vulnerable moment by tolerating males in the breeding nest. Parasites might, therefore, be an important force driving sexual segregation in this species.

An alternative hypothesis explaining sexual segregation during the birth season is the threat of infanticide. Even though infanticide has not been reported for mouse lemurs, we observed 2-week-old pups to threaten an adult male inspecting their nest while their mother was foraging. Besides the protein-rich meal, males would gain very little from infanticide. Confused paternity through polygamy and a short rainy season coupled with a two-month gestation and a six-week lactation period would limit the fitness benefits of infanticide by males. Moreover, survival from one season to the next is as low as $50 \%$, so that, even if the loss of a litter subsequently increased female fecundity, infanticide is most probably not a promising male strategy. Thus, there is little evidence for infanticide avoidance driving sexual segregation in this population.

In contrast to males, females did not increase group size during the birth season. It is plausible that the presence of pups may be limiting group size. Females in communal nests may need more space, and in the presence of the hottest temperatures, increased thermoregulation through group size augmentation could suppose a smaller advantage for developing pups. Hyperthermia derived from increased metabolism during lactation has been shown to be a problem for lactating females in other species where ambient temperatures are negatively correlated with milk production and pup growth ( $\mathrm{Wu}$, Zhang, Speakman, \& Wang, 2009; Simons et al., 2011; Valencak et al., 2013). The authors showed that during lactation, metabolism due to higher food intake and production of milk leads to increased heat production. Under high ambient temperature, the extra heat cannot be released. Thus, to avoid damages from hyperthermia, females need to reduce both energy 
intake and milk production. Although mouse lemurs have heterothermic adaptations that could help deal with overheating (Perret, 1998; Schmid, 1998), lactation also constrains this capacity. Females have been shown to avoid torpor during lactation probably as a mechanism for maintaining milk production even under relatively low temperatures in laboratory (Canale, Perret, \& Henry, 2012). Thus, under the heat of the austral summer with ambient temperature exceeding $35^{\circ} \mathrm{C}$, hyperthermia might pose a serious problem for lactating female mouse lemurs, making crowded nests a problem limiting female sociality.

Even though group size might be limited by costs associated with milk production or nest space, females also gain benefits from communal nesting. They have been shown to nurse and adopt each other's offspring (Eberle \& Kappeler, 2006). Thus, it is possible that communal breeding units improve offspring survival under high adult predation risk (Gadagkar, 1990). Moreover, pups in communal nests might benefit from increased attendance and more regularly spaced lactation bouts that could foster their growth rate. A study in the only other Microcebus species where female associations were monitored during the period of lactation ( $M$. griseorufus) suggests that communal breeding could be common in the genus (Génin, 2008). This observation adds to broader literature in both vertebrates and invertebrates pointing towards important benefits of communal nesting as a force in the evolution of sociality (Socias-Martínez \& Kappeler, 2019). Interestingly, solitary $M$. murinus females have been shown to bias the sex ratio of their offspring towards females while group-nesting females biased the litter sex ratio towards males (Perret, 1990). Since females recruit offspring to form sleeping groups (Ute Radespiel et al., 2001; Eberle \& Kappeler, 2006), all evidence suggests the existence of optimal group size. During lactation, female group size might have an optimum that maximizes the time of attendance and the spacing of feeding bouts and the chances of adoption in case of death while reducing the risk of parasitism and overheating. Thus, females might be choosing under severe constraints on group size those partners that offer the maximum benefits, i.e., other females, that are more hygienic and have the capacity for communal care and adoption if necessary.

\section{Non-reproductive season}

During the three coldest months, when food availability is at its lowest value, and most females hibernate (Schmid, 1998), sexual segregation waned. Males are more active than females and regularly come and go from their nests during the hibernation period (Rasoazanabary, 2006). Our results also indicate that both groups of females and solitary females are joined by males during this season. Thus, constraints impeding mixed-sex

groups are released during the three coldest months of the winter, and groups are especially beneficial at this time of year. 
Specifically, the dry, cool weather with great amplitude in daily minimum and maximum temperatures should hamper parasite development and survival. Thus, females might be more tolerant of more parasitized and less hygienic males precisely in these months when parasitism risk is lowest. In addition, thermoregulatory benefits of sleeping in groups with sub-normothermic body temperature have been suggested to explain sleeping groups in mouse lemurs (Perret, 1998; Schmid, 1998). In a study in captivity (Perret, 1998), animals nesting in groups of three individuals were found to maximize the energetic benefits of torpor. The author suggested that these energetic benefits might be translated into reduced time foraging, which represents a crucial moment of risk due to predation. Although females rarely forage during mid-winter, reduced energy expenditure during the winter could enhance survival and reproduction in the next birth season through a better body condition. When in groups, the volume to surface ratio would be diminished, and animals may be able to exhibit similar mean temperatures but with less pronounced shifts. A study measuring the insulation capacities of tree-holes at Kirindy found that living trees are the preferred nests of females and that they have a better insulation capacity (Schmid, 1998). Interestingly, the insulation benefit of living trees disappeared precisely during the coldest months of the winter, with no difference between dead and living trees found during July. Thus, females might be experiencing a decrease in the insulation capacity of their nests, which may impact the efficiency of energy-saving during hibernation. This could explain why females accept males in the coldest months of the year.

Moreover, males joined solitary females most often followed by groups of females, supporting the notion that females' propensity for letting males join is dependent on how far they are from an optimal group size in terms of thermic benefits (Perret, 1998). Thus, it is possible that males and females gain benefits from forming groups of, on average, 3 individuals in the coolest months.

With respect to group composition, one may wonder why females allow parasitized males to join them instead of joining other females. If kin selection drives female sociality (Eberle \& Kappeler, 2006; Kessler et al., 2016), given that the density of related females with overlapping home ranges is high, why wouldn't subparts of matrilines join each other? There is evidence for strong competition between groups for nesting sites in grey mouse lemurs (Dammhahn \& Kappeler, 2009). Thus, groups of females can be seen as competing entities in a group selection framework. If what is driving group formation and maintenance are the benefits in a group selection context, competition between groups might preclude cooperation even between related units. It is also important to note that local competition for resources and mates has been suggested to cancel the benefits of kin selection (West, Pen, \& Griffin, 2002). Furthermore, since female optimal group size might be constrained 
during the lactation period and the best nests for communal nesting might be limited, helping other groups might indeed relate to helping a potential future competitor. Thus, males might be providing the services that females cannot offer in the coldest months of the year.

Since groups of females in $M$. murinus are made up by close maternal relatives (Eberle \& Kappeler, 2006), and findings in two other Microcebus species in the wild (U. Radespiel et al., 2009) and in captivity (Jürges et al., 2013) also confirm a matrilineal structure of associations, gray mouse lemur sociality has been argued to be driven by kin-selected benefits and to be a model for the evolution of stable sociality through inclusive fitness benefits (Kessler et al., 2016). The assumption that group living relates to kin selection is a hotly debated topic (see Introduction), and direct fitness benefits and population dynamics can result in kinship being rather a consequence than a cause of cooperation (see Introduction and Chapter 1). Indeed, the results of Eberle and Kappeler (2006) also show that groups split when more than four females of the previous season, including offspring, survived (Fig. 1 in Eberle and Kappeler 2006). Interestingly, in the three cases when this happened, females preferred their daughter to any other female in the group to form a new unit. Since mating is polyandrous and litters often have more than one father (Eberle \& Kappeler, 2004a, 2004b), mother-daughter associations should often be the most closely related possible dyad, thus reinforcing the kin selection argument. Young females experience higher survival when staying within their mother's home range probably due to mothers teaching young females the emplacement of secure nests (Lutermann, Schmelting, Radespiel, Ehresmann, \& Zimmermann, 2006). Thus, mother-daughter preferred associations could be interpreted as a form of continued parental care. Moreover, since group sleeping benefits all members, including the mother, direct fitness benefits might be regarded as the driver of group benefits.

Previous studies have shown that mouse lemurs recognize paternal kin through mating calls (Kessler et al. 2012). Concretely, female mouse lemurs preferred the calls of unrelated males to that of their father despite being familiar to both. Thus, the authors suggest that kin recognition is key to mouse lemur sociality and that this reinforces kin selection as the force behind the evolution of sociality in females. However, in other studies, social groups of female $M$. murinus and $M$. ravelobensis lemurs also contained distant kin. The authors found that the mechanism generating these associations was through nest sharing by relatives in previous generations in both species (Radespiel et al., 2001; Radespiel et al., 2009). Thus, mouse lemur female sociality is not unambiguously linked to kin-selected benefits. Enhanced direct fitness might explain female-daughter preferences, and the benefits of grouping in thermoregulation and communal breeding might explain the adaptive value of groups. 
A possible test to disentangle the effects of kin selection on the evolution of communal breeding in Microcebus could come from comparative studies. To date, female behavior during the birth season has only been investigated in $M$. murinus and $M$. griseorufus, with no relatedness data for the second species and only indirect observations concerning allocare. A species that could contribute valuable comparative data is $M$. berthae, due to their low density and the apparent absence of kin structure (Dammhahn \& Kappeler, 2005). This species has been described as solitary and showing low potential for communal breeding due to the absence of clusters of female relatives. Nevertheless, although no close kinship between females was at play, female-female associations still occurred, although at lower levels than male-male and male-female associations (Dammhahn \& Kappeler, 2005). Associations in this species have been labeled as less stable because the percentage of days an individual slept alone was higher than in other Microcebus species. However, individuals could be re-associating with the same partners implying stability and cooperative neighbors of non-kin. Sociality in this species has not yet been studied during the lactation season when competition for resources between females might be reduced. Since this has been argued as the major force driving the absence of female sociality in this species (Dammhahn \& Kappeler, 2009), a study on female sociality in M. berthae during the lactating season could reveal whether the benefits of grouping alone in cooperative neighborhoods instead of kin selection are behind female sociality in Microcebus. Females that only rarely sleep together during most of the year could come together when constrains on the benefits of grouping are relaxed.

\section{b. Male perspective}

Males are expected to maximize their reproductive success by increasing the number of potential mates. Due to the biology of the species with female asynchronous oestrus, female dominance, and cryptic female choice, polygamous mating with strong sperm competition shapes reproductive strategies (Eberle \& Kappeler, 2004a, 2004b). Thus, when population density is high, females are predicted to aggregate, and males are expected to compete for exclusive access, but if the number of males is high, the operational sex ratio becomes male-biased, and a polygamous scramble competition should ensue (Schülke \& Ostner, 2005). Therefore, if male solitariness is a strategy that reduces competition for mates, male sociality might not be costly anymore at high population densities. In our population, the adult sex ratio is male-biased, and population density is the highest recorded for any mouse lemur population with approximately 10-15 individuals/ha (Clémence Poirotte, personal communication). In a captive study under very high population density, $M$. lehilahytsara males exhibited a similar social response to the males in the present study, characterized by a large number of male partners and low stability of their associations (Jürges et al., 2013). Moreover, in all species were male-male associations 
were found in the wild, the adult sex ratio was male-biased ( $M$. lehilahytsara, $M$. berthae; Table 1). In other species, such as Dunnocks, a male-biased adult sex ratio leads to a polyandrous mating system with aggregations of males (Davies, 1992).

The effect of the adult sex ratio is especially relevant when groups offer survival benefits because males may enjoy enhanced lifespan from associating with other males in a situation where increasing mating access through competition might be unfeasible. Thus, thermic and anti-predatory benefits of grouping in the context of competition for nesting sites might also play a role in determining the social environment chosen or imposed on males. We discuss the observed patterns of flexibility in male social organization in light of the changes in group benefits deriving from seasonality.

\section{Birth season}

Although previous studies have classified male grey mouse lemurs as solitary (Ute Radespiel, 2000), we found evidence for alternative social constellations. While about half of males either showed a solitary or a group-sleeping strategy during the non-reproductive season, a substantial part of the male population switched to a strategy that maximized the number of sleeping partners during the birth season. These males slept in big groups that changed regularly in composition. While this might be a consequence of unusually high population densities, it is possible that a sampling bias towards studying mouse lemur female sociality especially during the non-reproductive season, have precluded a better understanding of the nature of male sociality in Microcebus.

It is possible that during the birth season, with food abundance being at its maximum and no reproductive competition after the mating season, male tolerance increased. Nevertheless, some indirect evidence argues against the lack of competition for mates. During the birth season of 2017-2018, we observed the largest groups of males (up to 9 individuals) in January and February. Later that year, we captured a dozen individuals that were inferred from their small size to have been born later than the modal birth season, indicating that some females reproduced twice. While this is extremely rare in Kirindy, in the northern part of the distribution (Ampijoroa), females regularly produce two litters per year (Ute Radespiel, 2000; Ute Radespiel et al., 2001). Thus, the presence of large male aggregations may have coincided with periods of reproductive activity, suggesting that mate competition may not preclude male sociality in $M$. murinus.

Although we have discussed the possible group size constrains in females during the hot birth season, males could be benefiting from grouping by increasing the amount of time per day they can use torpor. This physiological mechanism has been found to have an upper temperature of $28^{\circ} \mathrm{C}$ (Schmid, 1998). In this sense, being in groups during the hottest months of the year could give some extra thermic inertia by increasing the volume to 
surface ratio of individuals huddling. Thus, males who do not suffer from the constraints of lactation could be benefiting by increased duration of torpor bouts during the morning when the air temperature rises above $28^{\circ} \mathrm{C}$. To date, no study has evaluated daily torpor activity during the birth season in Microcebus, impeding current evaluations of the plausibility of this hypothesis.

Moreover, competition for nesting sites might not be an exclusively female affair. Evidence for intersexual competition for good nesting sites is suggested by the monopolization of the most thermally isolating nests by females (Schmid, 1998). Moreover, males in most Microcebus species used a large number of nests but only for a few days at a given time (e.g. Radespiel, 2000; Rasoazanabary, 2006; Hending et al., 2017). Thus, several males might be able to monopolize certain high-quality nests. Future tests could analyze the timing of occupation of individual nests of known quality to test this possibility.

The benefits of grouping of males could also be a driver of the observed association, independent of population density and adult sex ratio. Cooperative predator mobbing might provide a key benefit in this context (Eberle \& Kappeler, 2008). Interestingly, one of the animals involved joined the mobbing event from the distance after hearing the conspecific calls. Thus, even when participants are unrelated, there might be a potential for a cooperative neighborhood with spatial selection for cooperators (Nowak, Tarnita, \& Antal, 2010). Additional observation may reveal whether joint nesting influences other types of cooperative acts, such as cooperative mobbing.

\section{Non-reproductive season}

In contrast to females, male social strategies change across the year. Half of the population appeared to prefer a mostly solitary strategy during the non-reproductive season, while the other half remained in groups on most days. Since this season is characterized by high mating competition between males and low abundance of resources, this could indicate that only part of the males managed to maintain the benefits of grouping. Since most males do not hibernate, scarcity of resources could require a longer daily foraging distance to maintain body condition. In such cases, maintaining group cohesion might be too difficult and promote a more solitary sleeping strategy during the non-reproductive season. Males that continued to sleep in groups could be those that entered short hibernation bouts or lived in a better-quality territory; both factors allowing the maintenance of continuous nest sharing.

Both, solitary and group sleeping males, appear to prefer joining females over forming groups with other males during the cool dry season. This tendency could be explained by male reproductive strategies (Eberle \& Kappeler, 2004b) It has been suggested that males 
win knowledge on female location prior to the mating season. Although the mating season takes place two months after, females have a limited number of nests and knowing their emplacement could maximize reproductive success (Eberle \& Kappeler, 2004b). Mating order has been shown to deeply impact reproductive success of males in this polygamous species, with earlier males enjoying most success in captivity (Eberle, Perret, \& Kappeler, 2007). Meeting females earlier in their single night of estrus could, therefore, increase siring probabilities. However, mating rarely occurs soon after females' emergence from nests. In the same study, older males were found to sire more offspring. Thus, the authors proposed that greater familiarity with an area allowed older males to track females' movements outside the nest more efficiently.

However, males may be joining females during the cool season as a way of forming social bonds that provide advantages during the mating season. Specifically, males may provide females with thermal benefits when between-group competition for nests among females prevents female associations from becoming larger. Through these close associations, females may learn about individual males, including their MHC profiles, which may influence their mating decisions (Schwensow, Eberle, \& Sommer, 2008). During the mating season, intense competition between males both in the form of chasing and mating interruption takes place. Females mate with multiple males, but siring is reserved to males that mate earlier and in longer bouts (Eberle et al., 2007). Eberle \& Kappeler (2004a, 2004b) observed that females determine guarding efficiency by males. When guarded by older males, females remained more often in tree holes enhancing their guarding efficiency (Eberle \& Kappeler, 2004a). Previous social relationships could affect females' mating decisions through knowledge on genetic compatibility and thermal services provided by males. Since older males had more opportunities for establishing partnerships with a higher number of females, this hypothesis could explain their higher reproductive success. If proven true, this could give more emphasis to the importance of intersexual bonds in nocturnal lemurs with scramble polygamy. Future studies collecting data on individual associations, kinship and paternity could test this hypothesis.

\section{Conclusions}

We found evidence for social flexibility in both sexes of grey mouse lemurs. Although high levels of mortality might induce temporal non-adaptive variation in social organization, our results support previous findings on evolved adaptations to cope with variation in environmental conditions involving social flexibility. Individuals adapt their social organization to the needs of specific periods, and the decisions might be conditional on the strength of competition for limited resources. Females appear to be more constrained in group size and composition, especially during the birth season. 
Although members of female groups may benefit through kin selection, there is evidence for direct fitness benefits of sociality and the presence of other mechanisms for maintaining cooperation. Moreover, we found evidence for high levels of male sociality, also suggesting the existence of a non-kin mediated benefit of associations. Importantly, male and female social strategies might be conditional on each other, reinforcing the notion that the social system is an emergent property of the combination of competition and cooperation within and between the sexes.

Merging kin selection frameworks with other mechanisms that can sustain cooperation may help focus on the effects of between-individual competition and cooperation as well as the effects of the strategies played by others in the population, including possibilities for cooperative neighborhoods and reciprocity in solitary foragers. Importantly, although there is evidence for group benefits in both sexes, to date, the fitness consequences of variation in social organization for male and females mouse lemurs remain unknown. Given the known variation in social strategies as well as the diversity of species and habitats occupied by them, mouse lemurs offer a promising model for studying the origins of sociality.

\section{Acknowledgements}

I would like to thank Peter Kappeler for his valuable comments and corrections on earlier versions of this chapter. I would also like to thank Louise Peckre for helpful discussions. I am very grateful to Brunot Tsiverimana, Remy d'Ampataka, Jean-Pierre Tolozanahary, Tianasoa D. D. Andrianzanahary, Mamy Razafindrasamba, Nielsen Rabarijaona and Léon Razafimanantsoa for conducting and organizing the long-term captures and monitoring of the Microcebus murinus population in Kirindy forest. Special thanks to Clémence Poirotte for leading on the finding of natural nests. Many thanks as well to Marta Mosna, Koloina Ramahandrizafy and Sophie Heckenbach for collecting part of the capture and nest sharing data on which this work is based.

\section{References}

Agnani, P., Kauffmann, C., Hayes, L. D., \& Schradin, C. (2018). Intra-specific variation in social organization of Strepsirrhines. American Journal of Primatology, 80(5), e22758. doi:10.1002/ajp.22758

Alexander, R. D. (1974). The evolution of social behavior. Annual Review of Ecology and Systematics, 5(1), 325-383.

Alvergne, A., Jokela, M., \& Lummaa, V. (2010). Personality and reproductive success in a high-fertility human population. Proceedings of the National Academy of Sciences, 107(26), 11745-11750. doi:10.1073/pnas.1001752107 
Andrews, C. A., Rambeloarivony, H., Génin, F., \& Masters, J. (2016). Why cheirogaleids are bad models for primate ancestors: a phylogenetic reconstruction. The Dwarf and Mouse Lemurs of Madagascar: Biology, Behavior and Conservation Biogeography of the Cheirogaleidae, 73, 94.

Armitage, K. B., \& Schwartz, O. A. (2000). Social enhancement of fitness in yellow-bellied marmots. Proceedings of the National Academy of Sciences, 97(22), 12149-12152. doi:10.1073/pnas.200196097

Becks, L., \& Agrawal, A. F. (2012). The Evolution of Sex Is Favoured During Adaptation to New Environments. PLOS Biology, 10(5), e1001317. doi:10.1371/journal.pbio.1001317

Bell, A. M., \& Sih, A. (2007). Exposure to predation generates personality in threespined sticklebacks (Gasterosteus aculeatus). Ecology Letters, 10(9), 828-834. doi:10.1111/j.1461-0248.2007.01081.x

Bloch, J. I., Silcox, M. T., Boyer, D. M., \& Sargis, E. J. (2007). New Paleocene skeletons and the relationship of plesiadapiforms to crown-clade primates. Proceedings of the National Academy of Sciences, 104(4), 1159-1164.

Borries, C., Gordon, A. D., \& Koenig, A. (2013). Beware of primate life history data: a plea for data standards and a repository. Plos One, 8(6), e67200. doi:10.1371/journal.pone.0067200

Braune, P., Schmidt, S., \& Zimmermann, E. (2005). Spacing and group coordination in a nocturnal primate, the golden brown mouse lemur (Microcebus ravelobensis): the role of olfactory and acoustic signals. Behavioral Ecology and Sociobiology, 58(6), 587-596. doi:10.1007/s00265-005-0944-4

Brockmann, H. J. (1997). Cooperative breeding in wasps and vertebrates: the role of ecological constraints. The Evolution of Social Behavior in Insects and Arachnids, 347.

Canale, C. I., Perret, M., \& Henry, P.-Y. (2012). Torpor use during gestation and lactation in a primate. Naturwissenschaften, 99(2), 159-163. doi:10.1007/s00114-011-0872-2

Charles-Dominique, P., \& Martin, R. D. (1970). Evolution of lorises and lemurs. Nature, 227(5255), 257.

Clutton-Brock, T., \& Janson, C. (2012). Primate socioecology at the crossroads: past, present, and future. Evolutionary Anthropology: Issues, News, and Reviews, 21(4), 136-150.

Dagosto, M., Gebo, D., Ni, X., \& Smith, T. (2018). Estimating body size in early primates: The case of Archicebus and Teilhardina. Journal of Human Evolution, 115, 8-19. doi:10.1016/j.jhevol.2017.02.005 
Dalerum, F. (2007). Phylogenetic reconstruction of carnivore social organizations. Journal of Zoology, 273(1), 90-97. doi:10.1111/j.1469-7998.2007.00303.x

Dall, S. R. X., Houston, A. I., \& McNamara, J. M. (2018). The behavioural ecology of personality: consistent individual differences from an adaptive perspective. Ecology Letters, 734-739. doi:10.1111/j.1461-0248.2004.00618.x@10.1111/(ISSN)14610248.joint-dynamics

Dammhahn, M., \& Kappeler, P. M. (2005). Social System of Microcebus berthae, the World's Smallest Primate. International Journal of Primatology, 26(2), 407-435. doi:10.1007/s10764-005-2931-z

Dammhahn, M., \& Kappeler, P. M. (2008a). Comparative feeding ecology of sympatric Microcebus berthae and M. murinus. International Journal of Primatology, 29(6), 1567.

Dammhahn, M., \& Kappeler, P. M. (2008b). Small-scale coexistence of two mouse lemur species (Microcebus berthae and M. murinus) within a homogeneous competitive environment. Oecologia, 157(3), 473-483. doi:10.1007/s00442-008-1079-x

Dammhahn, M., \& Kappeler, P. M. (2009). Females go where the food is: does the socioecological model explain variation in social organisation of solitary foragers? Behavioral Ecology and Sociobiology, 63(6), 939. doi:10.1007/s00265-009-0737-2

Davies, N. B. (1992). Dunnock behaviour and social evolution (Vol. 3). Oxford University Press.

Dehn, M. M. (1990). Vigilance for predators: detection and dilution effects. Behavioral Ecology and Sociobiology, 26(5), 337-342.

Ebensperger, L. A., Hurtado, M. J., \& León, C. (2007). An experimental examination of the consequences of communal versus solitary breeding on maternal condition and the early postnatal growth and survival of degu, Octodon degus, pups. Animal Behaviour, 73(1), 185-194. doi:10.1016/j.anbehav.2006.06.004

Eberle, M., \& Kappeler, P. M. (2004a). Selected polyandry: female choice and inter-sexual conflict in a small nocturnal solitary primate (Microcebus murinus). Behavioral Ecology and Sociobiology, 57(1), 91-100.

Eberle, M., \& Kappeler, P. M. (2004b). Sex in the dark: determinants and consequences of mixed male mating tactics in Microcebus murinus, a small solitary nocturnal primate. Behavioral Ecology and Sociobiology, 57(1), 77-90. doi:10.1007/s00265-004-0826-1 
Eberle, M., \& Kappeler, P. M. (2006). Family insurance: kin selection and cooperative breeding in a solitary primate (Microcebus murinus). Behavioral Ecology and Sociobiology, 60(4), 582-588.

Eberle, M., \& Kappeler, P. M. (2008). Mutualism, reciprocity, or kin selection? Cooperative rescue of a conspecific from a boa in a nocturnal solitary forager the gray mouse lemur. American Journal of Primatology, 70(4), 410-414. doi:10.1002/ajp.20496

Eberle, M., Perret, M., \& Kappeler, P. M. (2007). Sperm Competition and Optimal Timing of Matings in Microcebus murinus. International Journal of Primatology, 28(6), 12671278. doi:10.1007/s10764-007-9220-y

Eggert, A.-K., \& Müller, J. K. (1992). Joint breeding in female burying beetles. Behavioral Ecology and Sociobiology, 31(4), 237-242. doi:10.1007/BF00171678

Ferrari, M., Lindholm, A. K., \& König, B. (2018). Fitness Consequences of Female Alternative Reproductive Tactics in House Mice (Mus musculus domesticus). The American Naturalist, 193(1), 106-124. doi:10.1086/700567

Fichtel, C. (2016). Predation in the dark: antipredator strategies of Cheirogaleidae and other nocturnal primates. The Dwarf and Mouse Lemurs of Madagascar. Biology, Behavior and Conservation Biogeography of the Cheirogaleidae, 366-380.

Field, J., Paxton, R. J., Soro, A., \& Bridge, C. (2010). Cryptic plasticity underlies a major evolutionary transition. Current Biology, 20(22), 2028-2031.

Flegr, J. (2010). Elastic, not plastic species: Frozen plasticity theory and the origin of adaptive evolution in sexually reproducing organisms. Biology Direct, 5(1), 1-16.

Gadagkar, R. (1990). Evolution of eusociality: the advantage of assured fitness returns. Philosofical Transactions of the Royal Society of London B: Biological Sciences, 329(1252), 17-25. doi:10.1098/rstb.1990.0146

Génin, F. (2008). Life in Unpredictable Environments: First Investigation of the Natural History of Microcebus griseorufus. International Journal of Primatology, 29(2), 303321. doi:10.1007/s10764-008-9243-z

Gotzek, D., \& Ross, K. G. (2007). Genetic regulation of colony social organization in fire ants: an integrative overview. The Quarterly Review of Biology, 82(3), 201-226.

Gould, S. J. (1991). Exaptation: A Crucial Tool for an Evolutionary Psychology. Journal of Social Issues, 47(3), 43-65. doi:10.1111/j.1540-4560.1991.tb01822.x

Gray, J. C., \& Goddard, M. R. (2012). Sex enhances adaptation by unlinking beneficial from detrimental mutations in experimental yeast populations. BMC Evolutionary Biology, 12(1), 43. doi:10.1186/1471-2148-12-43 
Griesser, M., Drobniak, S. M., Nakagawa, S., \& Botero, C. A. (2017). Family living sets the stage for cooperative breeding and ecological resilience in birds. PLOS Biology, 15(6), e2000483. doi:10.1371/journal.pbio.2000483

Halliwell, B., Uller, T., Chapple, D. G., Gardner, M. G., Wapstra, E., \& While, G. M. (2017). Habitat saturation promotes delayed dispersal in a social reptile. Behavioral Ecology, 28(2), 515-522. doi:10.1093/beheco/arw181

Hämäläinen, A., Dammhahn, M., Aujard, F., Eberle, M., Hardy, I., Kappeler, P. M., ... Kraus, C. (2014). Senescence or selective disappearance? Age trajectories of body mass in wild and captive populations of a small-bodied primate. Proceedings of the Royal Society B: Biological Sciences, 281(1791), 20140830. doi:10.1098/rspb.2014.0830

Hending, D., McCabe, G., \& Holderied, M. (2017). Sleeping and Ranging Behavior of the Sambirano Mouse Lemur, Microcebus sambiranensis. International Journal of Primatology, 38(6), 1072-1089. doi:10.1007/s10764-017-9997-2

Holbrook, C. T., Clark, R. M., Jeanson, R., Bertram, S. M., Kukuk, P. F., \& Fewell, J. H. (2009). Emergence and Consequences of Division of Labor in Associations of Normally Solitary Sweat Bees. Ethology, 115(4), 301-310. doi:10.1111/j.14390310.2009.01617.x

Hughes, W. O., Oldroyd, B. P., Beekman, M., \& Ratnieks, F. L. (2008). Ancestral monogamy shows kin selection is key to the evolution of eusociality. Science, 320(5880), 12131216.

Jannett, F. J. (1978). The density-dependent formation of extended maternal families of the montane vole, Microtus montanus nanus. Behavioral Ecology and Sociobiology, 3(3), 245-263. doi:10.1007/BF00296312

Jürges, V., Kitzler, J., Zingg, R., \& Radespiel, U. (2013). First Insights into the Social Organisation of Goodman's Mouse Lemur (Microcebus lehilahytsara) - Testing Predictions from Socio-Ecological Hypotheses in the Masoala Hall of Zurich Zoo. Folia Primatologica, 84(1), 32-48. doi:10.1159/000345917

Kapheim, K. M., Nonacs, P., Smith, A. R., Wayne, R. K., \& Wcislo, W. T. (2015). Kinship, parental manipulation and evolutionary origins of eusociality. Proceedings of the Royal Society B: Biological Sciences, 282(1803), 20142886.

Kappeler, P. M. (2019). A framework for studying social complexity. Behavioral Ecology and Sociobiology, 73(1), 13. doi:10.1007/s00265-018-2601-8

Kappeler, P. M., \& Fichtel, C. (2012). A 15-year perspective on the social organization and life history of sifaka in Kirindy Forest. In Long-term field studies of primates (pp. 101121). Springer. 
Kappeler, P. M., \& Fichtel, C. (2016). The Evolution of Eulemur Social Organization. International Journal of Primatology, 37(1), 10-28. doi:10.1007/s10764-015-9873-x

Kappeler, P. M., \& van Schaik, C. P. (2002). Evolution of primate social systems. International Journal of Primatology, 23(4), 707-740.

Karanewsky, C. J., \& Wright, P. C. (2015). A preliminary investigation of sleeping site selection and sharing by the brown mouse lemur Microcebus rufus during the dry season. Journal of Mammalogy, 96(6), 1344-1351.

Kennedy, P., Higginson, A. D., Radford, A. N., \& Sumner, S. (2018). Altruism in a volatile world. Nature, 555(7696), 359.

Kessler, S. E., Radespiel, U., Nash, L. T., Zimmermann, E., Lehman, S. M., Radespiel, U., \& Zimmermann, E. (2016). Modeling the origins of primate sociality: social flexibility and kinship in mouse lemurs (Microcebus spp.). The Dwarf and Mouse Lemurs of Madagascar: Biology, Behavior and Conservation Biogeography of the Cheirogaleidae, 422-445.

Kocher, S. D., Pellissier, L., Veller, C., Purcell, J., Nowak, M. A., Chapuisat, M., \& Pierce, N. E. (2014). Transitions in social complexity along elevational gradients reveal a combined impact of season length and development time on social evolution. Proceedings of the Royal Society B: Biological Sciences, 281(1787), 20140627.

Kokko, H., \& Jennions, M. D. (2008). Parental investment, sexual selection and sex ratios. Journal of Evolutionary Biology, 21(4), 919-948.

Kokko, H., \& Johnstone, R. A. (1999). Social queuing in animal societies: a dynamic model of reproductive skew. Proceedings of the Royal Society of London B: Biological Sciences, 266(1419), 571-578. doi:10.1098/rspb.1999.0674

Kokko, H., Johnstone, R. A., \& Clutton-Brock, T. H. (2001). The evolution of cooperative breeding through group augmentation. Proceedings. Biological Sciences / The Royal Society, 268(1463), 187-196. doi:10.1098/rspb.2000.1349

Komdeur, J. (1992). Importance of habitat saturation and territory quality for evolution of cooperative breeding in the Seychelles warbler. Nature, 358(6386), 493.

Kulich, T., \& Flegr, J. (2010). Effects of multiple gene control on the spread of altruism by group selection. ArXiv:1002.4204 [q-Bio]. Retrieved from http://arxiv.org/abs/1002.4204

Lahann, P. (2008). Habitat utilization of three sympatric cheirogaleid lemur species in a littoral rain forest of southeastern Madagascar. International Journal of Primatology, 29(1), 117-134. 
Latham, N., \& Mason, G. (2004). From house mouse to mouse house: The behavioural biology of free-living Mus musculus and its implications in the laboratory. Applied Animal Behaviour Science, 86(3-4), 261-289. doi:10.1016/j.applanim.2004.02.006

Lindenfors, P., Fröberg, L., \& Nunn, C. L. (2004). Females drive primate social evolution. Proceedings of the Royal Society B: Biological Sciences, 271(Suppl 3), S101-S103.

Lucia, K. E., Keane, B., Hayes, L. D., Lin, Y. K., Schaefer, R. L., \& Solomon, N. G. (2008). Philopatry in prairie voles: an evaluation of the habitat saturation hypothesis. Behavioral Ecology, 19(4), 774-783.

Lukas, D., \& Clutton-Brock, T. (2012). Cooperative breeding and monogamy in mammalian societies. Proceedings of the Royal Society of London B: Biological Sciences, rspb20112468.

Lukas, D., \& Clutton-Brock, T. H. (2013). The evolution of social monogamy in mammals. Science, 341(6145), 526-530.

Lutermann, H., Schmelting, B., Radespiel, U., Ehresmann, P., \& Zimmermann, E. (2006). The role of survival for the evolution of female philopatry in a solitary forager, the grey mouse lemur (Microcebus murinus). Proceedings of the Royal Society B: Biological Sciences, 273(1600), 2527-2533. doi:10.1098/rspb.2006.3603

Martin, R. D., Soligo, C., \& Tavaré, S. (2007). Primate origins: implications of a Cretaceous ancestry. Folia Primatologica, 78(5-6), 277-296.

Masters, J. C., Génin, F., Silvestro, D., Lister, A. M., \& DelPero, M. (2014). The red island and the seven dwarfs: body size reduction in Cheirogaleidae. Journal of Biogeography, 41(10), 1833-1847.

Milleret, C., Wabakken, P., Liberg, O., \AAkesson, M., Flagstad, Ø., Andreassen, H. P., \& Sand, H. (2017). Let's stay together? Intrinsic and extrinsic factors involved in pair bond dissolution in a recolonizing wolf population. Journal of Animal Ecology, 86(1), 43-54.

Müller, J. K., Braunisch, V., Hwang, W., \& Eggert, A.-K. (2007). Alternative tactics and individual reproductive success in natural associations of the burying beetle, Nicrophorus vespilloides. Behavioral Ecology, 18(1), 196-203. doi:10.1093/beheco/arl073

Ni, X., Wang, Y., Hu, Y., \& Li, C. (2004). A euprimate skull from the early Eocene of China. Nature, 427(6969), 65. 
Nowak, M. A., Tarnita, C. E., \& Antal, T. (2010). Evolutionary dynamics in structured populations. Philosophical Transactions of the Royal Society B: Biological Sciences, 365(1537), 19-30. doi:10.1098/rstb.2009.0215

Nowak, M. A., Tarnita, C. E., \& Wilson, E. O. (2010). The evolution of eusociality. Nature, 466(7310), 1057.

Nunn, C. L. (2011). The comparative approach in evolutionary anthropology and biology. University of Chicago Press.

Perret, M. (1990). Influence of social factors on sex ratio at birth, maternal investment and young survival in a prosimian primate. Behavioral Ecology and Sociobiology, 27(6), 447-454. doi:10.1007/BF00164072

Perret, M. (1998). Energetic advantage of nest-sharing in a solitary primate, the lesser mouse lemur (Microcebus murinus). Journal of Mammalogy, 79(4), 1093-1102. doi:10.2307/1383001

Poirotte, C., \& Kappeler, P. M. (2019). Hygienic personalities in wild grey mouse lemurs vary adaptively with sex. Proceedings of the Royal Society B: Biological Sciences, 286(1908), 20190863. doi:10.1098/rspb.2019.0863

Radespiel, U., Jurić, M., \& Zimmermann, E. (2009). Sociogenetic structures, dispersal and the risk of inbreeding in a small nocturnal lemur, the golden-brown mouse lemur (Microcebus ravelobensis). Behaviour, 607-628.

Radespiel, Ute. (2000). Sociality in the gray mouse lemur (Microcebus murinus) in northwestern Madagascar. American Journal of Primatology: Official Journal of the American Society of Primatologists, 51(1), 21-40.

Radespiel, Ute, Cepok, S., Zietemann, V., \& Zimmermann, E. (1998). Sex-specific usage patterns of sleeping sites in grey mouse lemurs (Microcebus murinus) in northwestern Madagascar. American Journal of Primatology, 46(1), 77-84.

Radespiel, Ute, Sarikaya, Z., Zimmermann, E., \& Bruford, M. W. (2001). Sociogenetic structure in a free-living nocturnal primate population: sex-specific differences in the grey mouse lemur (Microcebus murinus). Behavioral Ecology and Sociobiology, 50(6), 493-502. doi:10.1007/s002650100402

Randrianambinina, B., Rakotondravony, D., Radespiel, U., \& Zimmermann, E. (2003). Seasonal changes in general activity, body mass and reproduction of two small nocturnal primates: a comparison of the golden brown mouse lemur (Microcebus ravelobensis) in Northwestern Madagascar and the brown mouse lemur (Microcebus rufus) in Eastern Madagascar. Primates, 44(4), 321-331. doi:10.1007/s10329-0030046-8 
Rasoazanabary, E. (2006). Male and Female Activity Patterns in Microcebus murinus During the Dry Season at Kirindy Forest, Western Madagascar. International Journal of Primatology, 27(2), 437-464. doi:10.1007/s10764-006-9017-4

Rehan, S. M., \& Toth, A. L. (2015). Climbing the social ladder: the molecular evolution of sociality. Trends in Ecology \& Evolution, 30(7), 426-433. doi:10.1016/j.tree.2015.05.004

Rödel, H. G., \& Meyer, S. (2011). Early development influences ontogeny of personality types in young laboratory rats. Developmental Psychobiology, 53(6), 601-613. doi:10.1002/dev.20522

Sakagami, S., \& Maeta, Y. (1995). Task Allocation in Artificially Induced Colonies of a Basically Solitary Bee Ceratina (Ceratinidia) okinawana, with a Comparison of Sociality between Ceratina and Xylocopa: Hymenoptera, Anthophoridae, Xylocopinae. Jpn. J. Ent., 63(1), 115-150.

Schliehe-Diecks, S., Eberle, M., \& Kappeler, P. M. (2012). Walk the line-dispersal movements of gray mouse lemurs (Microcebus murinus). Behavioral Ecology and Sociobiology, 66(8), 1175-1185. doi:10.1007/s00265-012-1371-y

Schmid, J. (1998). Tree Holes Used for Resting by Gray Mouse Lemurs (Microcebus murinus) in Madagascar: Insulation Capacities and Energetic Consequences. International Journal of Primatology, 19, 797-809. doi:10.1023/A:1020389228665

Schmid, J., \& Kappeler, P. M. (1998). Fluctuating sexual dimorphism and differential hibernation by sex in a primate, the gray mouse lemur (Microcebus murinus). Behavioral Ecology and Sociobiology, 43(2), 125-132. doi:10.1007/s002650050474

Schoepf, I., \& Schradin, C. (2012). Differences in social behaviour between group-living and solitary Affrican striped mice, Rhabdomys pumilio. Animal Behaviour, 84(5), 11591167. doi:10.1016/j.anbehav.2012.08.019

Schradin, C. (2013). Intraspecific variation in social organization by genetic variation, developmental plasticity, social flexibility or entirely extrinsic factors. Philosophical Transactions of the Royal Society B: Biological Sciences, 368(1618), 20120346.

Schradin, C., Hayes, L. D., Pillay, N., \& Bertelsmeier, C. (2018). The evolution of intraspecific variation in social organization. Ethology, 124(8), 527-536. doi:10.1111/eth.12752

Schradin, C., Lindholm, A. K., Johannesen, J., Schoepf, I., Yuen, C.-H., König, B., \& Pillay, N. (2012). Social flexibility and social evolution in mammals: a case study of the African striped mouse (Rhabdomys pumilio). Molecular Ecology, 21(3), 541-553. doi:10.1111/j.1365-294X.2011.05256.x 
Schülke, O., \& Ostner, J. (2005). Big times for dwarfs: Social organization, sexual selection, and cooperation in the Cheirogaleidae. Evolutionary Anthropology: Issues, News, and Reviews, 14(5), 170-185. doi:10.1002/evan.20081

Schwensow, N., Eberle, M., \& Sommer, S. (2008). Compatibility counts: MHC-associated mate choice in a wild promiscuous primate. Proceedings of the Royal Society B: Biological Sciences, 275(1634), 555-564. doi:10.1098/rspb.2007.1433

Shell, W. A., \& Rehan, S. M. (2018). Behavioral and genetic mechanisms of social evolution: insights from incipiently and facultatively social bees. Apidologie, 49(1), 13-30. doi:10.1007/s13592-017-0527-1

Shultz, S., Opie, C., \& Atkinson, Q. D. (2011). Stepwise evolution of stable sociality in primates. Nature, 479(7372), 219.

Silcox, M. T., \& López-Torres, S. (2017). Major Questions in the Study of Primate Origins. Annual Review of Earth and Planetary Sciences, 45(1), 113-137. doi:10.1146/annurev-earth-063016-015637

Silva, J. da, Macdonald, D. W., \& Evans, P. G. H. (1994). Net costs of group living in a solitary forager, the Eurasian badger (Meles meles). Behavioral Ecology, 5(2), 151-158. doi:10.1093/beheco/5.2.151

Simons, M. J. P., Reimert, I., Vinne, V. van der, Hambly, C., Vaanholt, L. M., Speakman, J. R., \& Gerkema, M. P. (2011). Ambient temperature shapes reproductive output during pregnancy and lactation in the common vole (Microtus arvalis): a test of the heat dissipation limit theory. Journal of Experimental Biology, 214(1), 38-49. doi:10.1242/jeb.044230

Socias-Martínez, L., \& Kappeler, P. M. (2019). Catalyzing Transitions to Sociality: Ecology Builds on Parental Care. Frontiers in Ecology and Evolution, 7. doi:10.3389/fevo.2019.00160

Solomon, N. G., \& Keane, B. (2018). Dispatches from the field: sociality and reproductive success in prairie voles. Animal Behaviour, 143, 193-203. doi:10.1016/j.anbehav.2018.07.001

Soper, D. M., King, K. C., Vergara, D., \& Lively, C. M. (2014). Exposure to parasites increases promiscuity in a freshwater snail. Biology Letters, 10(4), 20131091. doi:10.1098/rsbl.2013.1091

Stamps, J. A. (2007). Growth-mortality tradeoffs and 'personality traits' in animals. Ecology Letters, 10(5), 355-363. doi:10.1111/j.1461-0248.2007.01034.x 
Thierry, B. (2008). Primate socioecology, the lost dream of ecological determinism. Evolutionary Anthropology: Issues, News, and Reviews: Issues, News, and Reviews, 17(2), 93-96.

Traulsen, A., \& Nowak, M. A. (2006). Evolution of cooperation by multilevel selection. Proceedings of the National Academy of Sciences, 103(29), 10952-10955. doi:10.1073/pnas.0602530103

Valencak, T. G., Wright, P., Weir, A., Mitchell, S. E., Vaanholt, L. M., Hambly, C., ... Speakman, J. R. (2013). Limits to sustained energy intake. XXI. Effect of exposing the mother, but not her pups, to a cold environment during lactation in mice. Journal of Experimental Biology, 216(23), 4326-4333. doi:10.1242/jeb.092023

Valomy, M., Hayes, L. D., \& Schradin, C. (2015). Social organization in Eulipotyphla: evidence for a social shrew. Biology Letters, 11(11), 20150825. doi:10.1098/rsbl.2015.0825

van Schaik, C. (1983). Why are diurnal primates living in groups? Behaviour, 87(1), 120-144.

Wcislo, W., \& Fewell, J. H. (2017). Sociality in bees. In D. R. Rubenstein \& P. Abbot (Eds.), Comparative social evolution (pp. 50-83). Cambridge, United Kingdom: Cambridge University Press.

Weidt, A., Hagenah, N., Randrianambinina, B., Radespiel, U., \& Zimmermann, E. (2004). Social organization of the golden brown mouse lemur (Microcebus ravelobensis). American Journal of Physical Anthropology, 123(1), 40-51. doi:10.1002/ajpa.10296

West, S. A., Pen, I., \& Griffin, A. S. (2002). Cooperation and competition between relatives. Science (New York, N.Y.), 296(5565), 72-75. doi:10.1126/science.1065507

Wilson, E. O., \& Hölldobler, B. (2005). Eusociality: origin and consequences. Proceedings of the National Academy of Sciences, 102(38), 13367-13371.

Wolff, J. O. (1994). Reproductive success of solitarily and communally nesting white-footed mice and deer mice. Behavioral Ecology, 5(2), 206-209.

Wrangham, R. W. (1980). An ecological model of female-bonded primate groups. Behaviour, 75(3), 262-300.

Wu, S.-H., Zhang, L.-N., Speakman, J. R., \& Wang, D.-H. (2009). Limits to sustained energy intake. XI. A test of the heat dissipation limitation hypothesis in lactating Brandt's voles (Lasiopodomys brandtii). Journal of Experimental Biology, 212(21), 3455-3465. doi:10.1242/jeb.030338 

No: 10 . T. $x \rightarrow-1$ a. a d

$\rightarrow, 25$ - Mlo a

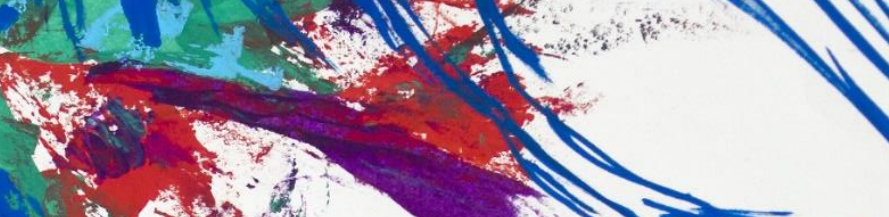
$2-7$

$\rightarrow$

61

ta

if)

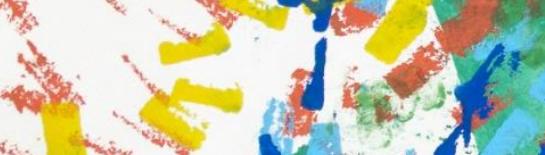

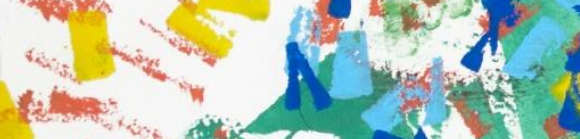
$4 \ln +\frac{1}{2}$

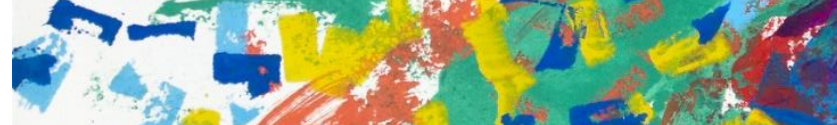
$4^{2}+x^{5}$

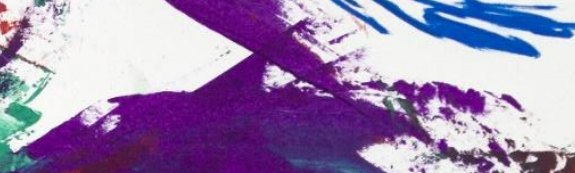
Lete

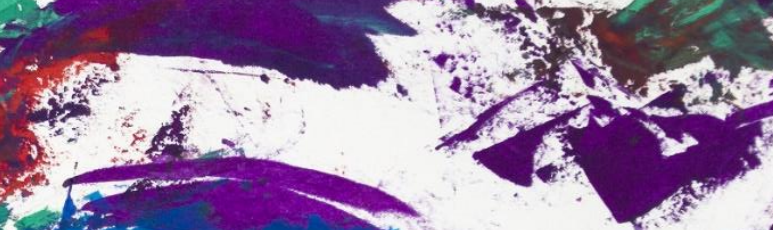
sents f .

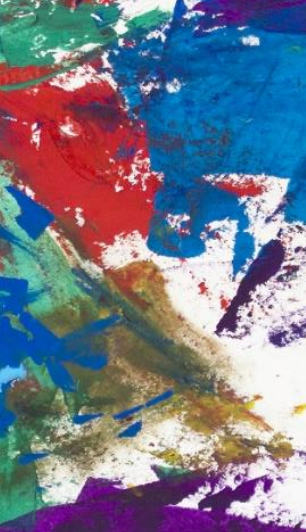
$x^{2}-1,20$

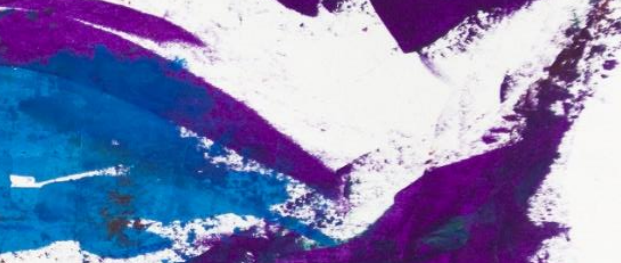
$n-\frac{1}{2}$

a) $A$

$x^{2}$

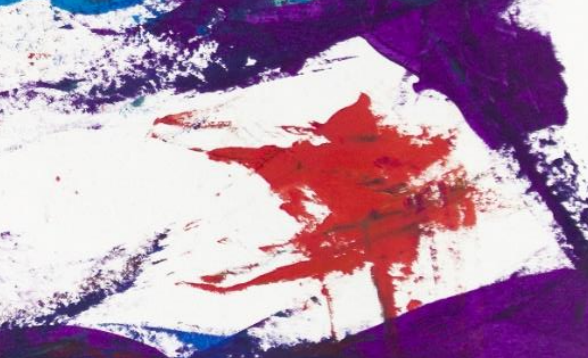

- 15 $5=$

sity

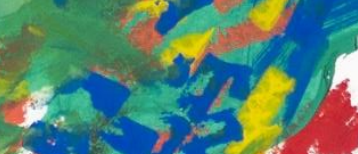

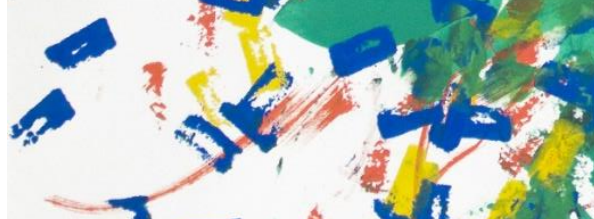
$7 \quad 4 / 4 f^{2}$

(f)

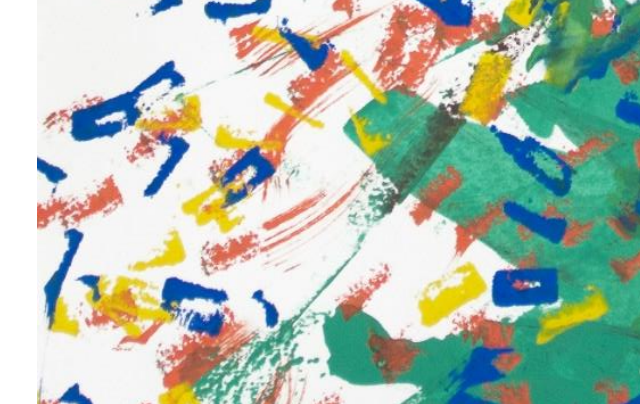

- $2 \pi$.

9 $-a$
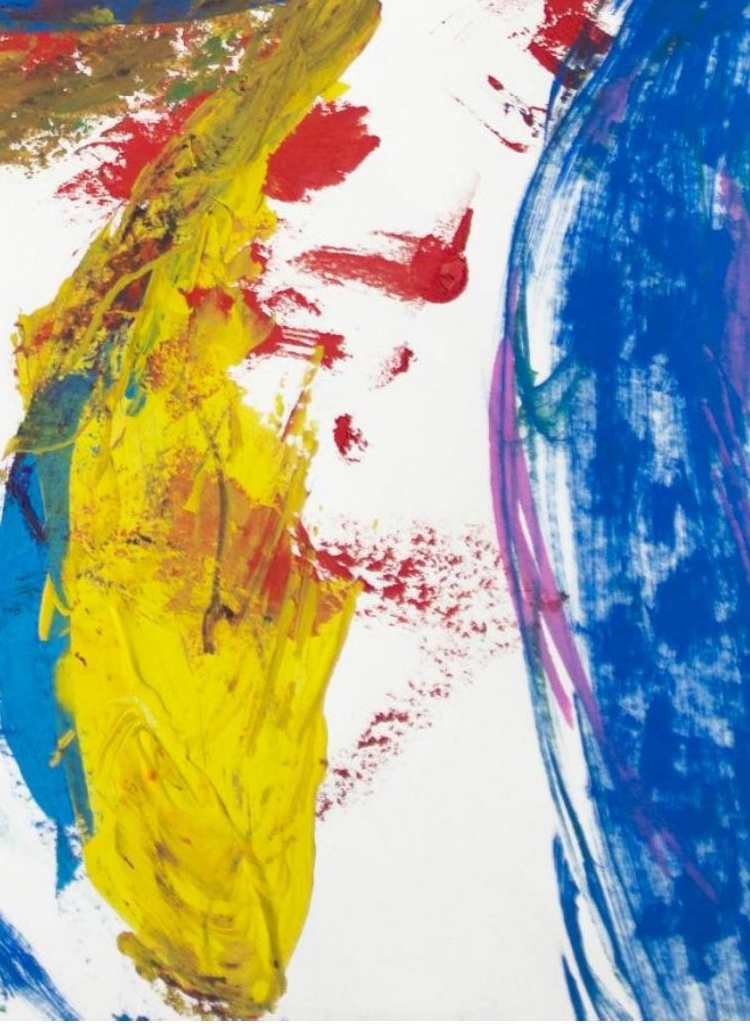


\section{Chapter 3.1: Effects of resources on gray mouse lemur sociality}

\section{Introduction}

In the context of social evolution, resource and space sharing are key for the transition from solitary to group-living. In the path towards group-living, home range sharing is a first prerequisite for solitary species. Several schools of thought have tried to explain interspecific variation in spatial distribution based on resource distribution. A suite of theoretical models has analyzed the consequences of various spacing patterns and quality of food resources on the spatial distribution and associated modes of competition between females (Emlen and Oring, 1977; Wrangham, 1980; Koenig, 2002). Mating systems, social structure, and caring systems were targeted dimensions of social systems in these analyses and were predicted to vary accordingly to the levels of competition and capacity for monopolization of resources and mates. Thus, socioecological models predicted at the same time the conditions allowing changes in social organization, including transitions to sociality.

Most models predict that the sex investing more energy per offspring should be more affected by the distribution of feeding resources while the other sex by the distribution of mates. Whether resources occur in patches or evenly distributed, the size of patches and their relative energy content will determine if the parental sex establish exclusive home ranges or overlapping foraging areas (Emlen and Oring, 1977; Carpenter, 1987). The sex investing more in mating is expected to map its strategy onto the resulting spatial distribution of the parental sex. The average size of territories of the parental sex, as well as the potential for monopolization of one or several partners during sexual receptivity, will determine whether the less parental sex establishes bigger or equal home ranges.

The mechanisms proposed to allow for spatial tolerance between several individuals and the resulting competitive and cooperative regimes explaining the origins of group-living in relation to feeding resources have been multiple. According to the emphasis put into the active or passive role of individuals in determining the costs and benefits of resource sharing, four major sets can be drawn. The first set of theories posit spatial sharing as a byproduct or influenced by resources alone, while the second set considers individuals' interactions and their emergent properties to affect the costs and benefits of sharing.

Since the environment is heterogeneous in the spatial and temporal distribution of resource production, individuals could start sharing home ranges and living in groups if there is no increased cost associated with tolerating others. In this sense, in territories with a high abundance of resources, individuals might be able to tolerate each other at no cost. This may come from two different interrelated mechanisms. First, there might be an upper limit 
in the capacity of organism for processing food. This boundary arises from limitations of the digestive system in the quantity of food it can process in any given moment and to limits in the efficiency of the digestive processes. Secondly, feeding is costly in terms of energy needed to find, process and digest food resources (Webster, 1980; Secor, 2009). Metabolism increases during digestion and generates associated costs in the form of DNA damage due to accumulation of free radicals (Koubova and Guarente, 2003; Rattan, 2006). In this sense, caloric restriction has been shown to widen the lifespan of captive animals in a wide range of organisms (Koubova and Guarente, 2003; Rattan, 2006; Colman et al., 2014). Thus, it has been suggested that there is an upper limit to sustained energy intake in animals and that this rather than food availability limits fitness even in wild populations (Speakman and Król, 2005). In this sense, natural habitats could regularly harbor enough resources to imply reduced feeding competition and allow for spatial sharing (Carpenter, 1987; Maher and Lott, 2000; but see Wolff, 1993).

Since tolerating others can result in costs due to infanticide (Wolff, 1993) and mating competition, individuals may instead reduce the area of their territories when food availability increases. Shrinking the size of the territory could further benefit the owner by reducing the energetic costs of locomotion during both foraging and patrolling. However, although energetic resources might be concentrated enough, different dietary requirements (e.g., proteins, sugars, micronutrients) might be located at distant places or distributed differently (e.g. homogeneous vs. spatially clumped) (Breed and Moore, 2016). This plurality of distributions might constrain the capacities for territory adjustment. Furthermore, the home range of an animal is not exclusively determined by feeding resources but also by other important resources such as shelters, water sources, routes to escape predators and possible needs for knowledge of adjacent areas in case of changing environmental conditions (e.g. flooding). Moreover, knowing where to find mates and which competitors are around might result in enhanced reproductive success during the breeding season. Thus, the lower boundary to territory size will be locally determined by that area encompassing all the different resources needed. Thus, the home range of an animal might be bigger than the feeding resources it needs and may, therefore, lead to spatial sharing.

The social organization may also be affected by the variability in resource abundance not only in space but in time as well. The patch-world hypothesis developed to explain carnivoran social evolution suggests that under spatial-temporal variation in productivity shown by most habitats, the minimum territory to sustain a breeding unit might regularly produce surplus of resources whose owners might be unable to exploit entirely (Macdonald and Johnson, 2015). For example, if a breeding territory of a putative hunting ancestor regularly allows the capture of prey items that are too big to be used entirely by the owner 
of a territory, no cost from tolerating additional members in the territory would ensue. Therefore, increased variation in resources production from day to day would lead to increased group size if the amounts produced in the days of low production allowed survival of additional group members.

The above-mentioned ideas pay special attention to the minimum requirements of animals and their relationship with spatiotemporal heterogeneity of different resources. Nevertheless, other hypotheses have also encompassed the possible benefits arising from individuals interacting with each other, including benefits against biotic (e.g. predators and parasites) and abiotic elements (e.g. low temperatures, aridity) (Socias-Martínez and Kappeler, 2019). Under environmental variability, spatial sharing and cooperative behaviors may also be selected if they stabilize fitness returns both within and between generations (Wenzel and Pickering, 1991; Sheehan et al., 2015; Carter et al., 2017; Kennedy et al., 2018). Since we have treated this extensively in chapter 1 , we will conclude briefly that under fitness benefits of cooperation, both arithmetical or geometrical, the minimum threshold of food availability needed for maintaining group living could be shifted towards lower values. Fitness could be maximized through other mechanisms than food intake especially if cooperation increases energetic efficiency (e.g. huddling in small mammals including offspring during lactation). If fitness benefits decrease exponentially with increasing group size one would predict an optimal group size somewhere in between the continuum of group sizes possible. The location of the optimum will be determined by the rate of increase in within-group competition with increasing group size and the regression line relating group size and benefits against environmental variability.

Increased competitiveness of groups for access to resources has also been the core for modeling changes in social organization. In this set of ideas, two branches, with socioecological models on the one hand and group-selection based models on the other can be distinguished based on the emphasis placed on within-group competition. In the former, models predicting sociality based on ecological characteristics insisted that whenever a species feeds on resources that are clumped in space and time and can be exploited simultaneously by several individuals, cooperation should arise as an enhancer of competitive capacities (Wrangham, 1980; Koenig, 2002). Individuals forming social units would be in advantage over solitary animals, and social strategies would thrive and invade the population. This mechanism would generate clusters of related individuals that increase the indirect fitness benefits of cooperation by sharing with kin. Importantly, this increased access through contest competition with other social units could invade the population even if individuals in groups had a lower per capita reproductive success. Since the groupliving strategy would be dominant, even though individuals in group could pay a cost 
impeding attaining their optimum by sharing the resources monopolized, a sort of prisoner's dilemma would make this strategy evolutionarily stable (Craig, 1984). The solitary strategy, despite resulting in a higher benefit per se, would be displaced by cooperative individuals and the whole population driven to a lower per capita reproductive success.

The other branch emphasizes the benefits of grouping as well but needs from the cooperative strategy to give higher fitness benefits than the solitary one (West et al., 2007). Selection at the group level can lead individuals moving in groups or living in a common neighborhood to cooperate in resource defense (Nowak, 2006). If by engaging in costly behaviors such as aggression of individuals from other social units or neighborhoods, all individuals in a unit gain increased access to feeding or nesting resources and do more so than other less aggressive units, selection at the group level could make cooperation stable. Even if units contain individuals not engaging in displacement that should thrive as cheaters, the benefits arising from the displacements and monopolization of non-members could lead to a spread at the population level of cooperative strategies (Nowak, 2006; Wynne-Edwards, 2017). Cooperative strategies could be at a disadvantage within social units but nevertheless expanding at the population level through higher fitness relative to adjacent units without cooperators (Eldakar and Wilson, 2011). Thus, one would predict that groups would occur more often in high-quality areas and this be associated with increased reproductive success.

\section{a. Resources and social evolution in primates}

In primates, most research has been related to understanding the evolution of interspecific variation in female social structure as a result of resource distribution (Wrangham, 1980; Koenig, 2002). Although criticized due to failures in such endeavors across primates (Thierry, 2008), the explanatory power of the socioecological model is supported by comparisons within clades (Koenig et al., 2013). The transition from solitary to social species has received comparatively less attention (see Chapters 1 and 2). In this sense, extant nocturnal solitary foragers are regarded as possible models for reconstructing the conditions at the early stages of sociality in primates ancestors (Kessler et al., 2016). Thus, assessing the role of the above-mentioned hypotheses in cheirogaleid species could lead to clarifying their possible role in primate social evolution (Dammhahn and Kappeler, 2009a).

The genus Microcebus is considered of great importance because of its ancestral primate characteristics coupled with social flexibility and across species variation in the extent of sociality (Kessler et al., 2016; Agnani et al., 2018). Although individuals are capable of sharing sleeping sites and form social units, foraging is done solitarily (Eberle and Kappeler, 2004; Dammhahn and Kappeler, 2009a). In this sense, the propensity for sociality across species has been suggested to be affected passively by feeding resource distribution (Schülke and Ostner, 2005). These animals have a low potential for cooperation in food 
resource defense because the protein component of their diet is obtained from insects, especially Coleoptera, and are unpredictable, ephemeral, and unexploitable simultaneously by several individuals (Dammhahn and Kappeler, 2008a, 2009a). Thus, sociality should only relate to feeding resources indirectly through population density (Schülke and Ostner, 2005).

Although the insect part of the diet might not be monopolizable, all the other components may be. The trees that produce gum, fruits, and flowers from which these animals feed on are long-lived, localized and the crop size or the amount of gum big enough to be shared by several individuals. Since, despite being solitary foragers, individuals do form social units through nest sharing, a form of cooperative neighborhood could be at play (Eberle and Kappeler, 2008, Chapter 2). In this sense, individuals have been shown to interact aggressively more often when not sharing sleeping sites (Dammhahn and Kappeler, 2009a). Thus, individuals could, even if foraging solitarily, engage in cooperative between-group competition through aggressive interactions. Individuals in an area would encounter fewer aggressions when sleeping in groups and the amount of aggression to be dependent on the number of partners. Thus, sleeping in groups could lead to benefits by accessing more easily the resources in a given area. In this sense, the prisoner's dilemma and group selection hypotheses described above could explain sociality in Microcebus. Groups would, therefore, be predicted to occur more often in areas with more abundant resources.

Nesting sites have also been suggested to play an important role in the evolution of Microcebus sociality. These are monopolizable resources for solitary foragers that offer advantages in terms of thermoregulatory and antipredator benefits (Schmid, 1998). The height, the form of the entrance, and its size can determine the abundance and the types of predators potentially inspecting a nest while the same variables together with the material and the thickness can determine the thermoregulatory benefits. Moreover, variation in nest quality is thought to affect females more importantly due to needing for pup concealment (Schülke and Ostner, 2005). In M. murinus which sleeps mostly on tree-holes, it has been shown that specific types of tree-holes monopolized by females are indeed yielding a thermoregulatory benefit of a $5 \%$ in Microcebus murinus (Schmid, 1998) and aggressive encounters occur in their vicinity which suggests the presence of between-group competition in this species (Dammhahn and Kappeler, 2009a). Despite competition observed in gray mouse lemurs, most species of Microcebus show nesting in open vegetation or leaf nests, suggesting neither a limitation nor thermal benefits from specific nesting sites (Schülke and Ostner, 2005). However, most species appear to show preferences for the species of plant or tree they nest on, and it is possible that specific emplacements are better to conceal from predators, especially when sleeping in open vegetation. Thus, 
limitation of nesting sites could generate a force of between-group competition analogous to that proposed by (Wrangham, 1980) in diurnal primates concerning clumped food resources (Dammhahn and Kappeler, 2009a; Lutermann et al., 2010). This effect should be reinforced in the presence of intrinsic benefits associated with communal nesting, thermoregulation, or antipredator benefits and groups should both inhabit better territories and have higher reproductive success. Nevertheless, if the benefits of grouping are high enough, groups should be most advantageous in territories with scarcity of resources. Thus, after a certain minimum threshold, groups should occur more often at lower values of resource abundance and decrease with improving ecological conditions. On the contrary, if the benefits of grouping are negligible, a positive correlation between feeding resources and occurrence of sociality and group size should be at play.

In this chapter we evaluate the correlations between resource availability and social strategies in Microcebus murinus. We expect a correlation between the resources in a given home range and the sociality of a given individual. The shape of this relationship should inform about the contribution of the competing hypotheses explained above to explain mouse lemur sociality. In the second part of Chapter (Chapter 3.2) we present a new method we developed for assessing the reliability of home range estimations when studying wild animals with low amount of information per individual.

\section{Materials and methods \\ a. Study population}

The study population is identical to that described in chapter 2 .

\section{b. Home range analyses}

In order to estimate the home range of males and females, we followed the method described in Chapter 3.2. Briefly, we used Michaelis-Menten models to describe the saturation curve of the described home range area by adding each time a new data point in the form of incremental analysis (Halbrook and Petach, 2018). We further added three criteria for model selection based on goodness-of-fit, model stability and extent of the confidence interval of the predicted home range size. By doing so we selected the models on which saturation of the information concerning space use was reached implying that enough information was gathered for a given individual and that the fitted model was robust. For the analyses included in this chapter, we used not only capture data since 2013 to establish the home ranges but also the coordinates of nest locations. Since captures were only conducted 3 days a month, we limited the amount of information coming from nest locations. We included one point per each nest occupied per month if individuals occupied more than 3 nests. If not, we included a point per each different nest location and added a randomly chosen data point until the monthly record contained 3 data points from nest 
location. By doing so we aimed at capturing the space use while avoiding the redundancy arising from nest reuse since mouse lemurs tend to occupy the same nests over days or weeks (Schmid, 1998; Eberle and Kappeler, 2006; Dammhahn and Kappeler, 2009a). Using the Michaelis-Menten model we obtained a value for the expected home range size for each individual (Fig. 1).

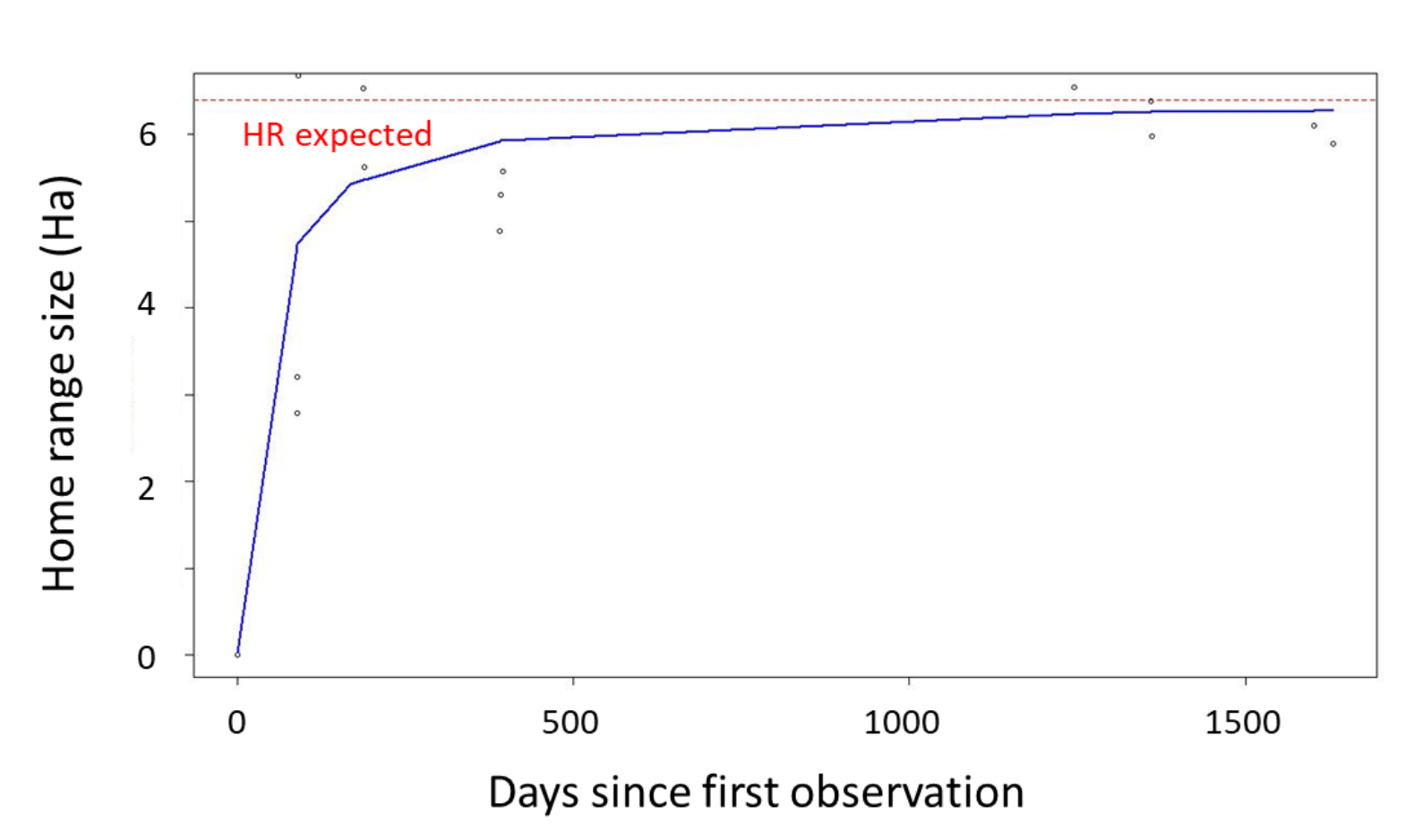

Figure 1. Example of incremental analyses of home range. Each dot represents the home range size calculated for the example individual with all data until each given day the individual was observed. Data used contain trapping and nesting locations. Blue line denotes the predicted home range size by the Michaelis-Menten model. Dashed red line shows the expected home range size calculated by the

\section{Home range size}

In order to assess whether our measures of home range corresponded with the values reported in the literature, we compared the home range size of males and females as well as the differences in home range size between non-reproductive and birth season. Importantly, since males are known to increase their home range size during the mating season (Eberle and Kappeler, 2002), we removed data points for males during the months of October and November. 


\section{Home range stability}

In order to understand whether grey mouse lemurs inhabit the same areas over different seasons, we investigated the extent of overlap between the home ranges obtained for each individual in different seasons.

\section{Home range overlap}

For each individual that a home range was calculated, we determined the number of individuals of each sex overlapping with him/her and the mean area of overlap relative to the total home range area of the focal individual.

\section{Home range overlap and nest-sharing}

We investigated whether the strength of the social relationship between two individuals was related to their extent of home range overlap aiming to understand if social relationships are related to resource sharing. In the first round of analyses we tested whether the occurrence of a relationship defined as sharing a nest at least once was associated with higher or lower extent of overlap within dyads. In the second round, we aimed to test if the strength of an existing social relationship was correlated with the extent of home range overlap. In this sense, we aimed to understand if the strength of social bonds is correlated with the strength of resource sharing.

\section{c. Resource diversity and abundance}

\section{Feeding trees}

We used the list of plants consumed by $M$. murinus described in Dammhahn and Kappeler (2008a). We added an additional species Astrocassine pleurostyloides following observations of regular nectar consumption during the flowering period in January. Furthermore, we estimated the abundance of a type of lianas of the local name Vahipindy. We did so after several observations throughout the study period that an important source of glucids, homopteran colonies of Flatida coccinea which secrete sugary exudates aggregated most prominently on these lianas (Hladik et al., 1980). These secretions are a key resource for mouse lemurs in Kirindy (Corbin and Schmid, 1995; Dammhahn and Kappeler, 2008a).

The species of plants consumed by $M$. murinus might differ in their importance during the birth (December to April) and the non-reproductive seasons defined in Chapter 2. Homopteran secretions are mostly reported during the dry season when the absence of leaves from trees allow lianas to grow and insects to feed on them. Moreover, the two species producing gum, Taly and Arofy are also main sources of protein and sugars that amount to $14 \%$ of the diet during the non-reproductive season (Dammhahn and Kappeler, 2008a). All the other species producing fruits and flowers from which mouse lemurs consume up to $50 \%$ of their diet during the birth season. However, these species might also 
harbor fruit during the non-reproductive season (Table 1). We used data on phenology from our study site to determine for each species available in the database whether it produced ripe fruit during the non-reproductive and/or the birth season. Then the species were used in the respective analyses per season.

Table 1. Plant species consumed by Microcebus murinus at Kirindy Forest, modified from Dammhahn and Kappeler (2008). Plant species, local name, parts eaten and phenology (presence) are shown together with the season for which the plants were included in the analyses.

\begin{tabular}{|c|c|c|c|c|c|c|c|c|c|}
\hline Genus & Species & Family & Local name & Consumed & $\begin{array}{l}\text { Non- } \\
\text { rep } \\
\text { flowers }\end{array}$ & $\begin{array}{l}\text { Non- } \\
\text { rep } \\
\text { fruit }\end{array}$ & $\begin{array}{l}\text { Birth- } \\
\text { flowers }\end{array}$ & $\begin{array}{l}\text { Birth- } \\
\text { fruits }\end{array}$ & Analyses \\
\hline Commiphora & arofy & Burseraceae & Arofy & Gum & Yes & No & Yes & No & Non-rep \\
\hline Terminalia & $s p$. & Combretaceae & Taly & Gum & - & - & - & - & Non-rep \\
\hline Strychnus & decussate & Loganiaceae & Hazomby & Pulp & Yes & Yes & Yes & Yes & Both \\
\hline Macphersonia & gracilis & Mimosaceae & Tsingena & Pulp & Yes & No & Yes & No & Both \\
\hline Enterospermum & $s p$. & Rubiaceae & Tolakena & Pulp & Yes & Yes & Yes & Yes & Both \\
\hline Canthium & $s p$ & Rubiaceae & Fatekahizy & Pulp & - & - & - & - & Both \\
\hline Rothmannia & tropophylla & Rubiaceae & Piropitsokala & Pulp & No & Yes & No & Yes & Both \\
\hline Grewia & $s p$. & Tiliaceae & Sely & Pulp & Yes & Yes & Yes & Yes & Both \\
\hline Grewia & $s p$. & Tiliaceae & Sele Sele & Pulp & - & - & - & - & Both \\
\hline Grewia & cyclea & Tiliaceae & Latabarika & Pulp & Yes & Yes & Yes & Yes & Both \\
\hline Phylloctenium & decaryanum & Bignoniaceae & Pitikala & $?$ & No & Yes & Yes & Yes & Both \\
\hline Baseonema & acuminatum & Apocynaceae & Mamiaho & $?$ & No & No & Yes & No & Birth \\
\hline Astrocassine & pleurostyloides & Celastraceae & Maronono & $\begin{array}{l}\text { Flower } \\
\text { nectar }\end{array}$ & No & No & Yes & No & Birth \\
\hline$?$ & $?$ & $?$ & Lopingo & Pulp & No & Yes & Yes & Yes & Both \\
\hline ? & ? & ? & Vahipindy & $\begin{array}{l}\text { Homopteran } \\
\text { secretion }\end{array}$ & & & - & - & Non-rep \\
\hline
\end{tabular}

\section{Sampling diversity and abundance}

In each intersection of the study area plus a buffer area of 50 meters on the northern, eastern and southern limits (i.e. 2 intersections) we sampled for the feeding trees of grey mouse lemurs. We determined a $25 \mathrm{~m}^{2}$ area starting from the center of each intersection towards the northeast as described in (Rakotoniaina et al., 2016). We then counted all adult trees in the area defined for each species on the list. We then obtained a measure of quantity by summing up all trees counted and a diversity score by applying Simpson's diversity index. Vahipindy lianas having a more diffuse nature were estimated according to a scale from 0 to 4, 0 meaning absent, and 4 a predominant coverage of the area. 


\section{Nesting sites}

In order to investigate the possible effects of nest limitation on social strategies, we estimated the density of trees per square based on data collected (Rakotoniaina et al., 2016). Rakotoniaina and colleagues estimated the density of trees in the intersections of our study area and other areas to assess the overall quality of different sites subjected to different anthropogenic disturbances. In their method they used each intersection as the center point and each of the 4 squares converging as a quadrant. Then they calculated the minimum distance to trees with a diameter superior to $10 \mathrm{~cm}$, which have been shown to offer shelter as tree-holes to Microcebus and Cheirogaleus species (Schmid, 1998; Dausmann, 2012). From the four measures obtained they calculated the mean distance, transformed it to area by powering to two and to density of trees by inversing this number. Since the quadrant of origin of the data was explicit, we slightly transformed their data to conform to our measures. Instead of taking the intersection as the center of analyses, we used the square. All distances to trees in quadrants that referred to the same square were taken as our measures for analyzing tree density. For example, the square A01 contained the mean of the distance measures of quadrant Northeast of intersection A01, quadrant Southeast of intersection A02, quadrant Southwest of intersection B02, and quadrant Northwest of intersection B01. We then followed the same procedure to extract the density of trees per area and obtained the estimation of total number of trees per square by multiplying by the total surface of the square.

\section{Resource abundance per individual home range}

To give each individual home range a diversity score, we considered only the fraction of the entire home range falling into the study area. From this fraction we estimated the percentage falling into each square of the study area. This percentage per square was then multiplied by the diversity score of the given square. Thus, we generated a relative value for each part of the home range of a given individual that falls into any measured square. We then summed all relative diversity scores measures obtained per individual to develop a single measure of an individual's home range. The exact same procedure was repeated with the abundance of feeding trees, the Vahipindy and the abundance of nests to generate a value of each variable per each individual's home range.

\section{Feeding trees and nests}

Aiming to reduce the number of variables relating to food resource diversity and abundance and the abundance of nests, we used principal component analyses. We included the diversity score of the home range as well as the abundance score, the Vahipindy score and the abundance of nest score to assess their possible correlation. 


\section{Relating sociality and resource abundance}

In order to understand whether the variation in social strategies described in Chapter 2 is linked with variables relating to the size and the quality of the habitat, we performed a correlation analysis. We included the PC1 of sociality developed in Chapter 2, where higher values indicating highly social individuals, PC1 and PC2 for nest and feeding resource abundance and diversity together with the expected home range size predicted by the Michaelis-Menten models.

\section{d. Statistical analyses and sample size \\ 1. Home ranges}

In order to study home range stability, we used all home ranges without applying model selection. We used this procedure since the sample size of models described adequately for the same individuals in different seasons was limited to 5 individuals, while the database contained 457 individuals recorded in different seasons since 2013. Thus, we used also home ranges that were not optimally described. We tested for the mean overlap between the different home ranges obtained per individual in a pairwise procedure. Importantly, consecutive seasons were excluded from the analyses to avoid possible effects of similar home ranges arising from close dates separated by our subjective division of seasons. This criterion resulted in a sample size of 23 females and 10 males. To define the percentage of overlap between two home ranges of the same individual, the area of overlap was divided by the smallest home range. By doing so we accounted for the possible incompleteness of home range estimation without model selection, which may have resulted in smaller estimated home range sizes. We then compared the means and variances between sexes in the proportion of home range overlap as a measure of home range stability over time.

Similarly, when studying home range overlap between different individuals, all home ranges were used. Using only the best-described home ranges per season would have led to important biases in the estimations of number of overlapping individuals by artificially reducing the number of individuals monitored. Using all home ranges, although our measures might be subjected to error especially due to smaller home ranges than expected, the results might approximate better the real extent of home range overlap.

When linking home range overlap and sociality, only individuals monitored at least 14 days in their social behavior were included in the analyses. Moreover, when comparing the extent of overlap between partners and non-partners, only individuals with partners and non-partners overlapping in their home range were considered in the analyses. Only one data point per individual per condition was introduced in the analyses to equal the contributions of each individual to each sample. When more than one datapoint was 
present, we chose one at random. Comparisons were conducted by the combinations of sex of the focal animal and sex of individuals overlapping with him/her.

\section{Resources}

For each type of season, those trees reported as producing ripe fruits and flowers in that season were considered for stablishing the map of diversity and abundance of feeding trees. Vahipindy was used in both types of seasons since we also observed a Homopteran colony producing sugary exudates during January. When assigning values of resources to each individual home range, the type of season of the home range was matched to the

Table 2. Summary sample size included in the PCA. Individuals included were monitored for at least 14 days and were described successfully with a Michaelis Menten models and model selection.

$\begin{array}{ccc}\text { Season } & \text { Sex } & \text { N } \\ \text { Non-reproductive } & \text { F } & 1 \\ \text { Non-reproductive } & \text { M } & 4 \\ \text { Birth } & \text { F } & 16 \\ \text { Birth } & \text { M } & 7\end{array}$
corresponding map of resources measured for that type of season.

Simpson's diversity index was used to calculate a measure of diversity in feeding resources per square in the study area. The higher the number of species present and the more even the distribution of individuals, the higher the score, 0 representing no diversity, and 1 infinite diversity. The abundance of trees was measured as the sum of all individual trees of the different species consumed by mouse

lemurs counted in each square. When correlating measures, Pearson's product-moment correlation analyses were used.

In order to assess the suitability of our data for factor analyses, we used Barlett's test of sphericity and Kaiser-Mayer-Olkin test for sampling adequacy. All variables were scaled before constructing the principal components, and only principal components with an eigenvalue superior to one were retained for interpretation. Only individuals observed at least 14 times per season and with a home range successfully described with MichaelisMenten models together with our criteria for model selection (see Chapter 3.2) were used for these analyses. We did so to target the data with the highest quality. This resulted in a reduced sample size (Table 2 ).

When comparing paired data, Wilcoxon-Mann-Whitney $U$ test for paired data was used to compare the means and paired $\mathrm{F}$ variance tests for comparing variances. When comparing unpaired data, the equivalent tests for unpaired data were used. When correlating variables, Pearson's product-moment coefficient was used. When conducting multiple correlation analyses, Holm's method was used to correct for increased probability of type-I error. 


\section{Results}

\section{a. Home range size}

The mean expected home range sizes for individuals that their model fulfilled the criteria for model selection ranged between $0.78 \pm 0.40$ during the non-reproductive season and $1.98 \pm 1.96 \mathrm{Ha}$ during the birth season for females (medians 0.79 and 1.48 respectively; $\mathrm{N}=6$ and 45 ). Males had a mean expected home range of $2.33 \pm 1.98$ Ha during the nonreproductive season and $3.9 \pm 4.22$ during the birth season (medians 1.91 and 2.57 respectively; $\mathrm{N}=18$ and 18). Home range size expected differed significantly during the nonreproductive season for males and females but not during the birth season (Nonreproductive: Wilcoxon-Mann-Whitney rank-sum test $w=18, p=0.018, N F=6, N M=18$; Birth: Wilcoxon-Mann-Whitney rank-sum test, $w=361, p>0.1, N F=45, N M=19$; Fig. 3). During both seasons, males had a higher variance than females in $\mathrm{HR}$ size expected significantly ( $\mathrm{F}$ variance test Non-reproductive $F=0.039 p<0.01$; Birth $F=0.216 p<0.0001$ ).

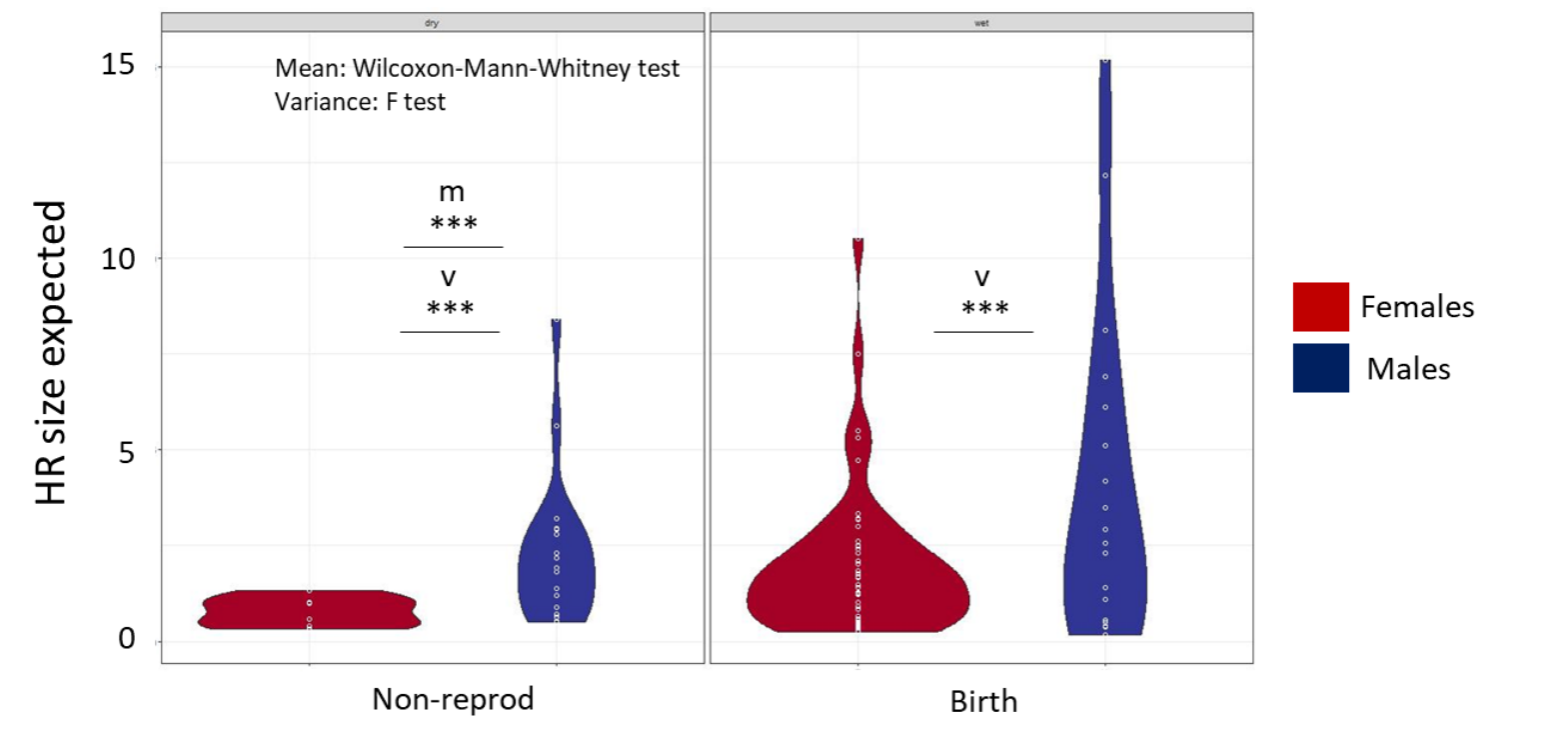

Figure 2. Comparison of home range size expected between sexes within seasons. Violin plot of home range size in $\mathrm{Ha}$ per sex and season. Dots within the distributions represent individual values. " $\mathrm{m}$ " represents mean and " $\mathrm{v}$ " variance comparisons. *indicates significant differences.

\section{b. Home range stability}

The mean home range overlap was above $80 \%$ in both sexes and did not differ significantly (Mean M 0.82 $\pm 0.20, F 0.78 \pm 0.19$, Wilcoxon-Mann-Whitney rank-sum $w=84.5$, test $p>0.1, F$ variance test $\mathrm{F}=0.876, \mathrm{p}>0.1 \mathrm{NF}=28, \mathrm{NM}=16$; Fig. 3). Thus, individuals of both sexes likely used the same area over different seasons. 


\section{c. Home range overlap}

Focal females overlapped with $9.49 \pm 3.61$ other females and 7.19 \pm 2.07 males on average $(\mathrm{N}=122$ and 111 respectively). Focal males overlapped with $9.68 \pm 2.09$ other males and $7.32 \pm 4.92$ females ( $\mathrm{N}=118$ and 119 respectively). Focal females overlapped with other females by an average of $31 \pm 18 \%$ and with males by $37 \pm 19 \%$ (medians $27 \%$ and $37 \%$, $\mathrm{N}=122$ and 111 respectively). Focal males overlapped with other males by $33 \pm 18 \%$ and with females by $24 \pm 15 \%$ (medians 29 and $21 \%, \mathrm{~N}=118$ and 119 respectively). Thus, most male and female dyads overlapped by a third of their home ranges.

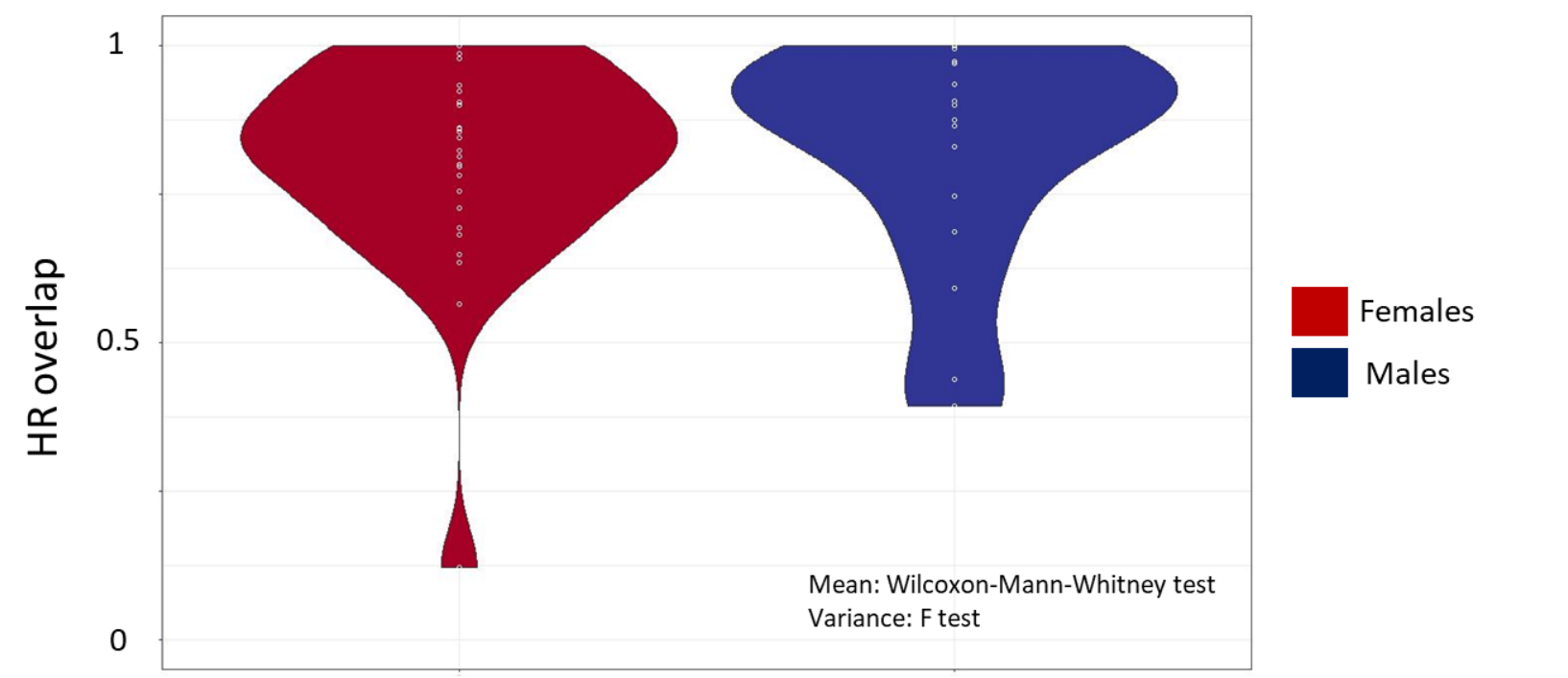

Figure 3. Comparison of home range overlap within individuals over non-consecutive seasons between sexes. Violin plot of home range overlap for each sex as a measure of home range stability. Dots within the distributions represent individual values. " $\mathrm{m}$ " represents mean and " $\mathrm{v}$ " variance comparisons. *indicates

\section{Home range overlap and nest-sharing}

The mean extent of overlap was greater between co-nesting females than non-co-nesting females, and between co-nesting males than non-co-nesting males ( $F$ partners $0.65 \pm 0.73$, non-partners $0.31 \pm 0.32$ Paired Wilcoxon-Mann-Whitney rank-sum test: $v=87, p<0.001, F$ variance test $F=1.05 \mathrm{p}>0.1 ; M$ partners $0.49 \pm 0.31$, non-partners $0.20 \pm 0.22$ Paired Wilcoxon-Mann-Whitney rank-sum test $v=37, p<0.001, F$ variance test $F=0.5 p>0.1 ; N F=38$, $\mathrm{NM}=21$; Fig. 4). Male female partners showed a trend for higher home range overlap than non-partners (partners $0.28 \pm 0.32$, non-partners $0.16 \pm 0.14$ Paired Wilcoxon-Mann-Whitney rank-sum test: $v=1, p=0.06, F$ variance test $F=0.18 p=0.08, N=6)$.

No significant correlation was found between the extent of home range overlap and the strength of a social relationship (Pearson's product-moment correlation F-F $r=0.26 p=0.111$, $M-M r=0.22 p=0.347, M-F r=0.48 p=0.331$ ). Thus, although animals in a relationship had 
higher overlap than non-partners, further variation in the extent of overlap was not related to the strength of the relationship.

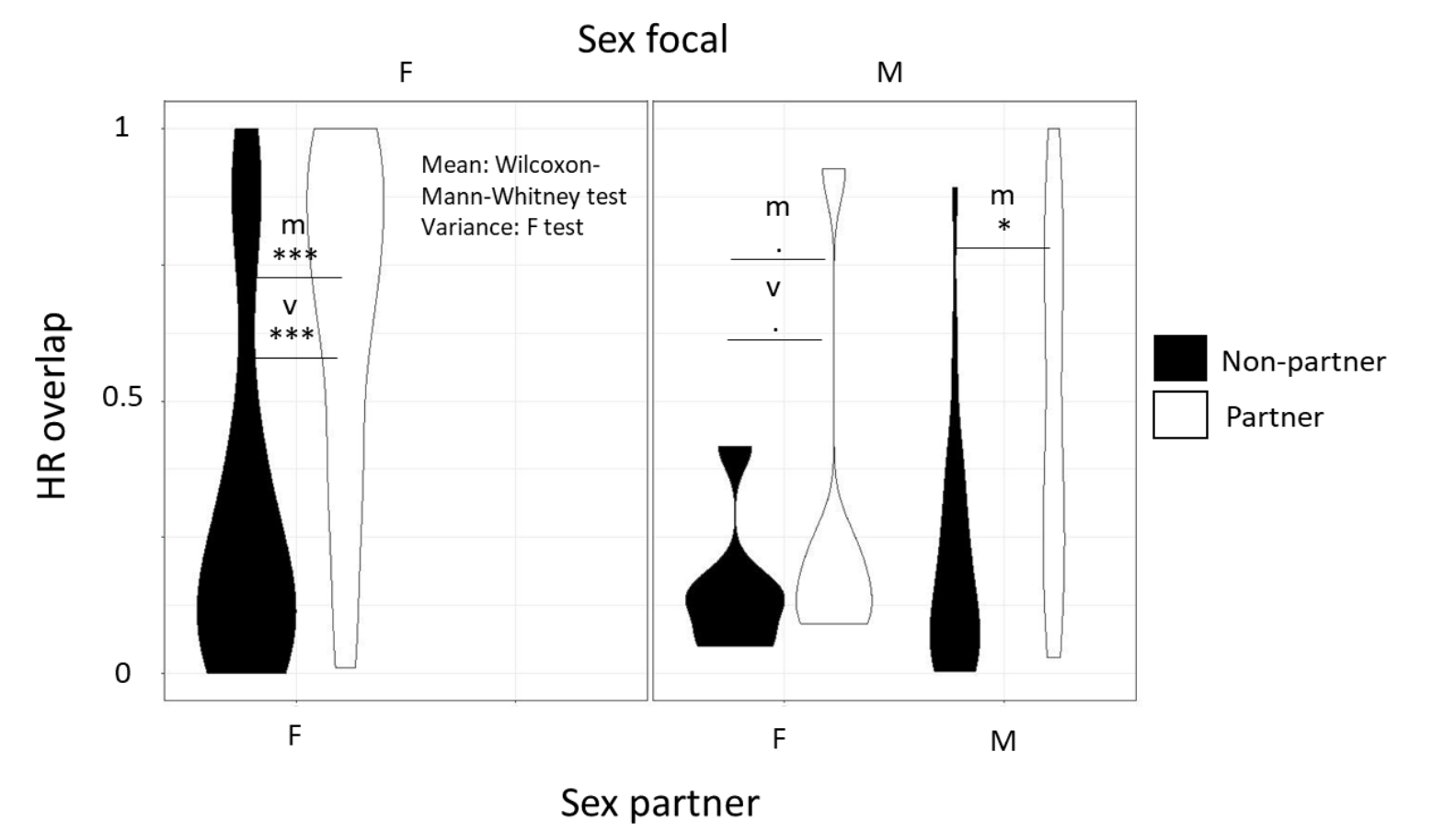

Figure 4. Comparison of home range overlap between nest-sharing and non-nest-sharing individuals. Violin plot of relative home range overlap. The sex of the focal individual divides the graph in two. For each sex then the sex of the given partner further divides the graph. " $\mathrm{m}$ " represents mean and " $v$ " variance comparisons. *indicates significant differences.

\section{d. Resource diversity and abundance}

\section{Sampling diversity and abundance}

In both seasons, the number of trees was slightly positively correlated with the diversity of trees per square (Pearson's product-moment, Birth $t=6.52 \mathrm{r}=0.35 \mathrm{p}<0.001$; Non-rep $\mathrm{t}=6.95$ $r=0.37 p<0.001 ; N=299$ ). Thus, our measures of the spatial distribution of diversity and abundance were not independent in the study area (Fig. 5). 


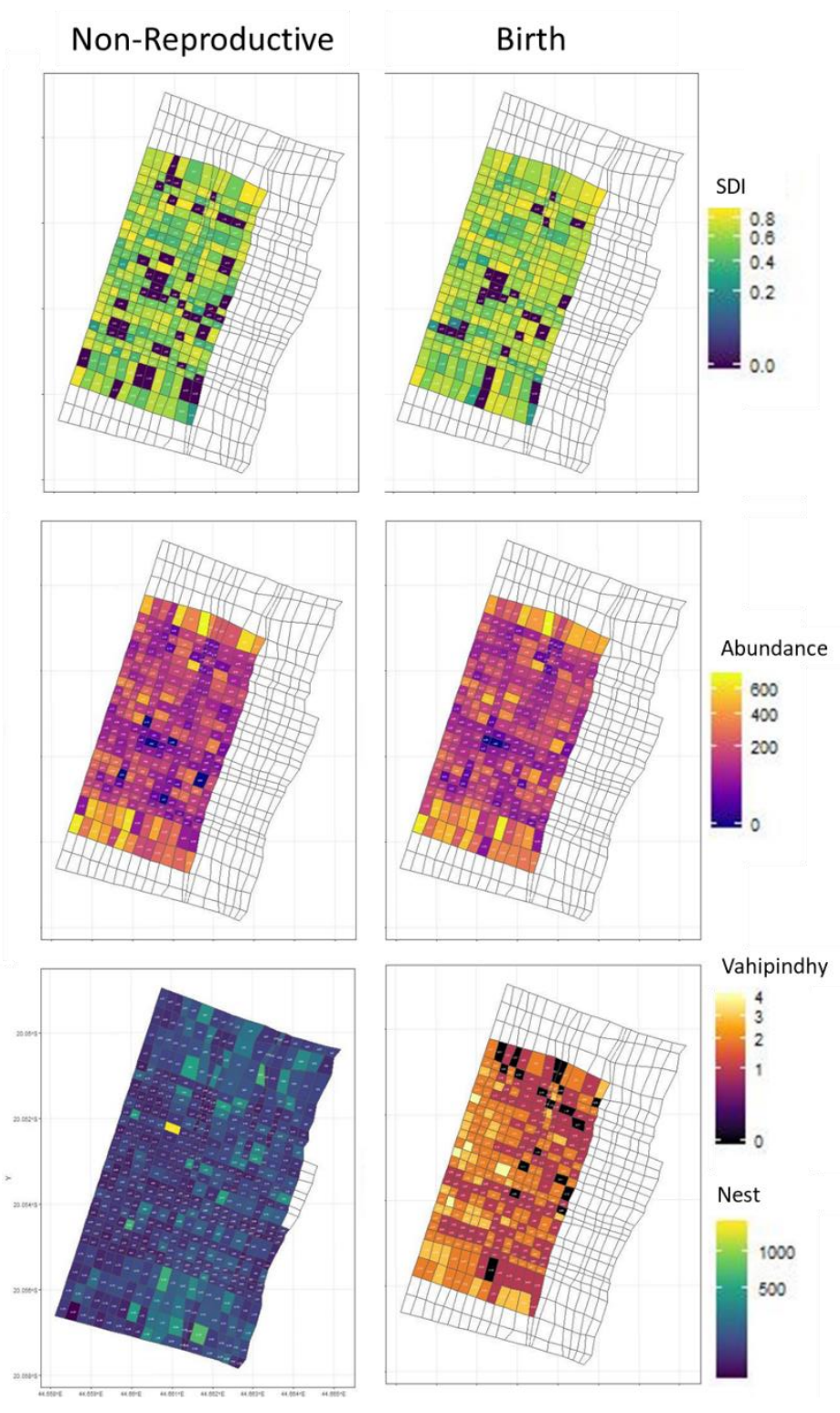

Figure 5. Map of the study area with measures of diversity and abundance per square. Each column represents a season, each line, Simpson's diversity index on feeding trees and abundance of feeding trees respectively from top to bottom. Nest abundance and relative abundance of Vahipindy (lianas) were assumed constant and are shown as unique values in the bottom line. 


\section{Resource abundance per individual home range}

Feeding trees and nests

Barlett's test for sphericity proved statistically significant $(p<0.001)$ indicating enough covariance between our variables while the Kaiser-Mayer-Olkin test of sampling adequacy revealed 0.37, indicating poor sampling adequacy. Only the first and second principal components had an eigenvalue superior to 1 and explained $42.24 \%$ and $32.37 \%$ of the variance respectively (Fig. 6). Diversity encompassed by the home range loaded $-80 \%$ and contributed $37.91 \%$ to the first PC while abundance loaded $92 \%$ and contributed $50.36 \%$ respectively. Thus, the first PC divided individuals across a spectrum from high diversity and low abundance to its contrary (Fig. 6). The Vahipindy abundance loaded positively by $83 \%$ and contributed $53.94 \%$ to explain the second PC. Nest abundance, on the contrary, loaded negatively to the second PC by $-76 \%$ and contributed $44.96 \%$ to explain this PC. Thus, the second PC divided individuals along a continuum from high nest abundance and low Vahipindy to its contrary (Fig. 6). 


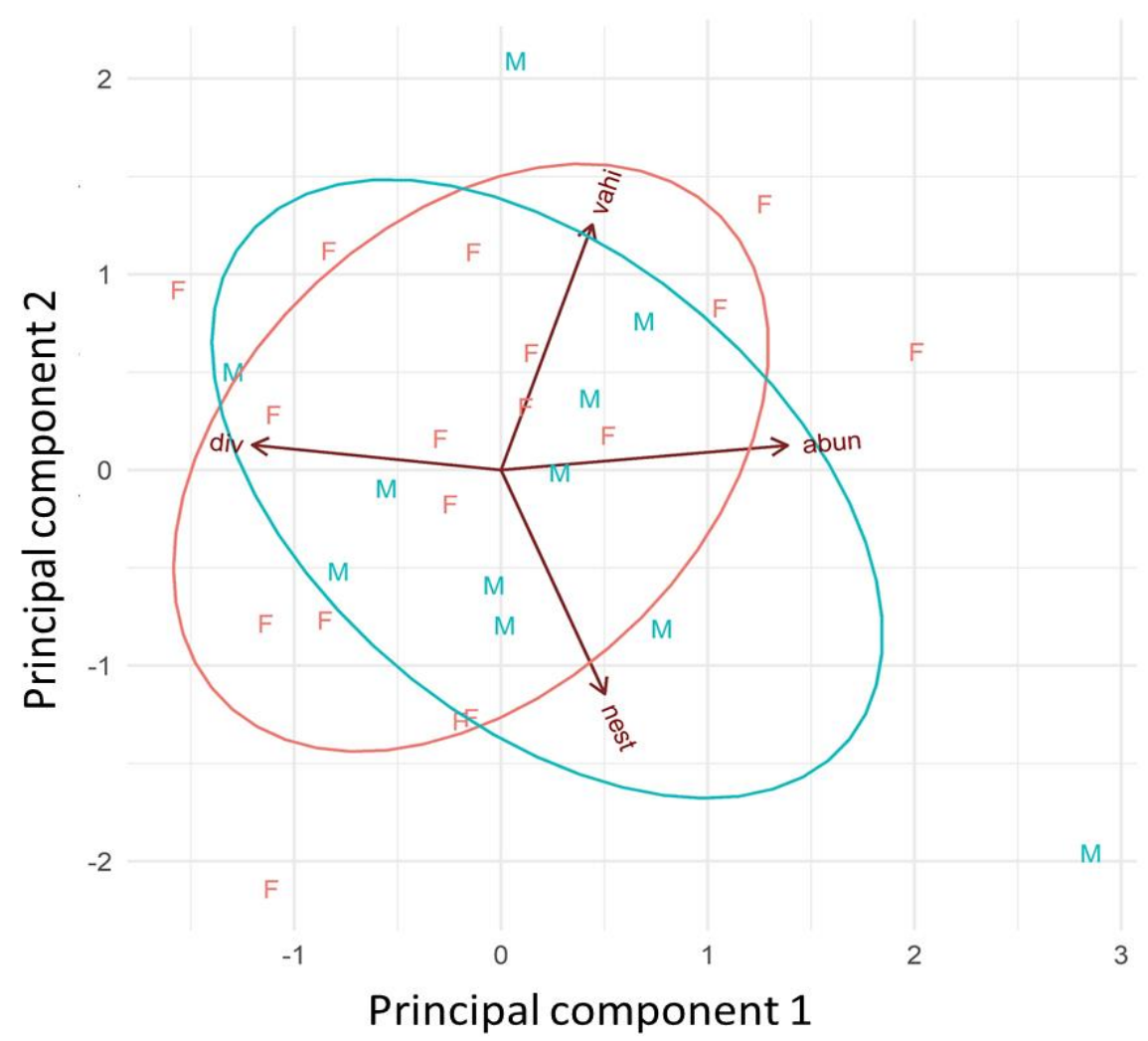

Figure 6. Principal component analysis relating the different measures of resource availability per home range. Principal component 1 explained $42.24 \%$ of the variance while PC2 explained and 32.37\%. "F" codes for Females, "M" for males. "Vahi" codes for the relative amount of Vahipindy (lianas), "abun" the abundance of feeding trees, "div" the Simpson's Diversity Index score for feeding trees and "nest" codes for the abundance of nests.

\section{Relating sociality and resource abundance}

Female variation in the PC1 relating to sociality did not appear to correlate statistically with any of our measures of resource abundance/diversity in terms of food or nesting sites. The extent of the home range correlated negatively with the social PC1 by $-54 \%$ but did not reach significance after Bonferroni's correction (Pearson Product Moment $p=0.02, p^{\prime}=0.14$, $\mathrm{N}=17$, Fig. 7). The predicted extent of the home range correlated $48 \%$ positively with the abundance of nests in the territory and showed a trend for significance that disappeared after Bonferroni's correction $\left(p=0.051, p^{\prime}=0.25\right)$. None of the other relationships exceeded $50 \%$ nor reached significance after Bonferroni's correction. Thus, no relationship was observed between resource abundance nor diversity and sociality in female grey mouse lemurs.

In males, the social PC1 was positively correlated only with the expected home range size by $64 \%$, but the significance disappeared after correcting with Bonferroni's method (Pearson 
Product Moment $p=0.034, p^{\prime}=0.20, N=11$, Fig. 7). None of the other correlations were pronounced nor reached statistical significance. Thus, no relationship between resource or nest abundance and sociality was observed for male mouse lemurs.

Since the tests for the adequacy of the PCA analyses showed mixed evidence with Barlett's test proving significant while Kaiser-Mayer-Olkin test revealed poor sampling adequacy, we decided to run an additional correlation analysis using the raw variables instead of the principal components. None of the variables (diversity, abundance, nest and vahipindy scores) proved significantly correlated with the sociality principal component 1 developed in the previous chapter neither before nor after Bonferroni's correction for any of the sexes. Thus, no relationship between resource or nest abundance and sociality was observed grey mouse lemurs.

\section{Discussion}

Contrary to all the predictions, we found evidence for no relationship between resource abundance and sociality. In either sex, the amount of feeding resources contained nor the expected amount of nesting sites in a given home range related to the social strategy of the individuals

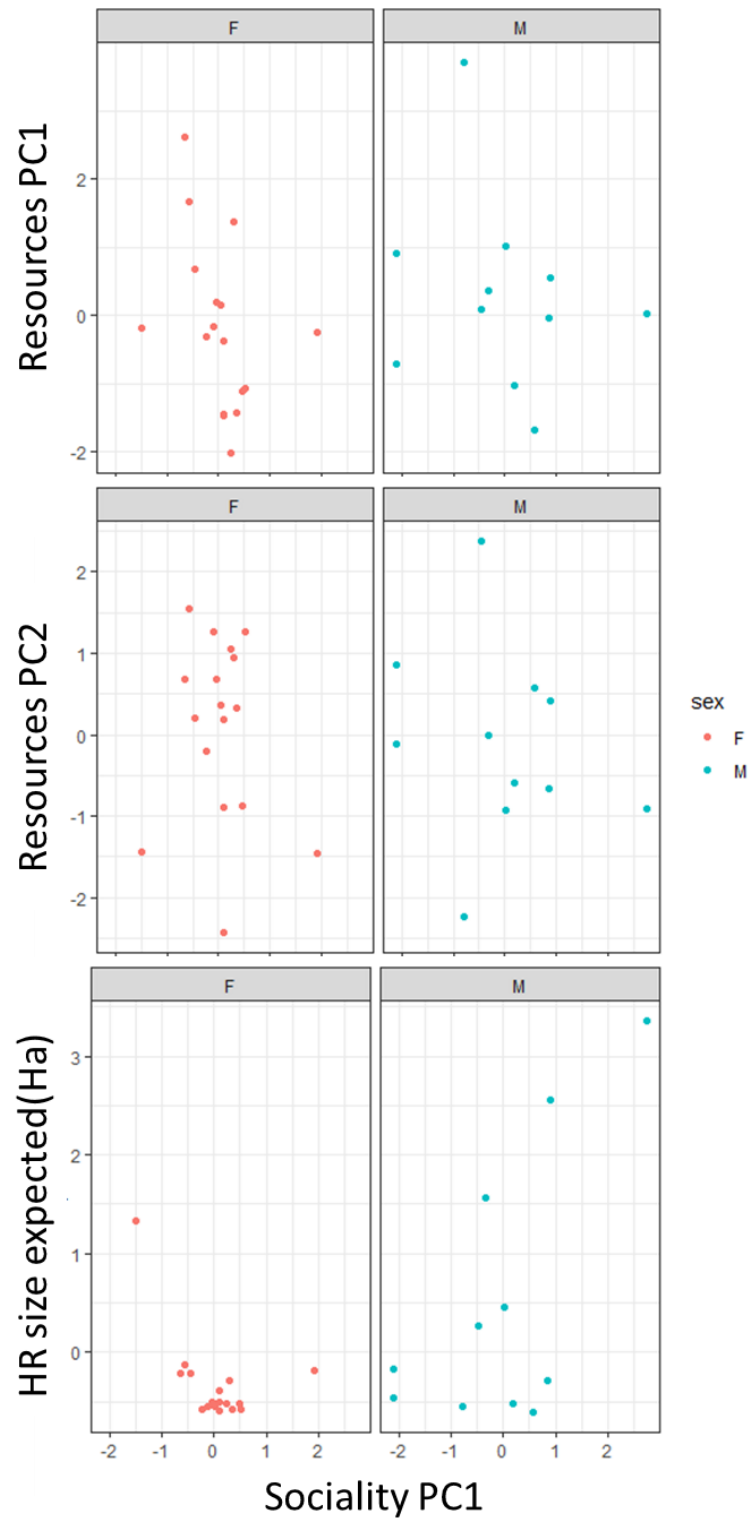

Figure 7. Correlation analyses relating sociality and resources. " $F$ " codes for Females, " $M$ " for males. The horizontal axes show the values for the principal component 1 on sociality. The vertical axes show respectively, the principal components 1 and 2 on resources and the expected homer range size.

inhabiting it. This is counterintuitive given that all hypotheses suggest a relationship between feeding resources and the occurrence and extent of sociality. Moreover, nest abundance should be negatively related to sociality if the benefits of groups include nest defense or if sociality is a response to habitat saturation. 
The absence of a relationship between feeding resources and sociality could occur if sleeping together and sharing feeding resources were decoupled. Our results on contrary, point out a link between social relationships and resource sharing through home range overlap in gray mouse lemurs. In both sexes, the mean percentage of home range overlap was bigger for dyads that shared a nest at least once than for dyads overlapping but not sharing nests. Females that ever shared a nesting site had a skewed median of $73 \%$ overlap. Thus, female mouse lemurs with a social relationship shared extensively their foraging areas with potential for within social unit scramble competition. Males sharing nests had similarly high overlap with a $58 \%$ median. Nevertheless, the distribution of overlap for co-nesting males was more uniform suggesting that associations with males living further apart were as likely. Thus, nest sharing among male partners appeared more independent from resource sharing than among female partners.

Since individuals in social units share foraging areas, the absence of relationship between feeding resources and sociality could be at play if our measures were inadequate. We maximized the accuracy of the data by reducing our effective sample size to individuals sampled at least 14 days for their nest sharing behavior in each season. Moreover, in the analyses relating sociality and resources we used exclusively those individuals for which a home range was optimally described through Michaelis-Menten model implementation on selection.

Females studied in the same area by (Dammhahn and Kappeler, 2009a) using radiotracking and Minimum convex polygon for home range estimation had a median of $0.26 \mathrm{Ha}$. The median obtained in our study with trapping and nest locations with Kernel density estimation at $95 \%$ for establishing home ranges was of $0.7 \mathrm{Ha}$. Since MCP has been shown to lead to 2.3 times lower values than 95 Kde (Halbrook and Petach, 2018), our methodology differences resulted in the expected differences suggesting reliable estimates of home ranges.

Nevertheless, our results on feeding tree abundance and diversity could be impacted by inadequate measures at several levels. Firstly, we measured $25 \mathrm{~m}^{2}$ per square in the study area. The average area of squares is $781 \mathrm{~m}^{2}$. This indicates we sampled $3 \%$ of the study area. Nevertheless, we proceeded as if in the knowledge of the entire surface. A possible increase of 4 times could come by sampling the other three corners of a square leading to a coverage of $12 \%$ of the area. Secondly, when defining the species to study we based our choice on the pioneering work of Dammhahn and Kappeler (2008). Nevertheless, their observations did not cover all year-round and a lack of observations during the months of January and February, the middle of the birth season could have led a part of the diet going unnoticed. This is illustrated by our observation of an undescribed source of food from nectar of the 
flowers of Astrocassine pleurostyloides during January 2018. Nevertheless, Dammhahn and Kappeler (2018) covered the beginning and the end of the Birth season which may be a good indicator of the overall diet. Thirdly, we assumed all adult trees from all species sampled as equally important. However, variation in age and crown size could relate to variation in the amount of fruit produced per tree. Indeed, sampling areas with bigger trees will be characterized as low abundance and low diversity while producing high amounts of fruits. Nevertheless, this effect might be contradicted by the fact that mouse lemurs forage on the lower parts of the canopy and that younger plants have higher productivity. Moreover, young adults might grow in high numbers under higher productive trees leading to high abundance scores in the presence of bigger trees.

Despite these possible errors, our analyses show that we characterized some dimension of resource abundance. We found a negative relationship between the abundance of resources and diversity within home ranges in both sexes. This is striking given that at the square level these two measures were positively correlated. Thus, individuals may adapt their space use to maximize one or the other dimension of resource availability. Abundance could allow for high profit when conditions are adequate but more diverse home ranges could allow for more constant harvesting across seasons and year to year variation. It would be important to test the effects of diversity and abundance of feeding resources on survival of individuals across a gradient of year to year variation in rainfall.

Moreover, throughout our analyses, we may have reduced the variation between individuals in two ways. First, we reduced the amount of data to avoid unbalanced contributions between individuals, which may nevertheless be an indicator of other individuals' characteristics, such as survival capacity. Similarly, using our criteria for model selection we might have centered our analyses on those individuals that managed to monopolize nests and areas effectively. Thus, the losing end on the competition for resources could be going unnoticed. However, as we have shown in Chapter 2 (Discussion), the simultaneous occupation of nests was relatively low. Thus, the coverage of individuals might have been wide enough to account for individuals in different competitive situations. Additionally, we used indexes of diversity and principal components of sociality which although condensing partly redundant information might have reduced variation in the variables analyzed. A possible solution would be to implement mixed-effects models controlling for individual identity. This type of analysis could allow us to gain statistical power and keep the "raw" variation present in the database. Since data collection will continue in the following years, the sample size should increase allowing to test the hypotheses with higher robustness. 
Despite the limitations in our methodology, there are other processes that could account for the present findings. The density of mouse lemurs in our study area is one of the highest recorded (Dammhahn and Kappeler, 2008b). Moreover, M. murinus appears to be nearly absent in the immediate vicinity, which could indicate the presence of high resource abundance within our study area. Individuals could have either no cost at tolerating others or face habitat saturation if in the near vicinity resources are absent. Nevertheless, a previous study on spatial coexistence between $M$. murinus and $M$. berthae indicates that resource abundance in the area is not responsible for the observed high densities. The areas inhabited by $M$. murinus didn't differ from adjacent areas in their abundance of lianas, feeding trees and nest availability (Dammhahn and Kappeler, 2008b), and the authors cite unpublished data indicating no preference of $M$. murinus for any specific microhabitat. Thus, Dammhahn and Kappeler (2008b) proposed that the life-history of M. murinus with female philopatry explains the occurrence of clusters with high densities. This implies that benefits of philopatry alone, which have been demonstrated in other populations in the form of increased survival of young females (Lutermann et al., 2006), and not resource distribution drive sociality in female mouse lemurs. Future tests on the benefits in reproductive success and survival of both males and females are needed to test this hypothesis. If proven true, this would suggest that contrary to other small mammal species with social flexibility (e.g. Wolff, 1994; Lucia et al., 2008; Schradin et al., 2012), population density is not the main driver of sociality. Such absence of a role for population density is further supported by comparative research on other mouse lemur species (summarized in the Introduction of Chapter 2, Table 1).

Constrains on female variation in sociality might also relate to an absence of effects of feeding resources. During the lactation period, females might be limited in the number of partners due to the litter requirements for space and low parasite load, as well as a need for increased heat dissipation (see chapter 2). Moreover, competition for nesting sites might ensue from limitations on group size even between units that descend from the same matriline. Thus, females might be unable to profit from the local abundance of resources to generate larger group sizes, while the benefits of survival might also reduce solitary strategies (Lutermann et al., 2006).

Importantly, the strength of the social relationships was not correlated with the strength of home range overlap in both sexes. Thus, further variation in the spatial repartition of individuals was at play within social units that defined the extent of within-group competition for resources. Survival benefits generate the spatial clustering between females and probably nest sharing for both sexes, thus, forcing resource sharing within units. Thus, the presence of further variation in spatial repartition of individuals within units could indicate a mechanism to deal with the costs of enforced sociality. Our analyses trying 
to correlate the extent of sociality with the presence of resources in a given home range could have failed to show an effect due to between unit scramble competition. Females overlapped on average with other 9 females and 7 males. Since the mean number of female partners varied between 4 during the non-reproductive season and 2 during the birth season (see chapter 2), this indicates that overlaps between social units occurred extensively. Thus, further tests should evaluate the possible covariance in competition between and within social units in extent of overlap as well as the effects of total level of competition in a given area on the mean group size and the number of partners.

To do so, an important further step would be to take into account all overlapping home ranges at the same time. In this sense, one could calculate which percentage of the home range is shared with nobody, another individual, two other individuals, up to the maximum number corresponding to the area where most individuals overlap. This could reveal the intensity of competition within each part of a home range. This approach could give a more accurate indication of the strength of competition for resources within any given home range. One could test whether the overall competition leveraged by the resource abundance relates to sociality. Furthermore, it would be important to know if the most frequented parts of the home range by all members of a unit are those containing more resources, which could then reveal more subtle forms of monopolization. Since females have been shown to interact agonistically more often with non-partners (Dammhahn and Kappeler, 2009b), the areas frequented by most individuals from a sleeping group might be frequented by individuals in other units with an increased cost of aggression. These individuals although encountering the resident matriline on a one by one basis would suffer from increased number of aggressive encounters. Thus, there is potential for both betweengroup scramble competition, and between-group dispersed contest competition. By now our analyses suggest that competition is determined through an overall scramble competition between adults in a given area.

Alternatively, the benefits of grouping could concern the monopolization of high-quality nesting sites by females (Dammhahn and Kappeler, 2009b). Our results show that the estimated density of nesting sites does not relate to sociality. Nevertheless, we derived our measures from small sampling areas ( $3 \%$ of the study area) that could fail to relate to the presence of less abundant high-quality nests, preferred by females, that might occur in specific emplacements. Nevertheless, density of trees and presence of high-quality nests should be positively correlated indicating that this is not the reason for the absence of results. Moreover, further nests characteristics might be as important in the decision to occupy them. Familiarity with an area and inheritance from generation to generation of a network of nests covering a foraging area could endorse individuals with a "knowledge" on 
their safety and adequacy. In animals with such high level of predation and diversity of predators, knowledge of the environment and especially of safe emplacements might be extremely important for survival (Lutermann et al., 2006). It would be interesting to observe whether young immigrating males follow a learning strategy from other more experienced males in the area. This could offer a mechanism for the knitting of social relationships between males, which similarly to those of females last over several seasons (chapter 2). Although previous work has shown nest reuse by females, it is not known whether males follow the same strategy. Given the similarities found between sexes, further analyses should test the existence of nest fidelity. The fact that artificial nests were readily accepted by a large number of individuals indicates that there might be indeed a high level of competition for nesting sites between females and males alike and that individuals are able to adopt new nesting sites. Similarly to our analyses concerning feeding trees, the assessment of nest limitation and competition would benefit from adopting a more holistic approach taking into account all individual home ranges and their overlap at the same time. This could help reveal whether local competition relative to the abundance of resources determines individual sociality.

Overall, other mechanisms could allow individuals to deal with the costs of sociality. For example, reducing food intake to allow others to inhabit the same territory could be beneficial in the face of between-group competition for nests and other group benefits such as increased thermoregulation and communal care. Thus, individuals, through varying their

extent of overlap as well as their intake, could balance the costs and benefits of being social. Generalized linear mixed models taking into account all the mentioned variables to predict the extent of social unit size would be required to understand the multifaceted phenomenon of sociality in gray mouse lemurs.

\section{References}

Agnani, P., Kauffmann, C., Hayes, L. D., and Schradin, C. (2018). Intra-specific variation in social organization of Strepsirrhines. American Journal of Primatology 80, e22758. doi:10.1002/ajp.22758.

Breed, M. D., and Moore, J. (2016). "Chapter 9 - Foraging," in Animal Behavior (Second Edition), eds. M. D. Breed and J. Moore (San Diego: Academic Press), 293-323. doi:10.1016/B978-0-12-801532-2.00009-X.

Carpenter, F. L. (1987). Food abundance and territoriality: to defend or not to defend? American Zoologist 27, 387-399.

Carter, G. G., Farine, D. R., and Wilkinson, G. S. (2017). Social bet-hedging in vampire bats. Biology Letters 13, 20170112. doi:10.1098/rsbl.2017.0112. 
Colman, R. J., Beasley, T. M., Kemnitz, J. W., Johnson, S. C., Weindruch, R., and Anderson, R. M. (2014). Caloric restriction reduces age-related and all-cause mortality in rhesus monkeys. Nat Commun 5, 1-5. doi:10.1038/ncomms4557.

Corbin, G. D., and Schmid, J. (1995). Insect secretions determine habitat use patterns by a female lesser mouse lemur (Microcebus murinus). American Journal of Primatology 37, 317-324. doi:10.1002/ajp.1350370406.

Craig, J. L. (1984). Are communal pukeko caught in the prisoner's dilemma? Behavioral Ecology and Sociobiology 14, 147-150.

Dammhahn, M., and Kappeler, P. M. (2008a). Comparative feeding ecology of sympatric Microcebus berthae and M. murinus. International Journal of Primatology 29, 1567.

Dammhahn, M., and Kappeler, P. M. (2008b). Small-scale coexistence of two mouse lemur species (Microcebus berthae and M. murinus) within a homogeneous competitive environment. Oecologia 157, 473-483. doi:10.1007/s00442-008-1079-x.

Dammhahn, M., and Kappeler, P. M. (2009a). Females go where the food is: does the socioecological model explain variation in social organisation of solitary foragers? Behav Ecol Sociobiol 63, 939. doi:10.1007/s00265-009-0737-2.

Dammhahn, M., and Kappeler, P. M. (2009b). Females go where the food is: does the socioecological model explain variation in social organisation of solitary foragers? Behavioral Ecology and Sociobiology 63, 939.

Dausmann, K. H. (2012). "Spoilt for choice: Selection of hibernacula by Cheirogaleus medius," in Leaping Ahead, eds. J. Masters, M. Gamba, and F. Génin (New York: Springer), 205-214.

Eberle, M., and Kappeler, P. M. (2002). Mouse lemurs in space and time: a test of the socioecological model. Behav Ecol Sociobiol 51, 131-139. doi:10.1007/s002650100409.

Eberle, M., and Kappeler, P. M. (2004). Sex in the dark: determinants and consequences of mixed male mating tactics in Microcebus murinus, a small solitary nocturnal primate. Behav Ecol Sociobiol 57, 77-90. doi:10.1007/s00265-004-0826-1.

Eberle, M., and Kappeler, P. M. (2006). Family insurance: kin selection and cooperative breeding in a solitary primate (Microcebus murinus). Behavioral Ecology and Sociobiology 60, 582-588.

Eberle, M., and Kappeler, P. M. (2008). Mutualism, reciprocity, or kin selection? Cooperative rescue of a conspecific from a boa in a nocturnal solitary forager the gray mouse lemur. American Journal of Primatology 70, 410-414. doi:10.1002/ajp.20496. 
Eldakar, O. T., and Wilson, D. S. (2011). Eight Criticisms Not to Make About Group Selection. Evolution 65, 1523-1526. doi:10.1111/j.1558-5646.2011.01290.x.

Emlen, S. T., and Oring, L. W. (1977). Ecology, sexual selection, and the evolution of mating systems. Science 197, 215-223. doi:10.1126/science.327542.

Halbrook, R. S., and Petach, M. (2018). Estimated mink home ranges using various homerange estimators. Wildlife Society Bulletin 42, 656-666. doi:10.1002/wsb.924.

Hladik, C. M., Charles-Dominique, P., and Petter, J.-J. (1980). Feeding Strategies of Five Nocturnal Prosimians in the Dry Forest of the West Coast of Madagascar.

Kennedy, P., Higginson, A. D., Radford, A. N., and Sumner, S. (2018). Altruism in a volatile world. Nature 555, 359.

Kessler, S. E., Radespiel, U., Nash, L. T., Zimmermann, E., Lehman, S. M., Radespiel, U., et al. (2016). Modeling the origins of primate sociality: social flexibility and kinship in mouse lemurs (Microcebus spp.). The dwarf and mouse lemurs of Madagascar: biology, behavior and conservation biogeography of the Cheirogaleidae, 422-445.

Koenig, A. (2002). Competition for Resources and Its Behavioral Consequences Among Female Primates. International Journal of Primatology 23, 759-783. doi:10.1023/A:1015524931226.

Koenig, A., Scarry, C. J., Wheeler, B. C., and Borries, C. (2013). Variation in grouping patterns, mating systems and social structure: what socio-ecological models attempt to explain. Philosophical Transactions of the Royal Society B: Biological Sciences 368, 20120348. doi:10.1098/rstb.2012.0348.

Koubova, J., and Guarente, L. (2003). How does calorie restriction work? Genes Dev. 17, 313-321. doi:10.1101/gad.1052903.

Lucia, K. E., Keane, B., Hayes, L. D., Lin, Y. K., Schaefer, R. L., and Solomon, N. G. (2008). Philopatry in prairie voles: an evaluation of the habitat saturation hypothesis. Behavioral Ecology 19, 774-783.

Lutermann, H., Schmelting, B., Radespiel, U., Ehresmann, P., and Zimmermann, E. (2006). The role of survival for the evolution of female philopatry in a solitary forager, the grey mouse lemur (Microcebus murinus). Proc Biol Sci 273, 2527-2533. doi:10.1098/rspb.2006.3603.

Lutermann, H., Verburgt, L., and Rendigs, A. (2010). Resting and nesting in a small mammal: sleeping sites as a limiting resource for female grey mouse lemurs. Animal Behaviour 79, 1211-1219. doi:10.1016/j.anbehav.2010.02.017. 
Macdonald, D. W., and Johnson, D. D. P. (2015). Patchwork planet: the resource dispersion hypothesis, society, and the ecology of life. Journal of Zoology 295, 75-107.

Maher, C. R., and Lott, D. F. (2000). A Review of Ecological Determinants of Territoriality within Vertebrate Species. amid 143, 1-29. doi:10.1674/00030031(2000)143[0001:AROEDO]2.0.CO;2.

Nowak, M. A. (2006). Five Rules for the Evolution of Cooperation. Science 314, 1560-1563. doi:10.1126/science.1133755.

Rakotoniaina, J. H., Kappeler, P. M., Ravoniarimbinina, P., Pechouskova, E., Hämäläinen, A. M., Grass, J., et al. (2016). Does habitat disturbance affect stress, body condition and parasitism in two sympatric lemurs? Conserv Physiol 4. doi:10.1093/conphys/cow034.

Rattan, S. I. S. (2006). Theories of biological aging: Genes, proteins, and free radicals. Free Radical Research 40, 1230-1238. doi:10.1080/10715760600911303.

Schmid, J. (1998). Tree Holes Used for Resting by Gray Mouse Lemurs (Microcebus murinus) in Madagascar: Insulation Capacities and Energetic Consequences. International Journal of Primatology 19, 797-809. doi:10.1023/A:1020389228665.

Schradin, C., Lindholm, A. K., Johannesen, J., Schoepf, I., Yuen, C.-H., König, B., et al. (2012). Social flexibility and social evolution in mammals: a case study of the African striped mouse (Rhabdomys pumilio). Mol. Ecol. 21, 541-553. doi:10.1111/j.1365294X.2011.05256.x.

Schülke, O., and Ostner, J. (2005). Big times for dwarfs: Social organization, sexual selection, and cooperation in the Cheirogaleidae. Evolutionary Anthropology: Issues, News, and Reviews 14, 170-185. doi:10.1002/evan.20081.

Secor, S. M. (2009). Specific dynamic action: a review of the postprandial metabolic response. J Comp Physiol B 179, 1-56. doi:10.1007/s00360-008-0283-7.

Sheehan, M. J., Botero, C. A., Hendry, T. A., Sedio, B. E., Jandt, J. M., Weiner, S., et al. (2015). Different axes of environmental variation explain the presence vs. extent of cooperative nest founding associations in Polistes paper wasps. Ecology letters 18, 1057-1067.

Socias-Martínez, L., and Kappeler, P. M. (2019). Catalyzing Transitions to Sociality: Ecology Builds on Parental Care. Front. Ecol. Evol. 7. doi:10.3389/fevo.2019.00160.

Speakman, J. R., and Król, E. (2005). Limits to sustained energy intake IX: a review of hypotheses. J Comp Physiol B 175, 375-394. doi:10.1007/s00360-005-0013-3. 
Thierry, B. (2008). Primate socioecology, the lost dream of ecological determinism. Evolutionary Anthropology: Issues, News, and Reviews: Issues, News, and Reviews 17, 93-96.

Webster, A. J. F. (1980). "Energy costs of digestion and metabolism in the gut," in Digestive Physiology and Metabolism in Ruminants: Proceedings of the 5th International Symposium on Ruminant Physiology, held at Clermont - Ferrand, on 3rd-7th September, 1979, eds. Y. Ruckebusch and P. Thivend (Dordrecht: Springer Netherlands), 469-484. doi:10.1007/978-94-011-8067-2_22.

Wenzel, J. W., and Pickering, J. (1991). Cooperative foraging, productivity, and the central limit theorem. Proceedings of the National Academy of Sciences 88, 36-38.

West, S. A., Griffin, A. S., and Gardner, A. (2007). Social semantics: altruism, cooperation, mutualism, strong reciprocity and group selection. Journal of Evolutionary Biology 20, 415-432. doi:10.1111/j.1420-9101.2006.01258.x.

Wolff, J. O. (1993). Why Are Female Small Mammals Territorial? Oikos 68, 364-370. doi:10.2307/3544853.

Wolff, J. O. (1994). Reproductive success of solitarily and communally nesting white-footed mice and deer mice. Behavioral Ecology 5, 206-209.

Wrangham, R. W. (1980). An ecological model of female-bonded primate groups. Behaviour 75, 262-300.

Wynne-Edwards, V. C. (2017). "Intergroup selection in the evolution of social systems," in Group selection (Routledge), 93-104. 


\section{Chapter 3.2: Michaelis-Menten modeling applied to Home Range analyses}

Socias-Martínez L., Peckre L. R.

Author contributions: LS-M: original idea and data analyses. LRP and LS-M: design of the study and writing of the manuscript.

\section{Introduction}

Home ranges have been defined as "...the area traversed by the individual in its normal activities of food gathering, mating, and caring for young" (Burt, 1943). In this sense, home ranges describe the species distribution in space and time. Improving tools for describing animals' home ranges accurately is key to achieve comprehension on important processes for species adaptation such as intensity of resource use, gene flow, mating systems and social interactions as well as the spread of information and diseases (Mueller \& Fagan, 2008; Nathan et al., 2008; Schick et al., 2008). Furthermore, applied knowledge for conservation of endangered species is designed based on empirical measures of space use (Law \& Dickman, 1998; Macdonald, 2016).

The correct estimation of home ranges is predated by a multitude of mismatches between the assumptions of the methods used for calculating animals' space use and the nature of the data collected (Fleming, Noonan, Medici, \& Calabrese, 2019; Powell \& Mitchell, 2012; Wszola, Simonsen, Corral, Chizinski, \& Fontaine, 2019). During the last 40 years, an extensive body of literature has arisen from trying to quantify and correct biases arising from the methods used. Several important areas of development included improving the methods for home range estimation (e.g. Minimum convex polygon, Kernel density estimation, Low convex hull) as well as the interaction with the nature of the data collected (e.g. sample size, time between measurements) (Fleming \& Calabrese, 2017; Fleming et al., 2019; Worton, 1989). Other spatial and temporal heterogeneities affecting home range estimation have been addressed as well (e.g. ecotypes, physical boundaries like rivers, capacity for travel given body size) (Halbrook \& Petach, 2018; Wszola et al., 2019). The methods available today are extremely sophisticated and may even allow accounting for limitations like small sample size in location information (Fleming et al., 2019) which is a general limitation of most home range studies (Noonan et al. 2019 in prep).

An important underlying assumption of most home range studies is that animals exhibit site fidelity (e.g. Ebersole, 1980; Halbrook \& Petach, 2018; Heupel, Simpfendorfer, \& Hueter, 2004; Powell, Zimmerman, \& Seaman, 1997; Reid \& Weatherhead, 1988; Spencer, 
Cameron, \& Swihart, 1990). While measures of site fidelity have been used in the past to tests against a null hypothesis of random movements (De Solla, Bonduriansky, \& Brooks, 1999; Kernohan, Gitzen, \& Millspaugh, 2001; Munger, 1984; Otis \& White, 1999), less concern is devoted to a necessary consequence of assuming site fidelity. If animals exhibit site fidelity, the information on the home range should follow a saturation curve if enough information has been gathered for a given individual. If such asymptote is reached, an adequate measure of the "real" home range may have been approximated. Thus, it is crucial when defining animal home ranges to test whether this asymptote has been reached for each individual included in the analyses (e.g. Harris et al., 1990; Wszola et al., 2019). Without evaluating the presence of this asymptote, there is no assessment of individuals for whom enough information has been gathered and therefore biased estimations of home range for subsequent hypothesis testing or decision making may ensue. In this sense, surprisingly, most studies do not report on the presence of asymptotes (reviewed in Laver \& Kelly, 2008).

Other studies address the issue of asymptotes but using visual inspection of plots representing the saturating process for a given individual or by assessing if home range size reached a point where adding new observations lead to a change inferior to $5 \%$ (Laver \& Kelly, 2008; Wszola et al., 2019). Visually assessing asymptotes gives much weight to the biases and the subjectivity of the observer and is virtually impossible when dealing with big sample sizes, which are required for inferring general patterns of species space use. On the other hand, using the $<5 \%$ rule does not control for the dependence of this measure on single observations. For example, while one last observation may induce a $<5 \%$ change in home range size in a hypothetical study and trigger an asymptote identification, it could be that the animal just made a shorter movement or returned to a previous location before continuing to explore its environment. If the data collection stopped at that point, one would conclude erroneously on the presence and value of the asymptotic home range size.

More generally, fixed rules for determining home ranges are unsuited when considering inter-individual variation in the way animals use space. Some animals may use shorter paths to go to similar places, differ in the size of their territory and the ways of patrolling them. Thus, fixed rules may not allow capturing such variation in space use. However, this interindividual variation may result in fitness variation and is therefore pivotal for understanding evolutionary trajectories relating to other processes and trade-offs with other phenotypic variation. Other sources of variation between individuals arise from the process of data collection. For example, many studies of space use from which knowledge on mating systems and other important social variables are derived, build on capture-recapture settings (e.g. Eberle \& Kappeler, 2004). In this type of studies, enormous variation in the 
information obtained per individual may arise because individuals are the ultimate decisionmakers on their trappings.

The application of Michaelis-Menten models to home range analyses can come to fill the current gap by taking into account 1) individual variation in data collection and 2) idiosyncrasy in space use. These models are flexible enough to be used to evaluate the amount of information obtained for each individual in species presumed to have stable home ranges or to test altogether for the existence of such stability in space usage.

Since its original formulation to describe the relationship between speed of a chemical reaction as a function of the concentration of a given substrate (Michaelis \& Menten, 1913), Michaelis-Menten models have been widely used in various scientific fields to describe saturating processes (Fig 1.). The basic structure of the model allows the calculation of the expected value towards which a system tends to, i.e. the asymptote. The saturation in home range information can be conceived analogously in the framework of MichaelisMenten models. Each new observation brings information about an individual's space use, but the importance of these new contributions decreases over time. That is to say, after a given sampling effort, the home range has been defined, and new locations only offer redundant information on the space use of this animal. The shape of the saturation curve might differ for each individual depending on the area the animal uses and how this animal uses it over time. Using current computation in combination with the flexibility of Michaelis-Menten models can allow taking individual idiosyncrasy into account.

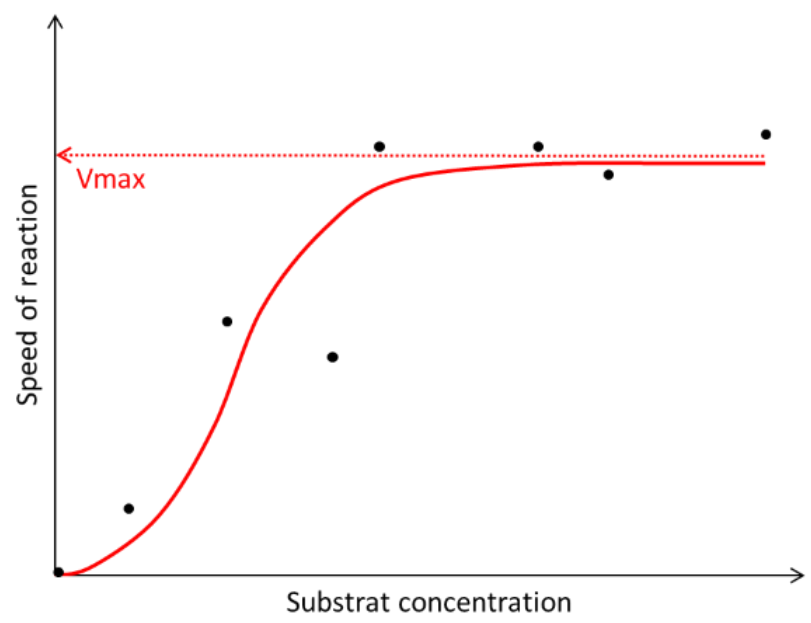

Figure 1. Michaelis-Menten equation predicting reaction velocity as a function of substrate concentration

In the last decade, a handful of studies have applied Michaelis-Menten models to wildlife space use to estimate the size of home ranges (Halbrook \& Petach, 2018; Soanes, Arnould, Dodd, Sumner, \& Green, 2013; Soanes et al., 2015; Warwick-Evans et al., 2016). The majority of these studies were conducted in marine bird species to elucidate the area used by these birds for foraging. Relocations from all individuals were pooled together to derive measures of the species home range, with potential implications for the establishment of protected zones. Halbrook and Petach (2018), on the contrary, used Michaelis-Menten models on an individual basis to assess the asymptote, i.e. the expected home range of 
minks (Neovison vison). In their article which served as inspiration for the present work, they used the flexibility of Michaelis-Menten models to compare traditional home range estimators with a new proposed measure the Ecological Home Range (HER). This new method is informed about habitat characteristics known to be important for the species studied and may, therefore, estimate more reliably the "real" home range. Shifting away from the meaningfulness of an area for animals is an important limitation of current broadly applied methods as pointed out by Powell and Mitchell (2012).

Nevertheless, to our knowledge, the above-mentioned studies lack a set of measures to evaluate the performance of the Michaelis-Menten models fitted to the data. It is necessary to capture 1) how good the model describes if at all the saturation process for determining the home range and 2) the reliability of the measures obtained. Here we offer a guide for the application of Michaelis-Menten models and selection based on three criteria. Our criteria are built upon three statistical measures that capture the reliability of the model estimations: goodness of fit, model stability and the confidence interval of the estimated values. Our methodology has the potential for being applied to studies with big sample sizes in an automated manner. To illustrate our approach, we use location data from trapping events of Grey mouse lemurs (Microcebus murinus) from a natural population in western Madagascar collected from 2013 to 2018. We provide the R code used for these analyses.

\section{Material and Methods}

\section{a. Study area and species}

A field station for scientific research hold by the Deutsches Primatenzentrum $\mathrm{GmbH}$ is active since 1994 in Kirindy forest, Western Madagascar. Capture procedures are embedded in a long-term research agenda investigating various socio-ecological aspects of several vertebrate and invertebrate species inhabiting the dry deciduous forest of Kirindy. The study area from which the present data was obtained ("N5"), has an approximate surface of 50 Hectares. It is traversed by a grid system with intersections every 25 meters allowing for orientation and establishment of regular sampling locations for trapping individuals.

Grey mouse lemurs are small Strepsirrhine primates $(60 \mathrm{~g})$ with a repartition area covering most of the western coast of Madagascar. Microcebus murinus forage at night solitarily and have a generalist diet based on fruits, gum, and insects (Dammhahn \& Kappeler, 2008). This species shows territorial behavior with stable home ranges, nevertheless overlapping extensively (Eberle \& Kappeler, 2002; Fietz, 1999; Radespiel, 2000). Importantly, the dense nature of the forest in all the study area avoid potential sources of variation in terms of different capture probabilities depending on the location of the trap (Wszola et al., 2019). 


\section{b. Capture procedure}

Since 2004, each month, a series of three capture nights were conducted. For the present article, only data from 2013 to 2019 is used. Sherman traps (180 to 210 units) baited with small banana pieces were set at the intersections of the grid system ( $25 \mathrm{~m}$ interval). Traps were set at down and recovered before dusk. This procedure was interrupted at two periods each year corresponding to the mating (mid-October- mid-November) and pregnancy-rearing season (December-April) to avoid interfering with the species reproductive activities. We also excluded all relocations of males around the mating period, from October and November. In the time surrounding the mating season, past research in Kirindy forest has shown that males increase their home range up to five times in order to search for receptive females (Eberle \& Kappeler, 2004b). Thus, we explicitly avoided information on this periodical increase to focus on the year-round home ranges.

Captured individuals were brought to the nearby DPZ research station $(2 \mathrm{~km})$. Each individual was identified with a subdermal transponder the day of its first capture. Measures on body condition and morphology as well as the GPS location of the trapping emplacement were recorded each time an individual was captured. All animals were released at down the day following the capture, and the procedure was repeated for 3 consecutive days.

On some occasions, individuals were observed to reenter a trap just after being released from a previous trapping session, attracted by the new baiting. To avoid misleading information based on such relocations, consecutive day locations in the same emplacement for a given individual were excluded from the analyses. Previous assessments of Grey mouse lemurs home ranges based on the overnight following of radio-collared individuals have shown their high mobility (Schliehe-Diecks, Eberle, \& Kappeler, 2012). Grey mouse lemurs are able to traverse their entire home range in the course of a night. Hence, we then assumed independence of our data points and our effective sample size equivalent to the number of locations (Fleming \& Calabrese, 2017; Rooney, Wolfe, \& Hayden, 1998). Only individuals that were captured in a minimum of 4 different locations were used for home range analyses.

We considered as key information variables for home range analyses 1) the number of observations, 2) the number of different locations and 3) the period of observation between the first and the last observation per individual. The mean values on these information variables per individual contained in the capture database are summarized in the first row of table 1 under the subset label "all" and depicted in Fig. 2. 
Table 1. Mean and standard deviation values of our key variables for the different subsets of the population.

\begin{tabular}{|c|c|c|c|c|c|c|c|}
\hline subset & $\mathbf{N}$ & m.nbobs & sd.nbobs & m.difloc & sd.difloc & m.days & sd.days \\
\hline all & 923 & 3.98 & 4.07 & 3.13 & 2.75 & 203.69 & 335.66 \\
\hline $\begin{array}{c}\text { Homerange } \\
\text { (subset 1) }\end{array}$ & 285 & 8.56 & 4.49 & 6.37 & 2.81 & 442.78 & 423.75 \\
\hline $\begin{array}{c}\text { noMMmodel } \\
\text { (subset 2) }\end{array}$ & 142 & 7.62 & 3.94 & 5.97 & 2.57 & 399.69 & 388.75 \\
\hline $\begin{array}{l}\text { MMmodel } \\
\text { (subset 3) }\end{array}$ & 143 & 9.50 & 4.80 & 6.77 & 2.97 & 485.56 & 453.17 \\
\hline $\begin{array}{c}\text { nobestmodels } \\
\text { (subset 4) }\end{array}$ & 58 & 7.98 & 3.66 & 6.09 & 2.44 & 427.33 & 403.04 \\
\hline $\begin{array}{c}\text { bestmodels } \\
\text { (subset 5) }\end{array}$ & 85 & 10.54 & 5.21 & 7.24 & 3.22 & 525.29 & 482.69 \\
\hline
\end{tabular}

\section{c. Data analyses}

Data analyses were conducted using R software (R Core Team, 2019). Data processing was performed using the R packages included in the "Tidyverse" compilation (Wickham, 2017). Kernel-density estimations using 95\% (Kde 95) were calculated to estimate home ranges using the R package "amt" (Signer, Fieberg, \& Avgar, 2019). The reference bandwidth was calculated per individual with the function $\mathrm{hr} \_$kde_ref().
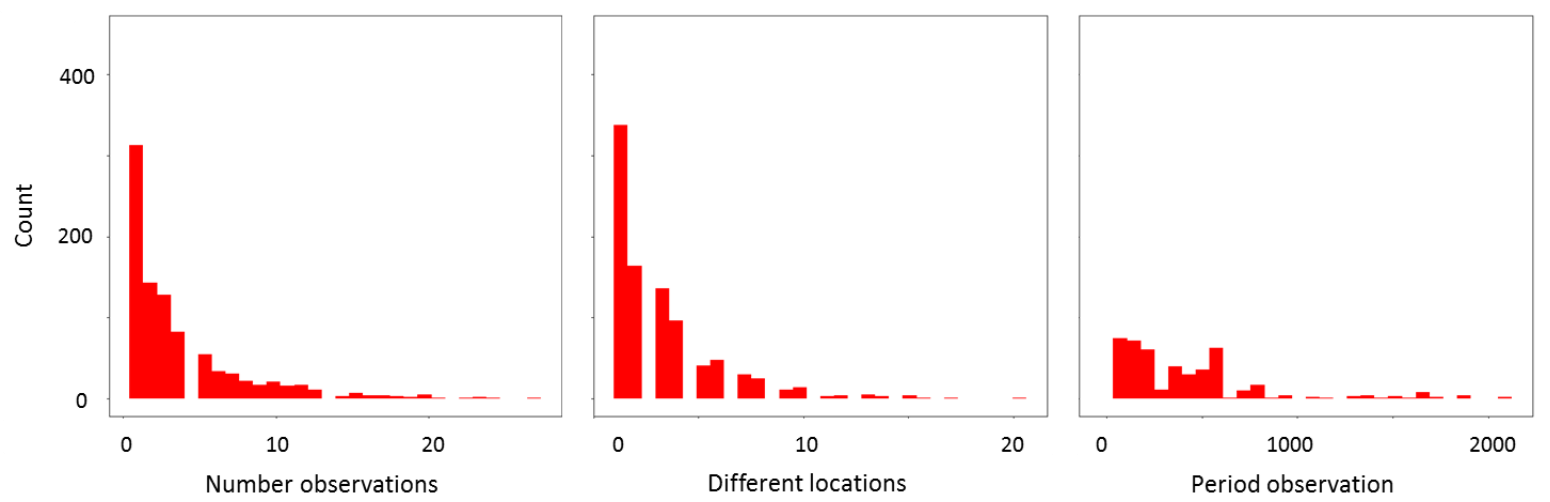

Figure 2. Distribution of the values of our three key variables for the capture database. 


\section{1. $\quad$ Fitting a Michaelis-Menten model for each individual}

\section{Calculate home range successively with incremental analysis}

For each individual, we calculated $\mathrm{n}$ home range areas ( $\mathrm{n}$ representing the total number of observations for the focal individual). We increased successively the number of location data points considered for Kernel density estimations from 1 to $\mathrm{n}$. These location data points were included one by one following a chronological order of observation so that, for each $i$ value, all observations from 1 to $i$ were included resulting in a home range area $\left(H R_{i}\right)$. Since the calculation of home ranges needs a minimum of 4 different locations we simulated 3 observations adjacent to the first real location resulting in a home range estimation of $18 \mathrm{~m}^{2}$ for the first data point per individual. These 3 simulated locations were retained for calculations until the moment where the individual dataset contained 4 real different locations. For each individual, the last home range area calculated (HRobs) was based on the total number of location data points available for this individual ( $n$ ). HRobs corresponds to the measure used in most studies to define the home range of a given individual (Laver \& Kelly, 2008; Schwab \& Ganzhorn, 2004). We proceed now to explain the use of Michaelis-Menten models for describing asymptotes in home range analyses.

\section{Modeling the incremental analyses results with Michaelis-Menten equation}

Once home range areas $\left(\mathrm{HR}_{\mathrm{i}}\right)$ were calculated including each time a further location as described in the previous section, we modeled the home range area obtained with a Michaelis-Menten model as described in Halbrook and Petach (2018). HR $\mathrm{R}_{\mathrm{i}}$ was described as a function of two unknown constants, the asymptotic expected value of the home range area (HRexp) and the rate of increase in HR area (b) and one known variable, the days elapsed between the first and the ith capture (daysi) (equation 1). The use of time instead of the location number was chosen to account for the fact that even if we assumed independence of the data due to the elapsed time between captures, similarities in recapture locations might arise due to the distributions of resources or sleeping sites. If resources are clumped at different locations during specific periods, animals will tend to forage and probably be trapped in these locations. Moreover, if animals sleep in specific locations for more than one night, baited traps near their sleeping site will become available right before animals start to forage. In this sense, including the days elapsed between the first and the ith capture should attenuate the effect of a possible autocorrelation. This is because under the assumption of site fidelity and autocorrelation, the higher the distance between two observations the higher weight of having redundant information on home range size. Thus, by including time elapsed we attenuate the weight of similar information close in time for modeling incremental analyses.

$$
H R_{i}=\frac{H R_{\text {exp }} \times \text { days }_{i}}{b+\text { days }_{i}}
$$


To give initial values to the unknown constants (HRexp and b), we implemented a selfstarting function using the R function getInitial() from the package "stats" (R Core Team, 2019). Then we fitted the model using the starting values calculated by implementing the $R$ function nls() from the same package "stats" with equation 1 . We compiled the models obtained for each individual and their results into list columns in Tibbles using the Tidyverse workflow set of packages (Wickham, 2017).

\section{Assessing the reliability of the Michaelis-Menten models \\ Measures of performance}

We categorized models based on three measures of their performance on the data and therefore we indirectly assessed the likelihood that our data approximates the "real" home range area of a given individual: 1) the goodness of fit, 2) the breadth of the confidence interval and 3) the model stability. As a measure of goodness-of-fit, we correlated for each individual the successive home range sizes $\left(\mathrm{HR}_{\mathrm{i}}\right)$ with the models' predicted values. We then evaluated the size of the confidence interval in relation to the size of HRexp by dividing for each individual the size of the confidence interval by the estimated HRexp. This pondered measure accounts for the fact that the same size of the confidence interval of HRexp (e.g. 0.5) will have different meanings depending on the value of HRexp (e.g. $5 \mathrm{Ha} \mathrm{vs.} 1 \mathrm{Ha}$ ).. Finally, we determined the stability of the model by using a "jackknife" method. We rerun each model $n-1$ times (with $n$ the total number of location data points available for a given individual), removing one observation after another each time ( $n-1$ data points included in each model). We compiled the values of HRexp obtained for each model and extracted their range. For each individual, we divided this range by the value of HRexp from the model with all the observations under the same rationale followed for the confidence interval. This range conformed our measure of model stability.

We further describe the relationships between the three variables used for describing model performance. We try to assess the possible dependence and redundancy between the different variables. We used Pearson correlation analyses corrected using Bonferroni's method to account for possible inflated type-1 errors.

\section{Adequate models selection}

To define a model as adequate, we used as threshold the coefficient of variation (CV) of the mean of HRexp at the population level. We divided the standard deviation of HRexp by its mean to have a value of the population variation in HRexp (hereafter CVpop). The breath of confidence interval as well as the model stability had to be smaller than the CVpop. With this criterium, we aimed to define as adequate those models where the variation at the population level was higher than the variation inside the model (i.e. intra-individual variation). Therefore, if for example, the standard deviation of HRexp represents $50 \%$ of the 
mean at the population level (CVpop $=0.5$ ), we kept those models for which the breath of confidence interval and model stability values represented less than $50 \%$ the value of HRexp. By doing this we aimed at considering possible important differences between individuals in the value of HRexp for which a same range of values for model stability wouldn't have the same meaning. In addition, a model needed to have a goodness-of-fit higher than 0.75 to be classified as an adequate model. In this sense, adequate models were those that (1) described well the saturation curve of home range information and (2) estimated HRexp robustly.

\section{Assessing the effects of model fitting and selection: What did model implementation and selection select for?}

Throughout the process of model fitting and selection described, a subsetting of individuals occurred. In order to assess what this subsetting process targeted for we compared a series of important variables between the different subsets obtained. Due to this process, some individuals may be present in different subsets, implying partial dependence between them. Thus, for assessing the effect of subsetting, we circumvented the problem of dependence in the following way. At each step of selection, we compared those individuals that succeeded against those that didn't succeed. This accentuates the differences but is necessary for testing for statistical differences appropriately (Hayes \& Berry, 2006).

Subset 1 (named homerange) consisted of those individuals for which at least 4 different locations were recorded; this is consistent with home range estimated without any model fitting or selection. It corresponds to the criteria applied for calculation of Microcebus home ranges in the past, but examples can be found in other taxa as well (Laver \& Kelly, 2008). Subset 2 (hereafter noMMmodels) consisted of all individuals for which a Michaelis-Menten model wasn't fitted successfully, and subset 3 (hereafter MMmodels) consists of those individuals for which a model was fitted successfully. Subset 4 (nobestmodels) consisted of those models that did not fulfill the standard deviation criteria for model selection, and subset 5 was its counterpart (bestmodels) (see Fig. 3). 


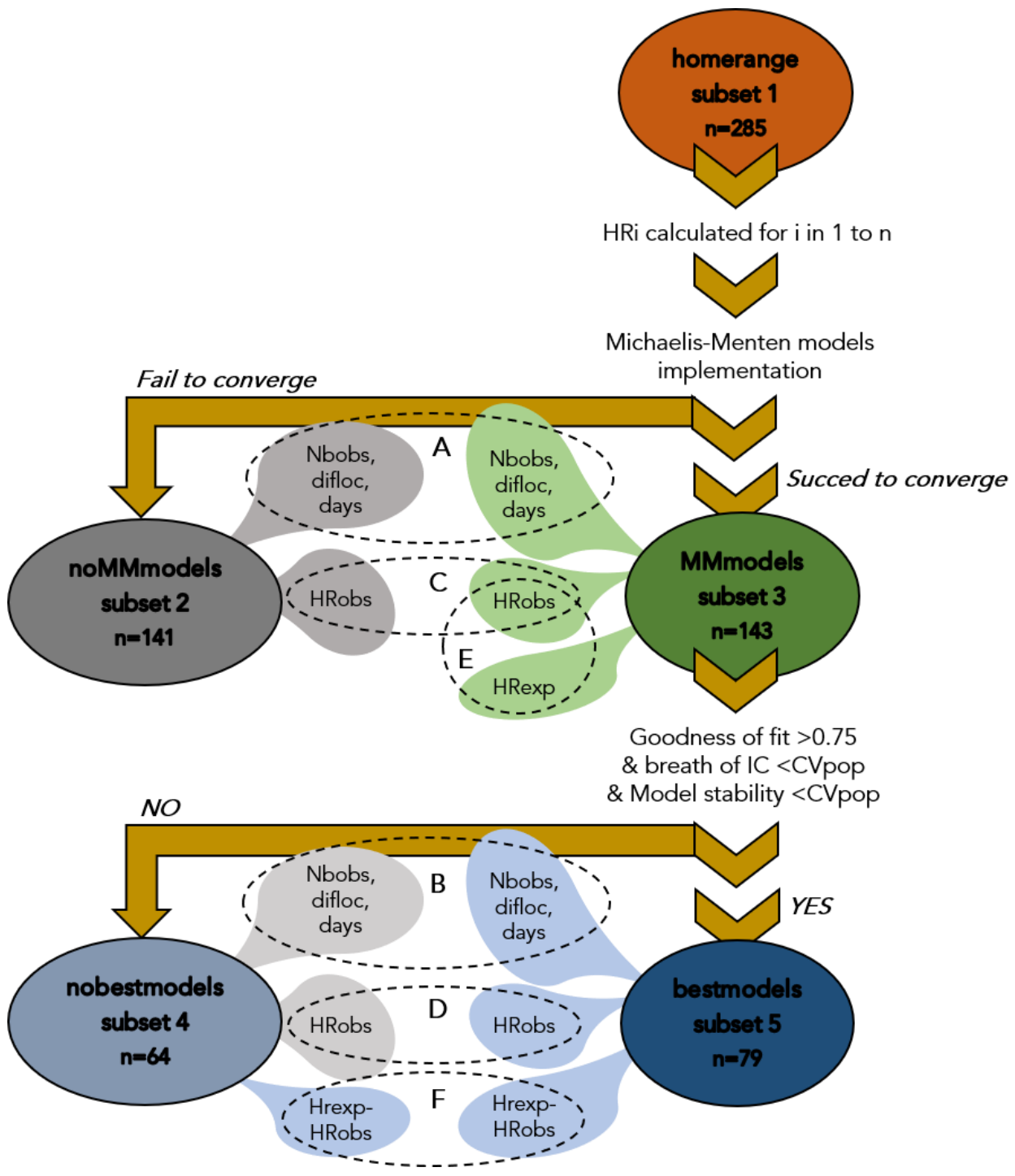

Figure 3. Schematic summary of our selection procedure and of the different comparisons (capital letters) discussed in the present study.

\section{Information variables}

Home range estimations can be affected by three key information variables: the number of observations, the number of different locations and the period between the first and the last observation per individual. To assess whether our methodology targeted individuals more extensively sampled or if on the contrary it targeted individuals for which enough information was gathered (the value of which might be individual specific) we compared the mean and the variance on the information variables throughout the selection process.

Thus, comparisons were made between MMmodels and noMMmodels to assess the effect of implementing models (A on Fig.3) and between bestmodels and their counterpart nobestmodels for assessing the effect of model selection (B on Fig.3). 
Comparisons of means were implemented using a "two-sided" permutation test with 20.000 iterations for independent samples using the function perm.test() from the package "jmuOutlier" (Garren, 2019). Comparisons of variances were implemented using a "twosided" F test with function var.test() from package "stats" (R Core Team, 2019).

\section{Home range size}

We compared the observed home range size throughout the selection process. We tested for an effect of model implementation by comparing HRobs between noMMmodels and MMmodels ( $\mathrm{C}$ on Fig.3). We further tested the effect of model selection on HRobs by comparing nobestmodels with bestmodels ( $\mathrm{D}$ on Fig.3). Means were compared using a "two-sided" permutation test for independent samples with 20.000 iterations using the function perm.test() from the package "jmuOutlier" (Garren, 2019). The variance was compared using a "two-sided" F tests for independent samples.

In order to assess the effect of using model predictions instead of raw measures of home range size, we tested for differences between the HRobs and HRexp of each individual for which a model was fitted (MMmodels) (E on Fig.3). A "two-sided" permutation test for dependent samples with 20.000 iterations using the function perm.test() was used.

Furthermore, we tested whether the extent of agreement between observed values and expected values changed during the selection process. We tested for changes in the difference between HRexp and HRobs between adequate models (bestmodels) and those models that didn't fulfill the criteria (nobestmodels; F on Fig.3). We compared the mean difference by using a "two-sided" permutation test for independent samples and the variance using a "two-sided" $F$ tests for independent samples.

\section{Results}

a. Models performance and reliability

We present here the distribution of the three measures of model performance proposed. We pay special attention to the skew of these distributions to understand whether Michaelis-Menten models are good descriptors of the incremental analyses of home range.

\section{Goodness of fit}

The mean of the goodness-of-fit calculated for each model falls at 0.91 , with a median at 0.92 (Tab. 2). The distribution highly skewed towards 1 , indicates that the majority of models described the process of home range estimation with low error (Fig. 4.a).

\section{Confidence interval}

The range of the confidence interval weighted by the size of HRexp has its mean at 1.07 and a median at 0.48 (Tab. 2, Fig. 4.b). Thus, most confidence intervals are half the size of the 
estimated HRexp. Thus, the majority of models have a robust measure of HRexp, indicating reliability.

Table 2. summary table of the mean and standard deviation values of the measures of model performance and reliability for the MMmodel subset

\begin{tabular}{|c|c|c|c|c|}
\hline subset & criteria & $\mathbf{N}$ & mean & sd \\
\hline MMmodel & gfit & 143 & 0.91 & 0.08 \\
\hline & confest & 143 & 1.05 & 1.5 \\
\hline & mstability & 143 & 1.1 & 2.76 \\
\hline
\end{tabular}

\section{Model stability}

The range of values for HRexp when performing model stability analyses, weighted by the size of HRexp, have a mean at 4.82 and a median at 0.28 (Tab. 2, Fig. 4.c). Thus, most models are stable, their results not depending on specific observations. This indicates models capture the shape of the saturation curve robustly.
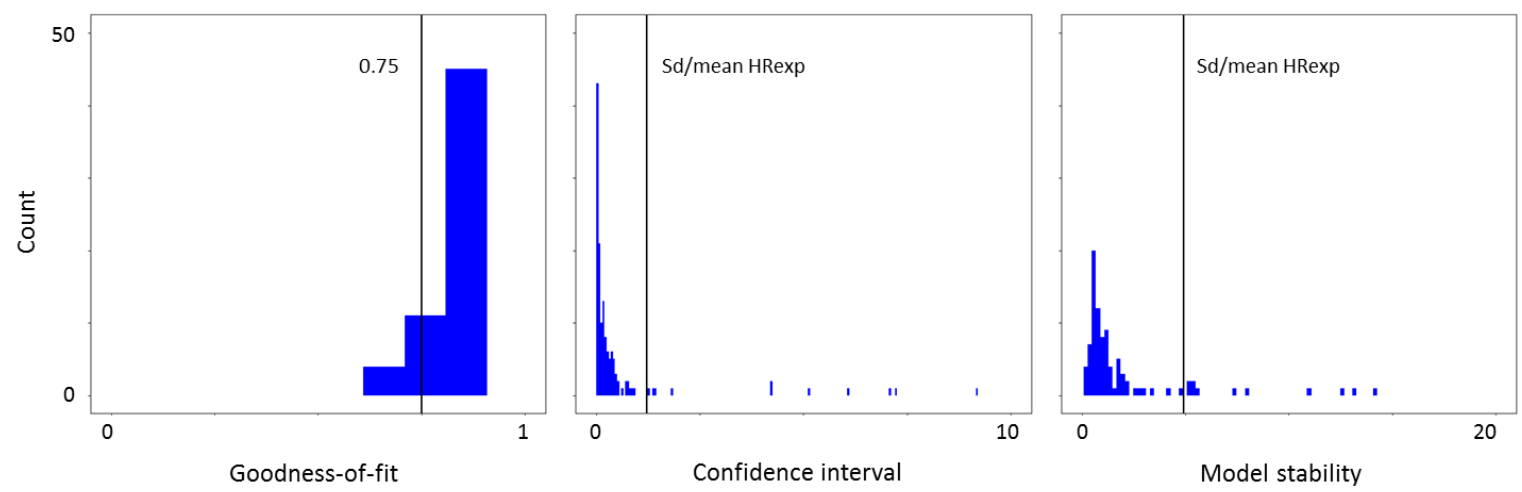

Figure 4. Distribution of the mean values of the measures of model performance and reliability for the MMmodel subset

\section{Relationships between the three measures}

A significant correlation between the extent of the confidence interval and model stability exists (Pearson $r=0.51, p^{\prime}<0.001$ ). A significant negative correlation between goodness-of-fit and model stability was also observed (Pearson $r=-0.27, p^{\prime}=0.003$ ). Out of three possible relationships, two proved significant indicating partial redundancy between the measures of confidence interval and model stability. 
b. What are we targeting through model fitting and selection?

\section{Sample size}

From a total number of 923 individuals captured, only 339 were captured at least 4 times. Out of these 339, 285 were relocated in at least 4 different places and were therefore suited for home range estimations. From these individuals with enough relocations for calculating a home range, 143 were described successfully fitting a Michaelis-Menten model. Among those suited individuals that weren't described using a Michaelis-Menten model, 104 lacked starting values for the model estimates (HRexp and b), while for 37, the model did not converge despite having starting values. From the 143 models fitted successfully, 79 fulfilled our criteria for model selection.

\section{Information variables (A in Fig.3)}

Number observations

We observed a significant increase in the mean number of observations of 1.76 (23\%) (twosided perm test independent samples, $\mathrm{p}=0.001$ ) when comparing noMMmodel with MMmodel (Fig. 5.a). The variance in the number of observations likewise increased by $16 \%$ when fitting the models this increase not being significant but showing a trend (two-sided $\mathrm{F}$ test independent samples, $\mathrm{p}=0.079$ ).

A significant increase of $2.6(36 \%)$ in the mean number of observations occurred when selecting for adequate models (two-sided perm test independent samples, $p<0.001$ ) (Fig. 5.b). The variance in the number of observations was significantly increased by $49 \%$ when selecting for adequate models (two-sided $F$ test, $p=0.001$ ). 

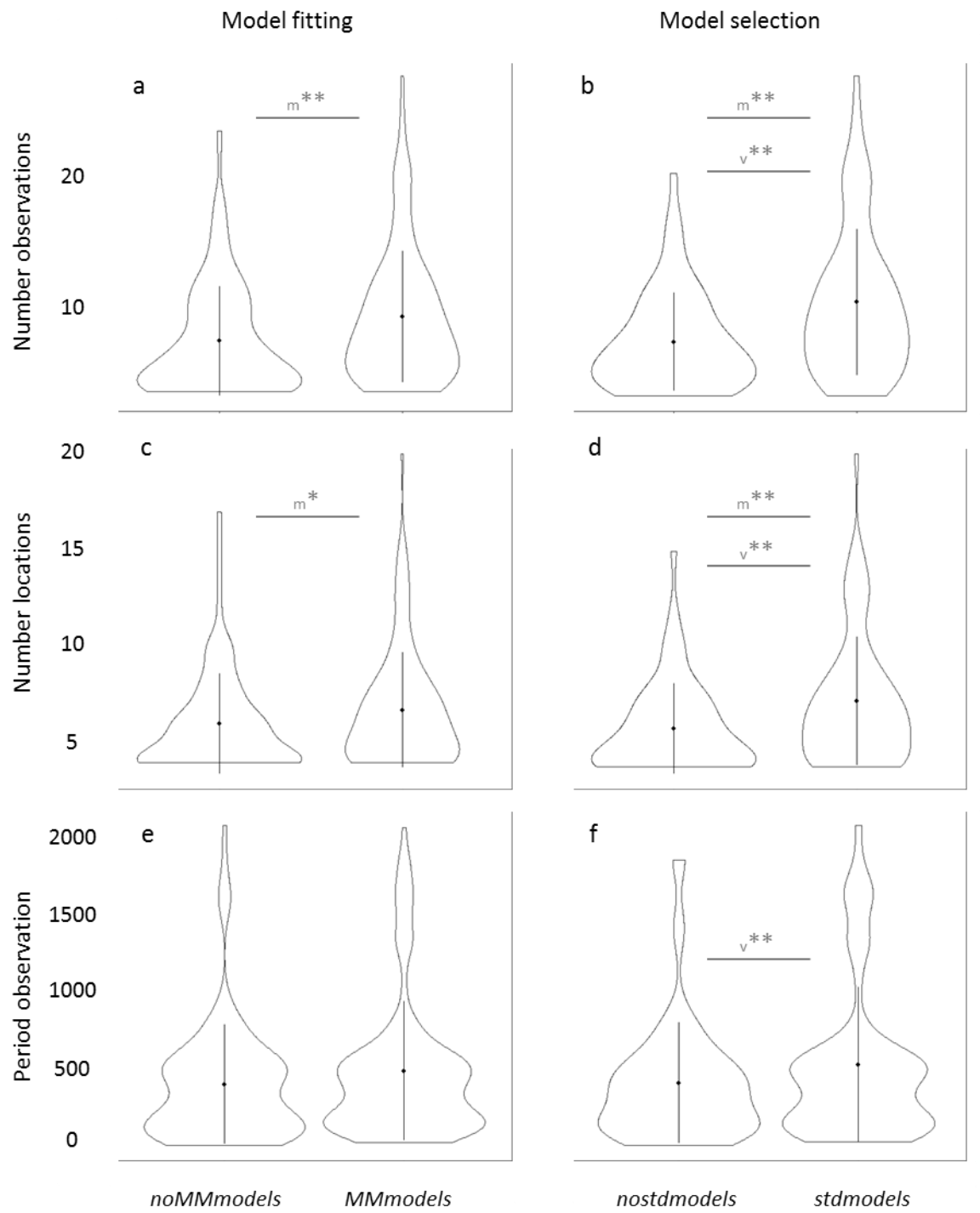

Figure 5. Comparisons of the mean and variance of the values of our key variables pre and post model fitting and model selection.

Number different locations

A small increase of $0.72(13 \%)$ was observed in the mean number of different locations when comparing noMMmodel with MMmodel (two-sided perm test, $p=0.019$ ) (Fig.5.c). The variance in the number of different locations showed a trend for significance with an increase of $15 \%$ (two-sided $F$ test independent samples, $p=0.092$ ).

A significant increase of $1.4(24 \%)$ in the mean number of different locations occurred when selecting for adequate models (two-sided perm test independent samples, $p=0.005$ ) (Fig.5.d). The variance in the number of different locations was significantly increased by $43 \%$ when selecting the models with our three criteria (two-sided $F$ test, $p=0.004$ ). 


\section{Period of observation}

An increase of 88 days (22\%) in the mean period was observed, but the difference was not significant (two-sided perm test, $p=0.08$ ) (Fig. 5.e). The variance in the period of observation per individual increased by $16 \%$ but failed likewise to reach statistical significance (twosided $F$ test, $p=0.07$ ).

A non-significant increase of 116 days (28\%) in the mean period when selecting for adequate models was observed (two-sided permutation test, $p=0.129$ ). The variance increased significantly by $28 \%$ when selecting for most adequate models ( $p=0.045$ ) (Fig. $5 . f)$.

\section{Home range size}

There was no significant difference in the mean home range size observed between those individuals for which a model was fitted successfully and those that were not (two-sided perm test, $p=0.535$ ). Nevertheless, the variance decreased significantly by $22 \%$ (two-sided $F$ test, $\mathrm{p}=0.004$ ).

There was no significant difference between the mean home range size observed between adequate and non-adequate models $(p=0.694)$. The variance showed a significant increase of $30 \%(p=0.034)$.

\section{Difference between observed and expected home range size}

For each individual to which a model was fitted successfully (MMmodels), we tested for differences between the observed home range size (HRobs) and the estimated expected home range by the Michaelis-Menten model (HRexp) (E in Fig. 3). The predicted home range size differed significantly by being on average twice as big as the observed size (HRobs=2.37 \pm vs. HRexp=4.97 $\pm \mathrm{Ha}$ ) when considering all models (MMmodels) (two-sided perm test paired samples, $p<0.001$ ) (Fig. 6.a).

We further compared this difference between the observed and the predicted home range sizes between the models selected as adequate and those that weren't (nobestmodels vs. bestmodels; F in Fig. 3). The mean difference between the observed and the predicted values was 4.16 times smaller (two-sided perm test independent samples, $p<0.001$ ) (Fig. 6.b). The variance in this difference decreased by an even greater extent; it became 20 times smaller (two-sided $\mathrm{F}$ test, $\mathrm{p}<0.001$ ). 

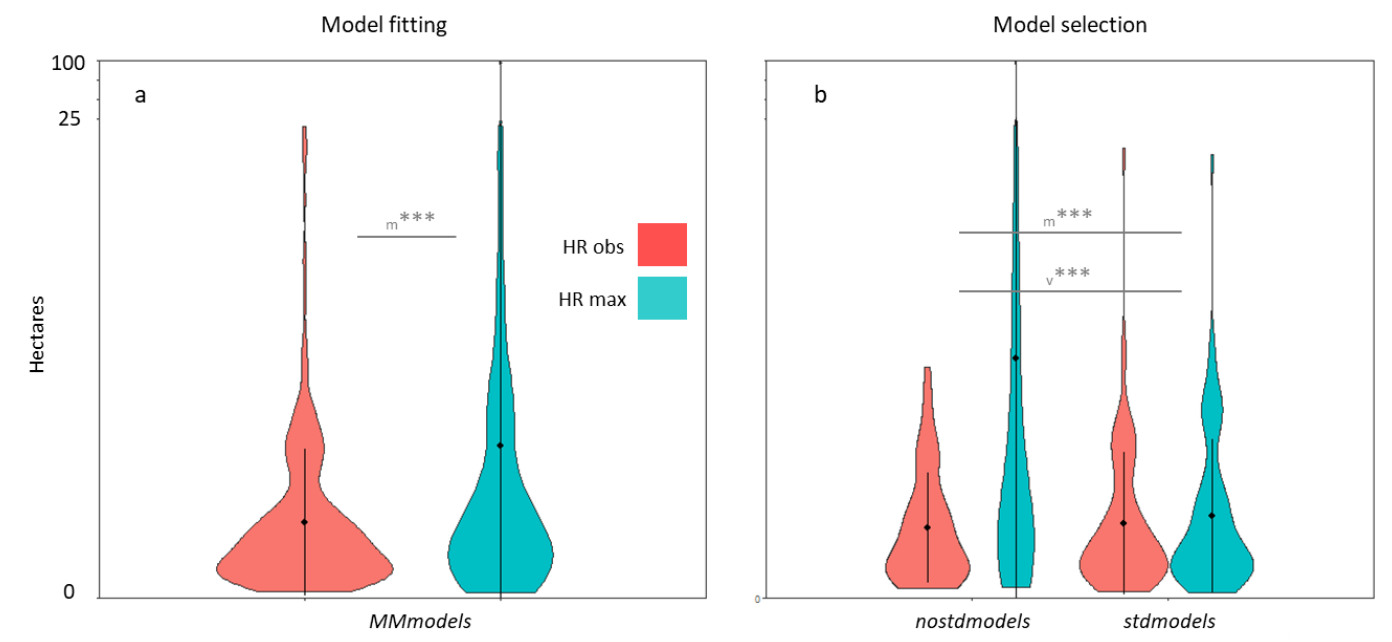

Figure 6. Comparison of the mean and variance values of HRobs and HRmax a) after fitting the models and b) between selected and non selected models.

\section{Discussion and conclusion}

As expected by the use of capture data from a wild population, the amount of information gathered among individuals varied considerably in our database. This is a general situation in many studies in wild populations and poses an important problem. Since different individuals may need different amounts of information to describe their home range accurately, additional complexity is added to the problem of defining home ranges for wild populations. To overcome this problem, we applied Michaelis-Menten models associated with model selection using a variation criterion on three variables representing model performance in order to tease apart individuals with unreliable information from those for which a good approximation of their space use was inferred.

Michaelis-Menten models performed well on data of captures of wild mouse lemurs as the distributions of the three proposed variables for describing model adequacy and robustness show. Nevertheless, an important drawback has to do with the reduction of sample sizes. Half of the individuals for which home range size estimation was possible were discarded because models did not converge, or due to the algorithm's inability to find initial starting values. A possibility for increasing sample size would be to set the initial parameters of the model manually. Here, nevertheless, we presented a general methodology that does not require the researcher to have a priori knowledge on the model parameters and can be applied directly to any species with consistent space use over time. Our model selection process further decreased the sample size by around $40 \%$. However, this reduction in sample size is to be regarded simultaneously with the nature of our database. Indeed, the initial database includes a considerable number of individuals for which trapping frequency was highly variable. Hence the observed reduction in sample size appears to represent in 
first place a refinement of our database. Moreover, even with a consequent decrease in sample size, the final sample size $(n=79)$ is appropriate to test hypotheses at both the individual and population level. Other datasets may not suffer this considerable decrease in sample size.

One can see that both model fitting and selection showed a similar trend regarding their effect on the information variables (number of observations, number of different locations, and period of observation). Those individuals succeeding in each step of the analyses had on average slightly higher number of observations, number of different locations and greater extent period of observation. However, most significantly, the variance in these same variables increased simultaneously by 27 to $50 \%$. The fact that the variance increased further than the mean can be interpreted in our opinion as evidence that our selection process did not exclusively target individuals for which more information was available. This is supported by the fact that looking at the shape of distribution of the information variables (Fig. 5), one can see that individuals with values higher than average are also present in the subsets that failed in the selection process. Thus, the presented results suggest that we targeted those individuals for which enough information was gathered and that this value was individual specific.

Supporting the idea of an individual specific targeting, model fitting and selection did not affect the mean values of home ranges at the population level. On the contrary, the variance in home range size increased by $30 \%$ during the same process. Again, when comparing the shapes of distributions of home range sizes between subsets succeeding and not on the selective process (Fig.6), it suggests that individual idiosyncrasy in space use is respected with our methodology. The selective process does not show a general trend for individuals with higher or lower home range sizes but rather targets those for which an accurate model was fitted.

The difference between observed and expected values of home range size indicate that using the model predictions without criteria for model selection may lead to substantial biases in home range sizes. Our three criteria for model selection, based on goodness of fit, model stability and confidence interval had a drastic effect on the extent of disagreement between the observed data and the predicted values, partially reflecting the nature of the criteria. This indicates, in our opinion the necessity for a coupled use of model fitting and selection.

Regarding the three criteria, redundancies between confidence intervals and model stability as well as between goodness-of-fit and model stability were observed. Choosing alternative measures of model performance capturing more variation might be a zone for further 
improvement. Nevertheless, the observed correlations did not overcome $50 \%$ showing that the chosen criteria captured partially different dimensions of model adequacy. In this sense, the effects of model selection on the disagreement between the observed and the expected home ranges and the fact that most outliers were removed from the dataset during this step reinforce the utility of the three criteria proposed beyond drawbacks.

In our opinion, the evidence here presented suggests a clear benefit and usefulness of our approach that combines Michaelis-Menten model fitting and selection when dealing with home range estimation. It is worth noting that above all, the proposed methodology appears to evaluate the trustworthiness of home range estimations while respecting individual idiosyncrasy in space use. The values on home range size did not differ at the population level throughout the process, but model selection targeted those individuals for which the hypothetical asymptote, i.e. the estimation of its "real" home range, was approximated with less uncertainty.

The proposed methodology complement and expands recent enhancements on home range analyses by using asymptotic curves to estimate the reliability of the information obtained on an individual basis (Halbrook \& Petach, 2018; Wszola et al., 2019). Importantly, our methodology does not require previous knowledge on the parameters of the models nor visual inspection of each individual plot. Thus, it can be readily implemented on large databases helping to answer important ecologically relevant questions.

Space use is an important descriptor of the way in which individuals may relate to their environment, being it resources, predators, sleeping sites, social or sexual partners. Thus, individual variation in space use is a pivotal axis for natural selection to drive evolutionary change. Since behavioral ecologists and conservation biologists among others build their knowledge into such processes, our method may help capture reliably individual variation in such an important variable as space use in wild animals.

\section{Acknowledgments}

We are very grateful to Brunot Tsiverimana, Remy d'Ampataka, Jean-Pierre Tolozanahary, Tianasoa D. D. Andrianzanahary, Mamy Razafindrasamba, Nielsen Rabarijaona and Léon Razafimanantsoa for conducting and organizing the long-term captures and monitoring of the Microcebus murinus population in Kirindy forest. We also thank Clémence Poirotte, Koloina Ramahandrizafy and Sophie Heckenbach for collecting capture data on shorter periods. We are very grateful to Johannes Signer for his advice on the implementation of functions from the R package "amt" to the M. murinus capture dataset and to Matthias Markolf for helpful discussions on the statistical measures. 


\section{References}

Burt, W. H. (1943). Territoriality and home range concepts as applied to mammals. Journal of Mammalogy, 24(3), 346-352.

Dammhahn, M., \& Kappeler, P. M. (2008). Comparative feeding ecology of sympatric Microcebus berthae and M. murinus. International Journal of Primatology, 29(6), 1567.

De Solla, S. R., Bonduriansky, R., \& Brooks, R. J. (1999). Eliminating autocorrelation reduces biological relevance of home range estimates. Journal of Animal Ecology, 68(2), 221234.

Eberle, M., \& Kappeler, P. M. (2002). Mouse lemurs in space and time: A test of the socioecological model. Behavioral Ecology and Sociobiology, 51(2), 131-139. https://doi.org/10.1007/s002650100409

Eberle, M., \& Kappeler, P. M. (2004a). Selected polyandry: Female choice and inter-sexual conflict in a small nocturnal solitary primate (Microcebus murinus). Behavioral Ecology and Sociobiology, 57(1), 91-100.

Eberle, M., \& Kappeler, P. M. (2004b). Sex in the dark: Determinants and consequences of mixed male mating tactics in Microcebus murinus, a small solitary nocturnal primate. Behavioral Ecology and Sociobiology, 57(1), 77-90. https://doi.org/10.1007/s00265004-0826-1

Ebersole, J. P. (1980). Food density and territory size: An alternative model and a test on the reef fish Eupomacentrus leucostictus. The American Naturalist, 115(4), 492-509.

Fietz, J. (1999). Mating system of Microcebus murinus. American Journal of Primatology, 48(2), 127-133. https://doi.org/10.1002/(SICI)1098-2345(1999)48:2<127::AIDAJP4>3.0.CO;2-4

Fleming, C. H., \& Calabrese, J. M. (2017). A new kernel density estimator for accurate homerange and species-range area estimation. Methods in Ecology and Evolution, 8(5), 571-579. https://doi.org/10.1111/2041-210X.12673

Fleming, C. H., Noonan, M. J., Medici, E. P., \& Calabrese, J. M. (2019). Overcoming the challenge of small effective sample sizes in home-range estimation. Methods in Ecology and Evolution. https://doi.org/10.1111/2041-210X.13270

Garren, S. T. (2019). jmuOutlier: Permutation Tests for Nonparametric Statistics. Retrieved from https://CRAN.R-project.org/package=jmuOutlier

Halbrook, R. S., \& Petach, M. (2018). Estimated mink home ranges using various homerange estimators. Wildlife Society Bulletin, 42(4), 656-666. https://doi.org/10.1002/wsb.924 
Harris, S., Cresswell, W. J., Forde, P. G., Trewhella, W. J., Woollard, T., \& Wray, S. (1990). Home-range analysis using radio-tracking data-a review of problems and techniques particularly as applied to the study of mammals. Mammal Review, 20(2-3), 97-123. https://doi.org/10.1111/j.1365-2907.1990.tb00106.x

Hayes, L. J., \& Berry, G. (2006). Comparing the part with the whole: Should overlap be ignored in public health measures? Journal of Public Health, 28(3), 278-282.

Heupel, M. R., Simpfendorfer, C. A., \& Hueter, R. E. (2004). Estimation of Shark Home Ranges using Passive Monitoring Techniques. Environmental Biology of Fishes, 71(2), 135-142. https://doi.org/10.1023/B:EBFI.0000045710.18997.f7

Kernohan, B. J., Gitzen, R. A., \& Millspaugh, J. J. (2001). Analysis of animal space use and movements. In J. J. Millspaugh \& J. M. Marzhluff (Eds.), Radio tracking and animal populations (pp. 125-166). San Diego, California, USA: Elsevier.

Laver, P. N., \& Kelly, M. J. (2008). A critical review of home range studies. The Journal of Wildlife Management, 72(1), 290-298.

Law, B. S., \& Dickman, C. R. (1998). The use of habitat mosaics by terrestrial vertebrate fauna: Implications for conservation and management. Biodiversity \& Conservation, $7(3), 323-333$.

Macdonald, D. W. (2016). Animal behaviour and its role in carnivore conservation: Examples of seven deadly threats. Animal Behaviour, 120, 197-209.

Michaelis, L., \& Menten, M. L. (1913). The kinetics of the inversion effect. Biochem. Z, 49, 333-369.

Mueller, T., \& Fagan, W. F. (2008). Search and navigation in dynamic environments-from individual behaviors to population distributions. Oikos, 117(5), 654-664.

Munger, J. C. (1984). Home ranges of horned lizards (Phrynosoma): Circumscribed and exclusive? Oecologia, 62(3), 351-360.

Nathan, R., Getz, W. M., Revilla, E., Holyoak, M., Kadmon, R., Saltz, D., \& Smouse, P. E. (2008). A movement ecology paradigm for unifying organismal movement research. Proceedings of the National Academy of Sciences, 105(49), 19052-19059. https://doi.org/10.1073/pnas.0800375105

Otis, D. L., \& White, G. C. (1999). Autocorrelation of location estimates and the analysis of radiotracking data. The Journal of Wildlife Management, 1039-1044.

Powell, R. A., \& Mitchell, M. S. (2012). What is a home range? Journal of Mammalogy, 93(4), 948-958. 
Powell, R. A., Zimmerman, J. W., \& Seaman, D. E. (David E. (1997). Ecology and behaviour of North American black bears: Home ranges, habitat, and social organization (1st ed). London; New York: Chapman \& Hall.

R Core Team. (2019). R: A Language and Environment for Statistical Computing. Retrieved from https://www.R-project.org/

Radespiel, U. (2000). Sociality in the gray mouse lemur (Microcebus murinus) in northwestern Madagascar. American Journal of Primatology: Official Journal of the American Society of Primatologists, 51(1), 21-40.

Reid, M. L., \& Weatherhead, P. J. (1988). Topographical constraints on competition for territories. Oikos, 115-117.

Rooney, S. M., Wolfe, A., \& Hayden, T. J. (1998). Autocorrelated data in telemetry studies: Time to independence and the problem of behavioural effects. Mammal Review, 28(2), 89-98. https://doi.org/10.1046/j.1365-2907.1998.00028.x

Schick, R. S., Loarie, S. R., Colchero, F., Best, B. D., Boustany, A., Conde, D. A., ... Clark, J. S. (2008). Understanding movement data and movement processes: Current and emerging directions. Ecology Letters, 11(12), 1338-1350.

Schliehe-Diecks, S., Eberle, M., \& Kappeler, P. M. (2012). Walk the line-Dispersal movements of gray mouse lemurs (Microcebus murinus). Behavioral Ecology and Sociobiology, 66(8), 1175-1185. https://doi.org/10.1007/s00265-012-1371-y

Schwab, D., \& Ganzhorn, J. U. (2004). Distribution, population structure and habitat use of Microcebus berthae compared to those of other sympatric cheirogalids. International Journal of Primatology, 25(2), 307-330.

Signer, J., Fieberg, J., \& Avgar, T. (2019). Animal movement tools (amt): R package for managing tracking data and conducting habitat selection analyses. Ecology and Evolution, 9, 880-890.

Soanes, L. M., Arnould, J. P. Y., Dodd, S. G., Sumner, M. D., \& Green, J. A. (2013). How many seabirds do we need to track to define home-range area? Journal of Applied Ecology, 50(3), 671-679. https://doi.org/10.1111/1365-2664.12069

Soanes, L. M., Bright, J. A., Bolton, M., Millett, J., Mukhida, F., \& Green, J. A. (2015). Foraging behaviour of Brown Boobies Sula leucogaster in Anguilla, Lesser Antilles: Preliminary identification of at-sea distribution using a time-in-area approach. Bird Conservation International, 25(1), 87-96.

Spencer, S. R., Cameron, G. N., \& Swihart, R. K. (1990). Operationally Defining Home Range: Temporal Dependence Exhibited by Hispid Cotton Rats. Ecology, 71(5), 1817-1822. https://doi.org/10.2307/1937590 
Warwick-Evans, V., Atkinson, P. W., Arnould, J. P. Y., Gauvain, R., Soanes, L., Robinson, L. A., \& Green, J. A. (2016). Changes in behaviour drive inter-annual variability in the atsea distribution of northern gannets. Marine Biology, 163. https://doi.org/10.1007/s00227-016-2922-y

Wickham, H. (2017). tidyverse: Easily Install and Load the "Tidyverse." Retrieved from https://CRAN.R-project.org/package=tidyverse

Worton, B. J. (1989). Kernel methods for estimating the utilization distribution in homerange studies. Ecology, 70(1), 164-168.

Wszola, L. S., Simonsen, V. L., Corral, L., Chizinski, C. J., \& Fontaine, J. J. (2019). Simulating detection-censored movement records for home range analysis planning. Ecological Modelling, 392, 268-278. https://doi.org/10.1016/j.ecolmodel.2018.10.01 


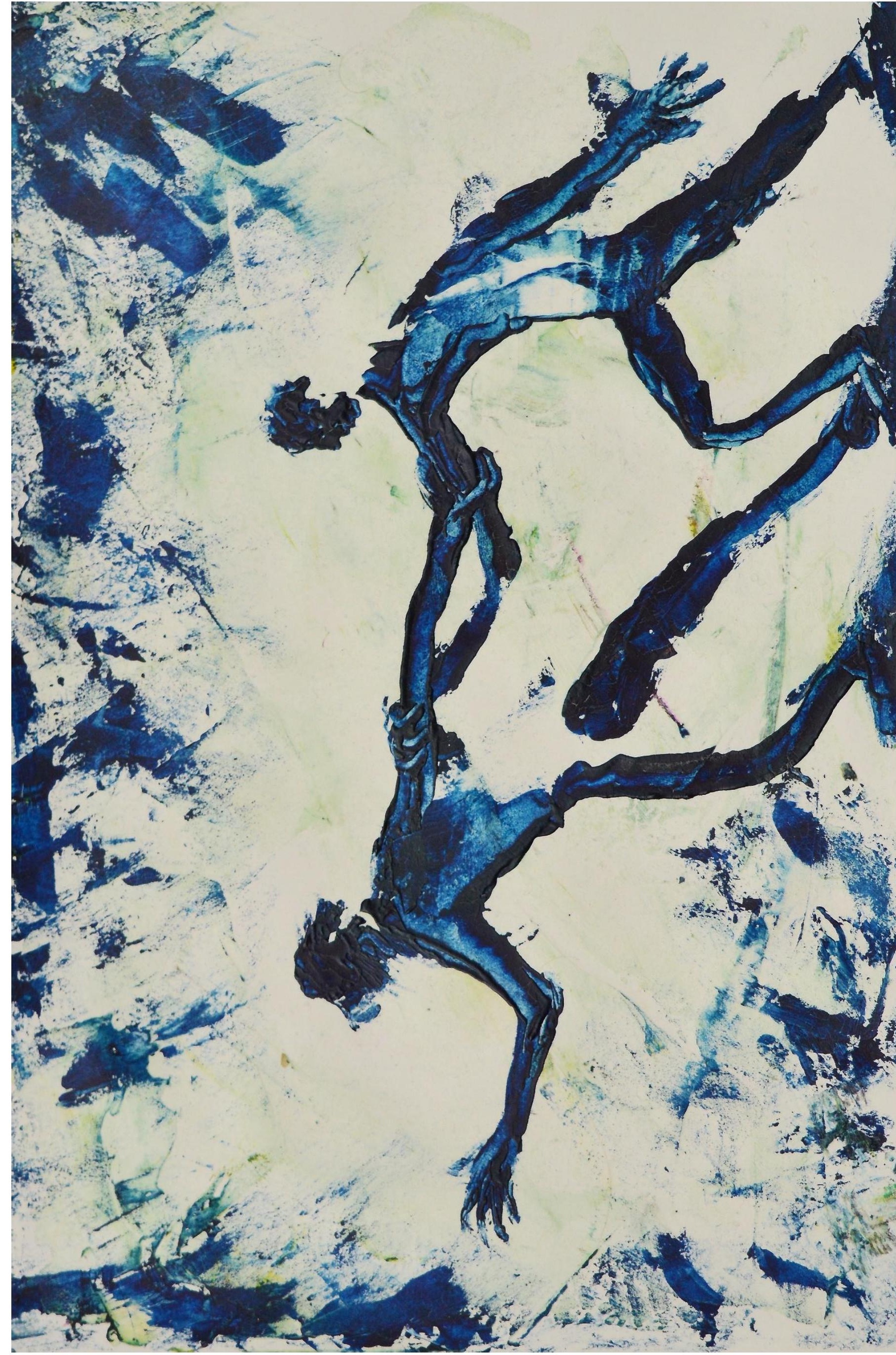




\section{General discussion and conclusion}

The speed of evolutionary processes is not constant. Flegr (2010) argue that the evolvability of a species decreases if the genetic architecture and diversity increase to a level where epistasis, pleiotropy, and frequency-dependent selection constrain natural selection to micro-evolutionary changes. Under this view, major transitions in evolution might be a way for "frozen species", i. e., species where the units of selection have become too complex, to renew their adaptive potential (Toman and Flegr, 2018). This idea and our proposition in Chapter 1 are analogous. Sociality can be understood as a new response to an old problem in species where coevolution has led to a parental "trap" (Socias-Martínez and Kappeler, 2019). Red-queen effects of coevolution with predators and parasites may lead to a situation where evolution of solitary parents is limited by energetic or developmental constrains. In this situation, cooperation with other parents and the synergies created by their interactions, may conform a new solution to the problems imposed by environmental hazards (see Chapter 1 ).

Toman and Flegr (2017) suggest that when major evolutionary transitions occur, there is a simplification of the lower-level entities in the new emerging whole. This is a consequence of specialization of the parts that form the new hierarchical level. For example, the ancestors of mitochondria got some of their vital functions carried out by their host when combining to form eukaryotic cells and specialized in the production of energy. In this process of specialization, the genome and breath of this specific part got simplified and optimized for its new narrower niche of action (McShea, 2002). Similarly, individuals in eusocial species with caste division of labor reduce the breath of their potential and specialize in a set of tasks. In comparison to a solitary bee or wasp which has the potential for all aspects of the life-history by its own they may be considered simpler. Simplification of the lower level entities has been termed "machinization" (McShea, 2016).

Machinization may sound rather awkward to vertebrate sociobiologists that are often confronted with theories linking sociality with the evolution of complex. Transitions to sociality and increases in social complexity have been linked to increases in complexity of communicative and cognitive systems in several vertebrate orders (Dunbar, 2009; Freeberg et al., 2012; Peckre et al., 2019). In primates, cetaceans, carnivores, corvids and psittacins, the new niche created by the social environment generated new selective pressures resulting in the evolution of higher capacities for learning, monitoring and communicating with others. Furthermore, far to the extreme of social complexity an analogous to eusocial insects, cooperative breeding social systems, are associated with the highest cognitive and communicative capacities (Freeberg and Krams, 2015); which in the case of human 
ancestors lead to language and greater cognition including theory of mind (van Schaik and Burkart, 2010; Tallerman and Gibson, 2012; Burkart and van Schaik, 2016).

One could then wonder what may be driving such differences in the perceived outcome of different major evolutionary transitions. "Machinization" may only occur after the point of no return, when the unit of selection has shifted more or less completely to a higher level of organization (West et al., 2015). In animals, the differences observed between eusocial invertebrates and vertebrates may relate to the degrees to which individual, kin and group selection operate. In vertebrates, although cooperative breeding is characterized by reproductive altruism, individuals remain capable of reproducing and the nature of altruism is facultative. On the contrary, in eusocial species, the group may become the unit of selection since it corresponds to the reproductive unit (Wilson and Sober, 1989). Thus, in a multilevel selection perspective, complexity may increase at the unit of selection and the tensions created between the higher and the lower level (e.g. the individual ad the group) may exacerbate this process. Under such divergences at the apex of social complexity in different taxa, should one expect differences in the causes for transitions from solitary to group-living?

\section{Inclusive fitness and social transitions}

Since the revolutionary ideas introducing the concept of indirect fitness benefits settled down in the form of Hamilton's rule, a bewildering amount of biological processes have been explained in such terms. Significant evidence in support of inclusive fitness theory includes the presence of cooperation between kin in animal societies of most taxa studied (Clutton-Brock, 2002; Rubenstein and Abbot, 2017) as well as kin-recognition mechanisms. Moreover, there is a consensus that due to the laws of competition and natural selection, in the absence of kin selection, free riding individuals would make cooperation evolutionarily unstable. Thus, kin selection has become the dominant paradigm for understanding the evolution of sociality.

Despite the widespread use of inclusive fitness arguments to explain cooperation, how to test for inclusive fitness as well as the structure of Hamilton's rule are not established laws like Newtonian physics. This mathematical approximations suffer from several limitations with notorious disagreement in the way of accounting for the benefits, the costs and the relatedness terms in the equation (Nonacs and Richards, 2015; Nowak et al., 2017, Introduction). Tests allowing to conclude on the role of indirect fitness benefits are rare (Nonacs and Richards, 2015). In Hymenoptera, the most studied taxa in this context, positive results on the role of indirect fitness (Yagi and Hasegawa, 2012) are one among other outcomes observed. Mutualism (Leadbeater et al., 2011; Ohkubo et al., 2018), parental manipulation (Kapheim et al., 2015) or by-products of nest reuse (Rehan et al., 
2014) have been concluded responsible for the observed altruistic acts in several socially flexible bee species. In vertebrates, only two studies to my knowledge have tested for inclusive fitness benefits of helping in cooperative breeding species, both being carried out in birds. No inclusive fitness difference between helping and non-helping was found (Wang and Lu, 2018) nor any difference between dispersers and non-dispersers (Green and Hatchwell, 2018). Nevertheless, indirect fitness accounted for a significant proportion of the overall fitness in both studies indicating that indeed, inclusive fitness theory can explain the maintenance of costly helping behavior.

The present limitations in tests to conclude on the importance of inclusive fitness should call for caution when concluding on the role of indirect fitness benefits on the evolution of sociality even in the presence of kin structure and kin recognition. In many studies, the sole presence of preferential interaction with relatives in social species is taken as evidence in favor of kin selection. Nevertheless, the ontogeny of relationships in kin structured groups with extensive parental care (Chapais, 2001; Silk, 2009), as well as in species with male reproductive skew can also account for the observed patterns between matrilineal and patrilineal kin (Widdig, 2013).

Mouse lemur sociality has been explained under kin selected arguments (Radespiel et al., 2001, 2009; Eberle and Kappeler, 2006; Dammhahn and Kappeler, 2009; Kessler et al., 2016). However, young mouse lemur females benefit strongly from staying within their mother home range with increased survival probability implying direct fitness benefits (Lutermann et al., 2006). Moreover, our results point towards the presence of non-kin sociality between males and in $M$. berthae sociality between unrelated females also occurs (Dammhahn and Kappeler, 2005, Chapter 2). As Schülke and Ostner (2005) suggest, if communal care is beneficial, clustering of relatives would be reinforced in a positive feedback loop with benefits of cooperation driving the kin structure and not the other way around. Thus, benefits of grouping, between group competition and spatial selection, are important candidates to explain the emergence and maintenance of mouse lemur sociality. Future tests taking into account direct and indirect fitness of alternative social tactics are needed for testing inclusive fitness benefits in this context.

It is, therefore, necessary to proceed with caution before concluding on the role of kin selection for the appearance of animal societies. Sociobiologists are confronted with an apparent co-occurrence in a wide variety of taxa of several traits, including natal philopatry, kin structures, parental investment asymmetries and sociality. Explaining such occurrence as well as exceptions to these co-occurrences is a task that needs from a diversity of approaches and might benefit from reducing the tendency for emphasizing nepotism (Wilson and Hölldobler, 2005; Nowak, 2006; Nowak et al., 2010, 2017). 


\section{Diversity in social evolution}

The plurality of mechanisms allowing the maintenance of sociality lies at the heart of an intricate relationship between the environment and the individual. It is, therefore, no wonder why there is no unique mechanism nor precondition for the evolution of sociality and authors have suggested a plurality of adaptive values, contexts and preconditions both between and within taxa (Table 1). Environmental variability and harshness, population density, the relative frequency of cooperators and defectors, the operational sex ratio, the amount of feeding and breeding resources and the threat of predators and parasites, all can affect the benefits and costs of forming social groups. Moreover, these variables coevolve and affect each other while building on the phylogenetically inherited traits of a species including the life-history and the care system. Complex biological systems and especially complex traits such as cooperative behaviors and permanent sociality are by their characteristics resistant to unifying theories.

Although we have emphasized the importance of caring systems for understanding social transitions (Chapter 1), there are forms of stable sociality in animal groups with the absence of elaborated forms if at all of parental care. For example, schools of marine pelagic fish are extremely common and constitute groups of individuals that forage together in the absence of individual recognition. These are the so-called anonymous crowds and probably serve an anti-predatory function, despite the laborious work of BBC documentaries in testifying the inefficiency of such strategy. In these species, eggs disperse long distances through water currents (Smith, 1973; Economou, 1991). Recruitment into adult fish schools is therefore likewise made by non-related individuals (Taborsky and Wong, 2017) and serves a mutualistic relationship between all individuals involved. Thus, neither parental care nor philopatry and kinship appear to explain the evolution of such societies.

Currently, no phylogenetic study offers insights on what is cause and consequence between parental care and social transitions. However, parental care probably appeared and diversified earlier in evolutionary history than sociality in the animal kingdom. For example, incredibly varied forms of paternal and maternal care are present in amphibians (Furness and Capellini, 2019), while no report on stable amphibian sociality is to our knowledge present in the literature. In reptiles, although most species show relative lower levels of care than in other vertebrate taxa, the few species with stable social groups appear to have evolved from viviparous ancestors (Whiting and While, 2017). Moreover, while parental care forms are varied in many insect taxa, stable social groups appear more restricted. In this sense, we believe there is evidence that parental care could be a precondition for the evolution of the other traits associated with sociality in a wide range of taxa (Wong et al., 2013; Kramer and Meunier, 2019; Socias-Martínez and Kappeler, 2019). 
Table 1. Summary of hypotheses on transitions to sociality in vertebrates and invertebrates. The table divides in to two major groups of hypotheses which explain either between species variation in sociality or within species variation. Furthermore, the division is structured under major groups of hypotheses which focus on the role of the environment or the characteristics of species contributing to social transitions. Finally, after each mechanism a brief explanation is provided.

\section{Hypotheses evolution of sociality}

\section{Across species}

Benefits of grouping (philopatry)

Environmental buffer

Harshness

Variability within generations Variability across generations Resource exclusion/monopolization

Niche expansion

Parental manipulation

Resource

inheritance

Physical

Biological

Cultural

Improved mating opportunities

\section{Ecological constraints}

Resource

abundance

Habitat saturation

Dispersal costs

Longevity

Non-adaptive

Patch world

Predisposition

Generalist diet
Cooperation may reduce the impact of harsh ecological conditions such as low temperatures, predation risk or periodical destruction of important resources

Bet-hedging against effect of environmental variation on fitness within generations favor cooperation

Bet-hedging against effect of environmental variation on fitness across generations favor cooperation Cooperation leads to higher competitive ability against solitary for resource monopolization

Groups through cooperation can access new resources and or habitats

Parents and not necessarily offspring benefit from living together. Parents win the conflict evolutionarily because selection act first in their generation. They do so by changing the phenotype of some offspring to become helpers

Social queuing may lead to benefits later in life

Individuals may benefit from inheriting the territory after the breeding animal dies. Moreover, grouping improves the value of the nesting capacity for generating fitness benefits, thereby increasing the adaptive value of this strategy

Individuals in groups may benefit by sharing bacterial communities necessary for correct development

Individuals benefit from learning important skills for future breeding Individuals may secure finding a mate

Only after a certain threshold of resource abundance groups can form

When breeding resources are saturated, individuals may reduce competition and form groups

Long lived species should have higher levels of habitat saturation leading to higher levels of sociality If dispersal is too costly due to predation or harshness of the environment individuals may forego reproduction

Spatiotemporal irregularities in resource distribution lead to minimum territory for breeding allowing more than a breeding unit through regular surplus production

A generalist diet allows for lower competition within-groups facilitating the evolution of sociality 
Iteroparity/multi-voltinism

bigger litters

Long lifespan

Parental care

Ovarian ground-plan hypothesis

Genetic release

Maternal heterochrony

Genetic toolkit

Mother of sociality

kin-selection

Monogamy hypothesis

Kin neighborhoods

Higher genetic architectural complexity
$>1$ brood per season offers possibility for one of broods to stay and help raising next brood Higher number of offspring lead to increased potential for benefits of helping

In long-lived species the chances of inheriting a territory may lead to benefits of social queuing

Extended maternal care behaviors get specialized in different individuals and give raise to caste differentiation Duplication genes for maternal behavior avoid epistasis and allow selection to act

Shift timing expression genes for maternal care give rise to workers that care for siblings

Changes regulation highly conserved developmental pathway genes lead to social organization

Hormonal and neural basis of vertebrate social and parental behavior shared, latter where exapted for second function

Monogamous mating systems generate higher relatedness among siblings which in-turn increase the inclusive fitness benefits of cooperation within the social unit

Extra-pair mating lead to shared parentage between adjacent territories which lead to inclusive fitness benefits of cooperation between social units

Species with genetic complexity are unable to adapt at the individual level because pleiotropy, epistasis and frequency dependent selection impede selection to shape the phenotype, under such conditions transition to group-living might allow adapting

\section{Within species}

\section{Environmental variability}

Within populations

Social flexibility

Developmental plasticity

Across populations

Genetic differentiation

\section{Predisposition}

Short life-span

Semelparity
The unpredictability of the environment leads to adaptations for flexible social organization

Changing but predictable environments lead to programming of the adaptive social organization during ontogeny

Different but stable environments drive sub-populations of a species towards genetic differences underlying differences in social organization

Individuals in short lived species can't wait for better times and should therefore be enforced to adapt by becoming flexible in their social organization

Individuals reproducing only once can't wait for better times and should therefore be enforced to adapt by becoming flexible in their social organization 
In Chapter 1, we have suggested that the parental sex could also be more prone to evolve sociality through coevolutionary mechanisms reinforcing parental investment and benefits for cooperation in care duties. However, in Chapter 2, the case of mouse lemurs shows that sociality stable partnerships and higher levels of sociality were found in males which provide no paternal care. Moreover, within the parental sex although sociality might be catalyzed by between group competition for breeding resources, group size can also be constrained by between-group competition and parasitism (Chapter 2). With the absence of further knowledge on other mouse lemur species that could allow for reconstructions of ancestral social organizations, it appears unclear if sociality among females preceded male sociality, if these evolved independently or if both evolved through common processes. Our results show evidence for a multitude of causes and consequences coevolving to set the costs, benefits and constraints on social evolution of Microcebus murinus.

Overall, the transition to sociality is usually portrayed as a rarity that needs from changes in evolutionary time through the appearance of genetic mutations. On the contrary, as we have seen in Chapters 1 and 2, in both vertebrates and invertebrates, solitary species might have the potential at a proximate level to become rudimentarily social. Transitions to sociality may be sustained at the proximate level by pre-adaptations and further maintained and elaborated over evolutionary time through mutation and selection. Communicative and cognitive systems of solitary species might allow for elaborated levels of cooperation in the absence of a long history of group-living. New theoretical perspectives link the neural and hormonal mechanisms regulating parental care with those used in adult-adult social interactions in vertebrates (Griesser et al., 2019). Thus, offering support for the role of parental care as a precondition for sociality and the proximate capacity of solitary species with parental care to become social.

Furthermore, the presence of intraspecific variation in social organization may support for the role of preconditions in social evolution. Some studies suggest that social flexibility might be a phase in the transition towards permanent group-living (Dalerum, 2007; Shultz et al., 2011; Kessler et al., 2016). However, others advocate for an adaptation to unpredictable environments (Schradin et al., 2012, 2018). In the latter case, social flexibility could be an evolutionary endpoint and be unlinked from the evolution of species with permanent sociality, or it could be that unpredictable environments select for social flexibility which later becomes stable. The selective forces canalizing such crystallization of social organization could concern colonization of more stable and rich habitats by flexible ancestors or niche expansion due to exaptation of the functions and benefits of grouping.

We found evidence for mouse lemurs social flexibility expressed according to changes in environmental conditions between seasons (Chapter 2). Moreover, the unpredictable 
nature of the climate in wester Madagascar suggests social flexibility might be an adaptation to unpredictable environments supporting claims by Schradin et al. (2012, 2018). High variability both between and within individuals in the social decisions was observed and remains unexplained by current socioecological frameworks focusing on between species and between sex differences. For example, although solitary females have been shown to have no kin around in several studies, group-sleeping females do not use a permanent sociality strategy. Variation in this trait was observed with more than $25 \%$ of the population of females sleeping under three-quarters of their sleeping time alone. Over the course of seasons, individuals changed strategy. In females this change appeared to relate to their capacity to retain partners from previous seasons which was independent on the number of surviving partners from last season. In males none of the investigated variables correlated significantly and further investigations would be needed in order to pierce the underlying determinants.

\section{Mouse lemurs and primate social evolution}

Although mouse lemurs have been suggested as models for the evolution of stable primate groups, which could indicate a route towards sociality through social flexibility (Kessler et al., 2016), the present state of the art on mouse lemur social organization calls for prudent conclusions. On the one hand, we know very little about the variation at the individual, seasonal and interspecific levels in the few species studied to date (Chapter 2). At the moment, it could be that the ancestor of mouse lemur was already sleeping in groups and the social organization as well as the level of flexibility of such ancestor is unknown. Moreover, an upcoming phylogenetic reconstruction suggests that the transition from solitary to group-living in primates proceeded through an intermediate pair-living stage (Kappeler and Pozzi, In press). This is consistent with the observation that social relationships observed between individuals in group-living species retain characteristics of pair-bonds in primates(Shultz and Dunbar, 2007). Similarly, pair-living could have preceded group-living in birds, lizards and snapping shrimps (Cockburn et al., 2017; Hultgren et al., 2017; Whiting and While, 2017). Thus, male-female cooperation could be a potential first step in social transitions and, under such view sexually segregated sleeping groups in nocturnal solitary foragers might not be an adequate model for studying the origins of primate sociality.

To date, reconstructions of primate social evolution show an inconsistency in the form of conceptualizing solitary foragers compared to other species. All reconstructions have considered Microcebus and other genera of cheirogaleids, as solitary, amalgamating species in which sleeping groups occur with those that are permanently solitary (Kappeler and Pozzi, In press; Shultz et al., 2011; Lukas and Clutton-Brock, 2012). Given the diversity of group compositions shown in Chapter 2 and other studies, the solitary forager label is 
grounded on a bias towards understanding social organization from the foraging perspective, essential for understanding diurnal primate groups. Microcebus could be understood as social animals with a solitary foraging activity. Since cheirogaleids are basal primates, changes in their attributed values for social organization could induce profound changes in the reconstruction of ancestral states and transitions. Thus, there is a need for integrating other forms of sociality into phylogenies concerning social evolution including intraspecific variation in social organization. Doing so may lead to new interesting discoveries in the evolution of social organization in primates and other animals.

\section{References}

Burkart, J. M., and van Schaik, C. P. (2016). Revisiting the consequences of cooperative breeding. Journal of Zoology 299, 77-83.

Chapais, B. (2001). Primate nepotism: What is the explanatory value of kin selection? International Journal of Primatology 22, 203-229. doi:10.1023/A:1005619430744.

Clutton-Brock, T. H. (2002). Breeding together: kin selection and mutualism in cooperative vertebrates. Science 296, 69-72.

Cockburn, A., Hatchwell, B. J., and Koenig, W. D. (2017). "Sociality in birds," in Comparative social evolution, eds. D. R. Rubenstein and P. Abbot (Cambridge, United Kingdom: Cambridge University Press), 320-353.

Dalerum, F. (2007). Phylogenetic reconstruction of carnivore social organizations. Journal of Zoology 273, 90-97. doi:10.1111/j.1469-7998.2007.00303.x.

Dammhahn, M., and Kappeler, P. M. (2005). Social system of Microcebus berthae, the world's smallest primate. International Journal of Primatology 26, 407-435.

Dammhahn, M., and Kappeler, P. M. (2009). Females go where the food is: does the socioecological model explain variation in social organisation of solitary foragers? Behavioral Ecology and Sociobiology 63, 939.

Dunbar, R. I. (2009). The social brain hypothesis and its implications for social evolution. Annals of human biology 36, 562-572.

Eberle, M., and Kappeler, P. M. (2006). Family insurance: kin selection and cooperative breeding in a solitary primate (Microcebus murinus). Behavioral Ecology and Sociobiology 60, 582-588.

Economou, A. N. (1991). Is dispersal of fish eggs, embryos and larvae an insurance against density dependence? Environ Biol Fish 31, 313-321. doi:10.1007/BF00002356. 
Flegr, J. (2010). Elastic, not plastic species: Frozen plasticity theory and the origin of adaptive evolution in sexually reproducing organisms. Biology Direct 5, 1-16.

Freeberg, T. M., Dunbar, R. I. M., and Ord, T. J. (2012). Social complexity as a proximate and ultimate factor in communicative complexity. Philosophical Transactions of the Royal Society B: Biological Sciences 367, 1785-1801. doi:10.1098/rstb.2011.0213.

Freeberg, T. M., and Krams, I. (2015). Does social complexity link vocal complexity and cooperation? Journal of Ornithology 156, 125-132. doi:10.1007/s10336-015-1233-2.

Furness, A. I., and Capellini, I. (2019). The evolution of parental care diversity in amphibians. Nat Commun 10, 1-12. doi:10.1038/s41467-019-12608-5.

Green, J. P., and Hatchwell, B. J. (2018). Inclusive fitness consequences of dispersal decisions in a cooperatively breeding bird, the long-tailed tit (Aegithalos caudatus). Proceedings of the National Academy of Sciences 115, 12011-12016.

Griesser, M., Burkart, J. M., and Uomini, N. (2019). Maternal care: the mother of cooperation between animals. in (Konstanz, Germany).

Hultgren, K., Duffy, J. E., and Rubenstein, D. R. (2017). "Sociality in shrimps," in Comparative social evolution, eds. D. R. Rubenstein and P. Abbot (Cambridge, United Kingdom: Cambridge University Press), 224-250.

Kapheim, K. M., Nonacs, P., Smith, A. R., Wayne, R. K., and Wcislo, W. T. (2015). Kinship, parental manipulation and evolutionary origins of eusociality. Proceedings of the Royal Society B: Biological Sciences 282, 20142886.

Kappeler, P. M., and Pozzi, L. (In press). Evolutionary transitions towards pair living in nonhuman primates as stepping stones towards more complex societies. Science advances.

Kessler, S. E., Radespiel, U., Nash, L. T., Zimmermann, E., Lehman, S. M., Radespiel, U., et al. (2016). Modeling the origins of primate sociality: social flexibility and kinship in mouse lemurs (Microcebus spp.). The dwarf and mouse lemurs of Madagascar: biology, behavior and conservation biogeography of the Cheirogaleidae, 422-445.

Kramer, J., and Meunier, J. (2019). The other facets of family life and their role in the evolution of animal sociality. Biological Reviews 94, 199-215. doi:10.1111/brv.12443.

Leadbeater, E., Carruthers, J. M., Green, J. P., Rosser, N. S., and Field, J. (2011). Nest inheritance is the missing source of direct fitness in a primitively eusocial insect. Science 333, 874-876. 
Lukas, D., and Clutton-Brock, T. (2012). Cooperative breeding and monogamy in mammalian societies. Proceedings of the Royal Society of London B: Biological Sciences, rspb20112468.

Lutermann, H., Schmelting, B., Radespiel, U., Ehresmann, P., and Zimmermann, E. (2006). The role of survival for the evolution of female philopatry in a solitary forager, the grey mouse lemur (Microcebus murinus). Proc Biol Sci 273, 2527-2533. doi:10.1098/rspb.2006.3603.

McShea, D. W. (2002). A Complexity Drain on Cells in the Evolution of Multicellularity. Evolution 56, 441-452. doi:10.1111/j.0014-3820.2002.tb01357.x.

McShea, D. W. (2016). Three Trends in the History of Life: An Evolutionary Syndrome. Evol Biol 43, 531-542. doi:10.1007/s11692-015-9323-x.

Nonacs, P., and Richards, M. H. (2015). How (not) to review papers on inclusive fitness. Trends in ecology \& evolution 30, 235-237.

Nowak, M. A. (2006). Five Rules for the Evolution of Cooperation. Science 314, 1560-1563. doi:10.1126/science.1133755.

Nowak, M. A., McAvoy, A., Allen, B., and Wilson, E. O. (2017). The general form of Hamilton's rule makes no predictions and cannot be tested empirically. PNAS 114, 5665-5670. doi:10.1073/pnas.1701805114.

Nowak, M. A., Tarnita, C. E., and Wilson, E. O. (2010). The evolution of eusociality. Nature 466, 1057.

Ohkubo, Y., Yamamoto, T., Ogusu, N., Watanabe, S., Murakami, Y., Yagi, N., et al. (2018). The benefits of grouping as a main driver of social evolution in a halictine bee. Science advances 4, e1700741.

Peckre, L., Kappeler, P. M., and Fichtel, C. (2019). Clarifying and expanding the social complexity hypothesis for communicative complexity. Behav Ecol Sociobiol 73, 11. doi:10.1007/s00265-018-2605-4.

Radespiel, U., Jurić, M., and Zimmermann, E. (2009). Sociogenetic structures, dispersal and the risk of inbreeding in a small nocturnal lemur, the golden-brown mouse lemur (Microcebus ravelobensis). Behaviour, 607-628.

Radespiel, U., Sarikaya, Z., Zimmermann, E., and Bruford, M. W. (2001). Sociogenetic structure in a free-living nocturnal primate population: sex-specific differences in the grey mouse lemur (Microcebus murinus). Behavioral Ecology and Sociobiology 50, 493-502. doi:10.1007/s002650100402. 
Rehan, S. M., Richards, M. H., Adams, M., and Schwarz, M. P. (2014). The costs and benefits of sociality in a facultatively social bee. Animal Behaviour 97, 77-85. doi:10.1016/j.anbehav.2014.08.021.

Rubenstein, D. R., and Abbot, P. (2017). Comparative social evolution., eds. D. R. Rubenstein and P. Abbot Cambridge, United Kingdom: Cambridge University Press.

Schradin, C., Hayes, L. D., Pillay, N., and Bertelsmeier, C. (2018). The evolution of intraspecific variation in social organization. Ethology 124, 527-536. doi:10.1111/eth.12752.

Schradin, C., Lindholm, A. K., Johannesen, J., Schoepf, I., Yuen, C.-H., König, B., et al. (2012). Social flexibility and social evolution in mammals: a case study of the African striped mouse (Rhabdomys pumilio). Mol. Ecol. 21, 541-553. doi:10.1111/j.1365294X.2011.05256.x.

Schülke, O., and Ostner, J. (2005). Big times for dwarfs: Social organization, sexual selection, and cooperation in the Cheirogaleidae. Evolutionary Anthropology: Issues, News, and Reviews 14, 170-185. doi:10.1002/evan.20081.

Shultz, S., and Dunbar, R. i. m (2007). The evolution of the social brain: anthropoid primates contrast with other vertebrates. Proceedings of the Royal Society B: Biological Sciences 274, 2429-2436. doi:10.1098/rspb.2007.0693.

Shultz, S., Opie, C., and Atkinson, Q. D. (2011). Stepwise evolution of stable sociality in primates. Nature 479, 219.

Silk, J. B. (2009). Nepotistic cooperation in non-human primate groups. Philosophical Transactions of the Royal Society B: Biological Sciences 364, 3243-3254.

Smith, P. E. (1973). The mortality and dispersal of sardine eggs and larvae. Rapp. PV Réun.(ICES/CIEM) 164, 282-292.

Socias-Martínez, L., and Kappeler, P. M. (2019). Catalyzing Transitions to Sociality: Ecology Builds on Parental Care. Front. Ecol. Evol. 7. doi:10.3389/fevo.2019.00160.

Taborsky, M., and Wong, M. (2017). "Sociality in fishes," in Comparative social evolution, eds. D. R. Rubenstein and P. Abbot (Cambridge University Press).

Tallerman, M., and Gibson, K. R. (2012). "Introduction: the evolution of language," in The Oxford Handbook of Language Evolution.

Toman, J., and Flegr, J. (2017). Stability-based sorting: The forgotten process behind (not only) biological evolution. Journal of theoretical biology 435, 29-41. 
Toman, J., and Flegr, J. (2018). A Virtue Made of Necessity: Is the Increasing Hierarchical Complexity of Sexual Clades an Inevitable Outcome of Their Declining (Macro) evolutionary Potential? Evolutionary Biology 45, 374-394.

van Schaik, C. P., and Burkart, J. M. (2010). "Mind the Gap: Cooperative Breeding and the Evolution of Our Unique Features," in Mind the Gap: Tracing the Origins of Human Universals, eds. P. M. Kappeler and J. Silk (Berlin, Heidelberg: Springer), 477-496. doi:10.1007/978-3-642-02725-3_22.

Wang, C., and Lu, X. (2018). Hamilton's inclusive fitness maintains heritable altruism polymorphism through $\mathrm{rb}=\mathrm{c}$. Proceedings of the National Academy of Sciences 115, 1860-1864.

West, S. A., Fisher, R. M., Gardner, A., and Kiers, E. T. (2015). Major evolutionary transitions in individuality. PNAS 112, 10112-10119. doi:10.1073/pnas.1421402112.

Whiting, M. J., and While, G. M. (2017). "Sociality in lizards," in Comparative social evolution, eds. D. R. Rubenstein and P. Abbot (Cambridge University Press).

Widdig, A. (2013). The impact of male reproductive skew on kin structure and sociality in multi-male groups. Evolutionary Anthropology: Issues, News, and Reviews 22, 239250.

Wilson, D. S., and Sober, E. (1989). Reviving the superorganism. Journal of theoretical Biology 136, 337-356.

Wilson, E. O., and Hölldobler, B. (2005). Eusociality: origin and consequences. Proceedings of the National Academy of Sciences 102, 13367-13371.

Wong, J. W., Meunier, J., and Kölliker, M. (2013). The evolution of parental care in insects: the roles of ecology, life history and the social environment. Ecological Entomology 38, 123-137.

Yagi, N., and Hasegawa, E. (2012). A halictid bee with sympatric solitary and eusocial nests offers evidence for Hamilton's rule. Nature communications 3, 939-939. 



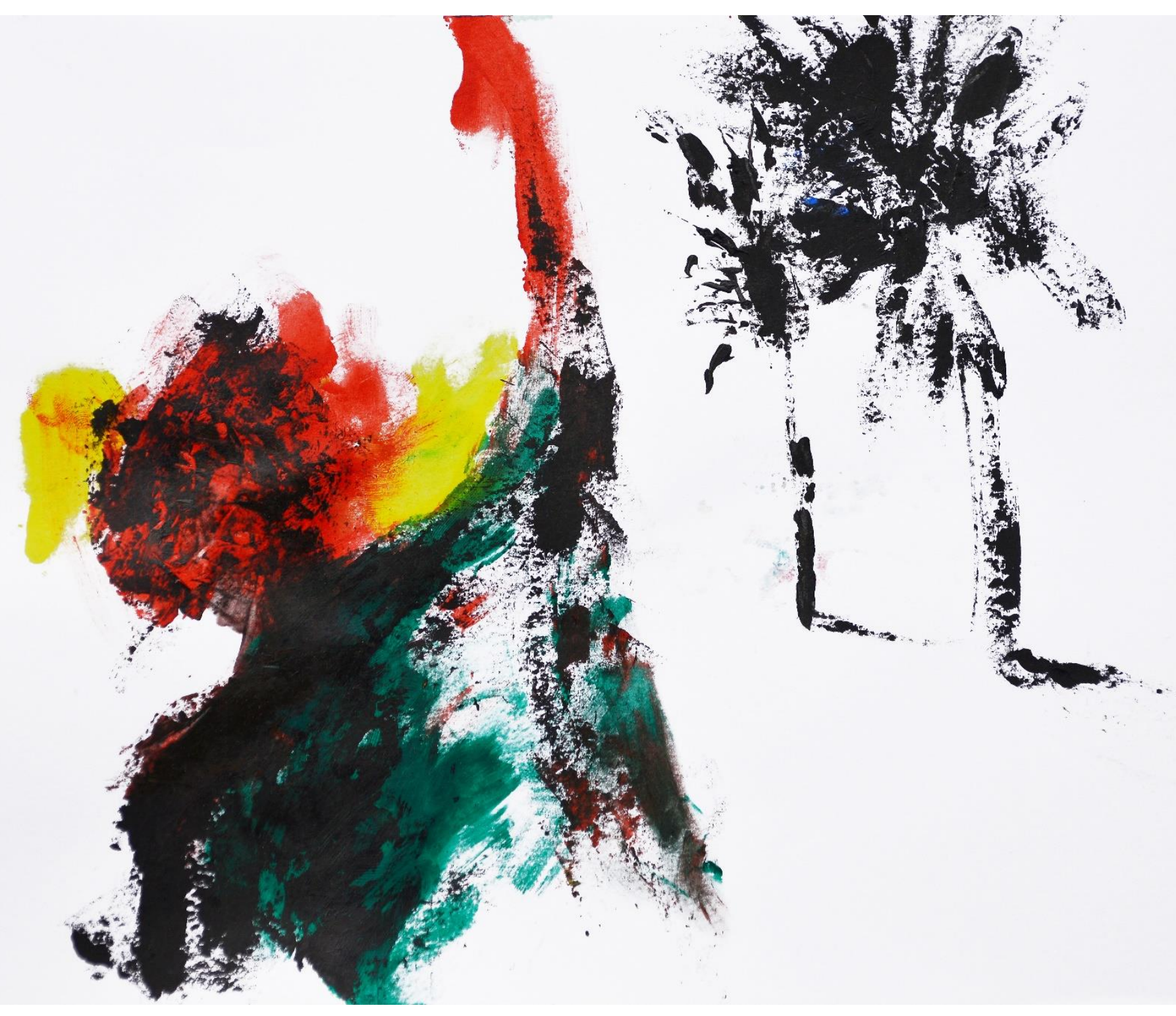


Untitled

Morondava, Madagascar 2019

\section{Socias Martínez}


19

fet

$\frac{2}{2}$

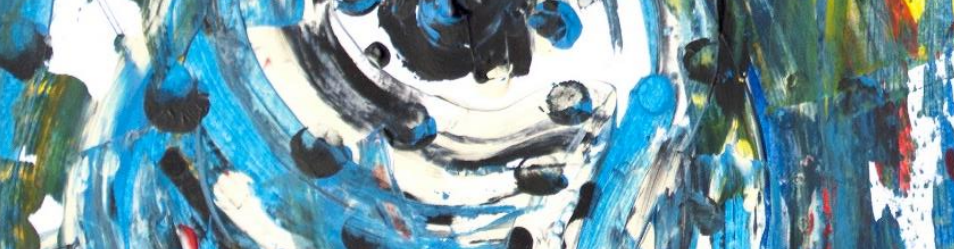

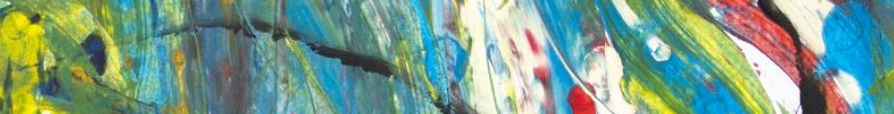

$$
y
$$
(f)

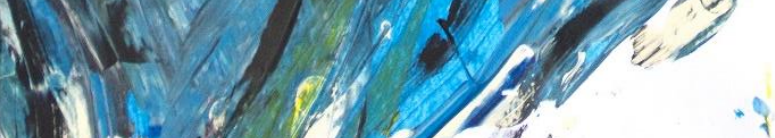

(1) $(1)$

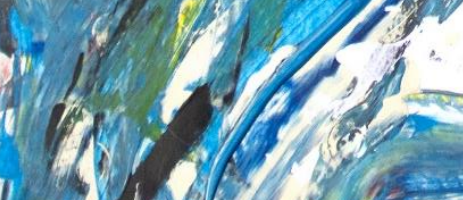

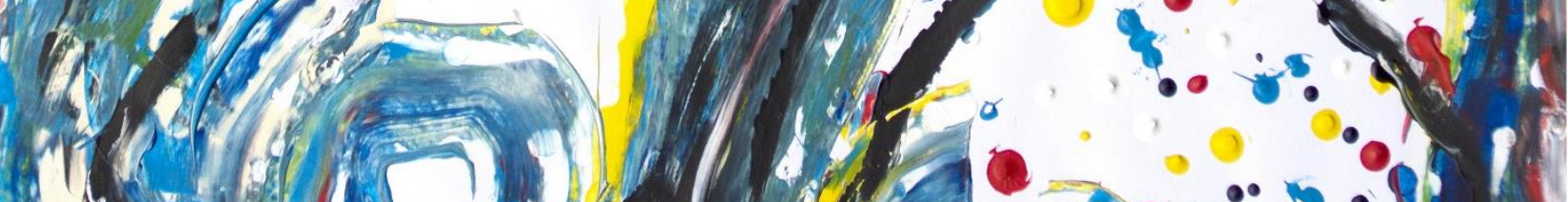

$$
\begin{aligned}
& 2+1,1 / 2 \text { and }
\end{aligned}
$$

